Elevated-Temperature Benchmark Tests of Simply Supported Beams and Circular Plates Subjected to Ti re-Varying Loadings

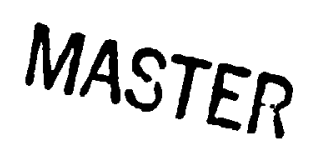




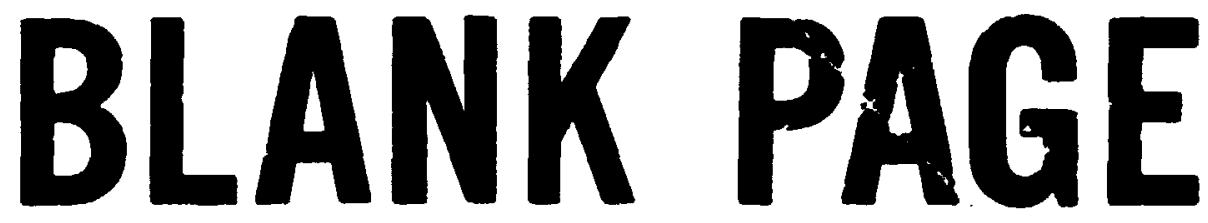




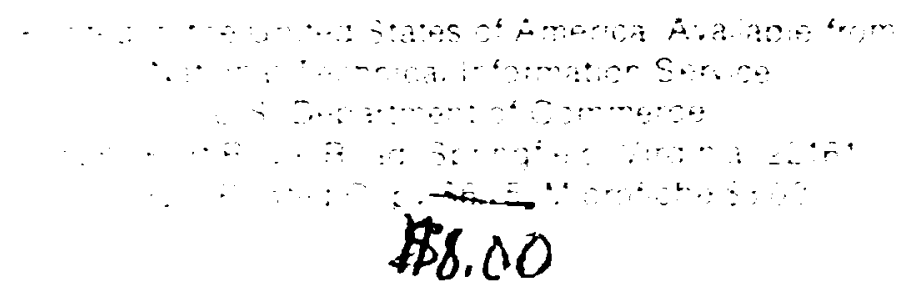


ORVL -5.301

Dist. Category UC-79, $-79 e,-79 h,-79 k$

Contract No. W-7405-eng-26

Engineering Technclogy Division

ELEVATED-TENPERATURE BENCHMARK TESTS OF SIMPLY SUPPORTED BEAMS AND CIRCI AR PLATES SUBJFCTED TO TIME-VARYING LOADINGS

J. M. Corum

M. Richardson

J. A. Clinarc'

Manuscript Completed - Augi: $:$ 8. 1977

Date Published - September : $: 77$

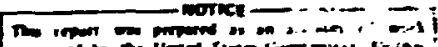

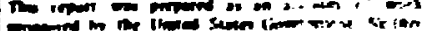

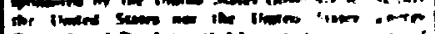

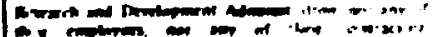

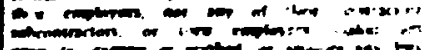

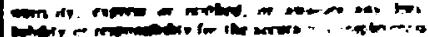

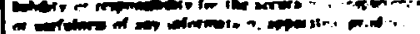

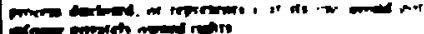

Prepared by tiin

OAK RIDGE NATIDNAL IAFORATORY

Oak Ridge, Tennessie $\quad .77830$

opcratcd by

UNION CARBIDE CORF IRATION

for the

ENERGY RFSEARCII AND DEVELOP:FLNT IDMINISTRATION 


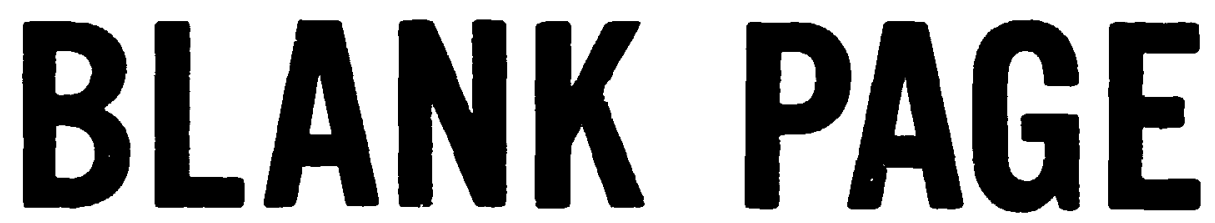


ABSTRACT $\ldots \ldots \ldots \ldots \ldots \ldots \ldots \ldots \ldots \ldots \ldots \ldots \ldots \ldots \ldots \ldots \ldots \ldots$

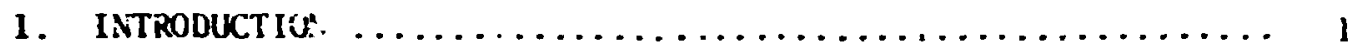

2. PROBIEN DESCRIPTIOS .....................

3. SPECIMEX IXSTRUAETTATION ..................

3.1 Displacement-Measuring Devices $\ldots \ldots \ldots \ldots \ldots \ldots \ldots$ is

3.2 Strain Gages .......................

3.3 Thermocouples $\ldots \ldots \ldots \ldots \ldots \ldots \ldots \ldots \ldots \ldots \ldots \ldots \ldots \ldots$

3.4 Data Acquisition System $\ldots \ldots \ldots \ldots \ldots \ldots \ldots \ldots \ldots \ldots \ldots \ldots$

4. EXPERIMEATAL FACIIITIES ANI TEST RROCEDURE $\ldots \ldots \ldots \ldots \ldots \ldots$ IS

4.1 Beam Facility ....................... 15

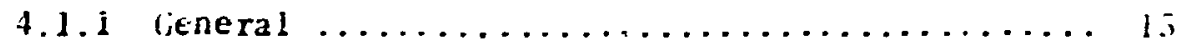

4.1 .2 Beam support system $\ldots \ldots \ldots \ldots \ldots \ldots \ldots \ldots \ldots 1^{-}$

4.1 .3 Load cells $\ldots \ldots \ldots \ldots \ldots \ldots \ldots \ldots \ldots \ldots \ldots \ldots$

4.1 .4 Deadweight loading system $\ldots \ldots \ldots \ldots \ldots \ldots \ldots \ldots$

4.1 .5 llydraulic loading system $\ldots \ldots \ldots \ldots \ldots \ldots \ldots$ l!

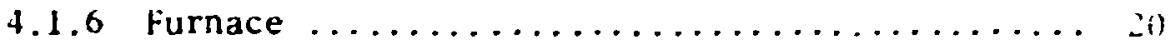

4.2 Circular plate lest facility $\ldots \ldots \ldots \ldots \ldots \ldots \ldots \ldots$ ib

$4 . \bar{j}$ Test Pro edure $\ldots \ldots \ldots \ldots \ldots \ldots \ldots \ldots \ldots \ldots \ldots \ldots$

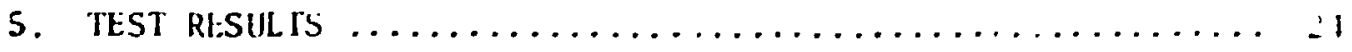

5.1 Load-Controllec Beam rests ............... 24

5.2 Veflection-Cont rolled Beam Tests ............. 29

5.3 Load-Controlled Plate lests ..............

5.4 beflect ion-controlled plate lasts $\ldots \ldots \ldots \ldots \ldots \ldots \ldots$ i:

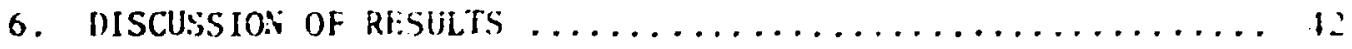

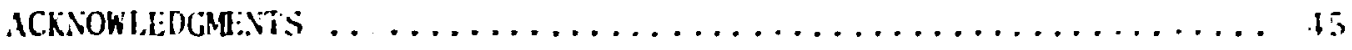

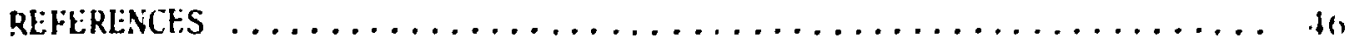

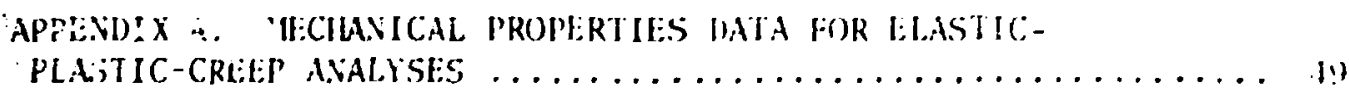

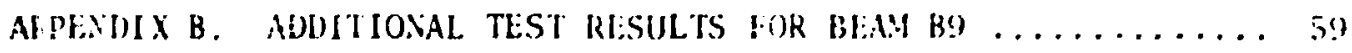

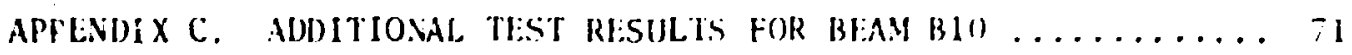

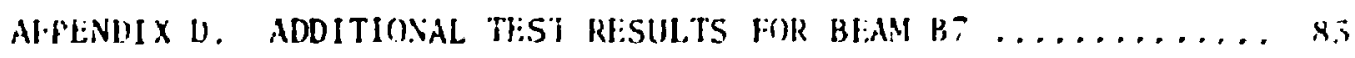

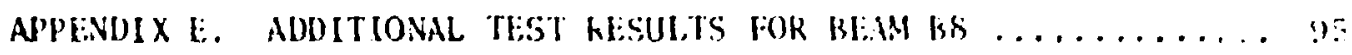

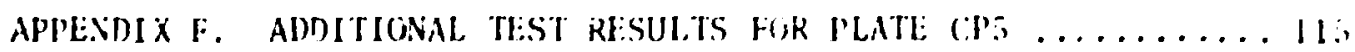


CONTENTS (continued)

APPENDIX G. ADDITIOATAL TEST RESULTS FOR PLATE CP2 $\ldots \ldots \ldots \ldots 131$ APPENDIX $\mathrm{H}$. AROITIONAL TEST RESULTS FOR PLATE CP4 $\ldots \ldots \ldots \ldots \ldots 14$ APPENDIX I. ADDITIONAL TEST RESULTS FOR PLATE CP3 ....... 155 APPENDIX J. TIME-DEPENDENT BEHAVIOR OF AILTECH SGA25

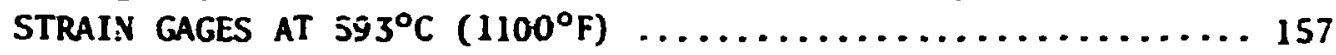


ELEVATED-TEMPERATURE BENCHMARK TESTS OF SIMPLY SUPPORTED SEAMS AND CIRCULAR PLATES SUBJECTED TO TIME-VIARYING LOADINGS

\author{
J. M. Comm \\ M. Richardson \\ j. A. Clinard
}

\begin{abstract}
This report presents the measured elastic-plastic-creep responses of eight simply supported type 304 stainless stee: beans and circular plates that were subjected to time-varyi 18 loadings at elevated temperature. The tests were peric .. $\perp$ to provide experimental benchmark problem data suitable for assessing inelastic analysis me hods and for validating computer programs. Beans and piates exhibit the essential features of inelastic structural behavior; $y \in t$ they are relatively simple and the experimental results are generally easy to interpret. The stress fields are largely uniaxial in beans, while multiaxial effects are introduced in plates. The specimens tested were laterally loaded at hie center and subjected to either a prescribed load or a center deflectiou history. The specimens were machined from a common well-characterized heat of material, and all the tests were performed at a tcmperature of $593^{\circ} \mathrm{C}\left(1100^{\circ} \mathrm{F}\right)$. Test results are presented in termof the load and center deficction behaviors, which typify the overall structural behavior. Additional deflection data, as well as strain gage results and mechanical properties data for the beam and plate material, are provided in the appendices.
\end{abstract}

\title{
1. INTROUUCTION
}

Detailed inelastic analyses may be required in the design of hightemperature reactor system components to demonstrate conformance with design codes and standards. Computer programs that employ complex constitutive theories and analysis procedures are used to perform these calculations, arad quesiions of validation and acceptance of the analysis results are thus introduced. An assessment of analysis predictions can best be made by performing benchmark ca'rulations, that is, by solving a number of carefuily chosen structural problems for which experimentally determined response data exist. 
Th: U.S. Atomic Energy Comission, predecessor of the Energy Research and Deveiorment Idministration, recognized the need for experimental benchm:ark problem data, particularly at elevated temperatures, in 1969. To meet this need, the commission initiated plans for a series of inelastic s:ruitural tests on a variety of structural geometries ranging from simpie to complex. Initial results from these efforts were presented in Ref. 1. Idditional results from beams and plates are presented in this rep: $r$. Although Ref. I discusses typical inelastic analysis predictions and shows some comparisons between theory and experiment, this report in: ludes only experimental data.

Simly supported beams and circular plate; loaded at their center are tro of the simplest possible type; of structural tests for investiint ing -lastic structural hehavior. In fact, it is their simplicity that makes them particularly valuable for evaluating the basic aspects or inelastic constitutive theories and analysis procedures and for verify ing features of inelastic analysis computer programs. Thus, tests of beams anc plates play a key role i:a the OR.VL lligh-Temperature Structural [hes in Program to systematically develop and evaluate high-temperature lesign inethods, and they can he a very useful and hasic part of a berchmark prohlem verification and qualification effort for computer programs. Fic cest results presented in this report are for a group of eight tests at $59.3^{\circ} \mathrm{C}$ ( $\left(1100^{\circ} \mathrm{F}\right)$ that were carefully planned and seiected to complement one another. The group consisted of four bean te:ts and four plate tests with similar load histograms. Tho of each t;pe of test sitre losd controlled, while the remaining two were deflection controlled. Half of the trsts hegan with short-time elastic-plastic cyclic loads, vile the other half hegan with periods of time-dependent creep or relaxat ion. Taken together, these trsts provide information on some of the essential aspects of elastic-p!astic and creep behavior as well as information regdrding the effects of irinr clastic-plastic deformation on subsequent creep behavior and the effects of prior creep on subsequent elastic-plast ic behavior. The results presented were chosen to illustrate the ascential hrhavioral features and to provide the anal,st with a selec$t i o n$ of simple benchmark problems which embody a variety of inelastic hehavioral characteristics. 
The beans used in this investigation were from 25.4-mm ( 1 -in.) plate product form of type 304 stainless steel, heat 9T2796; the circular plates were from 19-w (0.75-in.) plate of the same heat. This material, which is being used throughout the ORVL High-Temperature Struciural lesign Progran, is well characterized; the appropriate material properties required as input for inelastic analysis are given in Appendix $A$. To ensure that the material test data are applicable, the finished heams and plates, as well as the material test specimens, were subjected to identicai pretest heat treatments consisting of a full annea: $1093^{\circ} \mathrm{C}\left(2000^{\circ} \mathrm{F}\right)$ for $30 \mathrm{~min}$ ! followed by rapid forced-air cooling to room temperature.

The remainder of this report is divided into five major sections. Section 2 describes the beam and plate test specimens and presents the loading histograms and test parameters for the eight tests. The instrumentation used for the spesimens is described in Section 3 , while the test facilities and test procedures are discussed in Section 4. Finally, representative test results for each of the eight tests are presented in Section 5, and the results are discussed in Section 6.

To simplify the reader's task of assessing and comparing results from eight separate tests, each with several test phases, the results in the report are all in terms of the measured load-center deflection-time responses. For those interested in additional information, deflections at other locations, selected strains, and cemperacure variation data aro given in Appendices $B$ thäough $I$.

Appendix A contains a summary of the applicable natorial properi: data required as input to conventional clastic-piastic-crep aralyses of the beam and plate specimens. The data provided incluale cias:ic constiant. cyclic stress-strain data, and uniaxial constant-stres: crecp datis for type 304 stainless steel, heat 9 T2796, at $593^{\circ} \mathrm{C}\left(1100^{\circ} \mathrm{F}\right)$.

Appendix $J$ presents measured $t$ ime-dependent drift data for the hightemperature weldable resistance strain gages used in the test. . These data are provided to aid in interpreting and using the strain gage results presented in sarlier appendices. 


\section{PROBLEM EESCRIPTION}

The beam and plate specimens are depicted in Fig. 1 along with the dimensions and method of loading and supporting. The beans were each 50.8 high, 25.4 wide, and 0.66 long $(2 \times 1 \times 26$ in. $)$ and were simply supported so that the effective length was $0.61 \mathrm{~m} \mathrm{(24} \mathrm{in.).} \mathrm{The}$ center load was applied through 19-a-dian (0.75-in.) rollers downward $(+P)$ or the top surface or upward $(-P)$ on the bottom surface shown. The simple end supports were through 19 -dian $(0.75$-in.) rollere which passed through the beam on iis centerline.

The 12.7-mick (0.5c-in.) circular plate specimens hal an outside diameter of $0.527 \mathrm{~m}$ (20.75 in.) and were simply supported by a line of 12.i-mm-diam (0.50-in.) ball bearings on a $0.508-m$-diam (20-in.) circle. Since the center load could be applied either down $(+P)$ or up $(-P)$, ball bearing supports were required on both the bottom and top surfaces. The center load was applied through a 50.8-mm-diam (2-in.) boss and loading har as shown in the figure. A boss of the same dimensions was included on the bottom surface, and a nut and a 50.8-mm-OD (2-in.) washer were used to clanp the plate to a 25.4-mm-dian (1-in.) threaded extension of the loading bar which passed through a hole in the plate. The objective of this arrangement was to provide a configuration which could be modeled as a 50.8-mm-diam (2-in.) solid bar, top and bottom, at the center of the plate.

Figure 2 shows the histograms used for the load-controlled and the defiection-controlled tests, and Tablc 1 delineates the group of four beams and four plates from which the results presented in this report were chosen. The figure numbers and appendix designations in Table 1 show where results for each test are lucated in the report. Table 2 gives the values of the test parameters shown in Fig. 2. The numbered points shown on the histograms of Fig. 2, which are for reference purposes, are used throughout this report in the presentation of cata.

The times $\left(t_{1}, t_{2}\right.$, and $\left.t_{3}\right)$ for the hold perinds were nominally 312 $\mathrm{hr}$ in Fig. $2 a$ and $144 \mathrm{hr}$ in Fig. $2 b$. As can be seen in Table 2, the actual hold times sometimes differed from these nominal values and the loads 

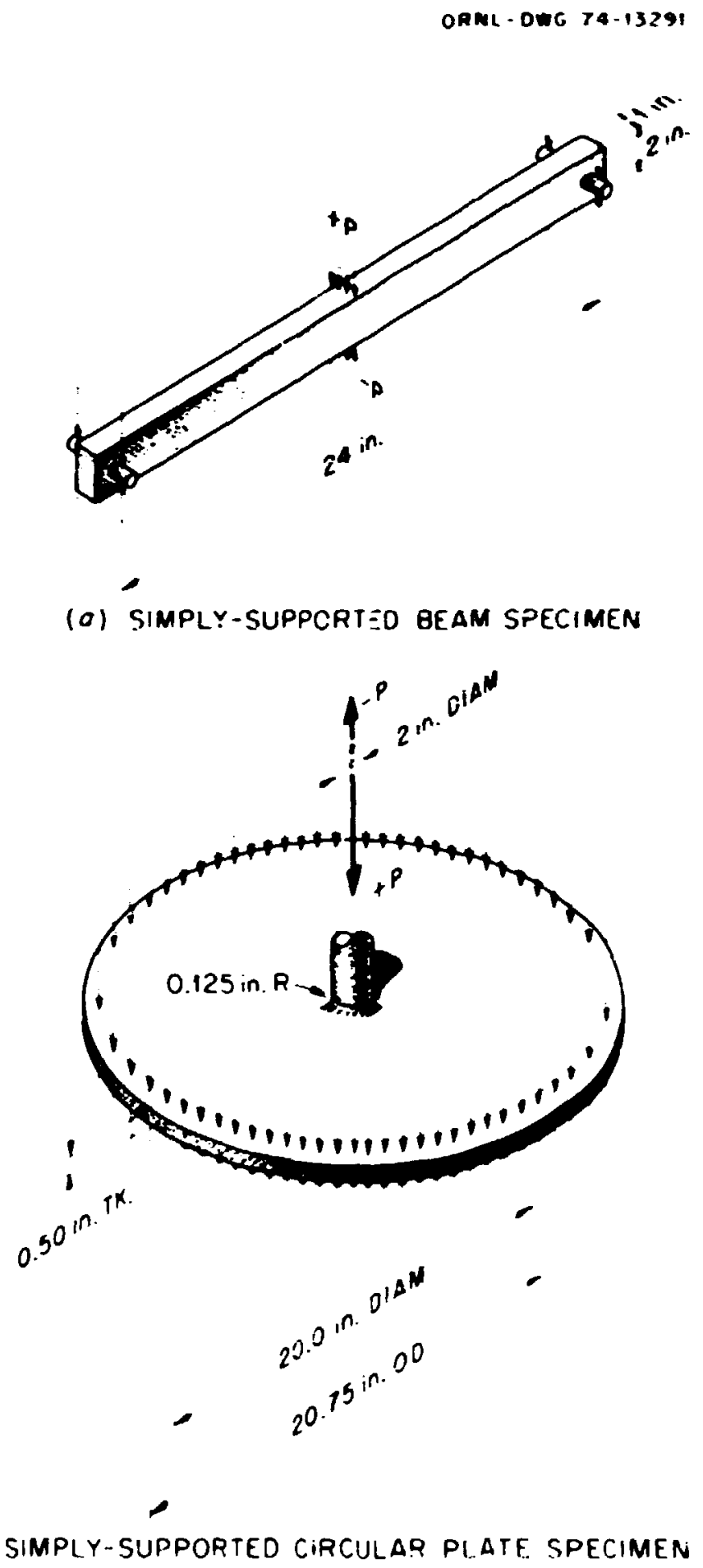

Fig. 1. Dimensions of simply supported beam and circular plate test specimens (in. $\times 25.4=\mathrm{mm}$ ). 
Table 1. Interrelated set of beam and plo:e tests at $593^{\circ} \mathrm{C}\left(1160^{\circ} \mathrm{F}\right)^{a}$

\begin{tabular}{|c|c|c|c|c|c|c|c|}
\hline & \multirow[b]{2}{*}{$\begin{array}{l}\text { Test } \\
\text { io. }\end{array}$} & \multirow[b]{2}{*}{$\begin{array}{l}\text { Type of } \\
\text { control }\end{array}$} & \multicolumn{4}{|c|}{ Test phase ${ }^{i}$ (refer to Fig. 2) } & \multirow[b]{2}{*}{$\begin{array}{c}\text { Location of } \\
\text { additional } \\
\text { results }\end{array}$} \\
\hline & & & $\begin{array}{l}\text { Precreep } \\
\text { cycles } b\end{array}$ & $\begin{array}{l}\text { Short-time load } \\
\text { or deflection } \\
\text { changes }\end{array}$ & $\begin{array}{c}\text { Creep or } \\
\text { relaxation }\end{array}$ & $\begin{array}{l}\text { Postcreep } \\
\text { cycles }\end{array}$ & \\
\hline \multirow{2}{*}{ 葛 } & $\begin{array}{l}39 \\
B 10\end{array}$ & $\begin{array}{l}\text { Load } \\
\text { Load }\end{array}$ & $\begin{array}{l}\text { None } \\
\text { Fig. } 14\end{array}$ & $\begin{array}{l}\text { Fig. } 11 \\
\text { Fig. } 15\end{array}$ & $\begin{array}{l}\mathrm{Fig} \cdot 12 \\
\mathrm{Fig} \cdot 16\end{array}$ & $\begin{array}{ll}\mathrm{Fig}, & 13 \\
\mathrm{Fig}, & 17\end{array}$ & $\begin{array}{l}\text { Appendix } B \\
\text { Appendix } C\end{array}$ \\
\hline & $\begin{array}{l}\text { B7 } \\
\text { B8 }\end{array}$ & $\begin{array}{l}\text { Deflection } \\
\text { Deflection }\end{array}$ & $\begin{array}{l}\text { None } \\
\text { Fig, } 21\end{array}$ & $\begin{array}{ll}\mathrm{Fig}, & 18 \\
\mathrm{Fig} \cdot & 22\end{array}$ & $\begin{array}{l}\mathrm{Fig} \cdot 19 \\
\mathrm{Fig}_{\mathrm{g}} \cdot 23\end{array}$ & 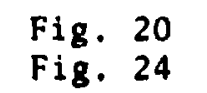 & $\begin{array}{ll}\text { Append } 1 \times & D \\
\text { Appendix } & E\end{array}$ \\
\hline \multirow{2}{*}{ 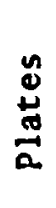 } & $\begin{array}{l}\text { CP5 } \\
\text { CP2 }\end{array}$ & $\begin{array}{l}\text { Load } \\
\text { Load }\end{array}$ & $\begin{array}{l}\text { None } \\
\text { Fig. } 28\end{array}$ & $\begin{array}{ll}\text { Fig. } & 25 \\
\text { Fig. } & 29\end{array}$ & $\begin{array}{ll}F i g \cdot & 26 \\
F i g . & 30\end{array}$ & $\begin{array}{ll}\text { Fig. } & 27 \\
\text { Fig. } & 31\end{array}$ & $\begin{array}{l}\text { Appendix F } \\
\text { Appendix G }\end{array}$ \\
\hline & $\begin{array}{l}\text { CP4 } \\
\text { CP3 }\end{array}$ & $\begin{array}{l}\text { Deflection } \\
\text { Deflection }\end{array}$ & $\begin{array}{l}\text { None } \\
\text { Fig. } 35\end{array}$ & $\begin{array}{ll}\text { Fig. } & 32 \\
\text { Fig. } & 36\end{array}$ & $\begin{array}{l}\mathrm{Fig}, \quad 33 \\
\mathrm{Fig} \cdot \quad 37\end{array}$ & $\begin{array}{ll}\mathrm{Fjg}, & 34 \\
\mathrm{Fig} \cdot & 38\end{array}$ & $\begin{array}{l}\text { Append IX } \mathrm{H} \\
\text { Append } 1 \times \mathrm{I}\end{array}$ \\
\hline
\end{tabular}

$a_{\text {The figure numbers identify the center load/center deflection results presented }}$ in the body of this report.

${ }^{b}$ Each test consisted of four phases, except that beams B9 and B7 and plates CPJ and CPA were not subjected to precreep cycling. 
Table 2. Parameter values in beam and plate test histograms (refer to Fig. 2)

\begin{tabular}{|c|c|c|c|c|c|c|c|c|c|c|c|}
\hline & \multirow{2}{*}{$\begin{array}{l}\text { Test } \\
\text { No. }\end{array}$} & \multirow{2}{*}{$\begin{array}{l}\text { Number of } \\
\text { precreep } \\
\text { cycles }\end{array}$} & \multicolumn{4}{|c|}{ load $[N(1 b)]$} & \multirow{2}{*}{$\begin{array}{l}\text { Deflection, } \delta \\
\text { [mm (in.;] }\end{array}$} & \multicolumn{3}{|c|}{ Time $(h r)$} & \multirow{2}{*}{$\begin{array}{l}\text { Number of } \\
\text { postcreep } \\
\text { cycles }\end{array}$} \\
\hline & & & $\mathrm{P}$ & & $P_{2}$ & & & $t_{1}$ & $t_{2}$ & $t_{3}$ & \\
\hline \multirow{4}{*}{ 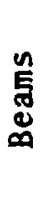 } & 139 & 0 & 8,896 & $(2000)$ & 10,008 & $(2250)$ & & 312 & 312 & 312 & 10 \\
\hline & 810 & 10 & 8,896 & $(2000)$ & 10,008 & $(2250)$ & & 312 & 312 & 312 & 10 \\
\hline & 37 & 0 & & & & & $2.54(0.10)$ & 144 & 163 & & $\therefore \mathrm{J}_{\mathrm{p}}$ \\
\hline & B8 & 10 & & & & & $2.54(0.10)$ & 144 & 144 & & $10^{b}$ \\
\hline \multirow{4}{*}{$\stackrel{\ddot{0}}{\stackrel{4}{9}}$} & CPS & 0 & 17,458 & $(3925)^{x}$ & 21,71, & $(4881)$ & & 313 & 335 & 484 & 10 \\
\hline & $\mathrm{CP} 2$ & 30 & 17,347 & $(3900)$ & 21,795 & $(4900)$ & & 312 & 333 & 285 & 10 \\
\hline & CP4 & 0 & & & & & $2.79(0.11)$ & 144 & 144 & & 10 \\
\hline & $\mathrm{CP3}$ & 10 & & & & & $2.79(0.11)$ & 144 & 144 & & 10 \\
\hline
\end{tabular}

$a_{\text {for CP5 }, ~} f_{1}=-17,347 \times(-390016)$.

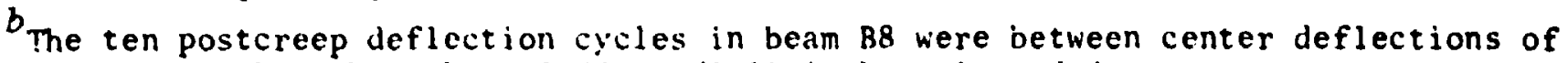
$\pm 2.79 \mathrm{~mm}(0.11 \mathrm{in.})$ rather than $\pm 2.54 \mathrm{~mm}(0.10 \mathrm{in.})$ as intended. 

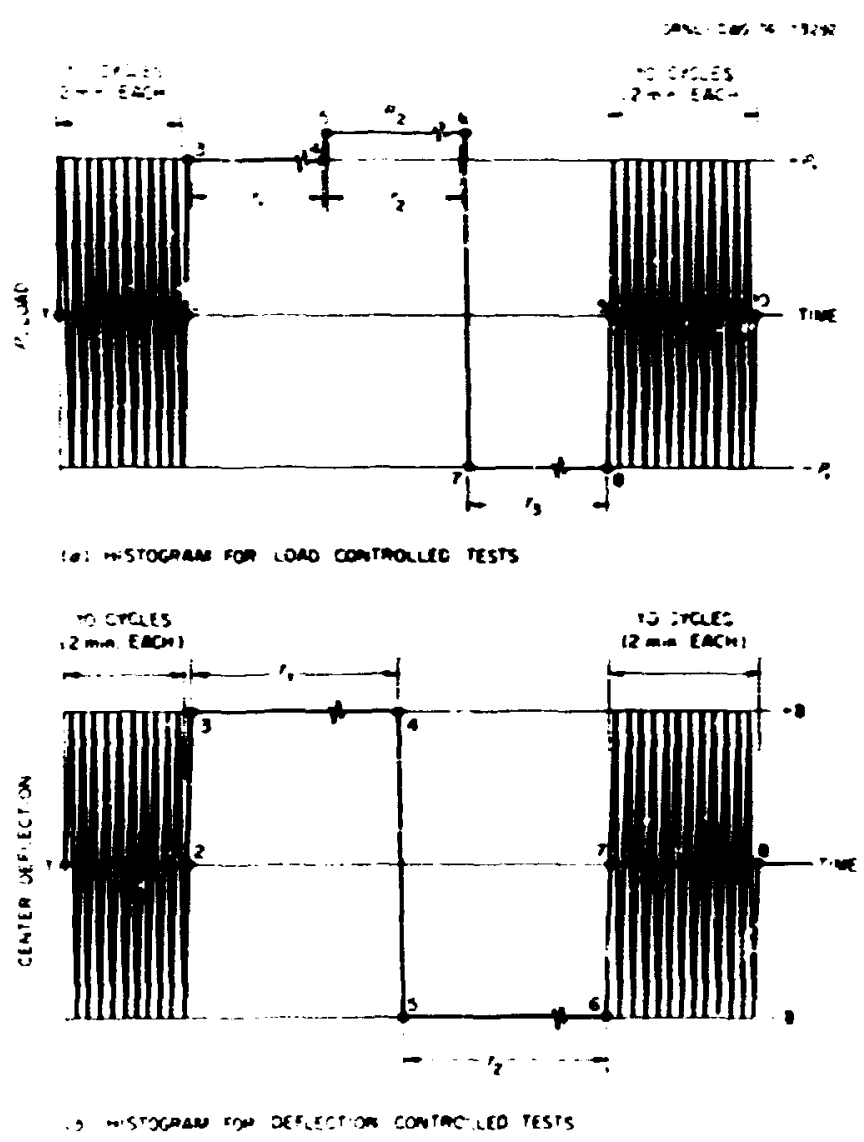

Fig. 2. General for, of histograms for load- or deflection-controlled beam anci circular plate tests. Refer to Tabie 2 for parameter values.

in plate test CP5 differed slightly from the intended values, which are those shown for piate test CP2.

All short-time load and deflection changes shown in Fig. 2 were ramp shaped, with the rate based on 2 min per complete load or deflection cycle (30 sec per quarter cycle, such as points 2 to 3 ). The 2 -min/cycie rate corresponds approximately to a maximun strain rate (calculated on an elastic basis) of $0.005 / \mathrm{min}$, which was the standard rate used in obtaining the uniaxial cyclic stress-strain data included in Appendix $A$.

The loading and deflection histories in Fig. 2 and Tables 1 and 2 for the separate tests were contrived to systematically study the effects of plastic and creep behaviors interspersed. Consider, for example, the pair of beam tests B9 and B1f. Test B10 was subjected to the full histogram 
shown in Fig. 2a. Thus the first ten short-time load cycles may be analyzed as elastic-plastic behavior only. The creep portion of the test is considered to begin at point 2 and end at point 9. In the final ten short-time load cycles, creep effects can again be neglected. Test B9 was exactly the same as B10, except that the initial ten short-time cycles were eliminated; the 59 test started $2 t$ point 2 . Thus, taken together, the bean $B 9$ and $B 10$ test results provide both elastic-plastic response lata and creep response data for a virgin specimen. They also provide data regarding the effects of prior elastic-plastic behavior on suosequent creep (the creep response of beam B10 compared to that of B9) and the effects of prior creep on subsequent plasticity (the short-time response from points 4 to 5 in $B 9$ compared to the response from 2 to 3). The responses in the creep hold periods also allow an assessment of creep-hardening rules and procedures. The two tests in each of the remaining pairs of tests in Table 1 are related in the same manner as are beams $B 9$ and BLO. 


\section{SPECIME. INSTRUMENTATION}

The instrumentation for measuring displacement, strain, and temperature is show in Figs. 3 and 4 for the beans and the circular plates, respectively. Each specimen had seven displacement-measuring devices for deteraining lateral strains, at least four symetrically located resistance strain gages, and ten therancouples located on the top and botton surfaces. The instruner.tation nubering system shown in figs. 3 and 4 is used for all the results presented in this report.

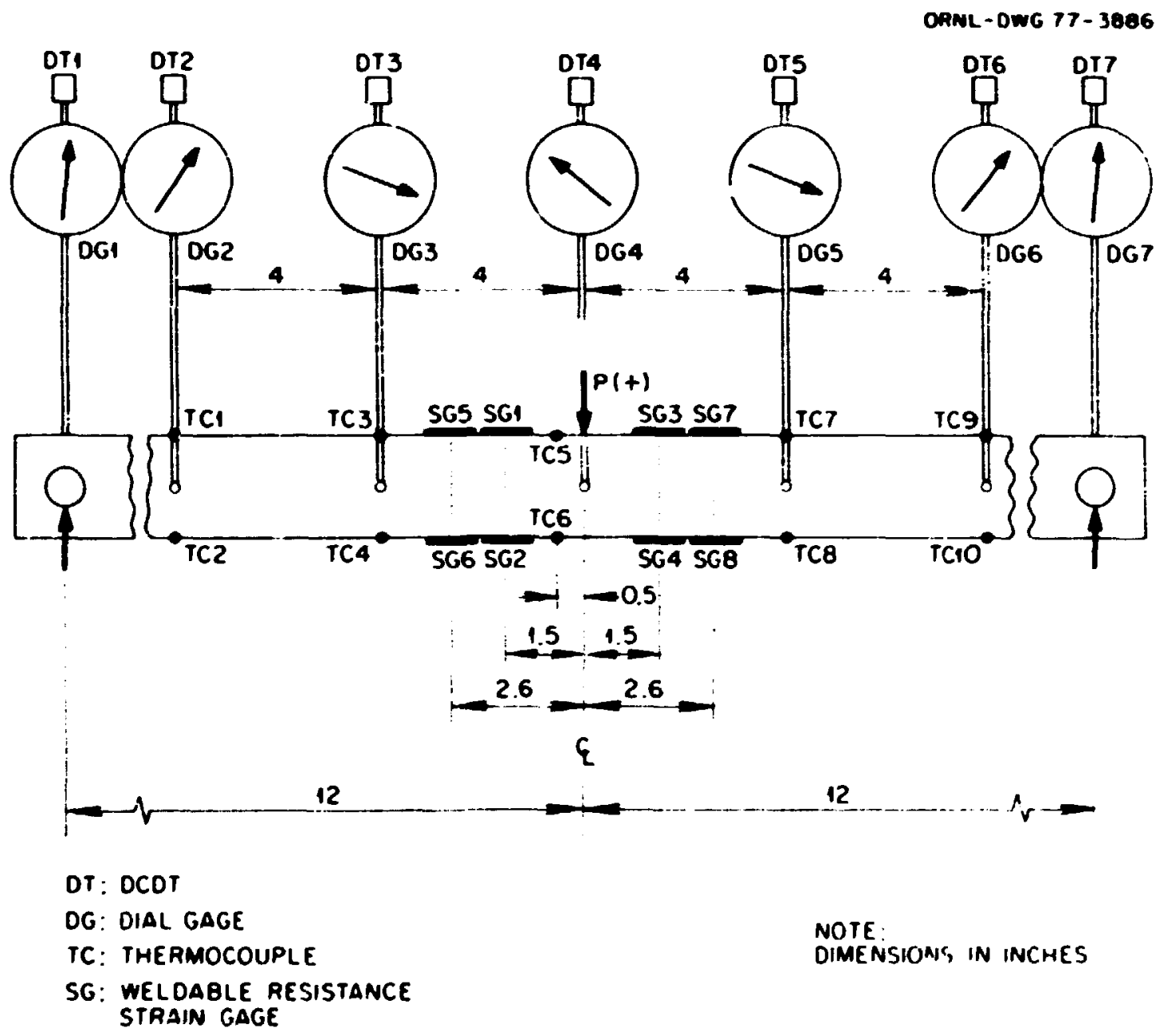

Fig. 3. Schematic of instrumentation used on beam specimens. Only beam B8 had strain gages SGS-SG8 (in. $\times 25.4=\mathrm{mm}$ ). 


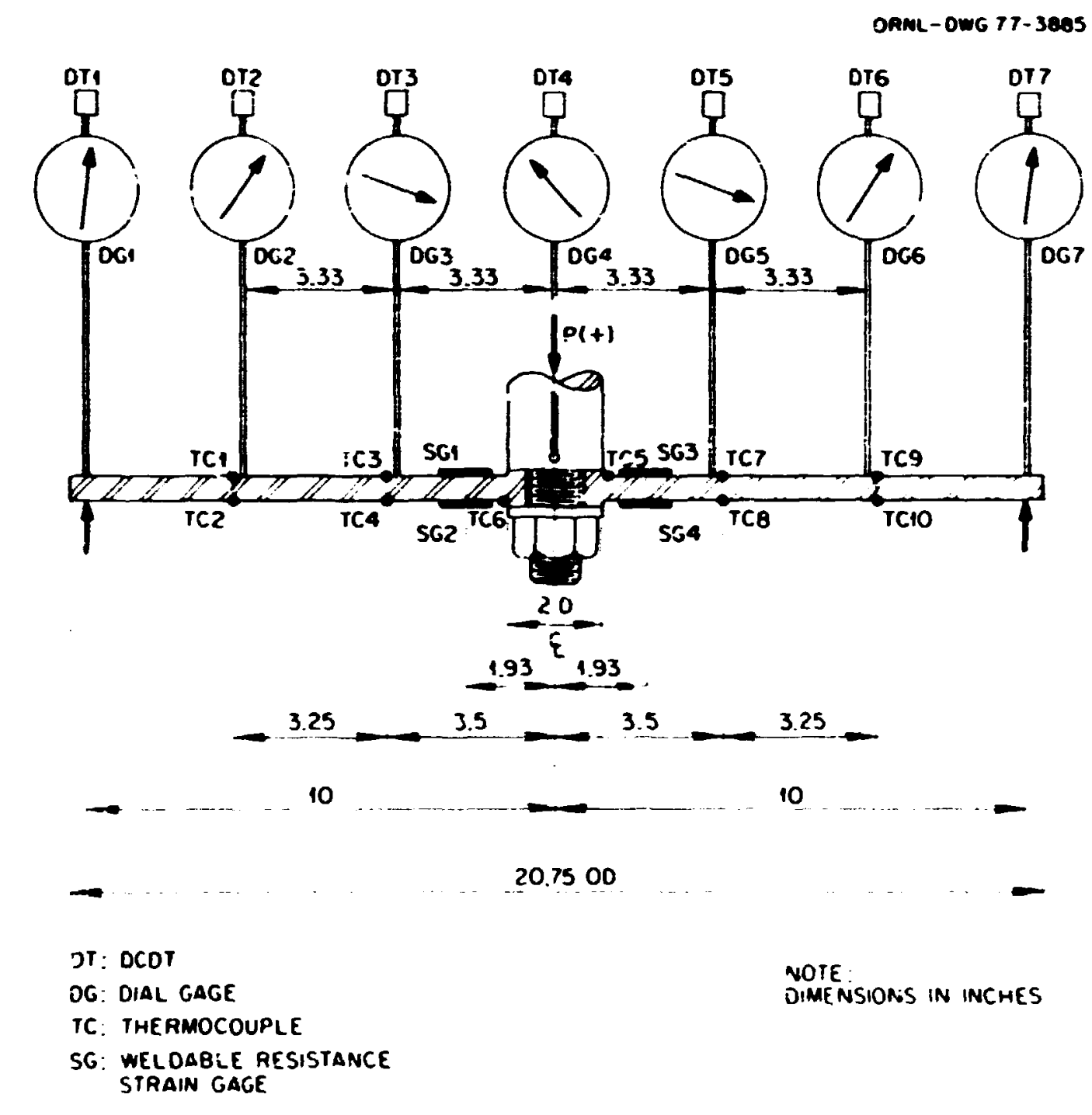

Fig. 4. Schematic of instrumentation used on circular plate specimens. The instrumentation shown is located in the vicinity of a single diametral plane (in. $\times 25.4=m$ ).

Tigure 5 shows a bean specimen partially installed in the test facility. The displacement-measuring devices shown consisted of a quartz rod connected to a standard dial gage, which, in turn, was connected to a direct-current differential transformer (DCDT). Readings from the DCDTs, as well as from the strain gages, thermocouples, and load cell, vere recorded on a data acquisition system. The dial gages were read periodically and served as backups for the DCDT data, particularly during periods when the data acquisition system was inoperable. The instrumentation 


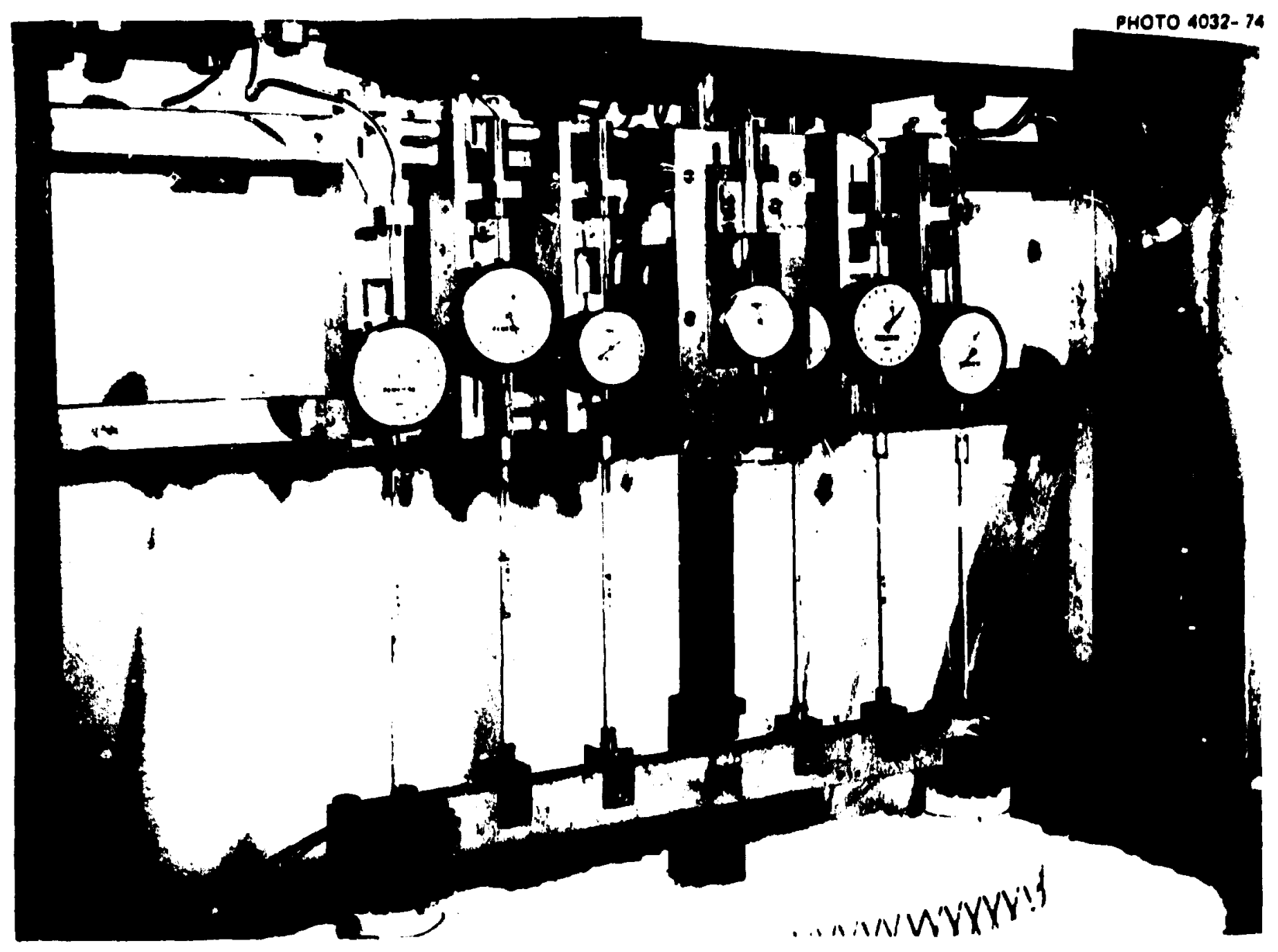

Fig. 5. Instrumented bean mounted in tost facility. 
and data acquisition system are described worc fully in the following subsectiuns.

\subsection{Disolacement-Measuring Devices}

The DCDTs, Hew :ett-Packard model 24 , had ranges of 1.27 . 0.05 in.) for positions 1 and $?$ (Figs. I and 4); 0.35 (0.25 in.) for positions $2,3,5$, and 6 ; and $25.4 \mathrm{~m}$ ( $1.00 \mathrm{in.})$ for position 4 . These devices are dc input-output differential transformers. The output is proportional to the linear displacement. The DCDTs consist of a core which woves axially inside a cylindrical co:l assembly. The core is mounted on a small rod which, in this case, was attached to extensions of the iial gage operator shafts using specia! adapters. These, in turn, kere connected to quartz rods which exterded to the specinun irside the test furnace.

The four outboard dial gages (positions 1, 2,6, and 7) were 0.0025 (0.0001-in.) gages, while the center three (positions 3, 4, and 5) were 0.025 - $(0.001-i n$.$) gages.$

Fo. the beams, the quartz rods were seated in sadiles (Fig. 5) which were attached to the midsurface of the beam.* For the plates, the quartz rods were capped with pointed metal tips that rested in small indentations in the top surface. The rods were spring loaded so as to ensure continued contact with the plates.

Prior to each test the DCDTs were calibrated by inserting gage blocks into the linkage described ahove. In addition to providing a check on the DCDT output, this procedure provided the factors used by the data acquisition s;stem for converting tinc voltage output irto engineering units.

\subsection{Strain Gages}

The strain gages used for these tests, Ailtech model SG 425, are 120- $\Omega$ half-bridge gages with one active gage $1 \mathrm{eg}$ and one zero gage factor temperature-compensating leg. The gage consists of a U-shaped active

*The quartz rods at the end supports hore direc:ly on the cop surfare of the beam. The center rod (position 4) was attached to the beam in only one side as can be seen in Fig. 5. 
leg with a helical dury leg wrapped around it. Both legs are insulated with $M g 0$ powder and con:ained inside a stainless steel tube. The tube is welted to a flange wilich is then welded to the specinen surface.

The gages, as purchased, include integral sheathed lead wires. The active gage length is 17.78 ( $C .70$ in.), and the maxim strain range is \pm 0.67 . The gage factor, which is a function of terperature, is $4.0 \pm$ 0.5.

Each gage was sonditioned prior to installation to improve hightemperature stability. They were thermilly cycled at least three times through the temperature range 427 to $593^{\circ} \mathrm{C}\left(800\right.$ to $\left.1100^{\circ} \mathrm{F}\right)$.

Since individual gage calibration could not easily be accomplished due to the nature of the attachnent method, a representative gage from each batch was calibrated at room temperature against a fiil gage.

In addition to the four or eight active gages used on each specimen, two gages of the same batch were attached to an unstrained block which was attached to the test specimens. These reference gages were monitored for drift throughout each test; representative results are presented in Appendix $\mathrm{J}$.

\subsection{Thermocouples}

The thermocouples used were sheathed type $K$ Chrowel-Alumel, 1.59 (0.0625 in.) diam $\times 0.61 \mathrm{~m}$ (24 in.) 1 ing, made to ORNL Instrumentation and Controls Division specifications. All thermocouples were calibrated and certified at $593^{\circ} \mathrm{C}\left(1100^{\circ} \mathrm{F}\right)$ as a minimis, and only those therrucouples that were within the limits of $\pm 1.67^{\circ} \mathrm{C}\left( \pm 3^{\circ} \mathrm{F}\right)$ at $593^{\circ} \mathrm{C}$ were utilized. In service, all thermocouples were referenced to a temperature of $65.6^{\circ} \mathrm{C}$ $\left(150^{\circ} \mathrm{F}\right)$ through a reference junction box.

\subsection{Data Acguisition System}

A Datum system with a PDP-8 computer was used for data acquisition. The system had the capability of scanning all the data points 200 times per second, averaging each point, and placing these averages on magnetic tape at a rate of one full data record per second. The actual rates used were varied as required. 
4. EXPERIUATAL FACIITIIES ANO TEST PROCFDURI:

A special elevated-teqperature test fiacility as designed and built specifically for testing beams, and a second facility was buili for tesiing circular plates. With the exception of the specimen loading and st.pport details and the furnaces, the facilities ar essentially identical.

\subsection{Bean lac 1ity}

\section{1 .1 General}

The beam facility is shown schamatically in Fig. 0 , and a photograph of the facility is shown in Fig. $\therefore$. The out line oit the simply supportid,

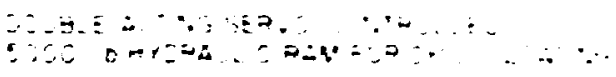

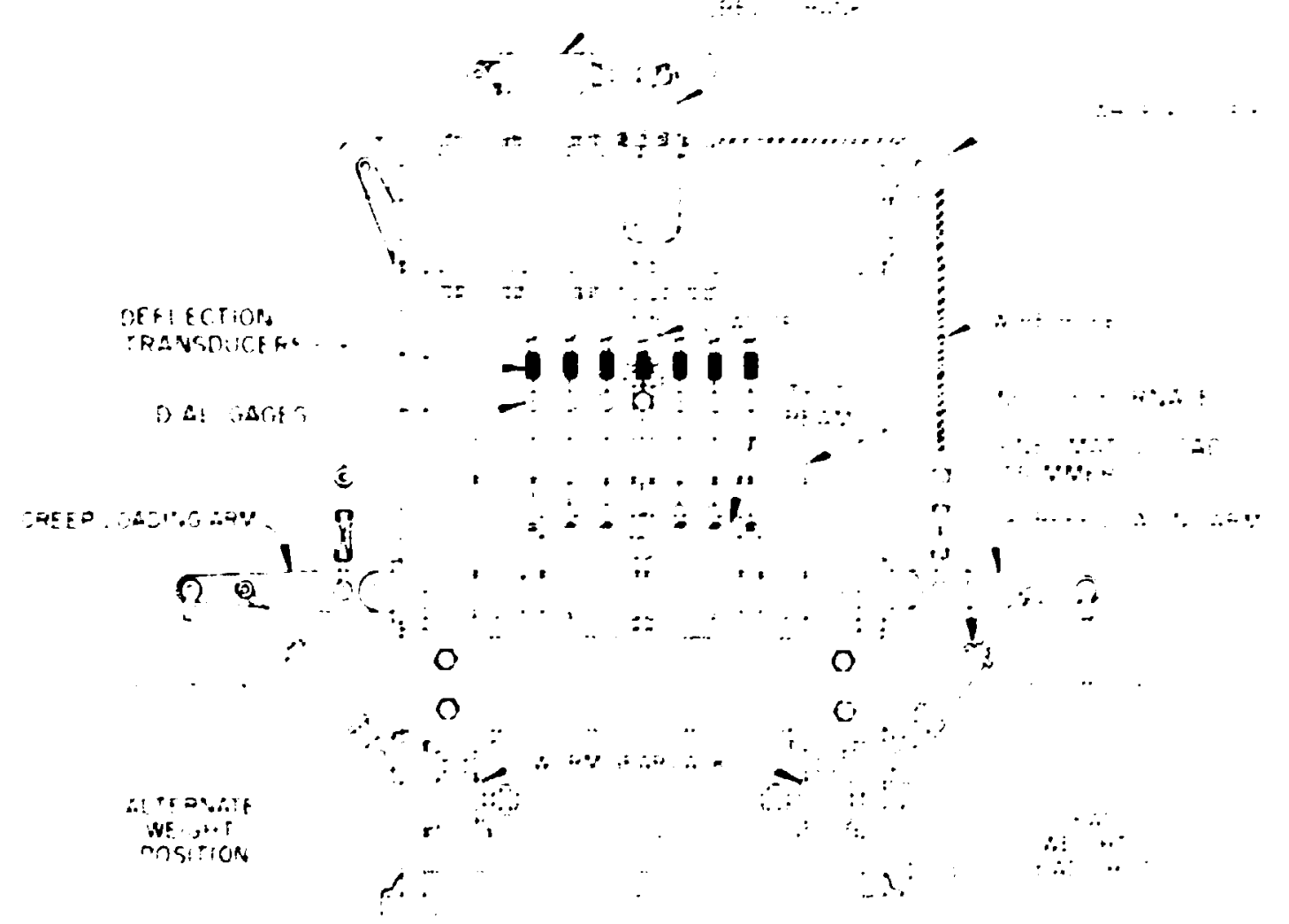

Fig. 6. Schematic drating wi cievated-tcmperature beam test facility $\left(1200^{\circ} \mathrm{F}=649^{\circ} \mathrm{C}\right)$. 


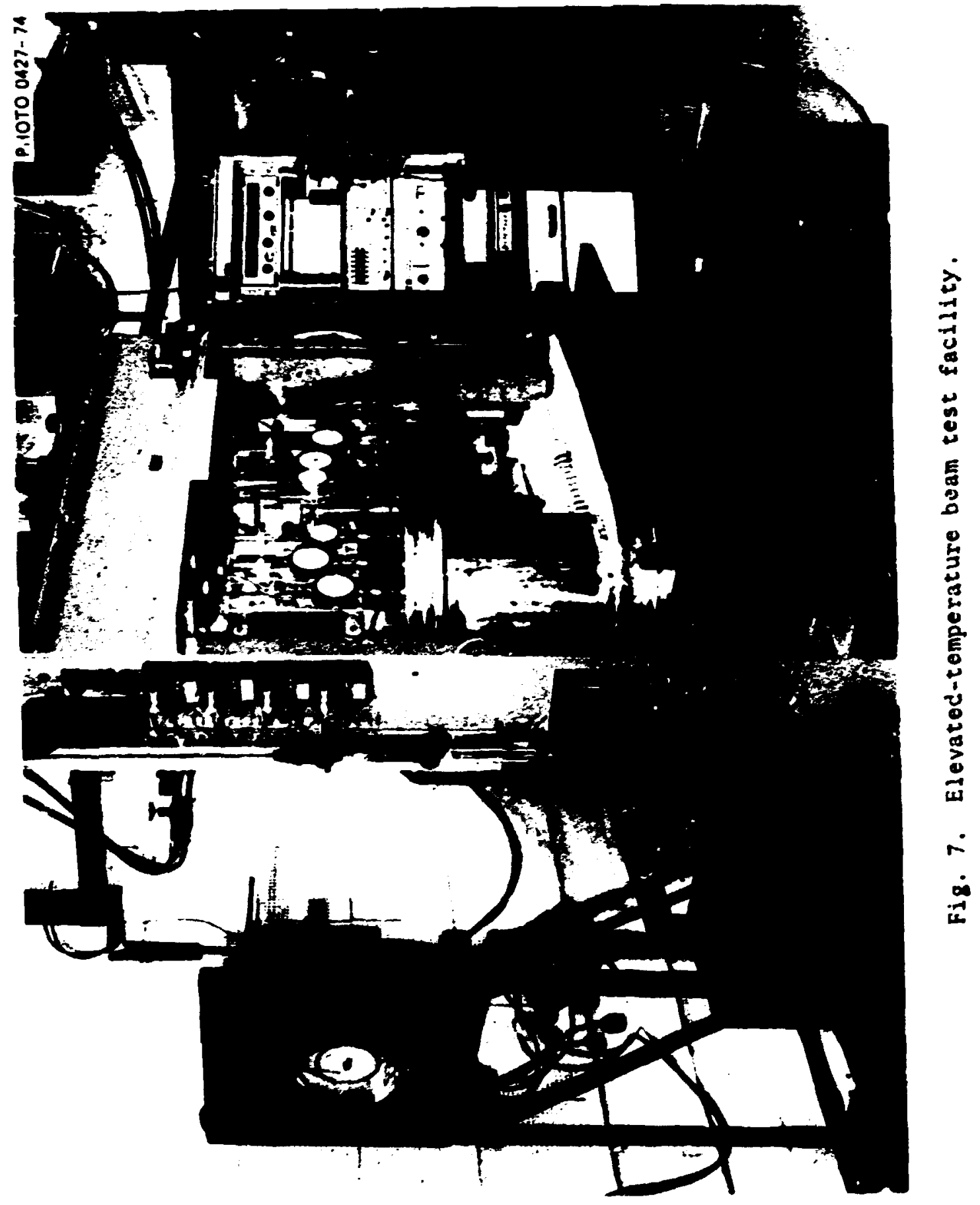


center-loaded bean specimen can be seen inside the furnace in Fig. 6, and in Fig. ? the front portion of the furnace has been removed so that the bean can be seen. For i jng-term constant-load creep periods, a system of deadweights acting through cables, pulleys, and a bell crank arrangement is used to apply a vertical load up or down through the creep loading arms shown on each side of the loading frame. To overcome the relatively small effects of friction, pneunatic load trimers (one of which can be seen attached to the loading arm in Fig. 7) are used. These automatically controlled trimers have a maximu capability of $200 \mathrm{lb}$.

For short-time cycling and load changes and for all deflection-controlled testing, the loading arms are disconnected at the bell crank and a double-acting hydraulic ram that operates in the horizontal position is attached to it. A servocontrolled hydraulic system with an MTS controller and a Data-Trak programer a:e used to activate the hydraulic ran.

The motor-driven camera setup in 5 ig. 7 was $u=e d$ tr. record data, again as a backup, during short-time load or deflection changes. By positioning precision voltmeters for load and strain display and a timer on top of the furnace, load, deflections, strains, auc time could all be recorted simultaneously by the camera, which is capalie of photographing at a rate of up to four frames per seccnd.

\subsubsection{Beam support system}

The beam support system is shown in Fig. 8. The lastelloy B dowel pins through each end of the beam were supported in $31.7 \mathrm{j}$ mm-long (1.25in.) slots in the 50.8-mm-dian $(2-i n$.$) support posts. To avoid probiems$ of self-welding during the long-term, high-temperature tests, the end post slots were faced with thin stellite inserts, top and bottom, which contacted the beam support dowels.

The center load $P$ was applied through llastelloy B dowels mounted within the centir loading arm. Alignment of thic loading arm was waintained by an extension guide rod which passed through a cylindricai uushing in the raction surface of the loading frame $t$ : : ow the beam. 


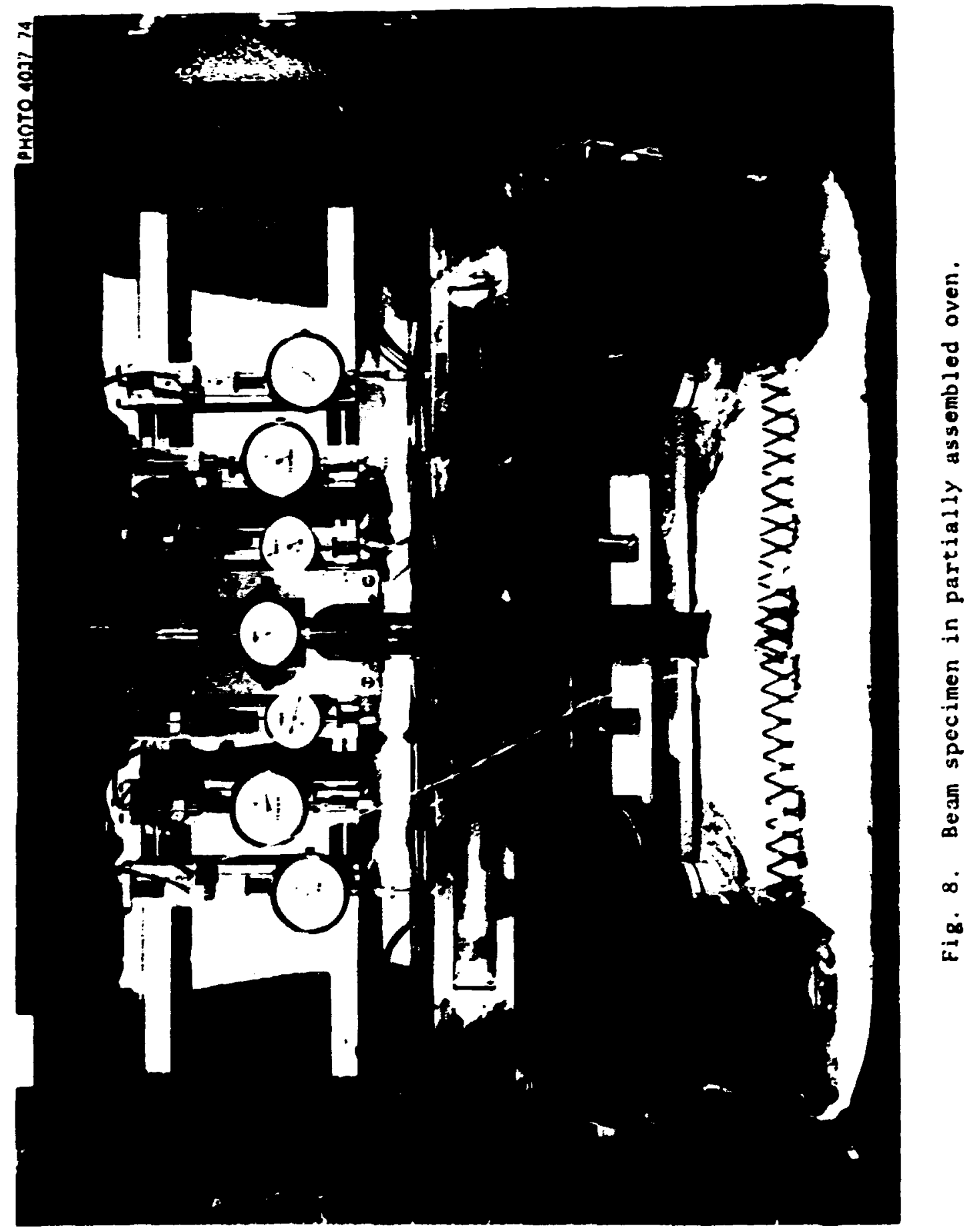




\subsection{3 load cells}

Appropriate!y sized dual-bridge load cells (BLH U3G2) were used for 2!: the tests. The dual bridge permitted dedication of one bridge to the data acquisition system and the other to the MTS control system for control, chart recording, and digital readout. Each load cell was periodically calibrated at a standards laboratory and then rechecked prior to each test using a $\mathrm{a} / \mathrm{V}$ calibrator.

\subsubsection{Deadweight loading system}

During constant-load creep periods the servocontrolled ran was disconnected at the bell crank and the deadweight syster was utilized. The bell crank (see fig. 6) provided a 4:1 mechanical advantage and was connected by cables to the cresp loading arms wounted at each side of the frame. The overall arrangement (bell crank and loading arms) provided a 20:1 wechanical advantage. The deadweight was provided by lead-filled containers attached to the creep loading arus. These containers were always preloaded to the appropriate loal to provide a smooth transition from ran to decdweight loading.

As in all mechanical systems, small friction forces were present and potentially troublesome. Without the pneumatic load trimer shown in Figs. 6 and 7 , the load would tend to drop slightly during the creep periods with intermittent abrupt step recoveries. The trimer was controlled by the load cell output through a current-t.j-air proportional converter. Deviations from the loall were sensed by a Foxhoro pnewatic controller which supplied sufficient force to the load arm to maintain the applied load within the preset limits of $=1$ : of the specified value.

\subsubsection{Hydraulic loading system}

Oil pressure to the hydraulic loading system was supplied from a 600 series Denison hydraulic puap with a variable-volume cylinder control. At one-fourth volume flow, the pump was capable of supplying 10.2 liter/ min (2.7 $\mathrm{gpm}$ ) at $6.895 \mathrm{MPa}(1000 \mathrm{psi})$ to the servovalve. The output from the pump was constant, and flow to the hydraulic ram was controlled hy the closed-loop servocontrol system from an MTS 442 contrnller. 
The planned load or defisction program was inscribed on a Data-Trak chart. The Data-Trak applied a signal to the MTS controller, which controlled the oil flow through the servovalve. The controller employed several safety devices - overpressure protectior, out-of-limits protection, etc. - that automatically closed high-pressure solenoid valves located in the entrance and sit ines to the servoralve, thus producing an instantaneous stop-action situation.

\subsubsection{Furnace}

The beam facility furnace, shown partially assembled in Figs. 7 and 8, was cesigned to permit simple assembly and disassembly over an extended period of tim:. It consisted of lig: stainless steel frame sections filled with 127 ( 5 in.) of high-temperature insulation and lined on the inside with perforated metal. Resistance heaters (27.7 V) attached to the four inside wall sections provided up to $8 \mathrm{~kW}$ of heat. Less than $2 \mathrm{~kW}$ was required to maintain a test specimen at $593^{\circ} \mathrm{C}\left(1100^{\circ} \mathrm{F}\right)$, thus greatly extending the 1 ife of the heaters.

The heaters were wired to permit three-zone control. The main heaters along the length of the bean made up one zone, while guard heaters at each end of the toam made up the other two. The main heaters were controlled by a Honeywell pneumatic temperature controller, with the total power limited by a hand-set Variac. Hand-se+ Variacs were used to control the two end zones.

\subsection{Circular Piate Test Facility}

As previously mentioned, the plate facility differs from the beam facility only in the details of the specimen support system and the furnace design. The plate facility is shown in Fig. 9; the load/deflection controller is on the left of the loading frame and the temperature controller is on the right.

Figure 10 shows a plate specimen mounted in the partially assembled furnace with the races of stainless steel ball bearings showing on the top and bottom surfaces. A slight vertical gap was maintained in the race supports to prevent binding of the plate as it deflected. 


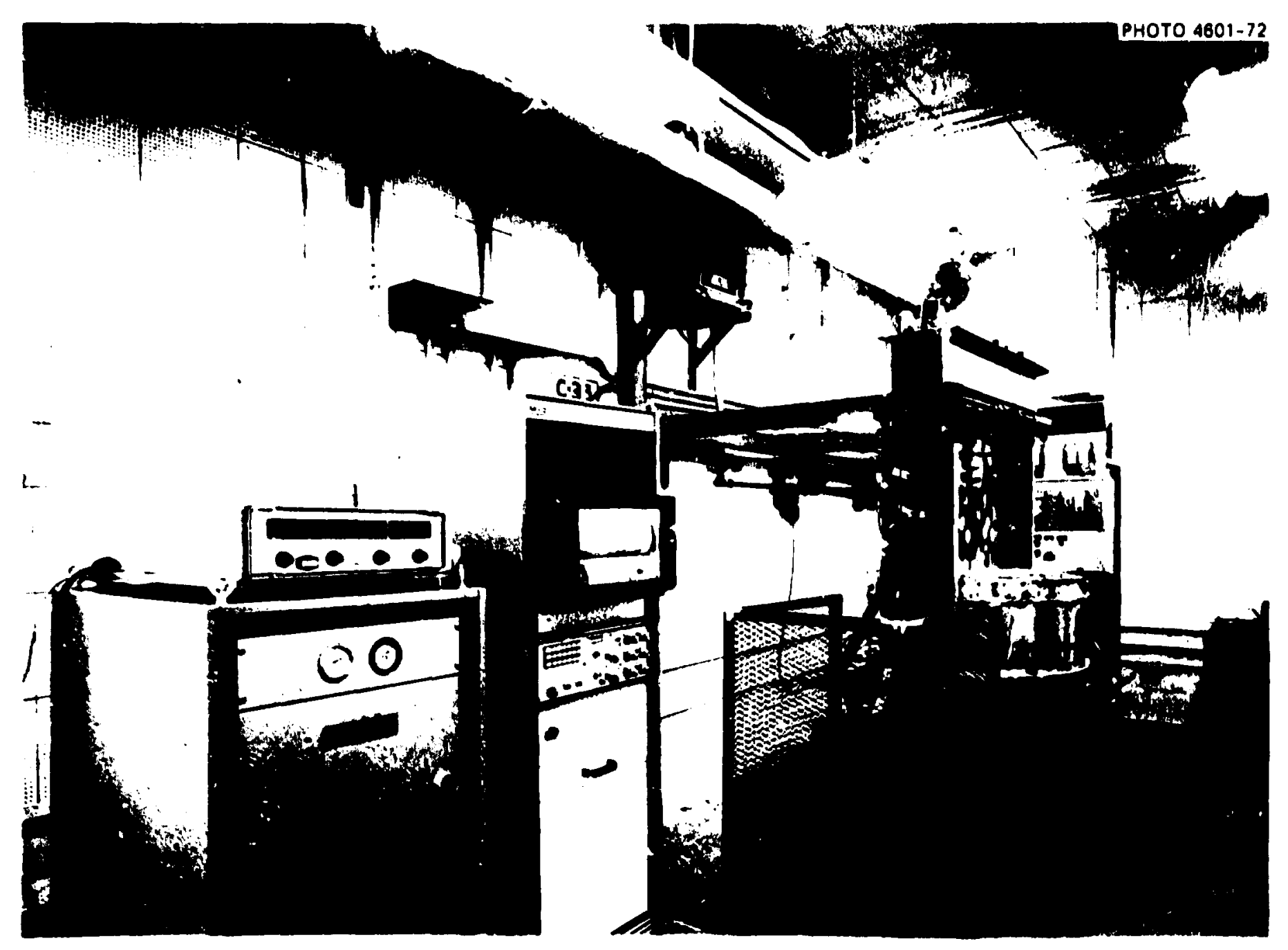

Fig. 9. Elevated-temperature circular plate test facility. 


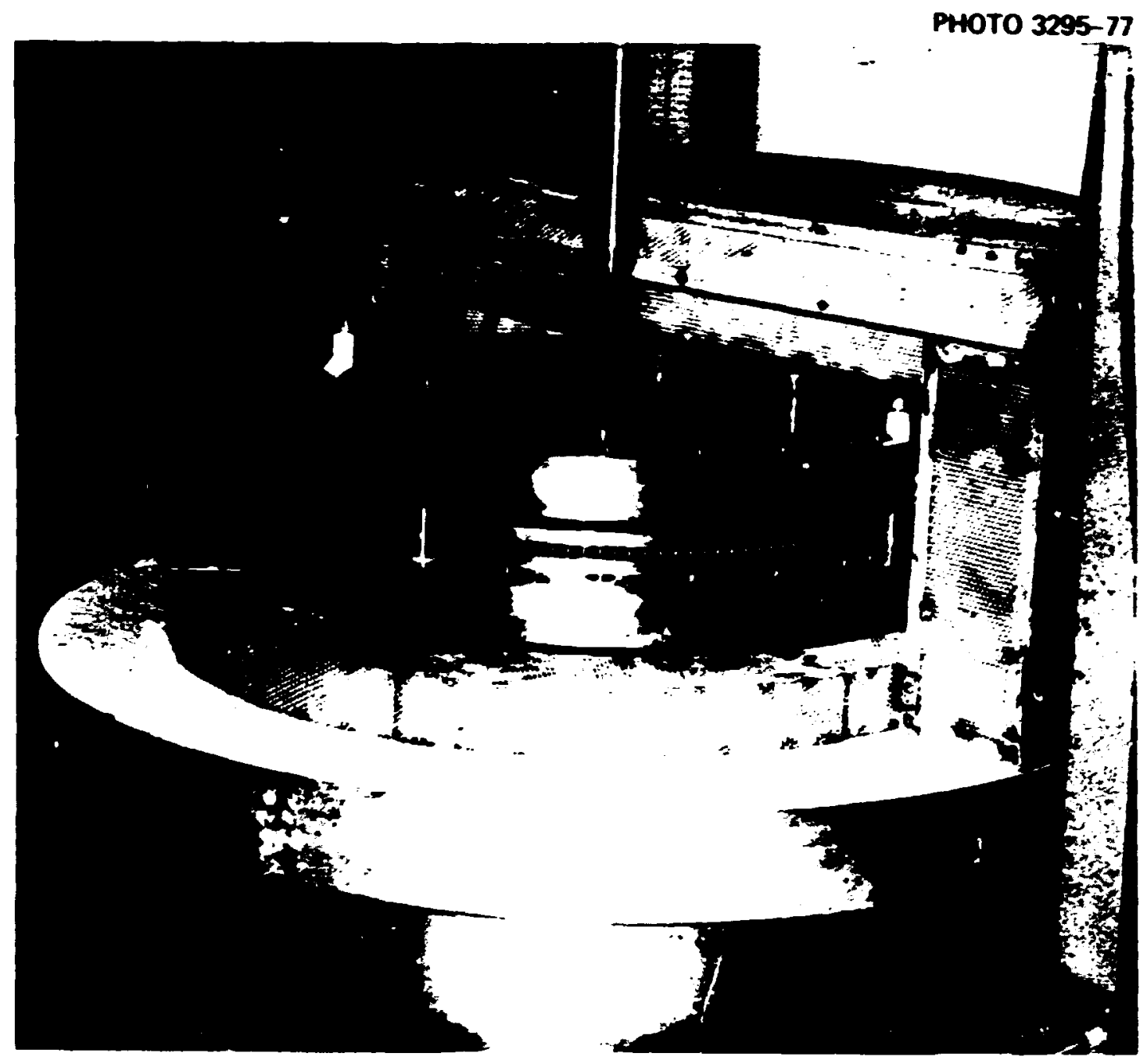

Fig. 10. Circular plate specimen in partially assembled oven.

The resistance heaters for the plate were located in a serpentine manner around the periphery of the plate and in a plane configuration below it. These heaters were controlled as a single zone. No additional guard heaters were required.

\subsection{Test Procedure}

The sast proisedure for both beam and plate tests consisred in heating the unloaded specimen to $593^{\circ} \mathrm{C}\left(1100^{\circ} \mathrm{F}\right)$ and obtaining a uniform temperaturz over the specimen surface prior to starting the lcading. This 
heatup anc adjustment period was generally kept to less than $24 \mathrm{hr}$. During the tests an attempt was made to maintain the indicated terperatures at $593 \pm 2.78^{\circ} \mathrm{C}\left(11 \mathrm{CO} \pm 5^{\circ} \mathrm{F}\right)$. The actual neasured teaperature ranges during each of the tests are shown as functions of tine in Appe. $\because$ ices : through I. As shown there, the cemperature variation sometimes exceeded the specified limits by a few degrees, usually for only short periods of tibe.

The loads and deflections were controlled to \pm 18 of the nominal values. 


\section{TEST RESULTS}

The test :esults given in this section are in terms of the response of the center loads and cer.ter deflections, which typify the overall structural response. The results are arranged in the order shown in Tables 1 and 2. Figure 2, the load and deflection histograns, and Tables 1 and 2 should be referred to along with the results given in this section. As previously mentioned, the numbered points in Fig. 2 are referenced on each of the grapnical presentations of tlie test data.

\subsection{Load-Controlled Bean Tests}

Beams B9 and B10 were companion load-controlled tests. The only difference between the two is that bean Blo was subjected to ten precreep load cycles and bean B9 was not.

The measured center deflection vs load for the initial loading of beam B9 to $8896 \mathrm{~N}$ (2000 1b), as well as for the other load changes associated with the creep portions of the test, is shown in Fig. 11. The creep

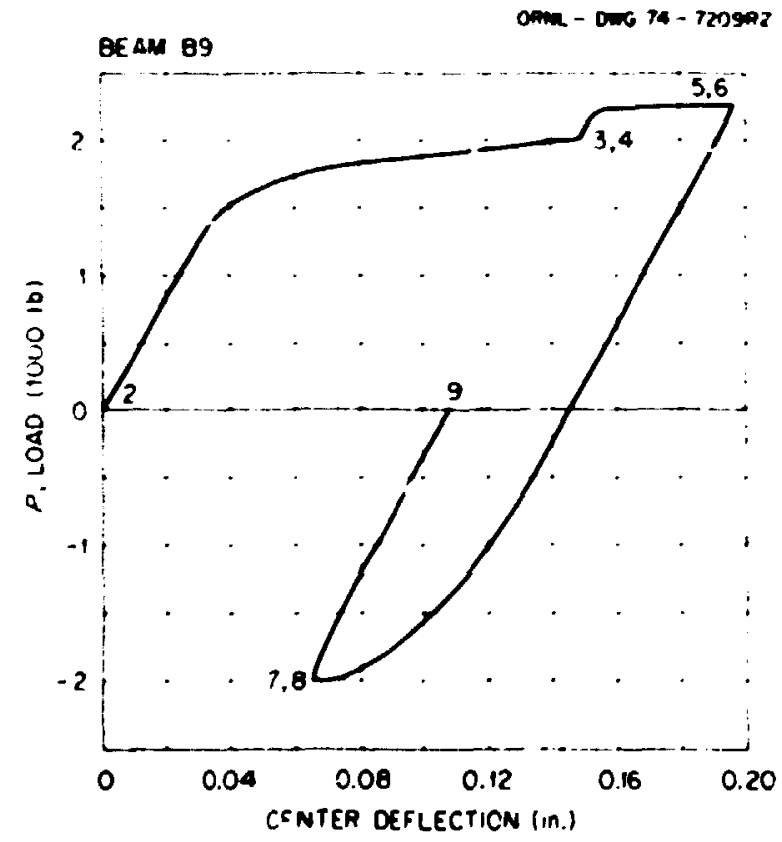

Fig. 11. Loaci vs center deflection for short-time load changes associated with creep portions of bean $B 9$ test $(1 b \times 4.448=N$, in, $x$ $25.4=\mathrm{mm}$ ). 
deflections that occurred at $8896,10,008$, and $-8896 \mathrm{~N}(2000,2250$, and -2000 1b) have been subtracted so that the deflections shown are essentially elastic-plastic. Referring to Fig. $2 a$, the curves in Fig. 11 depict the measured response between points 2 and 3,1 and 5,6 and 7 , and 8 and 9. These points are identified on Fig. 11, as they are on all of the figures in this section. Figure 12, a companion plot to Fig. 11, shows the creep deflection at the center of beam $B 9$ as a function of time. Figure 13 depicts the load vs center deflection behavior during the final ien short-time load cycles (points 9 to 10 in Fig. 2a) of beam B9. For clarity, only the first, second, and tenth cycle responses are shown, and thsse are labeled by the circled numbers; the uncircled numbers always refer to points on the histogram.

The load-deflection behavior for the initia: ten short-time load cycles of beam B10 is depicted in Fig. 14. Figures 15 and 16 for bean B10 are analogous to Figs. 11 and 12 for beam B9; they depict the shorttime load-deflection response and the creep-deflection response, respectively, during the long-term portions of the test. Figure 17, which shows the postcreep load-cycling response of beam $B 10$, is comparable to Fig. 13 for beam B9.

Additional results for beams $B 9$ and $B 10$ are given in Appendices $B$ and $C$, respectively. All the measured deflections and strains for $B 9$ are

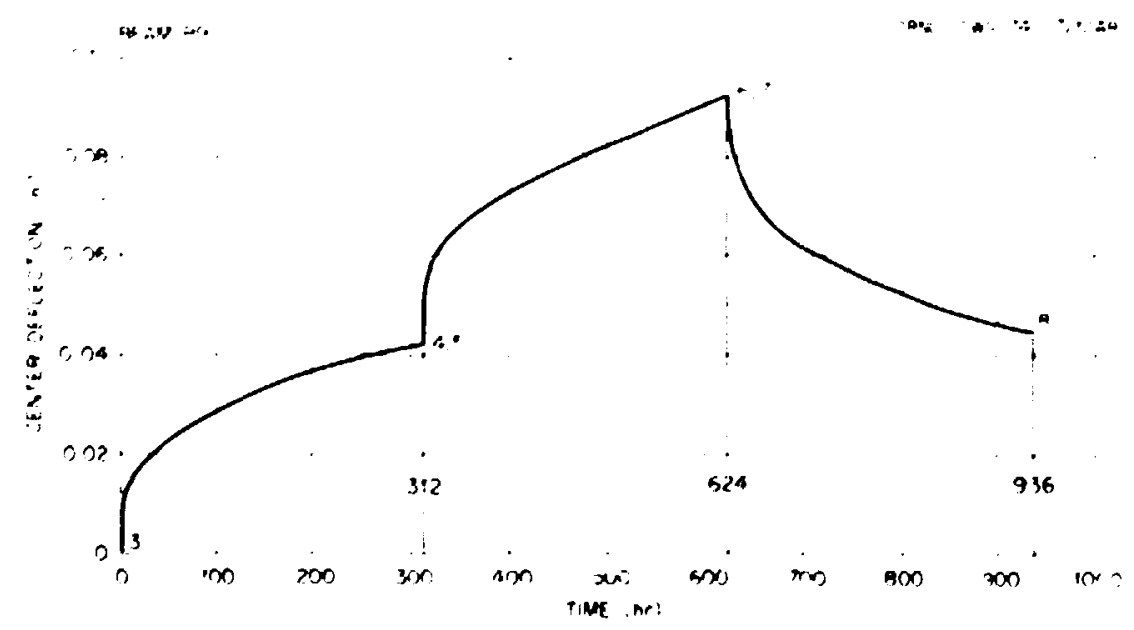

Fig. 12. Creep deflection vs time for center of bean $B 9$ (in. $x$ $25.4=\mathrm{mm}$ ) 


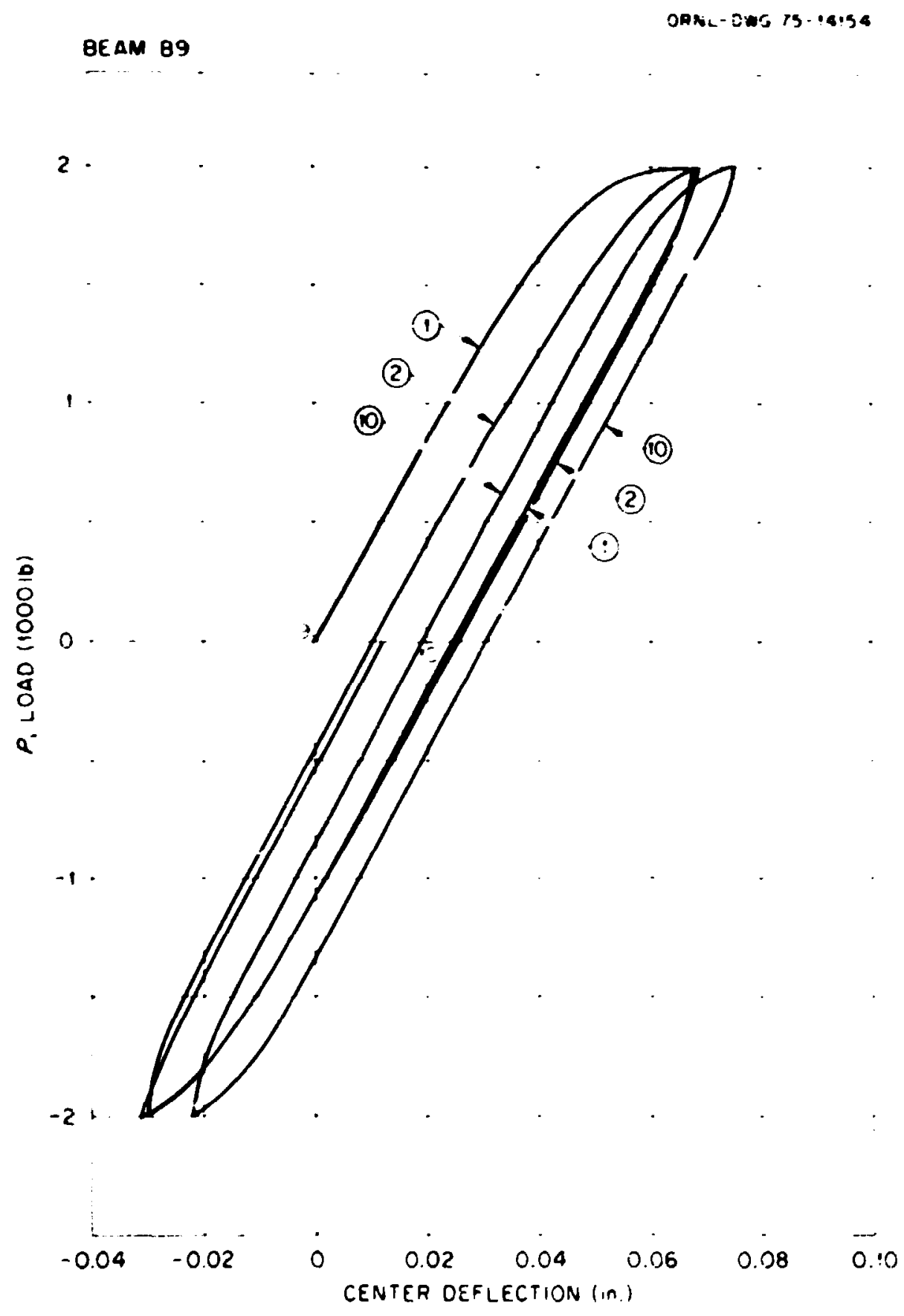

Fig. 13. Load vs center deflection during ten short-time, postcreep load cycles of beam B9. The measured deflection was zeroed at point 9 for this plot $(1 \mathrm{~b} \times 4.448=\mathrm{N}$, in. $\times 25.4=\mathrm{mm})$. 


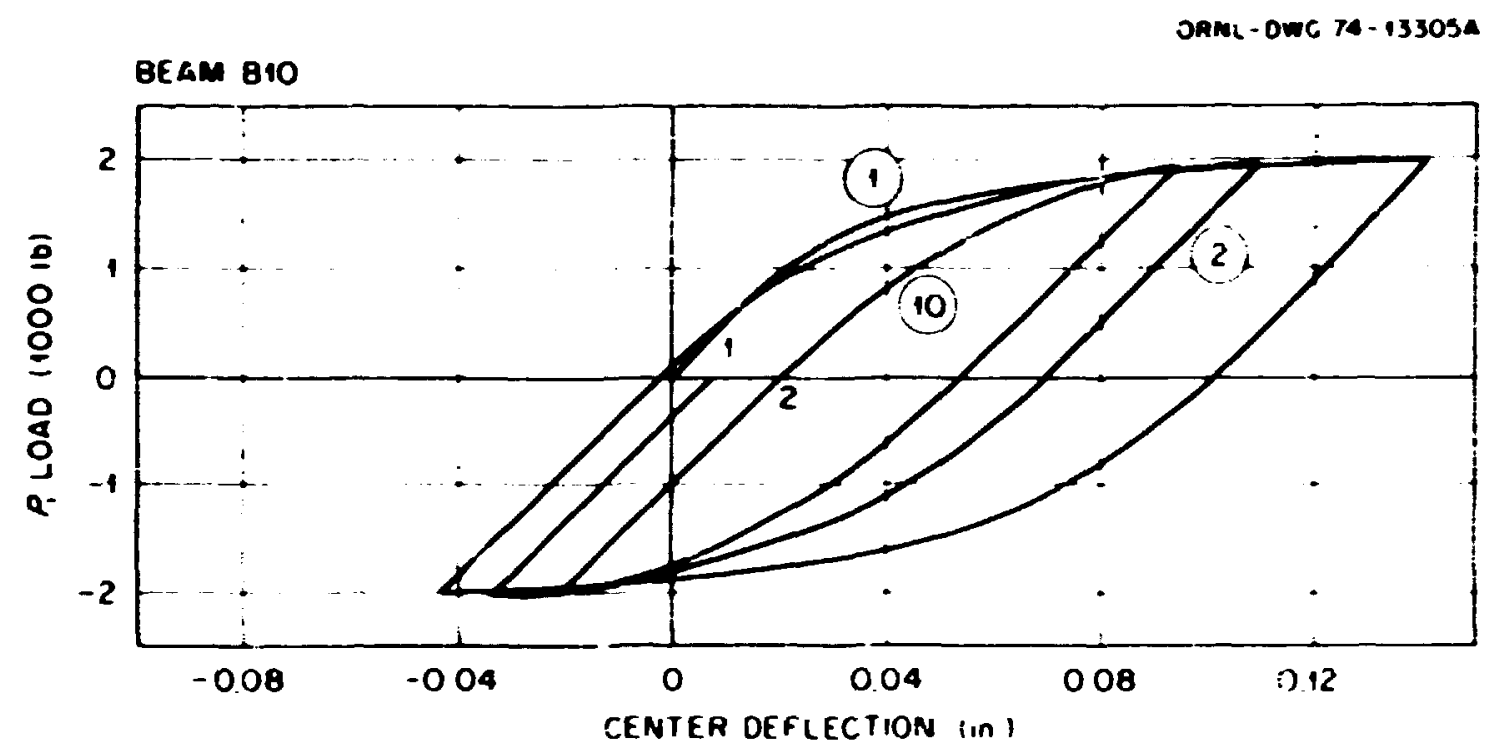

Fig. 14. Load vs center deflection during ten short-time, precreep load cycles of bean B10 ( 1 b $\times 4.448=N$, in. $\times 25.4=m$ ).

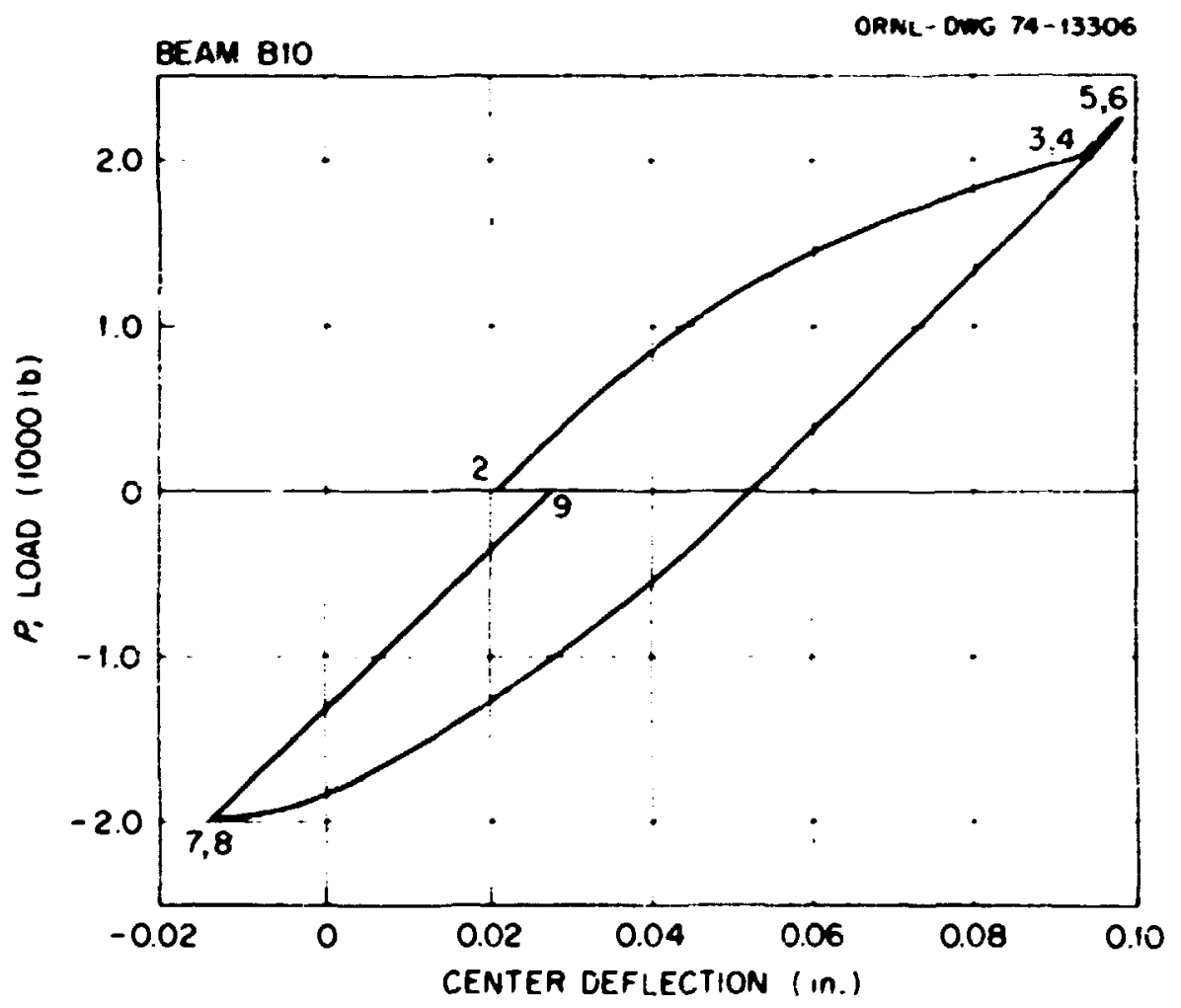

Fig. 15. Load vs center deflection for short-time load changes associated with creep portions of bean BlO. The measured deflection was zeroed at point 2 for this piot $(1 \mathrm{~b} \times 4.448=\mathrm{N}$, in. $\times 25.4=\mathrm{mm})$. 


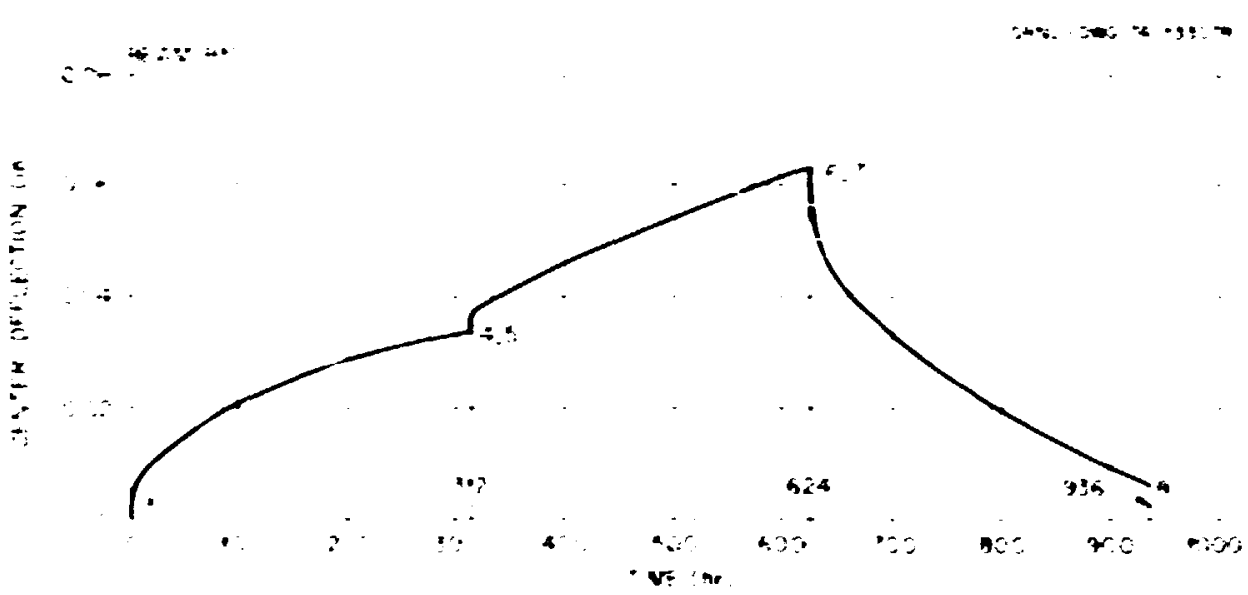

Fig. 16. Creep deflection vs time for center of bean $B 10$ (in. $x$ $25.4=m$ ).

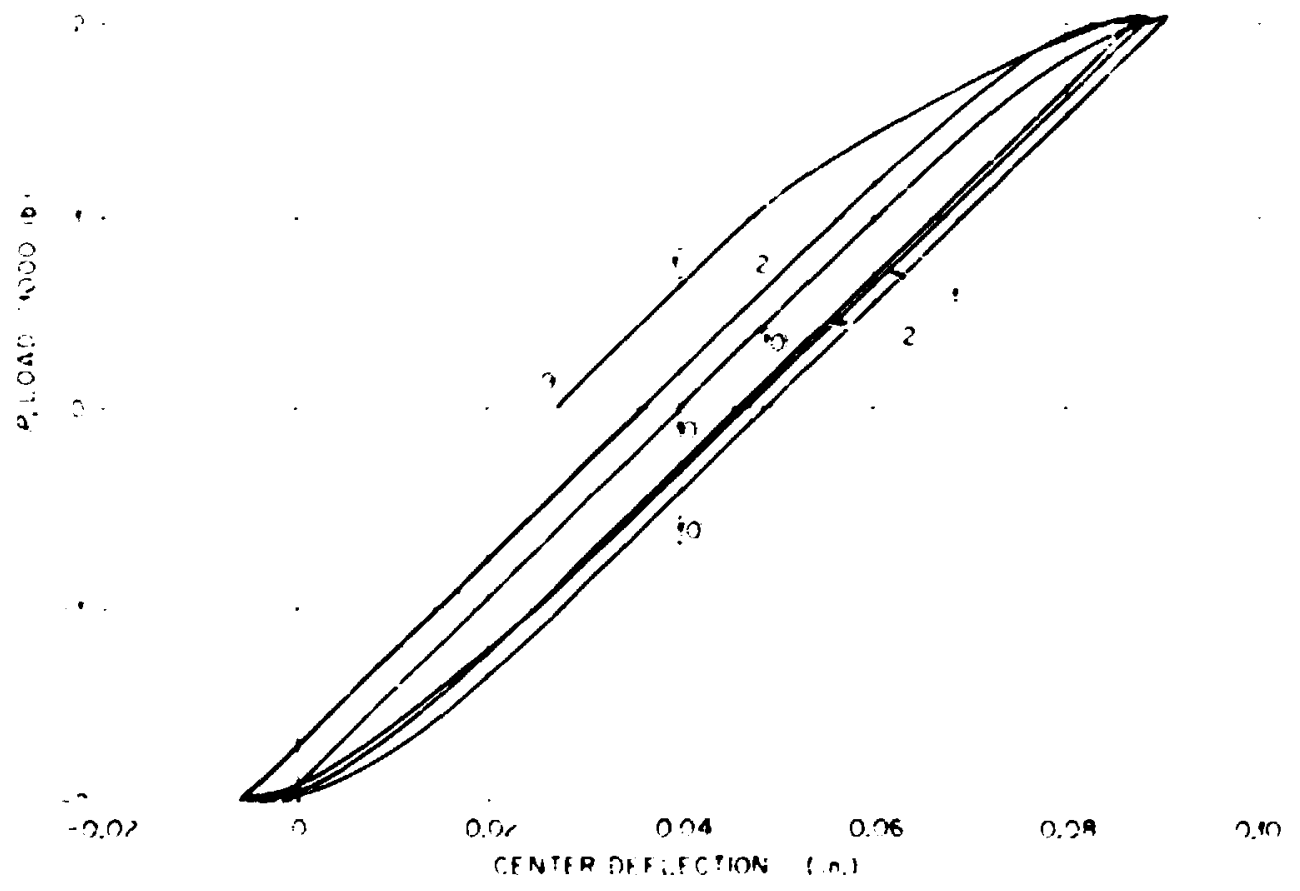

Fig. 17. L.oad vs center deflection during ten short-time, postcreep load cycles $\because$ bean $B 10(1 \mathrm{~b} \times 4.448=N$, in. $\times 25.4=\mathrm{mm})$. 
presented for the entire test history. The measured strains are presented for bean 810 .

\section{S.2 Deflection-Controlled Bean Tests}

Beans $B 7$ and $B 8$ were companion deflection-controlled tests, with $B 8$ having the ten short-time precreep deflection cycles.

Figure 18 shows tha load vs center deflection for the deflection changes associated with the relaxation portions of beam test $B 7$. The initial loading to a center deflection of $2.54 \mathrm{ma}(0.10 \mathrm{in}$ ) is shown by the curve from 2 to 3 (refer to Fig. $2 \hat{c}$ ). The load decrease at a deflection of $2.54 \mathrm{~m}(0.10 \mathrm{in.})$ (points 3 to 4$)$ corresponds to the initial relaxation period. Figure 19 shows the load vs $t$ ime response for the two relaxation hcld periods, and Fig. 20 depicts the response durirg the ten short-i ime postcreep defl zction cycles.

The precreep cyclic deflection response of beam $B 8$ is shown in Fig. 21. Figures 22 to 24 for bean B8 correspond to Figs. 18 to 20 for beam B7. Comparisons of the corresponding figures show that the prior cycling in beam $B 8$ resulted in higher loads at the beginning of each relaxation

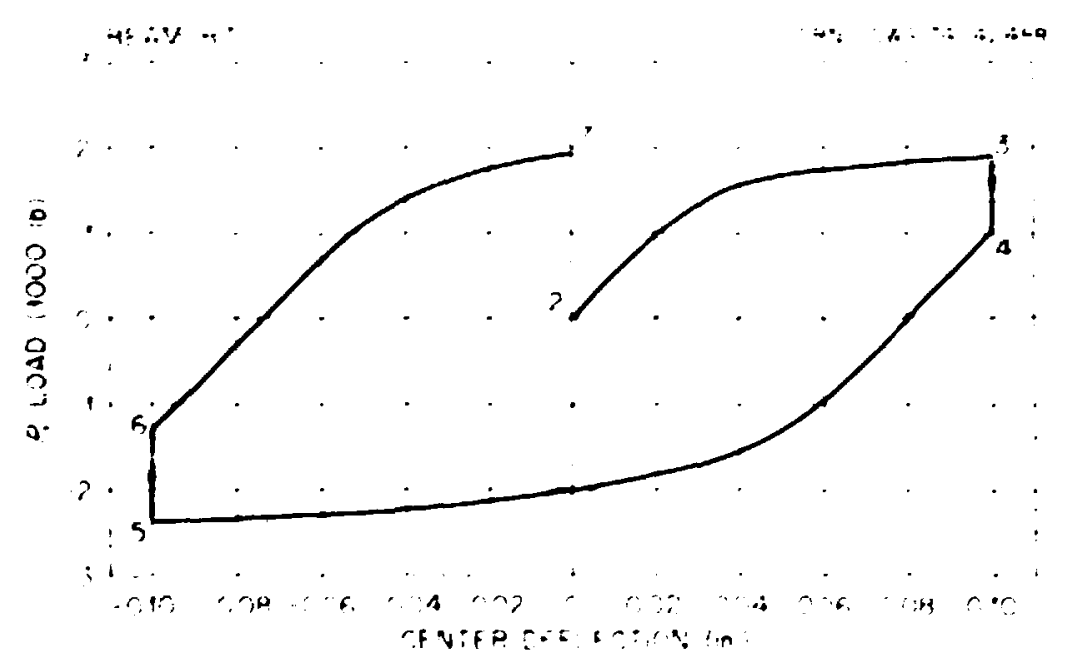

Fig. 18 Load vs center deflection changes associaced with relaxation portions of beam $B i(1 b>4.448=N$, in. $\times 25.4=\mathrm{mm})$. 


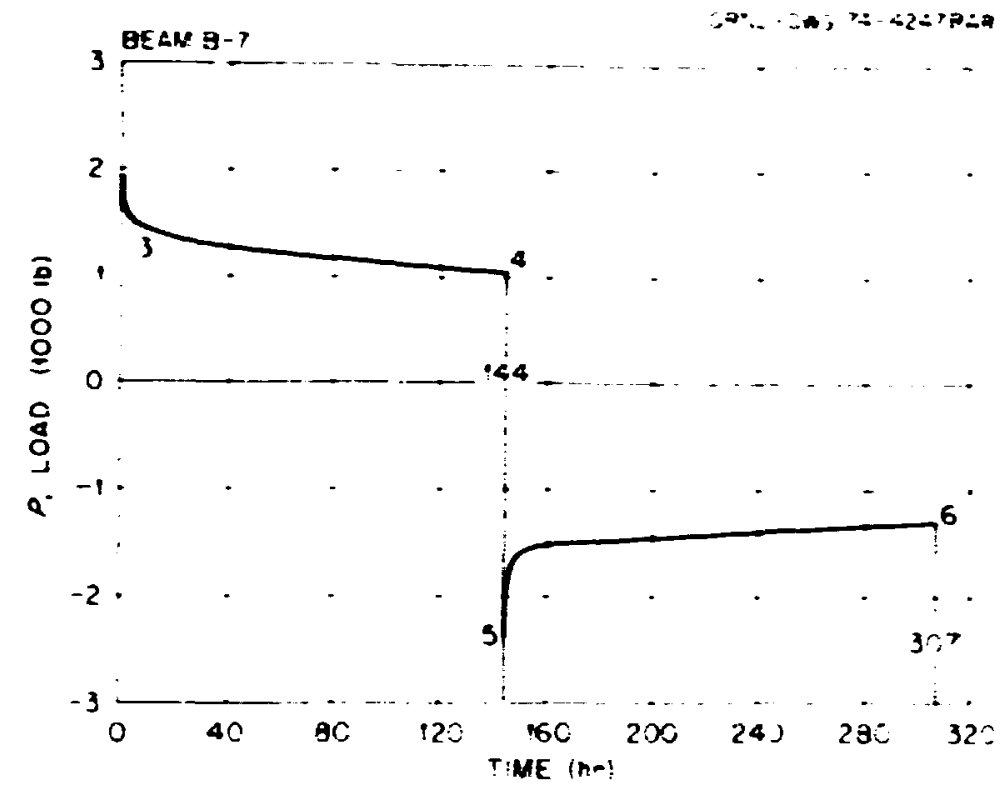

Fig. 19. Load relaxation vs time for beam $B 7(16 \times 4.448=N)$.

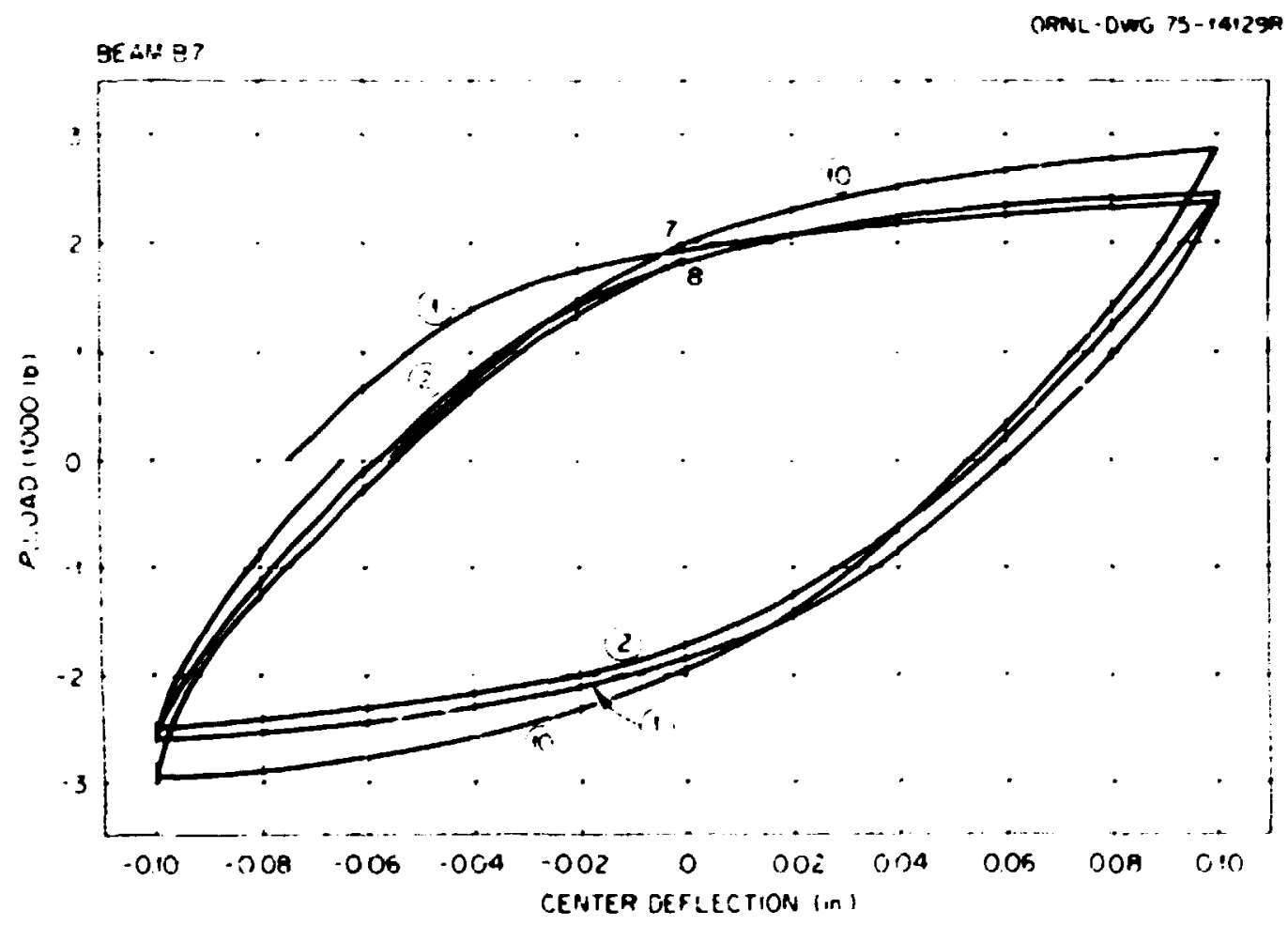

Fig. 20. Load vs center deflection during ten shott-time, postcreep deflection cycles of bean $B 7(1 b \times 4.448=N$, in. $\times 25.4=m$ m). 


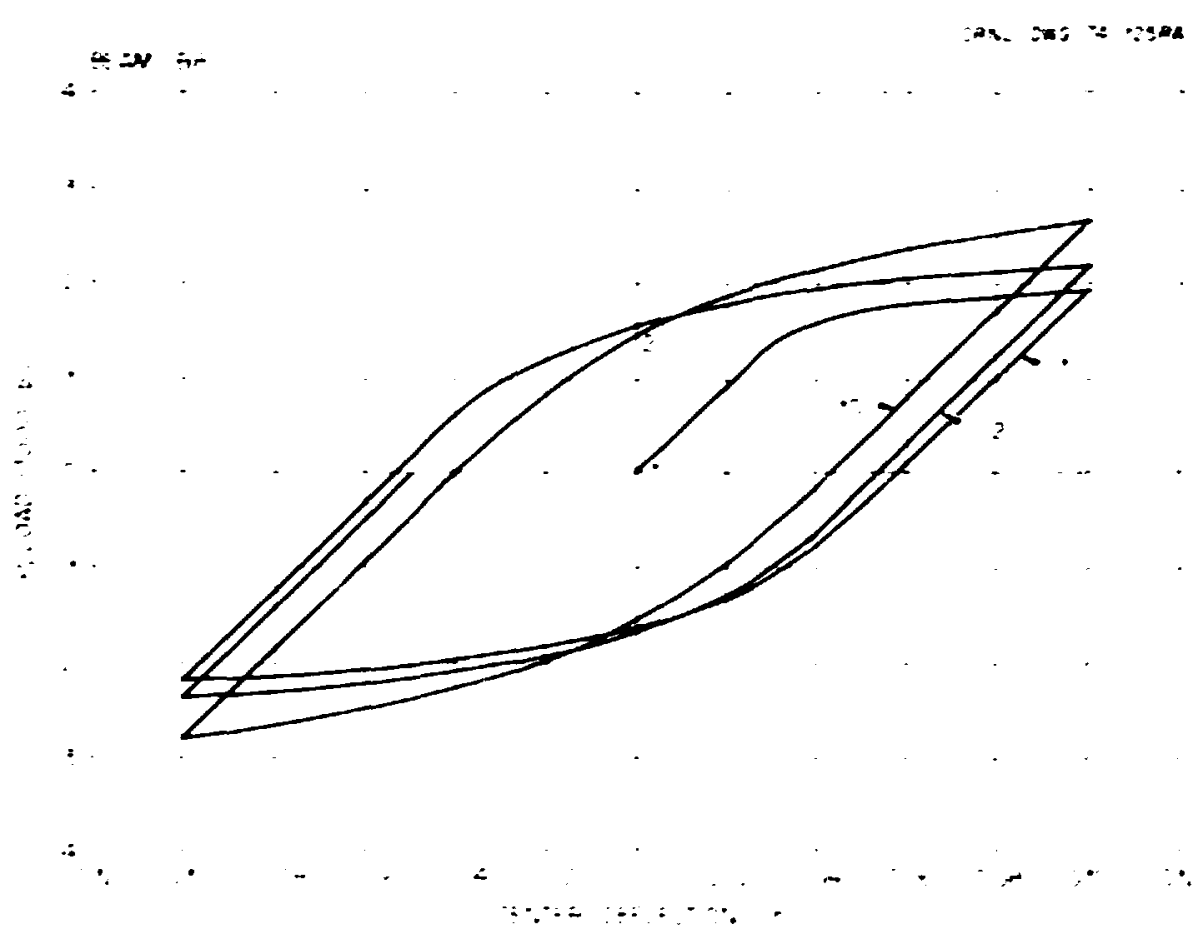

Fig. 21. Load vs center deflection during ten short-time, precreep deflection cycles of beam B8 $(1 b \times 4.448=x$, in. $\times 25.4=\mathrm{mm})$.

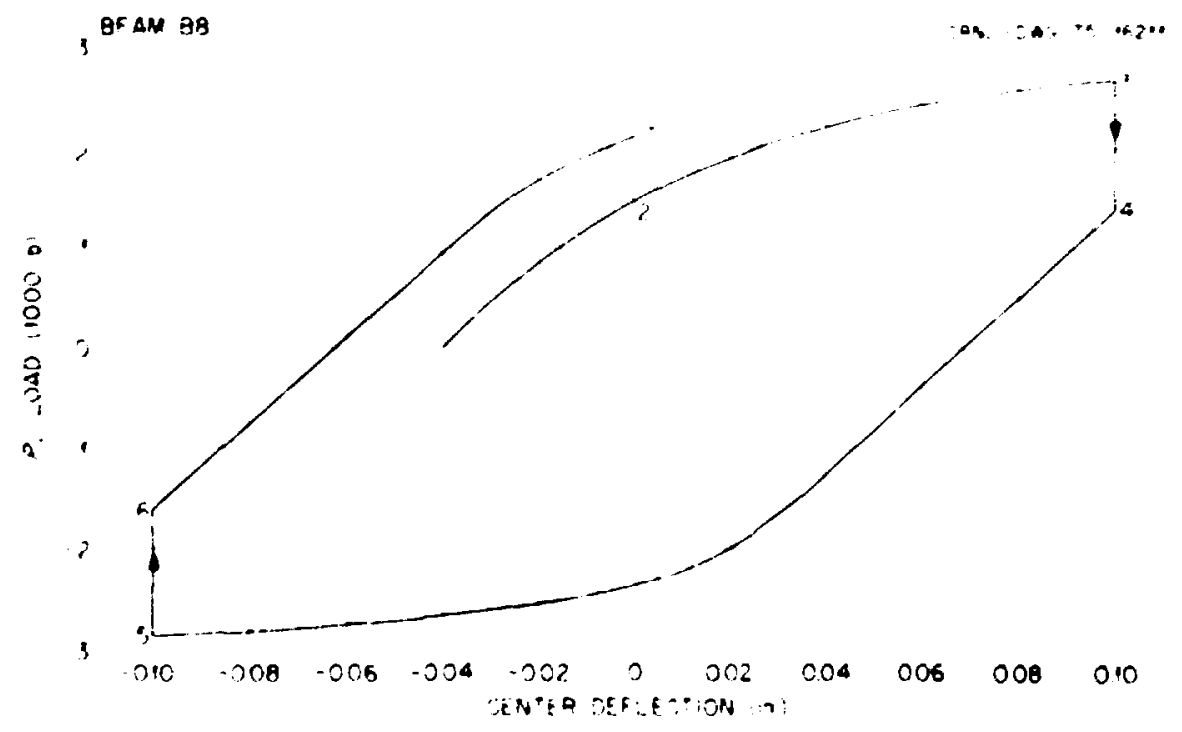

Fig. 22. Load vs center deflection changes associated with relaxation portions of beam B8 ( $1 \mathrm{~b} \times 4.448=N$, in . $\times 25.4=\mathrm{mm}$; . 


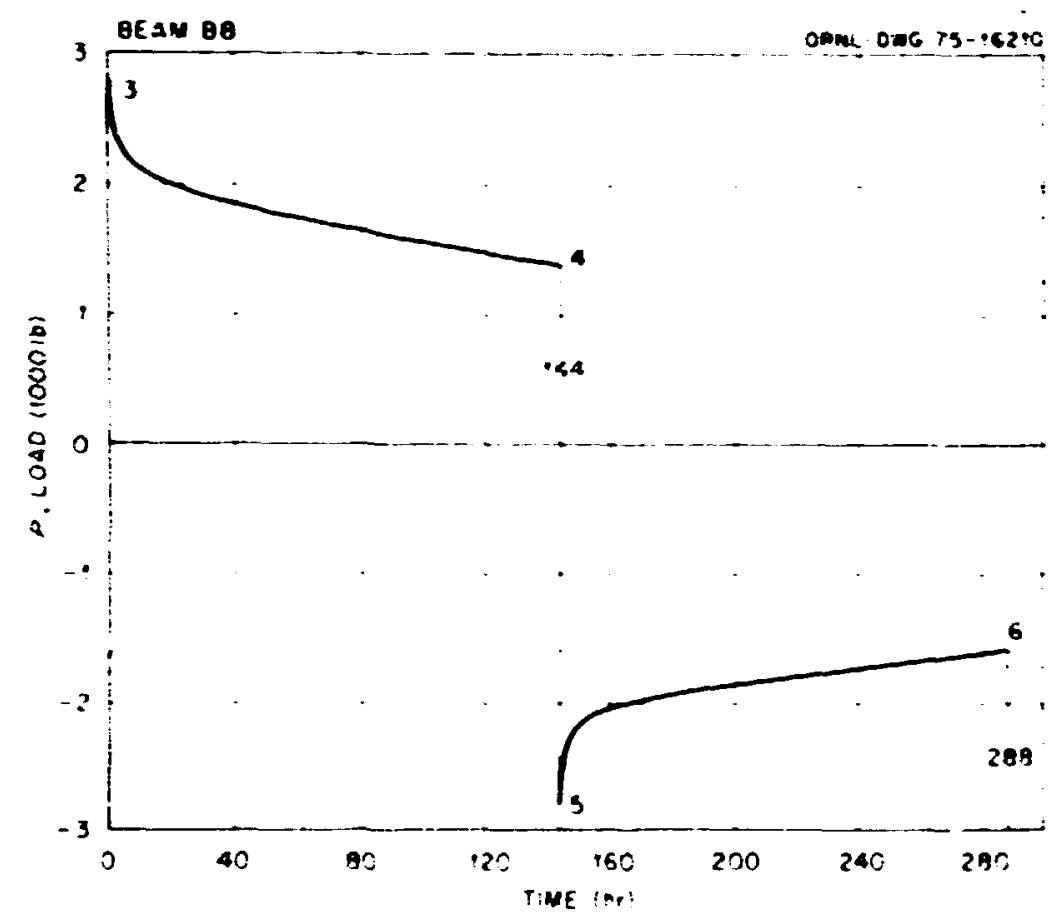

Fig. 23. Load relaxation vs time for beam $B 8(1 b \times 4.448=N)$.

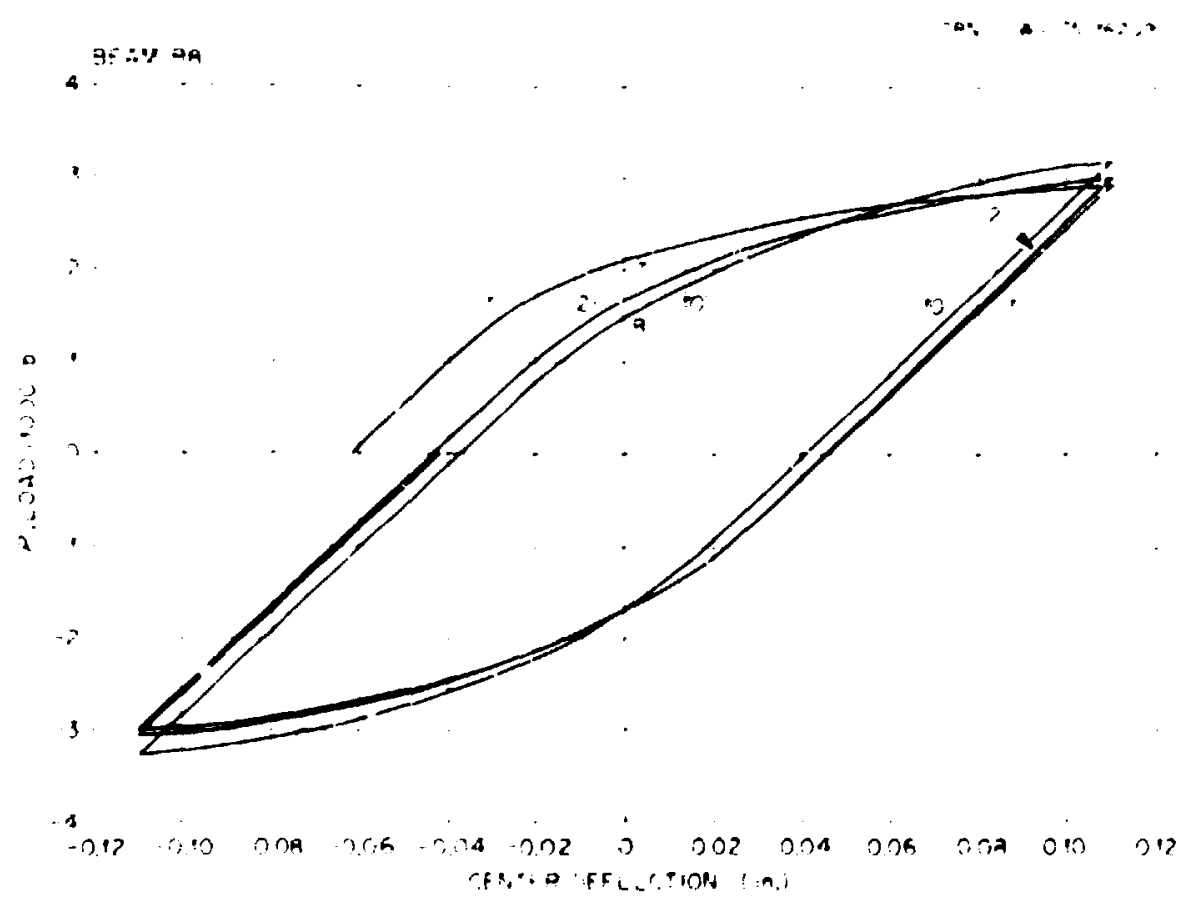

Fig. 24. Load vs center deflection during ten short-time, postcreep deflection cycles of bean $B 8(1 b>4.448=N$, in. $\times 25.4=\mathrm{mm})$. 
period and, consequently, in more relaxation. Note that the deflection range for the postcreap cycles was $\pm 2.79=(0.11$ in.) for bear $B 8$ but $\pm 2.54 \mathrm{~m}(0.10 \mathrm{in.})$ for bean $B 7$.

Additional results for beans 37 and 68 are given in Appendices $D$ and E, respectively. All the measured deflections and strains for beal B7 are presented for the entire test history. Deflection and strain responses during the ten precreep cycles are given for bean 88 . as is the strain response during the ten postcreep deflection cycles.

\subsection{Load-Controlled Place Tests}

Circular plates CPS and CP2 were companion load-controlled tests akin to load-controlled bean tests $B 9$ and B10. Like the bean tests, the only difference between the two plate tests was that plate CP2 was subjected to ten precreep load cycles while plate CPS was not.

The measured load vs center deflaction response of plate CPS is shown in Fig. 25 for the load chang's associated with the creep portions of the test. Figure 26 shows the creep defler:tion at the center of F!ate CPS as a function of $t$ ims. and Fig. 27 depicts the load vs center defiection behavior during the final ten short-time load cycles.

The load-deflection behavior for the initial ten short-time load cycles of plate CP2 is depicted in Fig. 28. Again, comparison of this figure with the previous figure for the postcreep cyclic response of plate CPS illustrates the hardening effact of the previous inelastic history in the case of CPS.

Figures 29 and 30 for plate CP2 are analogous to Figs. 25 and 26 for plate CP5; they depict the short-time load-deflection response and the creep-deflection response, respectively, during the long-term portinns of the test. Finally, fig. 31 shows the postcreep load cycling response of plate CP2.

Additional results for plates CPS and C.P2 can he found in Appendices $F$ and $G$, respectively. All the measured deflections and strains for plate CPS are presented for the entire test history. The measured strains during the precreep and postcreep load cycles are presented for plate CP2. 


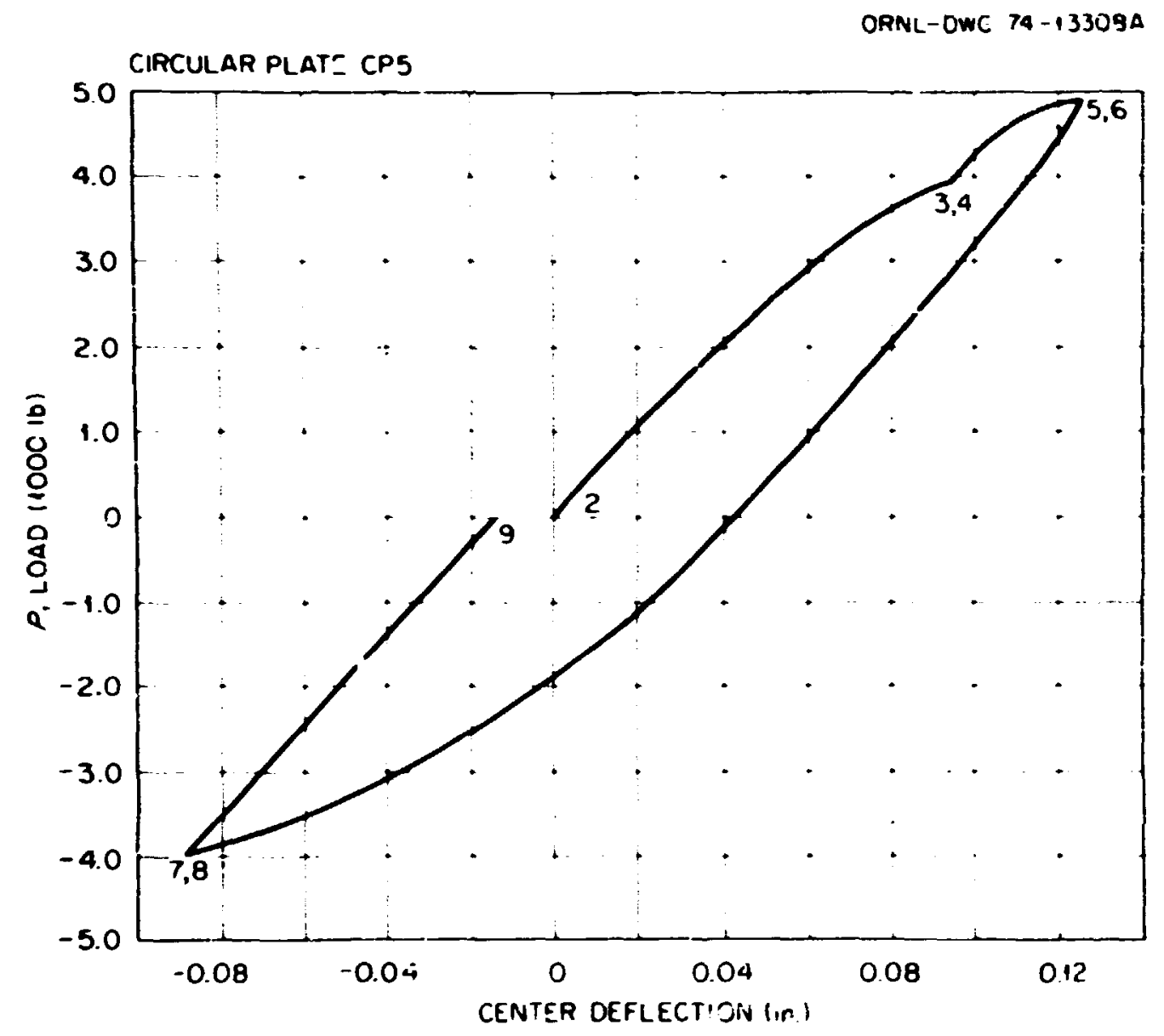

Fig. 25. Iriad vs center deflection for short-time load changes associated with creep portions of plate CPS (1b $\times 4.448=N$, in. $x$ $25.4=\mathrm{mm})$.

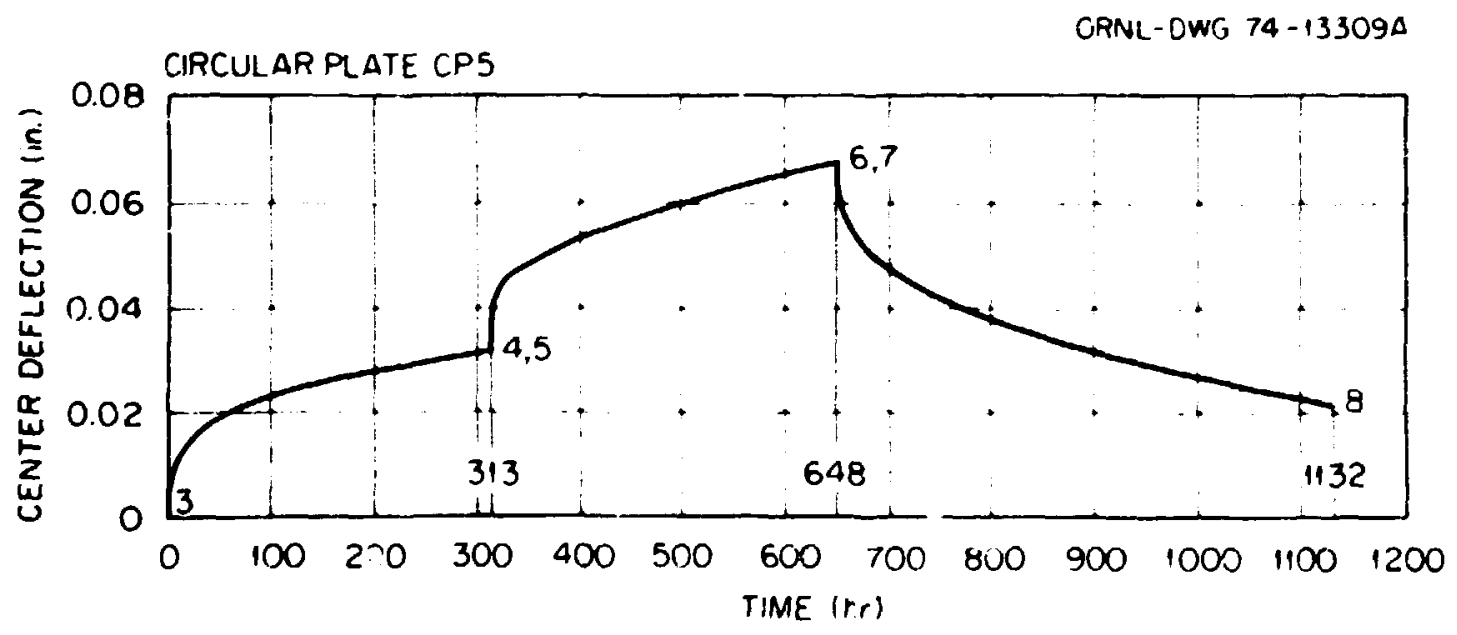

Fig. 26. Creep deflection vs time for center of plate CPS (in. $x$ $25.4=\mathrm{mm})$. 


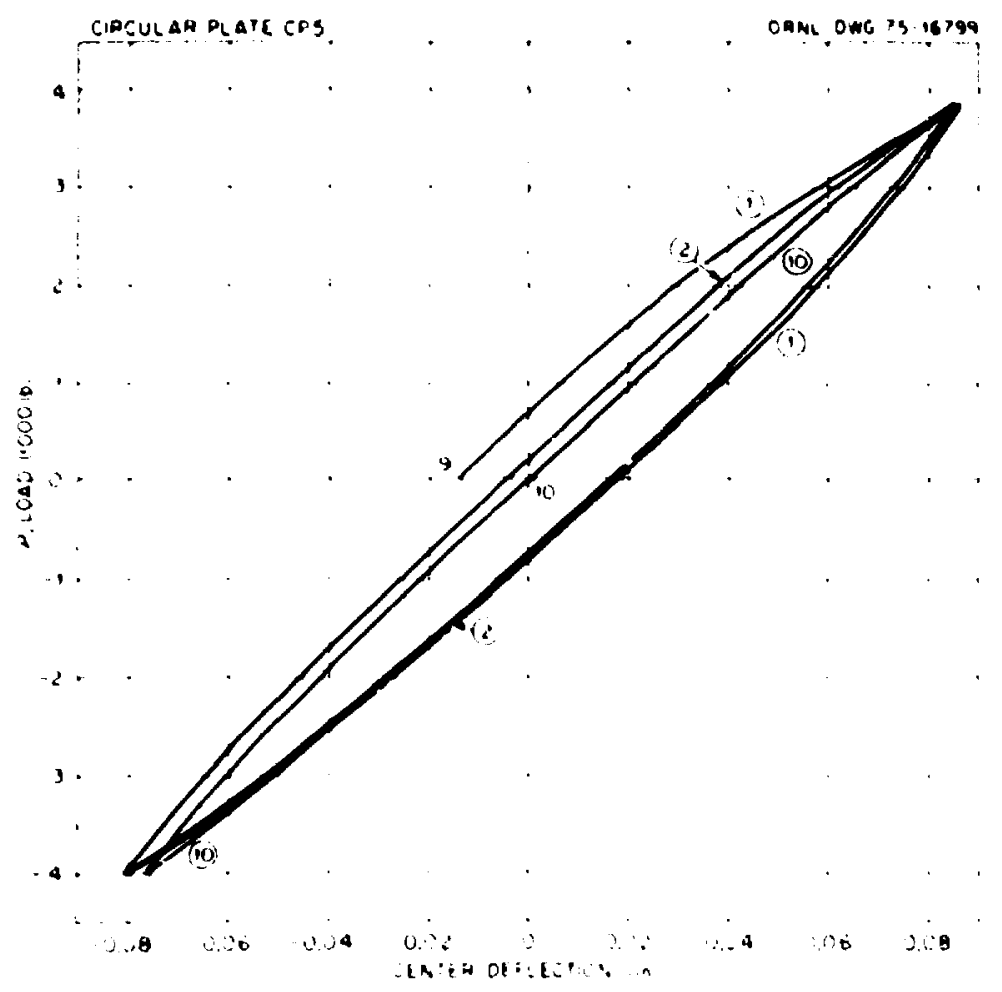

Fig. 27, Load vs center deflection during ten short-time, postcreep load cycles of plate CP5. The measured deflection was zeroed at point 9 for this plot $(1 \mathrm{~b} \times 4.448=\mathrm{N}$, in. $x$ $25.4=\mathrm{mm}$ ).

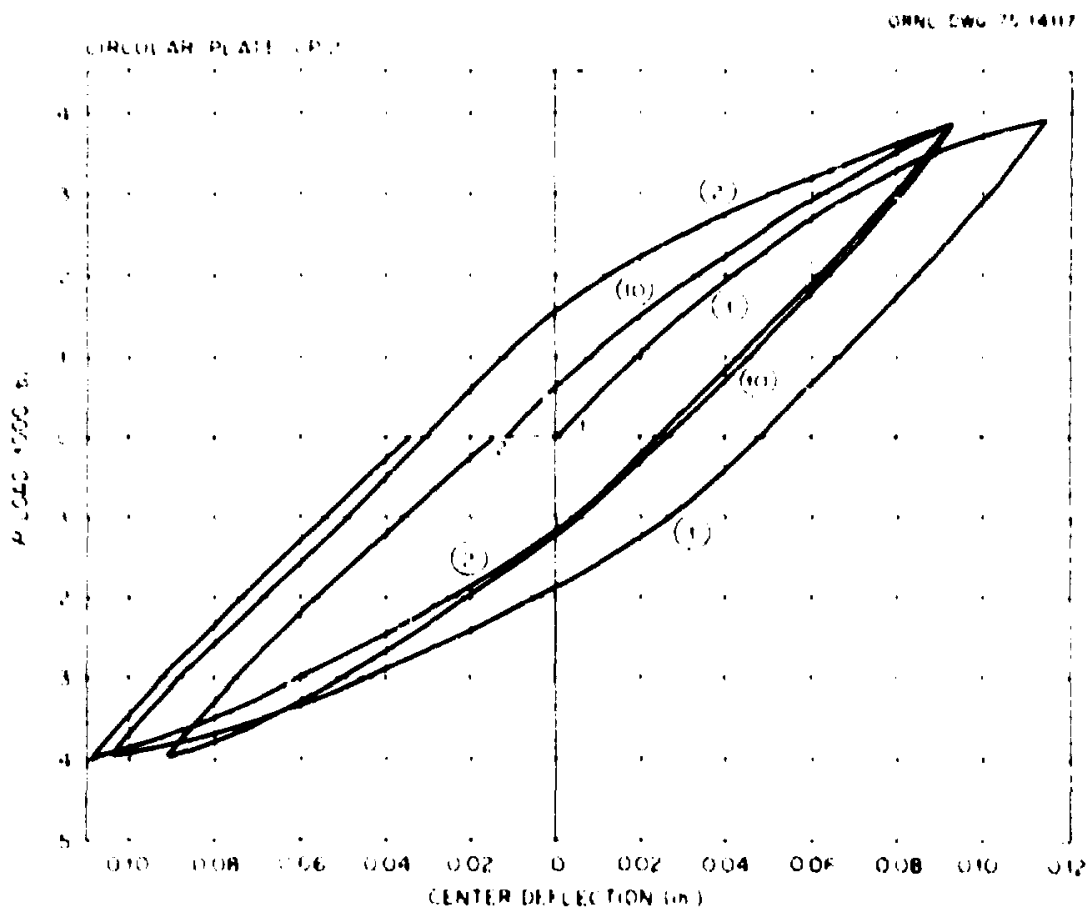

Fig. 28. Load vs center deflection during ten short-time, precreep load cycles of plate C.P2 $(1 \mathrm{~b} \times 4.448=\mathrm{N}, 1 \mathrm{n} . \times 25.4=\mathrm{mn})$. 
36

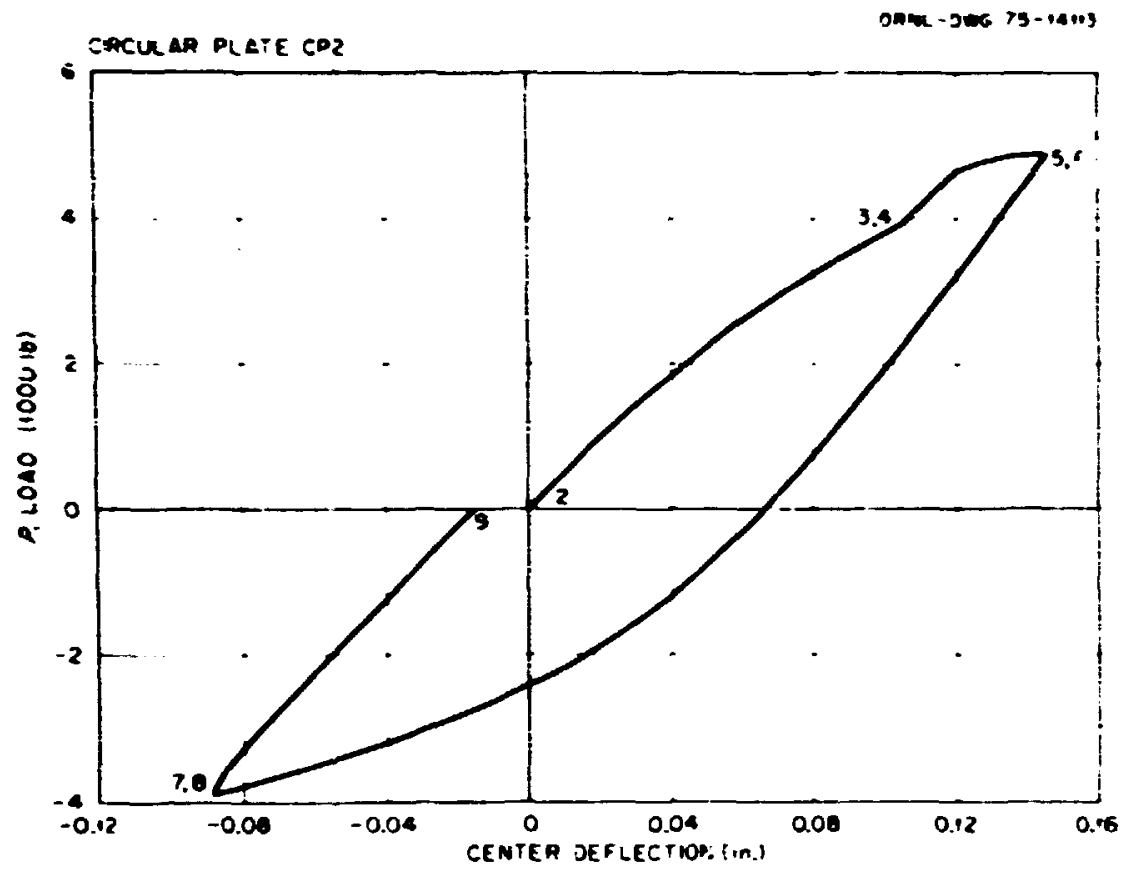

Fig. 29. Load vs center deflection for short-time load changes associated with creep portions of plate CP2. The measured deflection was zeroed at point 2 for this plot $(1 b \times 4.448=N$, in. $\times 2.54=\mathrm{mm})$.

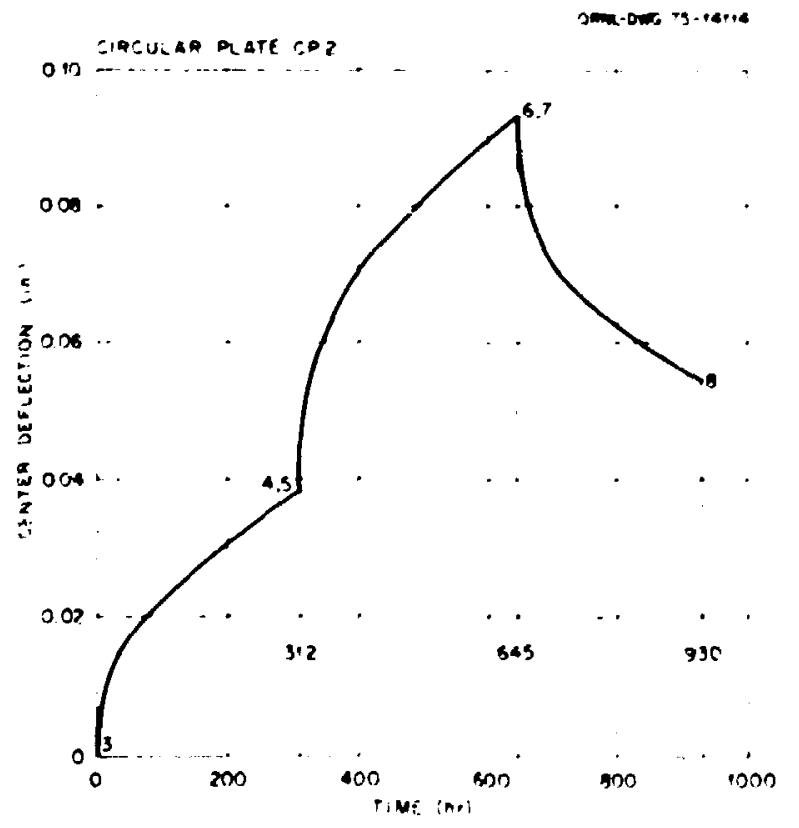

Fig. 30. Creep deflection vs time for center of plate CP 2 (in. A $25.4=\mathrm{mm})$. 


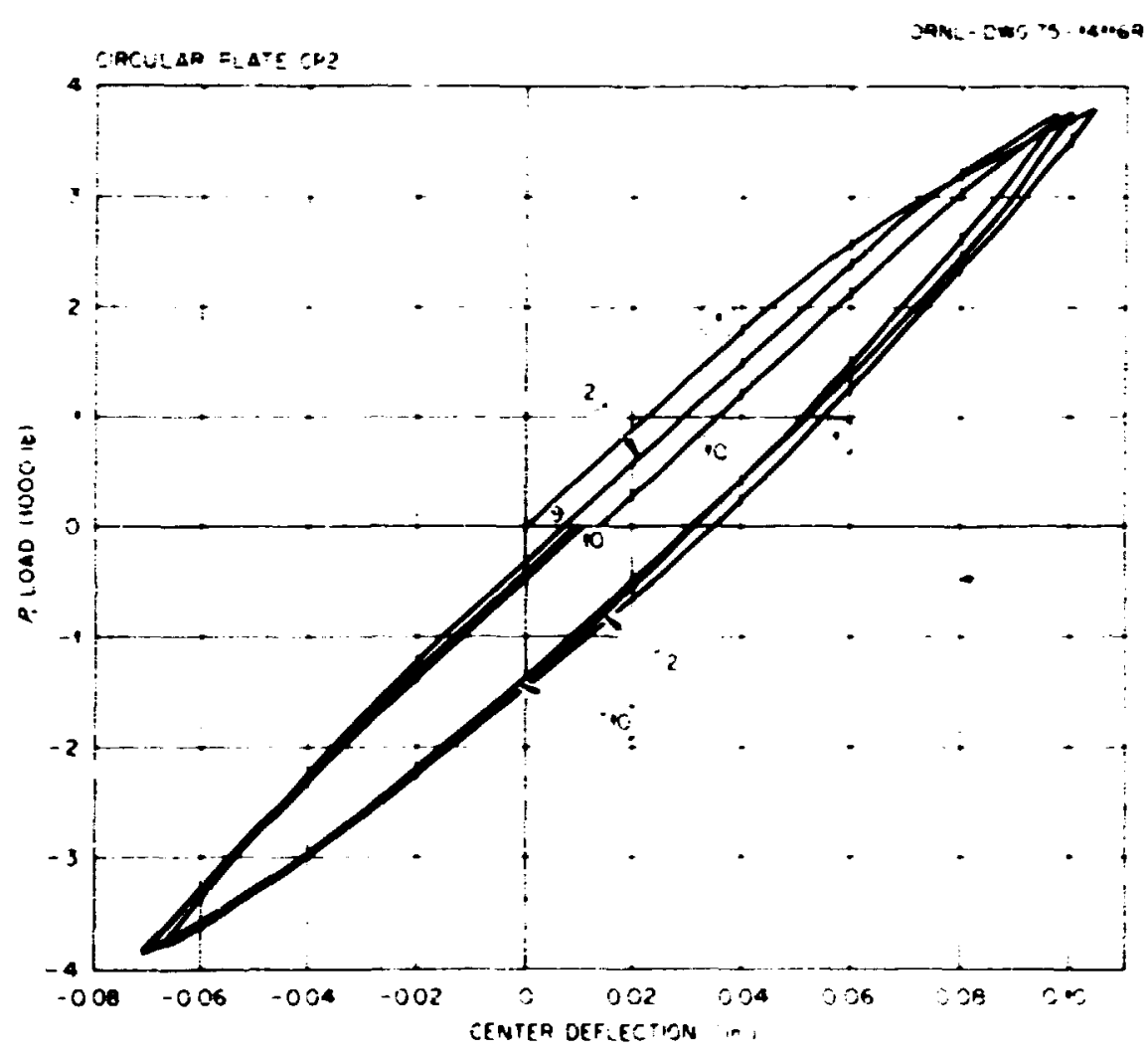

Fig. 31. Load vs center deflection during ten short-tine, postcreep load cjcles of plate CP2. The measured deflection was zeroed at point 9 for this plot $(1 b \times 4.448=N$, in. $\times 2: .4=\operatorname{mm})$.

\subsection{Deflection-Controlled Plate Tests}

Plates CP4 and CP3 were companion deflection-controlled tests, with CP3 having the ten short-time precreep deflection cycles. These tests were akin to the beam $B 7$ and $B 8$ tests, which were also deflection controlled.

The load vs center deflection response of plate CP4 during the deflection changes associated with the relaxation portions of the test are shown in Fig. 32. Figure 33 shows the load vs time response for the two relaxation hold periods, while Fig. 34 depicts the response-during the ten short-time postcreep deflection cycles.

The precreep cyclic deflection response of piate CP3 is shown in Fig. 35. Figures 36 to 38 ccrrespond to Figs. 32 to 34 for plate CP4. 


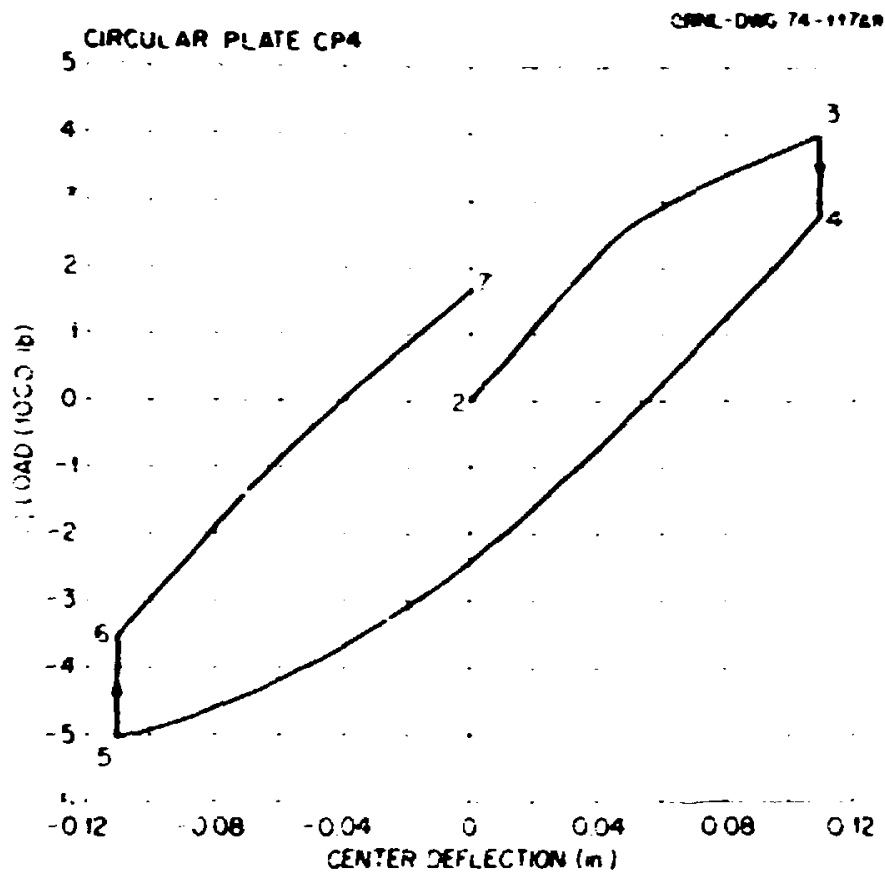

Fig. 32. Load vs center deflection changes associated with relaxation portions of plate CP4 $(1 b \times 4.448=N$, in. $\times 25.4=m)$.

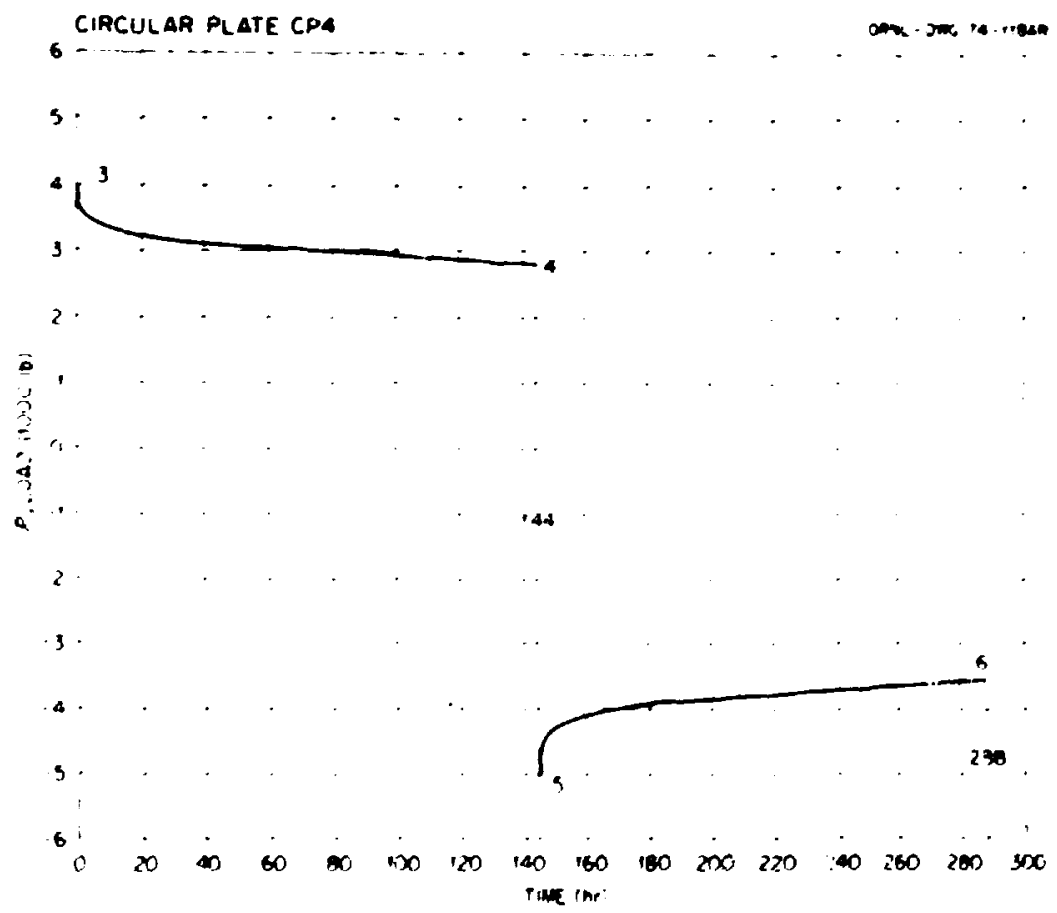

Fig. 33. Load relaxation vs time for plate CP4 $(1 b \times 4.448=N)$. 
39

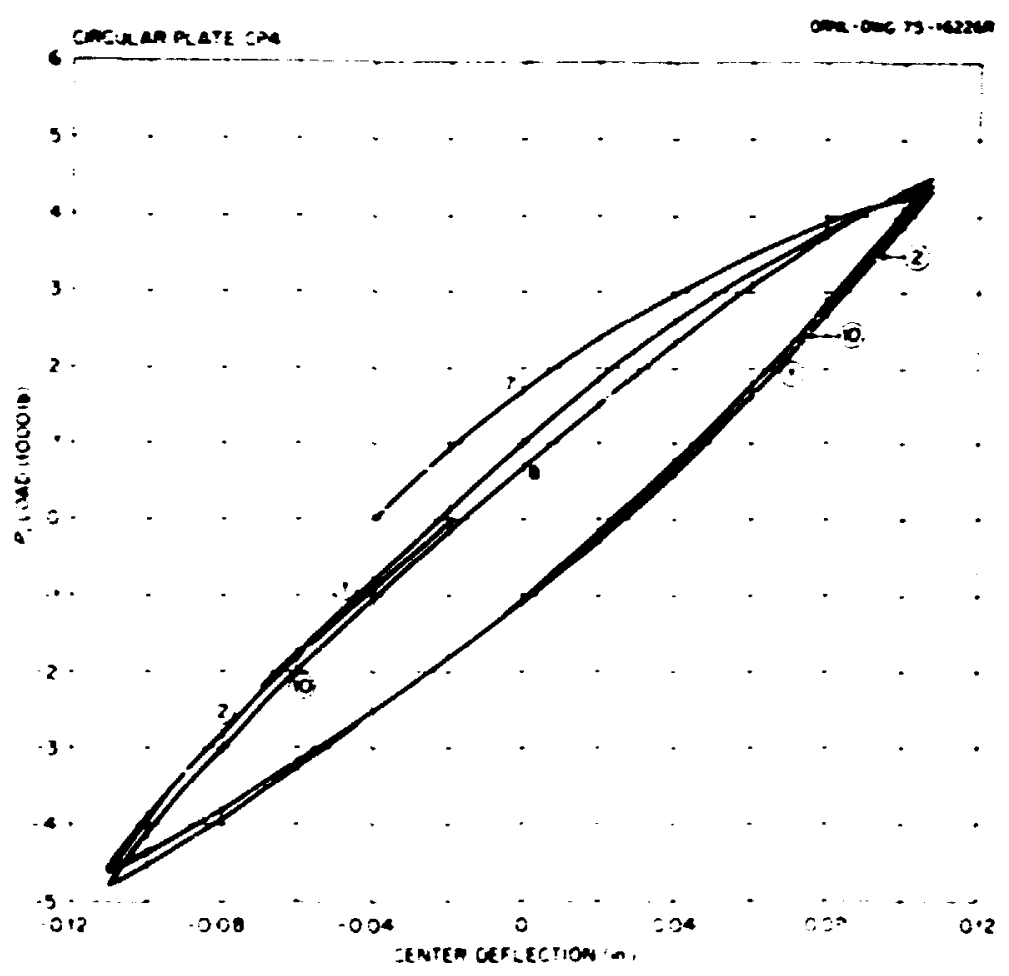

Fig. 34. Load vs center deflection during ten short-time, postcreep deflection cycles if plate CP4 $(1 b \times 4.448=N$, in. $\times 25.4=\mathrm{mm})$.

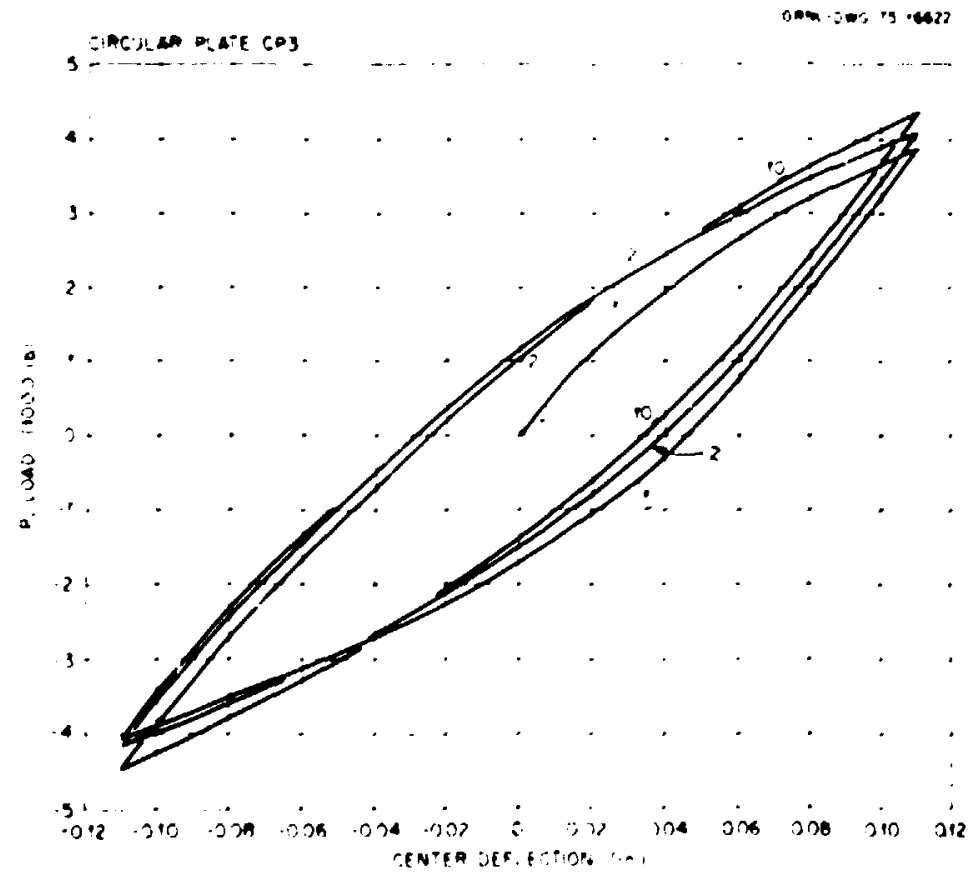

Fig. 35. Load vs center deflection during ten short-time, precreep deflection cycles of plate CP 3 ( $1 \mathrm{~b} \times 4.44 \varepsilon=\mathrm{N}$, in, $\times 25.4=\mathrm{mm})$. 


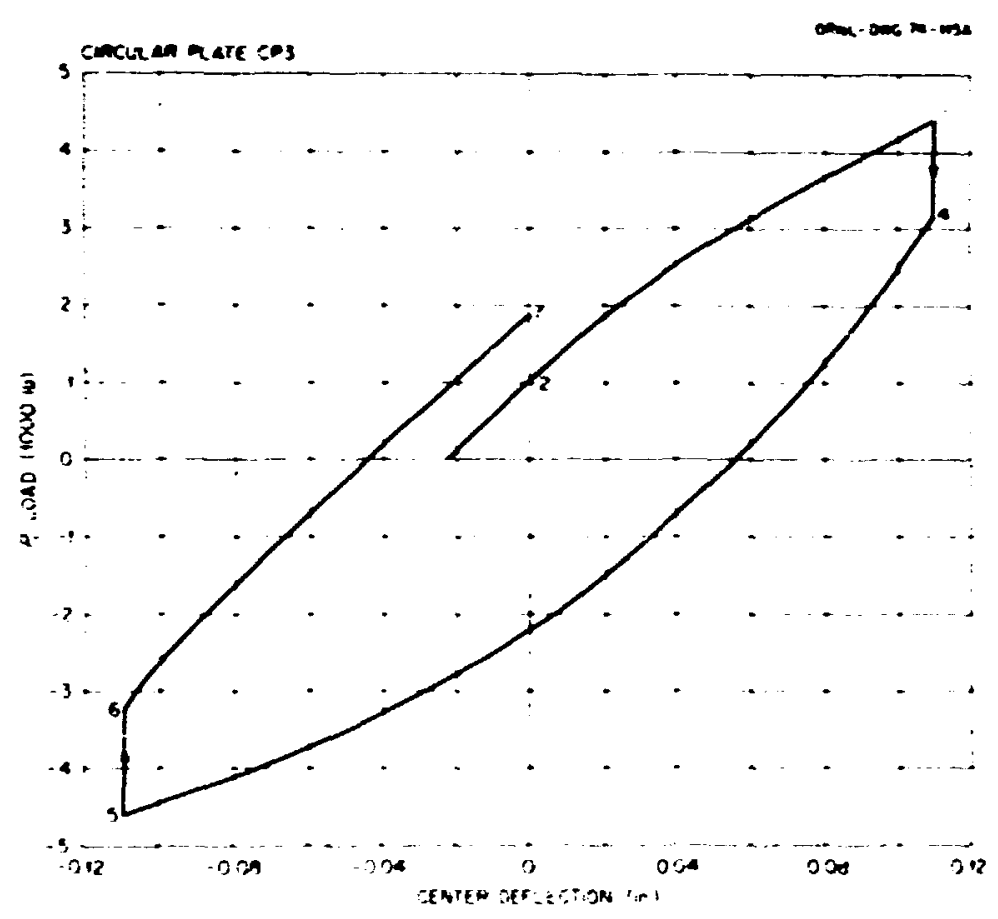

Fig. 36. Load vs center deflection changes associated with relaxation portions of plate CP3 $(1 b \times 4.448=N$, in. $\times 25.4=m)$.

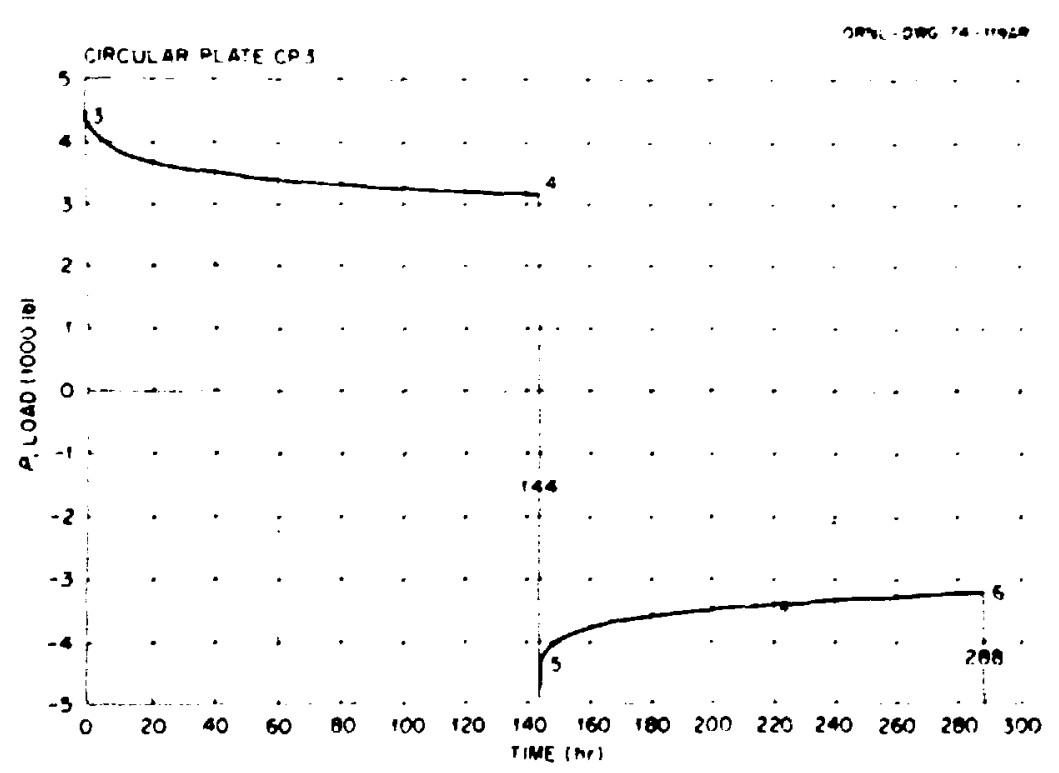

Fig. 37. Load relaxation vs time for plate CP3 $(1 b \times 4.448=i v)$. 


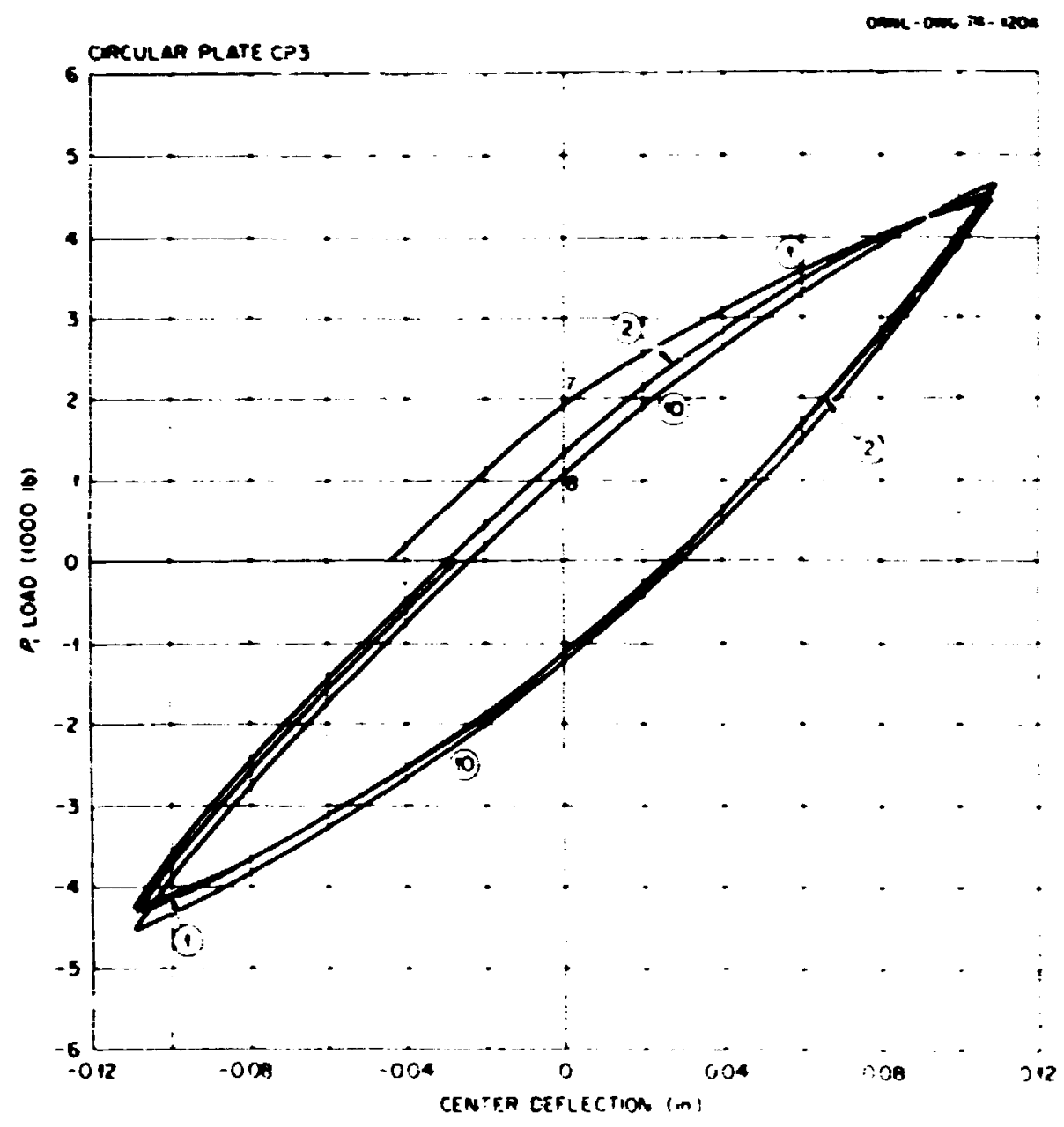

Fig. 38. Load vs center deflection during ten short-time, postcreep deflection cycles of plate CP3 $(1 \mathrm{~b} \times 4.448=\mathrm{i}$, in. $\times 25.4=\mathrm{mm})$.

Additional results for plate $\mathrm{CP} 4$ are $g i v e n$ in Appendix $H$, along with additional load deflection data and strain gage data for the entire load history. Appendix I, for plate CP3, contains only the measured specimen temperature data for the test. 


\section{DISCUSSION OF RESULTS}

High-temerature test results have been presented for eight bean and plate tests that were carefully planned and selected to compleaent one another. The results exeaplify tine basic features of elastic-plastic and creep behaviors for relatively complex load histories. Because of this, and because beans and plates are relatively simole, the results should be ideally suited for benchark problea calculations.

Although the test data that have been presented are intended to be used primarily as benchark problen results for comparison with inelastic structural analysis predictions, an exanination of the test data alone re reals several important characteristics of inelastic behavior. First, Figs. 11, 15, 25, and 29, which depict the short time responses of the load-controlled tests to the load changes associated with the creep periods, indicate the hardening effect that prior creep has on subsequent plasticity. Consider Fig. 11 specifically; the load change from 8896 to $10,008 \mathrm{~N}(2000$ to $2250 \mathrm{lb})$ (points 4 to 5$)$ after the fis:st creep period initially results in a near-elastic response even though considerable plastic deformation had occurred during the initial load application to $8896 \mathrm{~N}$. This apparent hardening may be due in small part to some stress redistribution that takes place during the creep period, but it is more directly the result of hardening due to prior creep. *

Figure 14, which depicts the initial cyclic response of bean B:0 to a cyclic load, illustrates the pronounced effect that cyclic hardening can have on structural behavior. Cyclic hardening, which is discussed at some length in Ref. 2 , is a prominent feature of the inelastic response of typa 304 stainless steel. Cyclic hardening is also illustrated in Fig. 21, which shows the initial cyclic response of beam B8 to a cyclic deflection, and in Figs. 28 and 35 for plates CP2 and CP3, respectively.

It is of interest to compare the initial cyclic response of beam $B 10$ (Fig. 14) with the cyclic zesponse of bean B9 to the ten postcreep load cycles shown in Fig. 14. In the latter case the loop wioth (at zero load)

-This basic feature of the inelastic behavior of type 304 stainless steel is described in Ref. 2 on the basis of uniaxial tests. It also is illustrated in Appendix $A$ of this report. 
for the first cycie was about $0.660=(0.026$ in.) and about 0.305 (0.012 in.) for the tenth cycle. These are considerably less than the loop widths in Fig. 14 and further illustrate the hardening effects of prior inelastic deformation.

A comparison of the creep responses of beans $B 9$ and $B 10$ in Figs. 12 and 16 , respectively, seens to indicate that the additional prior plastic deformation in bean $B 10$ resulted in 2 slight decrease in subsequent creep response. The difference is probably due nore to normal test-to-test variation than to the effects of prior plasticity. Uniaxial test results indicate little effect of prior small plastic strains on subjeque.te creep.:

One final structural response feature can be identified by comparing Figs. 11 and 25, which are for bean $B 9$ and plate CP5, respectively. Relative to the bean, the plate remains stiff after initial yielding. In fact, the plastic deflection is swall in the plates even when the load is approximately twice the value at which initial yielding occurs. This response is typical of plate structures and is, of course, due to the basic biaxial load-carrying mechanism in the plates.

It is believed that the test results presented in this report are representative and rzasonably reproducible. For example, plate test CPS was an exact duplicate of an earlier test, CPI. Comparisons of the results for the two identical tests show that the elastic-plastic deflection response of CPS was about $10 \%$ less than that for plate CPI; the creep response was about $25:$ less. These discrepancies are reasonably representative of the normal variations to be expected from test to test.

One final and important point should be made relative to the interpretation of inelastic benchwark calculation results. The correlation of analytical prediciions with experimental results for inelastic problems is by no means a straightforward prored ure. Unlike the elastic case, where exact agreement can theoreticaily be expected and strived for, there will always be differences between predicted and measured inelastic structural behavior. This is because carefully controlled high-temperature tests are difficult to pertorm, accurate measurements are difficult to make, and inelastic material betavior is a highly complex phenomenon consisting of processes and interacticns that defy complete understanding and exact descriptinn. There can be considerable variation in behavior 
from specimen to specinen, and the constitutive equations that are likely to be used represent only first approxientions to the descriptions of inelastic behavior. Thus, rather than exact quantitative predictions, inelastic analyses qualitatively predict the basic characteristics or the essential features of inelastic response. 


\section{ACX.YWLEDGAEYTS}

The authors wish to ackno:iledge with appreriation the contributions of several individuals at Dak Ridge Vational Laboratory to the effort described herein. T. G. Hill and S. J. Claiborne instrumented the specimens and helped to perfore the tests; T. M. Cate assisted with the instrumentation and controls; and D. T. Godwin was responsible for converting the recorded test data to usable figures. 


\section{REFEREICES}

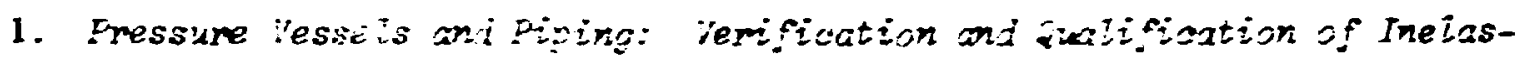

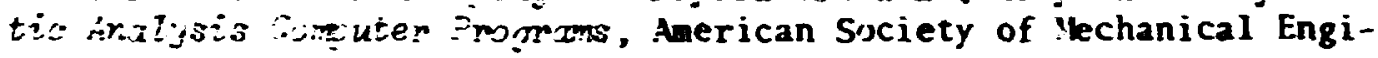
neers, G00088, 1975.

2. J. M. Corum et al., interim didelines for jetailed ineixstis inaljsis

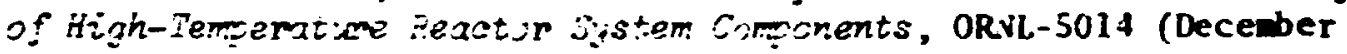
1974). 
APPEXDICES 
BLANK PAGE 


\section{APPENDI: A. MECHANICAL PICPERTIES DATA FOR ELASTIC-PLASTIC-CREEP ANALYSES}

This appendix contains a sumary of the applicable material property data required as input to conventionsl elastic-plastic-creep analyses of the experimental benchmar: problems described in this report. The data provided include elastic constants, cyclic ztress-strain information, and uniaxial constant-stress creep data, all for a temperature of $593^{\circ} \mathrm{C}$ $\left(1100^{\circ} \mathrm{F}\right)$.

\section{Introduction}

All the beam and plate sprcimens descrited in this report were machined from plate product forms of a single heat of type 304 stainless steel. This heat, which is designated as 972796 , was purchased in several product forms for use in the ORVL program to develop high-temperature structural design methods and in various mechanical property testing progiams as well. Table $A .1$ gives the vendor chemistry obtained on the two plate thicknesses from which the structural models were obtained along with the applicable RDT or ASTM standard. To assure a uniformity and consistency of material response in the various test efforts, all material and structural test specimens were fully annealed prior to testing.* Characterizstion tests have shown that the mechanical properties of the product forms in the fully annealed condition are very similar. ${ }^{i}$ Thus, although some of the data presented in this appendix were obtained from tests using $19.1-\operatorname{mm}(0.75-\mathrm{in}$.$) plate product form and others from$ tests using 25.4-mn (1-in.) plate product form, they are applicable to either.

"Each product form of heat 9T2796 was annealed at the mill. However, straightening operations after annealing often induce additional work hardening and necessitate a reanneal, or laboratory anneal, for consistency. The reannealing consisted in heat ing to $1093^{\circ} \mathrm{C}\left(2000^{\circ} \mathrm{F}\right)$ for 30 min, followed by rapid cooling to room temperature. 
Table A.1. Vendor chemistry ${ }^{a}$ obtained on plate product forms

of type 374 stainless steel hear $9 T 2796$ from which

beam and plate specimens were obtained

\begin{tabular}{|c|c|c|c|c|c|c|c|c|c|c|c|}
\hline $\begin{array}{l}\text { Structural } \\
\text { specimens }\end{array}$ & Specification & $\begin{array}{l}\text { Thickness } \\
{[m m(i n .)]}\end{array}$ & C & $\sin$ & $p$ & $\mathbf{S}$ & $\mathbf{S i}$ & $\mathrm{Ni}$ & $\mathrm{Cr}$ & Mo & $\mathrm{N}$ \\
\hline Plates & RDT MS-1T (A240) & $19.1(3 / 4)$ & 0.051 & 1.23 & 0.027 & 0.017 & 0.48 & 9.68 & 18.52 & 0.33 & $N A^{b}$ \\
\hline Beams & RDT MS-1T (A240) & $25.4(1)$ & 0.048 & 1.28 & 0.030 & 0.016 & 0.48 & 9.72 & 18.44 & 0.32 & $\mathrm{NA}^{b}$ \\
\hline
\end{tabular}

$a_{\text {Weight percent. }}$

$b_{\text {NA }}=$ not available. 


\section{Stress-Strain Data}

The elastic constants for type 304 stainless steel at the temperature of interest $\left[593^{\circ} \mathrm{C}\left(1100^{\circ} \mathrm{F}\right)\right]$ are Young's modulus ${ }^{2}$ (E), $149.6 \times 10^{3} \mathrm{MPa}$ $\left(21.7 \times 10^{6} \mathrm{psi}\right)$, and Poisson's ratio, ${ }^{3} 0.31$.

To analyze the beam and plate specimens, cyclic stress-strain data are required. Figure $A .1$ shows a representative cyclic curve at $593^{\circ} \mathrm{C}$ for a total strain range of 0.48 and a strain rate of $0.005 / \mathrm{min}$. The maxinum strain of $0.2 \%$ is reasonably representative of the elastic-plastic strains reached in the beam and plate tests.

Bilinear representations of cyclic curres are usually used in cyclic inelastic analyses; thus, bilinear representations of the cyclic curve in Fig. A.l were determined according to the recomendations of Ref. 4 . These bilinear representations are illustrated on the original nonlinear curve. Note that the slope $E_{p}$ of the elastic-plastic portions of the bilinear representations is $4619.7 \mathrm{MPa}\left(0.67 \times 10^{6} \mathrm{ps} i\right)$ for each cycle.

Reference 4 suggests two procedures for approximately accounting for cyclic hardening in an analysis. In each, kinematic hardening relations are used, but the size of the yield surface, or loading surface, is increased during the course of plastic flow to account for the hardening. The procedures are:

1. For the initial plastic loading of each element of the structure, the bilinear representation of the initial monotoric curve is used, and for the first reversed loading and all subsequent loadings, the bilinear representation of the tenth cycle is usec. The appropriate strain range curve is chosen on the basis of the piastic strains expected in the component being analyzed.

2. As an alternative to the single jump from the monotonic initial loading stress-strain curve to the tenth-cycle curve, a gradual change may be used. The analyst may have sufficient data to adequately approximate the bilinear yield stress as a function of accumulated plastic strain. The yield stress at each load step in a given element of the structure may then be based on the actual accumulated plastic strain at that point. This procedure retains the kinematic hardening relations and the bilinear stress-strain representations but avoids the abrupt change 
in hardening that is associated with the switch from the initial curve to the tenth-cycie curve.

The information necessary to employ either of the above alterriatives is presented in Fig. A.2, which shows the bilinear yield stresses determined from Fig. A.I (and similar results at other temperatures) as a function of accumulated plastic strain (sumed without regard to sign). The inset in Fig. A.2 illustrates hrw the yields were determined, and the numbered tick marks on the curves identify the yield point for each roversal.

Recent studies at ORNL have shown that bilinear yield stress correlates well with prior inelastic work. This represents another option, or procedure, for gradually changing the yield stress during the course of an inelastic analysis. Figure A.3 shows the correlation at $593^{\circ} \mathrm{C}\left(1100^{\circ} \mathrm{F}\right)$. In this figure, the yield parameter $\kappa$ is used, where $k$ is related to the yield stress $\sigma$ by $\sigma=\sqrt{3 k}$. Data points are shown for cyclic stress-strain tests at total strain ranges of 0.4, 0.6, and 1.0\%. Data from precrept specimens are also shown, suggesting that total prior inelastic work (accumated during creep ard plastic deformations) can be used to establish the current yield stress. This procedure thus takes some account of the effects of prior creep on subsequent elastic-plastic hardening.

Hopefull $\%$, the data given in Figs. A.l through A.3 will be sufficient not only for the analyst to apply any one of the procecures out lined above, but also for the application and evaluation of other constitutive relations and procedures.

\section{Creep Data}

To perform a time-dependent elevated-temperature structural analysis, the analyst must have a description of the uniaxial constant-stress creep response of the material at the temperature(s) of interest. This description is derived from the usual uniaxial creep curves and may take the form of a mathematical relation (creep law) or simply tabular data describing the curves. Since the relatively simple creep laws developed to represent the uniaxial constant-stress creep test data never exactly fit the data over the entire stress and time :arge of interest, an error is introduced into the resulting creep analy;is predictions. Although this error is usually small and of little cons'quence in design-type analyses, it 
does introduce an undesirable uncertainty into comparisons of predictions and structural test results, and more basic sources of error may thereby be masked.

To eliminate the uncertainty associated with using a specific creep law, a tabular creep Jata matrix was jeveloped and is given in Table A.2. This matrix is based on approximatel: 30 creep tests at $393^{\circ} \mathrm{C}\left(1100^{\circ} \mathrm{F}\right)$, with stress values ranging from 51.7 to $275.8 \mathrm{MPa}$ ( 7.5 to $40 \mathrm{ksi}$ ). The tabular values, which were obtained by a repeated process of smoothing and cross-plotting the test results, appear to be a good representation of the creep behavior of type 304 stainless steel heat $9 \mathrm{~T} 2796$ at $593^{\circ} \mathrm{C}$. The uniaxial creep curves described by the data matrix in Table $\lambda .2$ are shown in Figs. A.4a and $b$. The dashed lines in Fig. A.4a represent straight-line extrapolations beyond the last entries in Table A.2.

The analyst may either use the tabulated creep values directly or a creep law based on the tabulated data may be developed and used.

\section{Acknowledgme:it}

The cyclic stress-strain representations given in this appendix are based on test data obtained by $R$. W. Swindeman of ORVL and C. F. Jaske of Battelle-Columbus Laboratories. The tabular creep data are based on test data obtained by Swindeman. The authors gratefully acknowiledge the contribution of these individuals.

\section{References}

1. R. W. Swindeman et al., Product Form Characteriation of Type 304 Stainiess Steel (üt 9T3796), OR.VL-522i (February 1977).

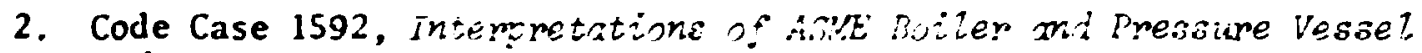
Code, American Society of Mechanical Engineers, New York, 1974.

3. Nulear Fotems Materixis Han Hoot, Vol. 1, Soction 2, "304 SS Annealed," Property Code 2110 (3-15-71), puilishr's by HEDL, TID-26666.

4. J. M. Corum et al., Interin Suigelines for Detailed Inelastic Analysis of High-lemperature Reactor sizstem Componerts, ORNL-5014 (Deceinber 1974). 


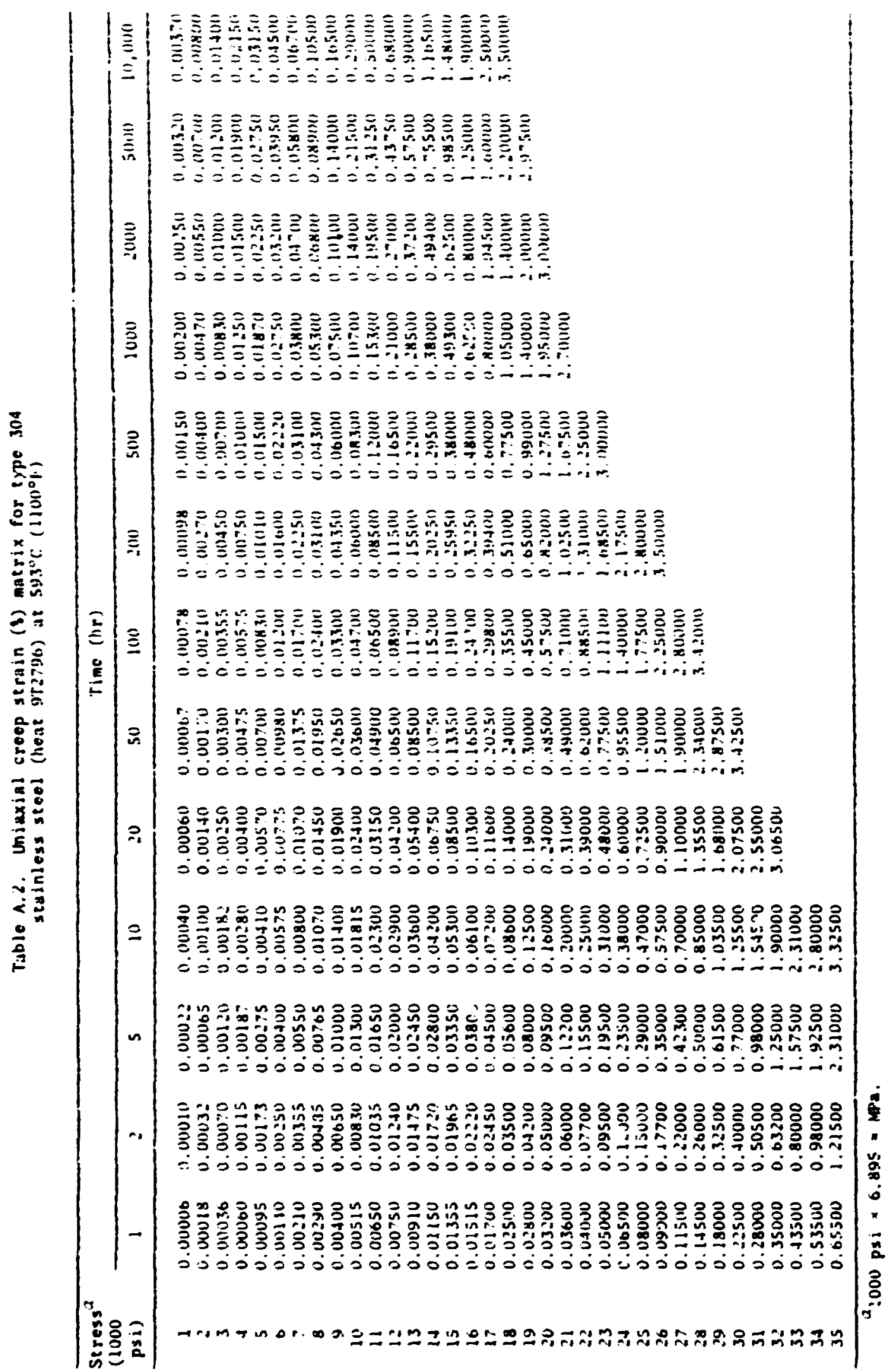




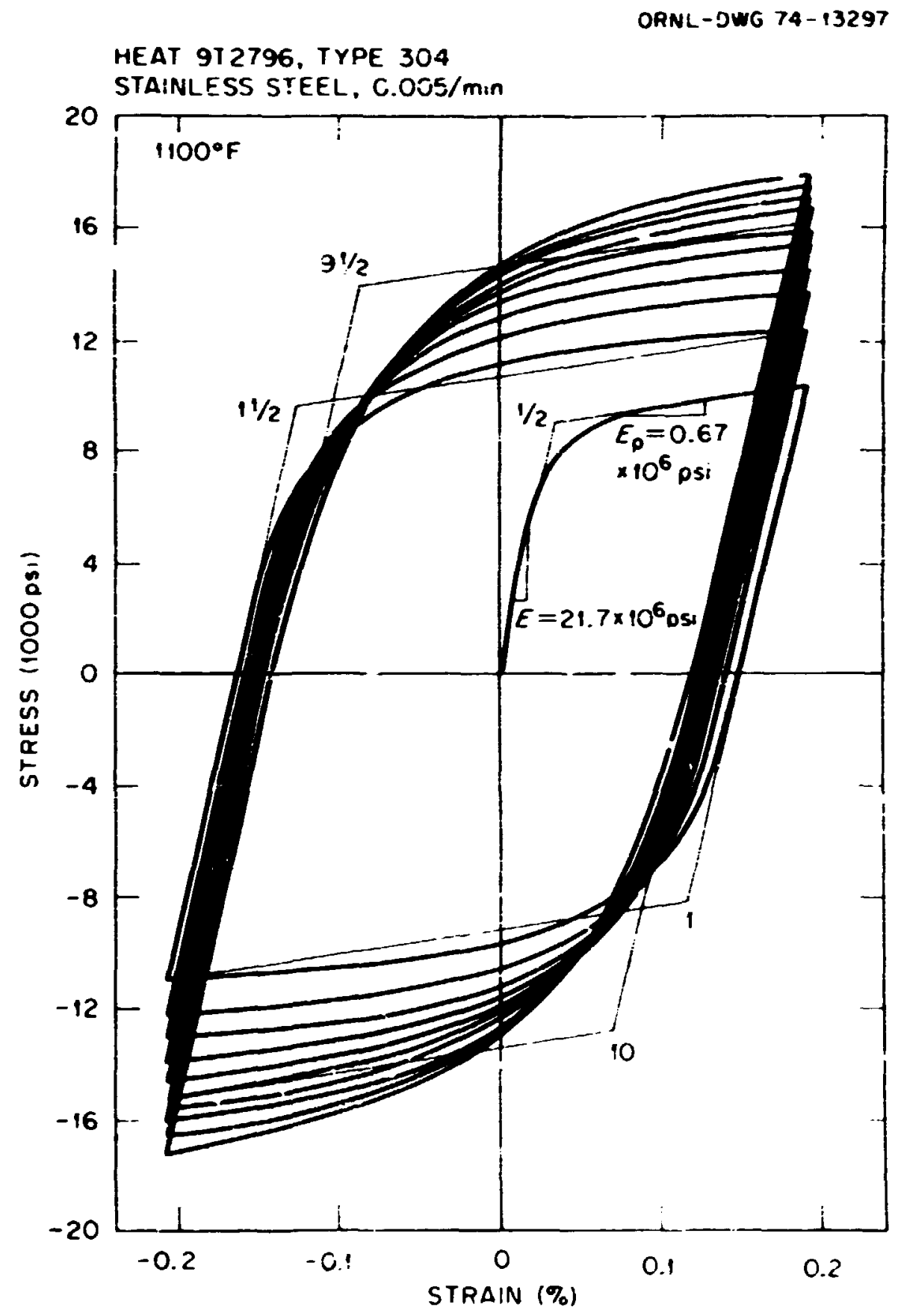

Fig. A.1. Cyclic stress-strain curve for annealed type 304 strinless ; tee 1 , heat $9 \mathrm{~T} 2790$, at $593^{\circ} \mathrm{C}\left(1100^{\circ} \mathrm{F}\right)-0.4 \%$ total strain range $(1000 \mathrm{ps} j \times 6.895=\mathrm{MPa})$. 


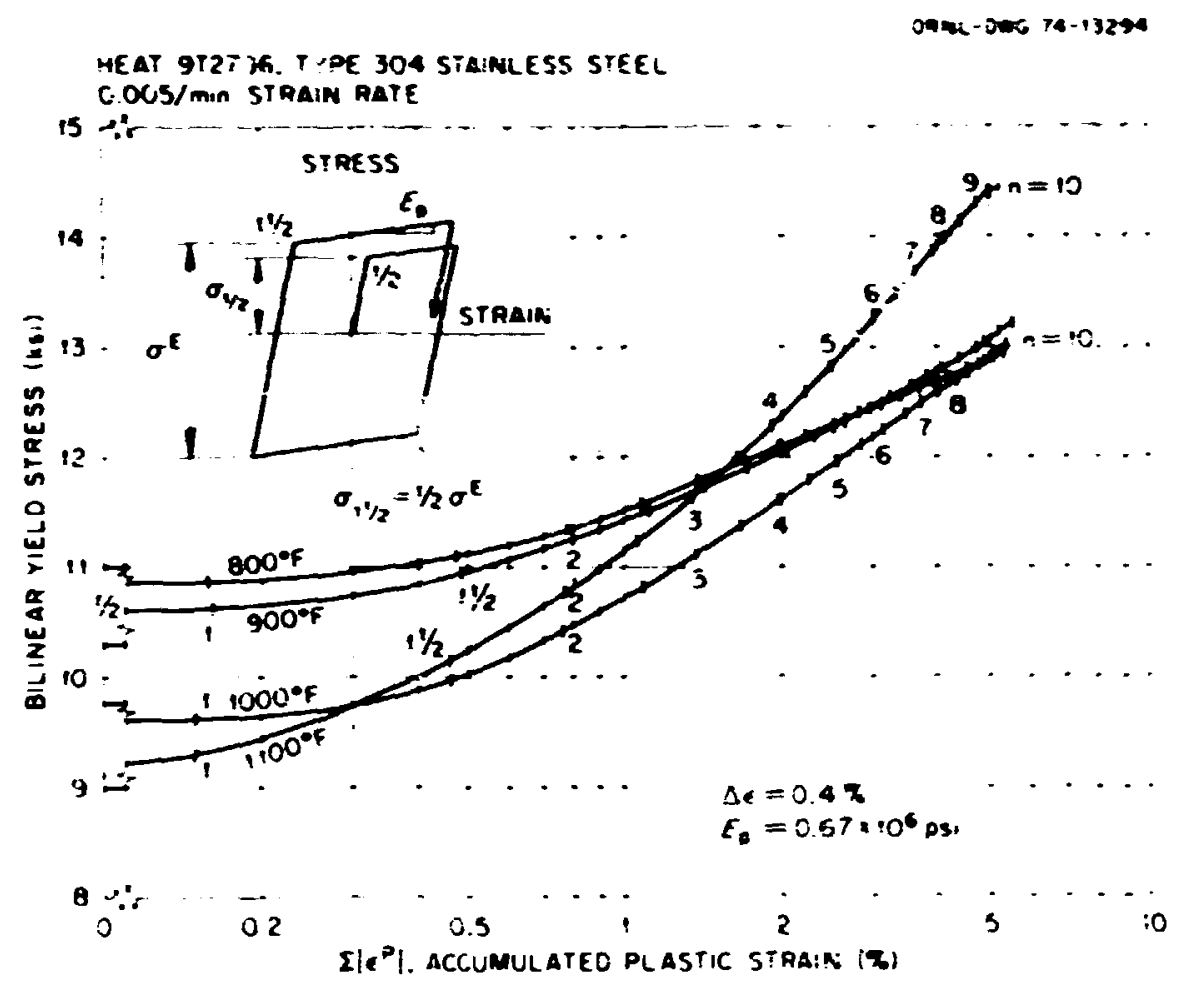

Fig. A.2. Bilinear yield stress vs accumulated piastic strain for annealed type 304 stainless steel, heat 9T2796, at various temperatures $\left[1000\right.$ psi $\times 6.895=\mathrm{MPa},\left({ }^{\circ} \mathrm{F}-32\right) \times 0.5556={ }^{\circ} \mathrm{r}_{\mathrm{j}} \mathrm{j}$.

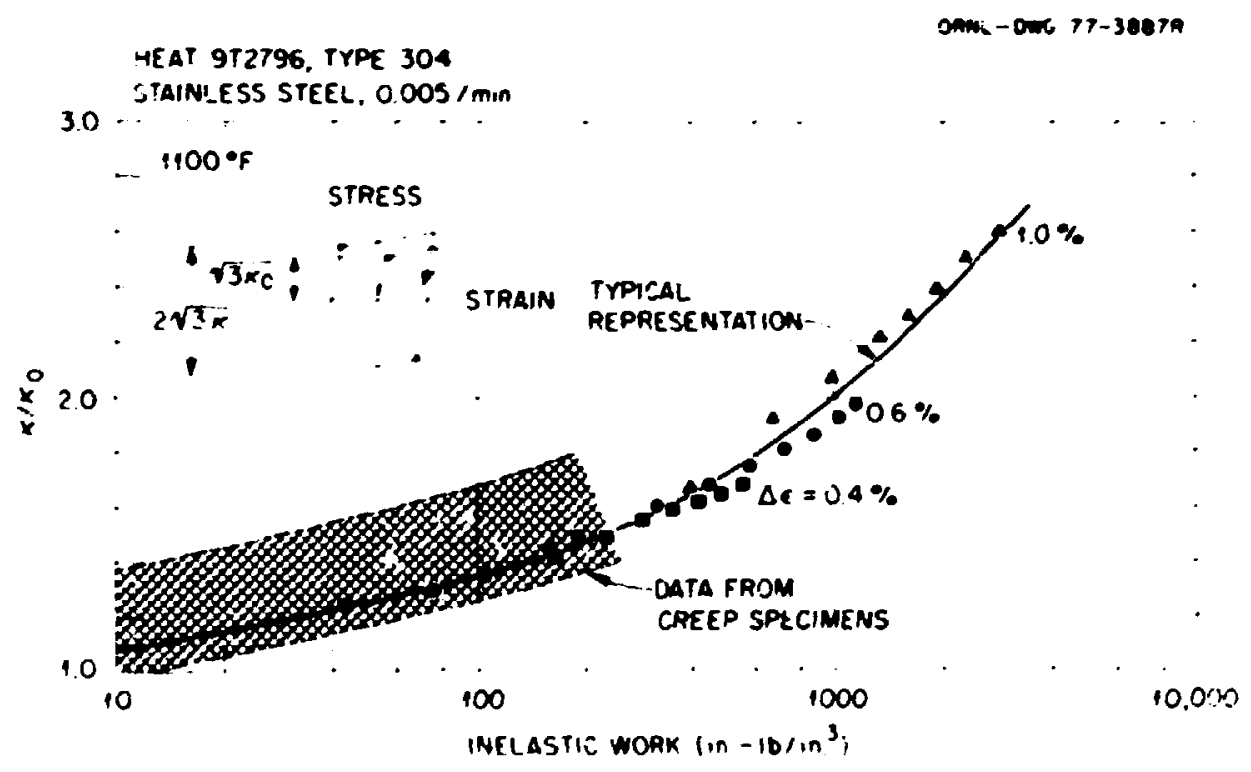

Fig. A.j. Yield parameter ratio $k / k_{0}$ vs accumulated inelastic work for annealed type 304 stainless steel, heat 972796 , at $593^{\circ} \mathrm{C}\left(1100^{\circ} \mathrm{F}\right)$. Data are from cyclic stress-strain tests of virgin specimens and stressstrain tests of precrept specimens (in. $-1 \mathrm{~b} / \mathrm{in}^{3} \times 6895=\mathrm{J} / \mathrm{m}^{3}$ ). 

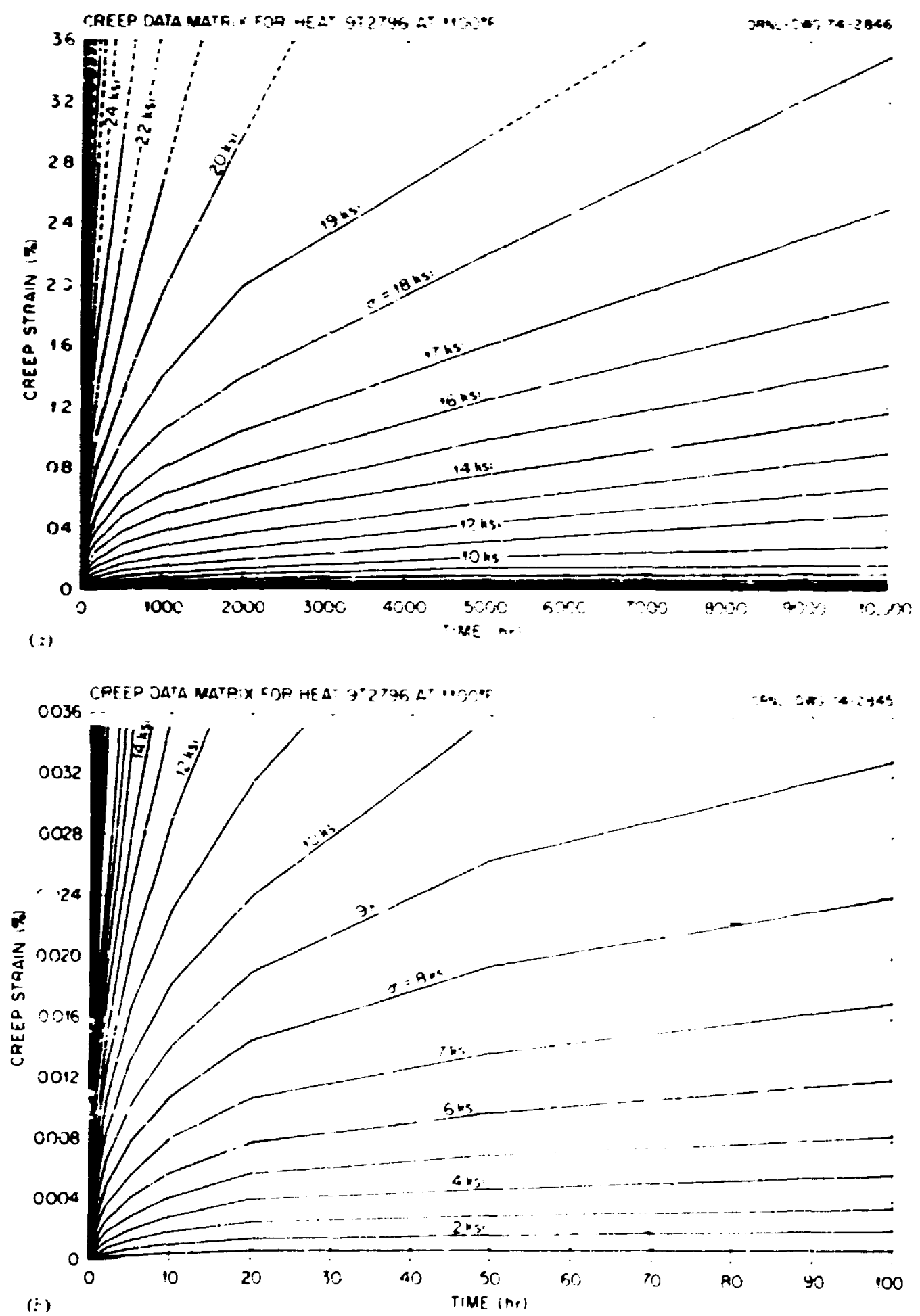

Fig. A.4. Predicted uniaxial constant-stress creep response of type 304 stainless steel, heat $9 \mathrm{~T} 2796$, at $593^{\circ} \mathrm{C}\left(1100^{\circ} \mathrm{F}\right)$ based on tabulated creep dat.a matrix (Table A.1) ( $\mathrm{s} s \mathrm{i} \times 6.895=\mathrm{MPa})$. 


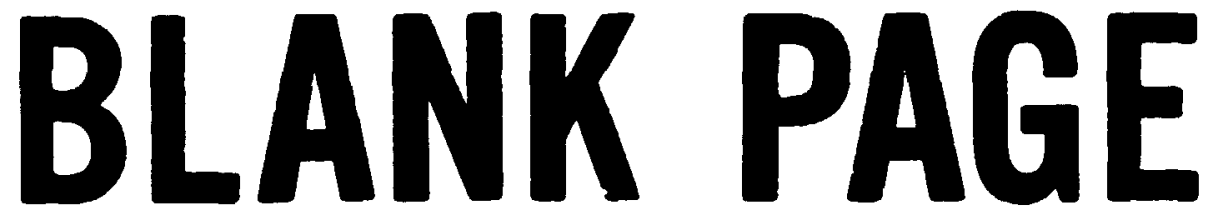


APPENDIX B. ADDITIONAL TEST RESULTS FOR BEAM B9

Bean 89 was a load-controlled test without precreep cycles. Figure B.I depicts tive arige of temperatures during the test as indicated at discrete times by the ten thermocouples whose locations are depicted in Fig. 3. These thermocouples were located over the widdle 406 m (16 in.) of the bean. As can be seen, the goal of maintaining the indicated temperature at $593 \div 2.8^{\circ} \mathrm{C}\left(1100 \pm 5^{\circ} \mathrm{F}\right)$ was closely approached for wost of the test.

Figures B.2 through B.4 show additional load vs deflection and load vs strain data* for the load changes associated with the creep portions of the test. The creep deflections and strains have been subtracted out in these figures.

Figures B.5 through B.7 show the corresponding deflection vs time and strain vs time data, and Figs. B.8 through B.15 depict the load vs deflection and load vs strain results for the postcreep cycles.**

*Refer to Fig. 3 for locations of the deflectiors and strains. The gage numbers are shown circled on the figures.

** In the figures for the postc seep cyrles, the circled numbers refer to the cycle. Results are shown fo: the first, second, ar:d enth cycles. 


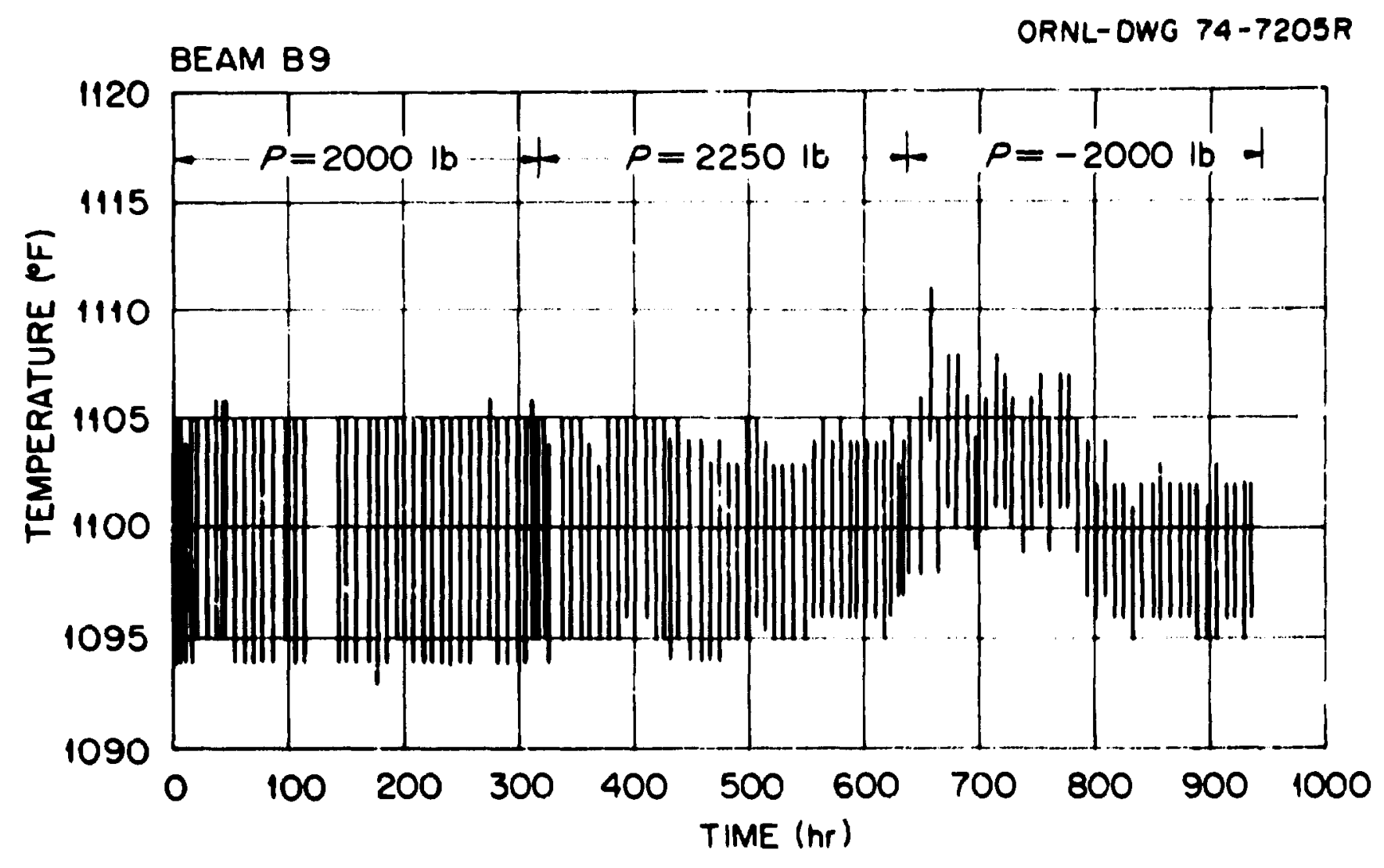

Fig. B.l. Measured temperature range over middle $406 \mathrm{~mm}$ ( $16 \mathrm{in}$ ) of beam 89 during $593^{\circ} \mathrm{C}\left(1100^{\circ} \mathrm{F}\right)$ test [1b $\times 4.448=\mathrm{N},\left({ }^{\circ} \mathrm{F}-32\right) \times(.555 \mathrm{~h}$. $\left.{ }^{\circ} \mathrm{C}\right]$. 


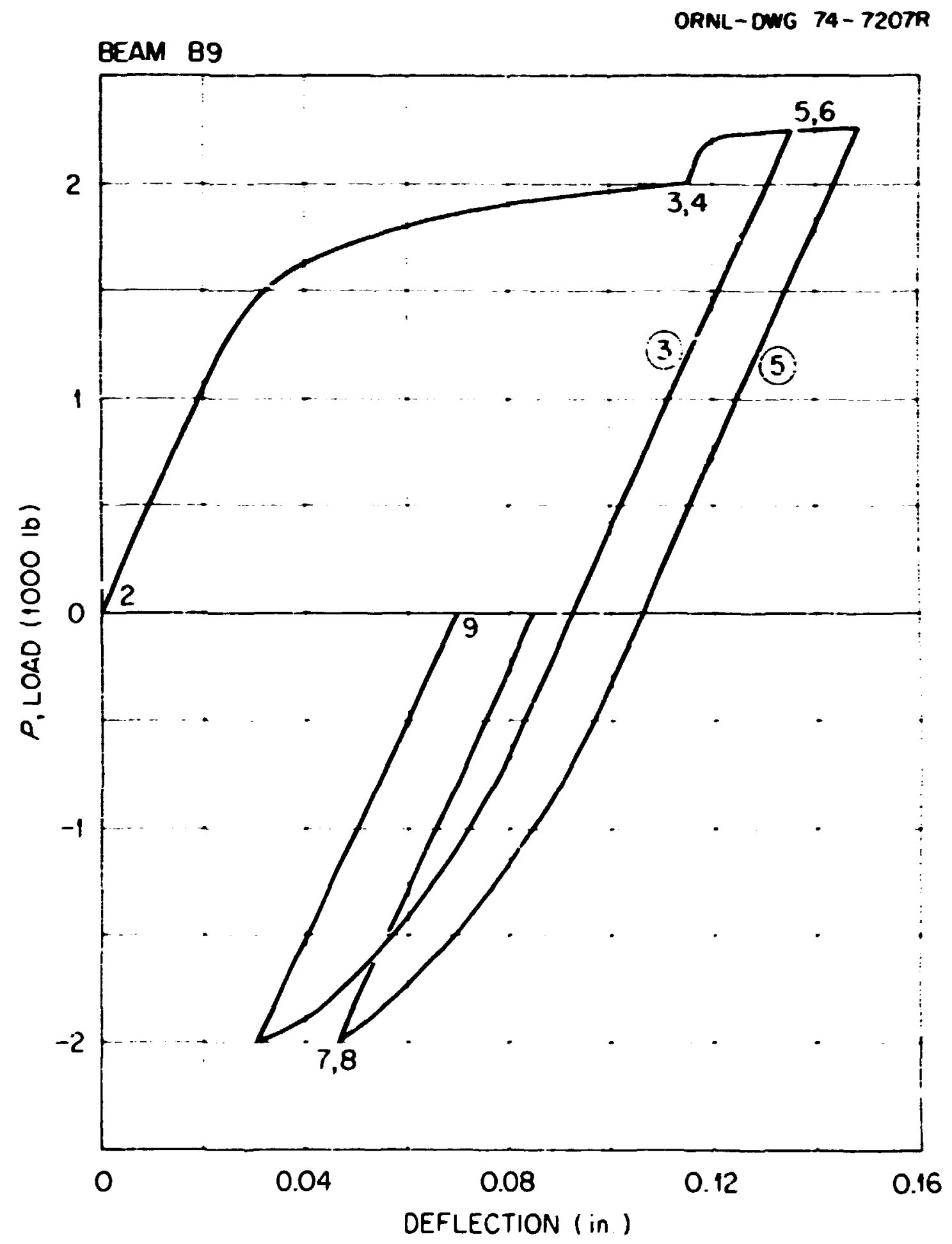

Fig. B.2. Load vs deflection (UT.3 and ITS) for short-time load changes associated with creep portions of beam B? test $(1 \mathrm{~b} \times 4.448=\therefore$, in. $\times 25.4=\mathrm{mm}$ ). 


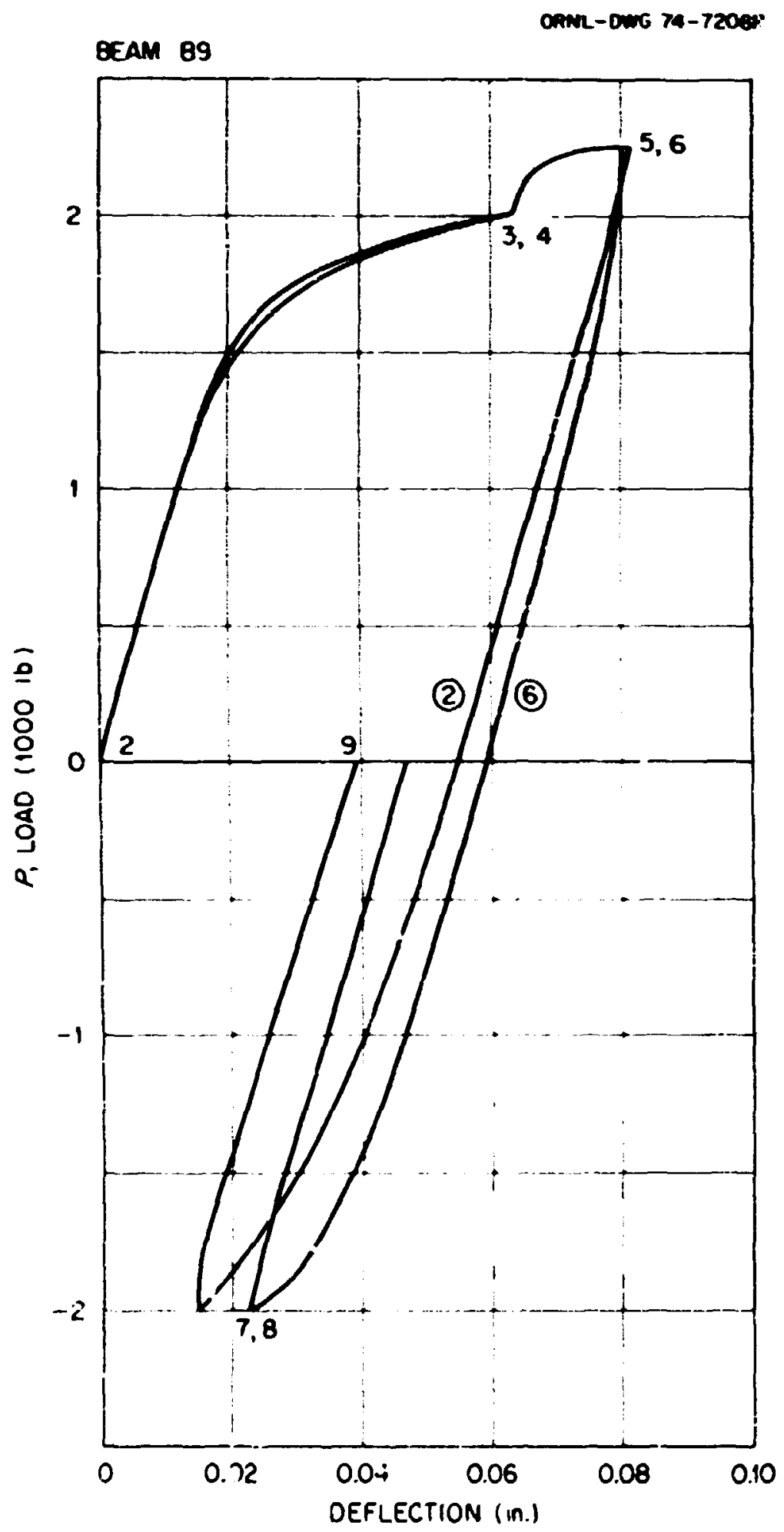

Fig. B.3. Load vs deflaction (DT2 and DT6) for short-time load charges associated with creep portions of beam is test ( $1 \mathrm{~b} \times 4.448=N$, in. $\times 25.4=\mathrm{mm}$ ) . 


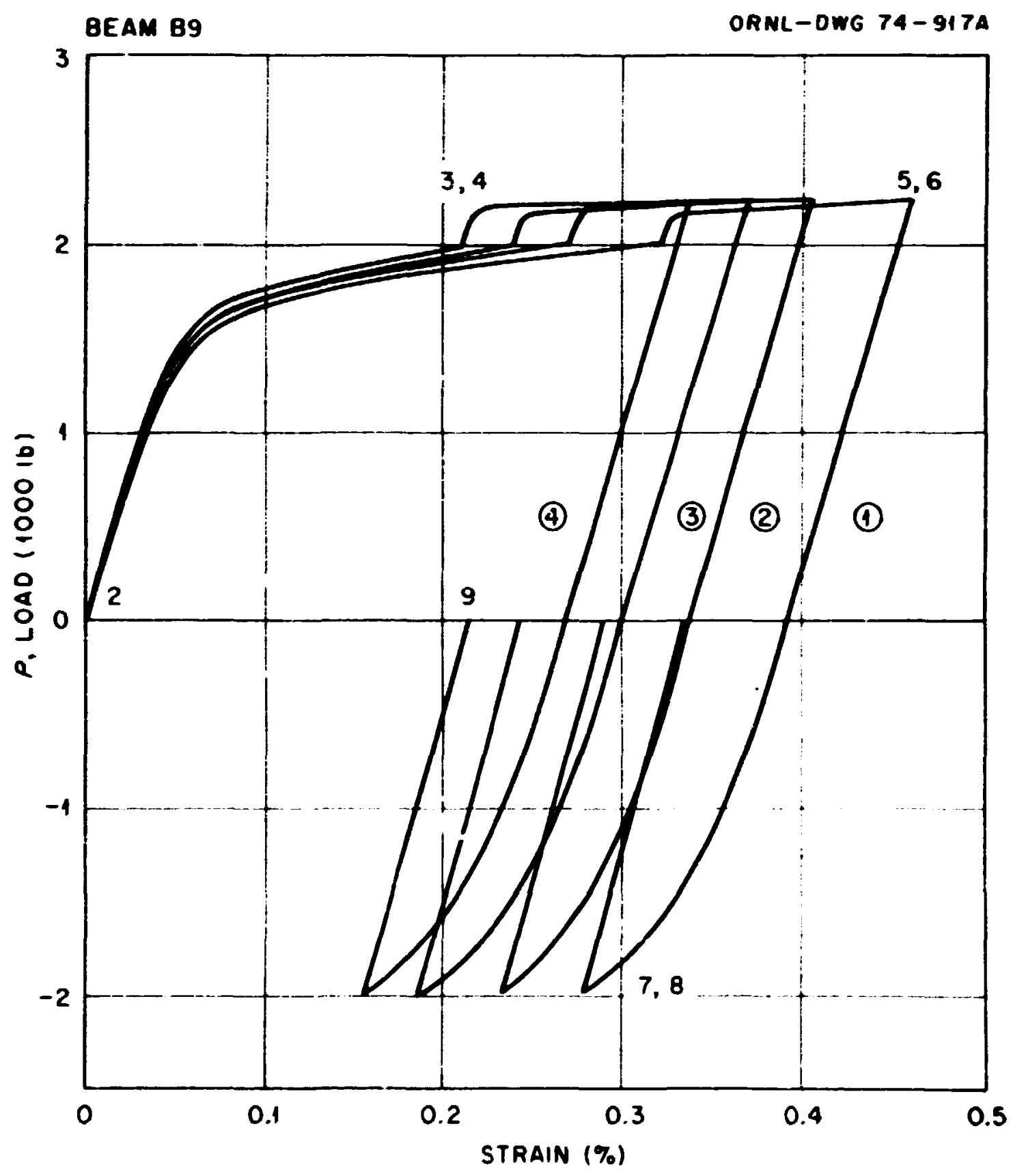

Fig. B.4. Load vs strain ( $\$ G 1-\delta G 4)$ for short-time load changes associated with creep portions of beam B9 test. Note that the signs of SGl and SG3 have been changed $(1 \mathrm{~b} \times 4.448=N)$. 


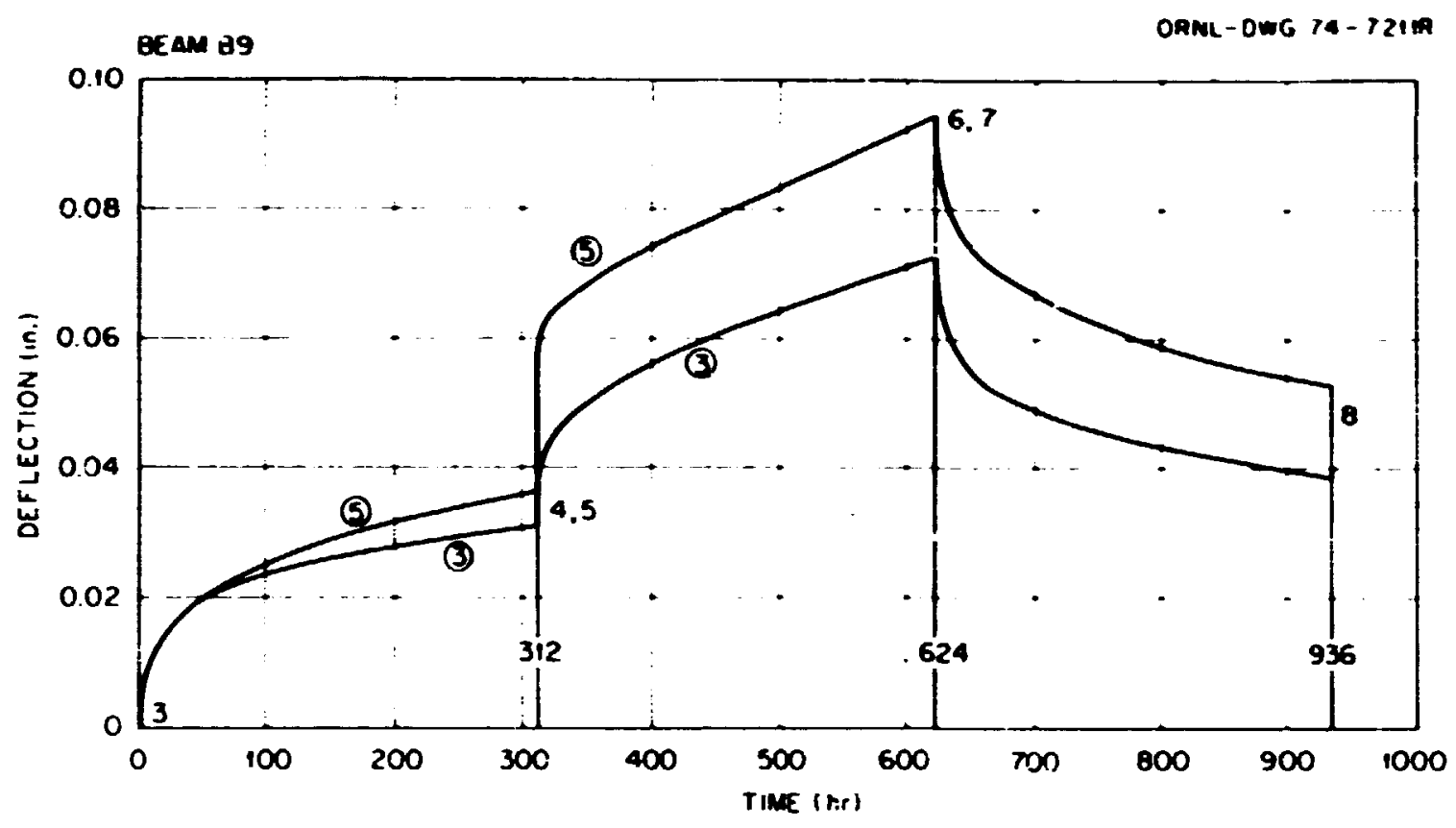

Fig. B.5. Creep deflections (DT3 and DT5) vs time for bean B9 (in. $\times 25.4=m$ ).

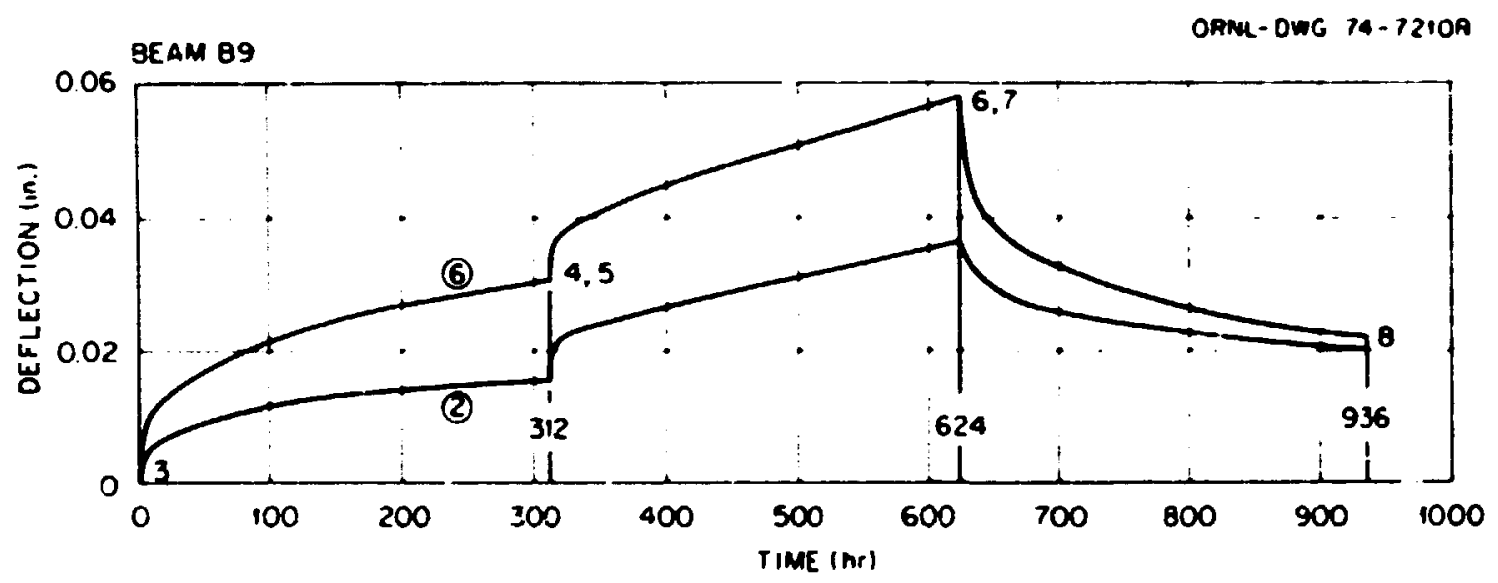

Fig. B.6. Creep deflections (DT2 and DT6) vs time for beam B9 (in. $\times 25.4=\mathrm{mm}$ ). 


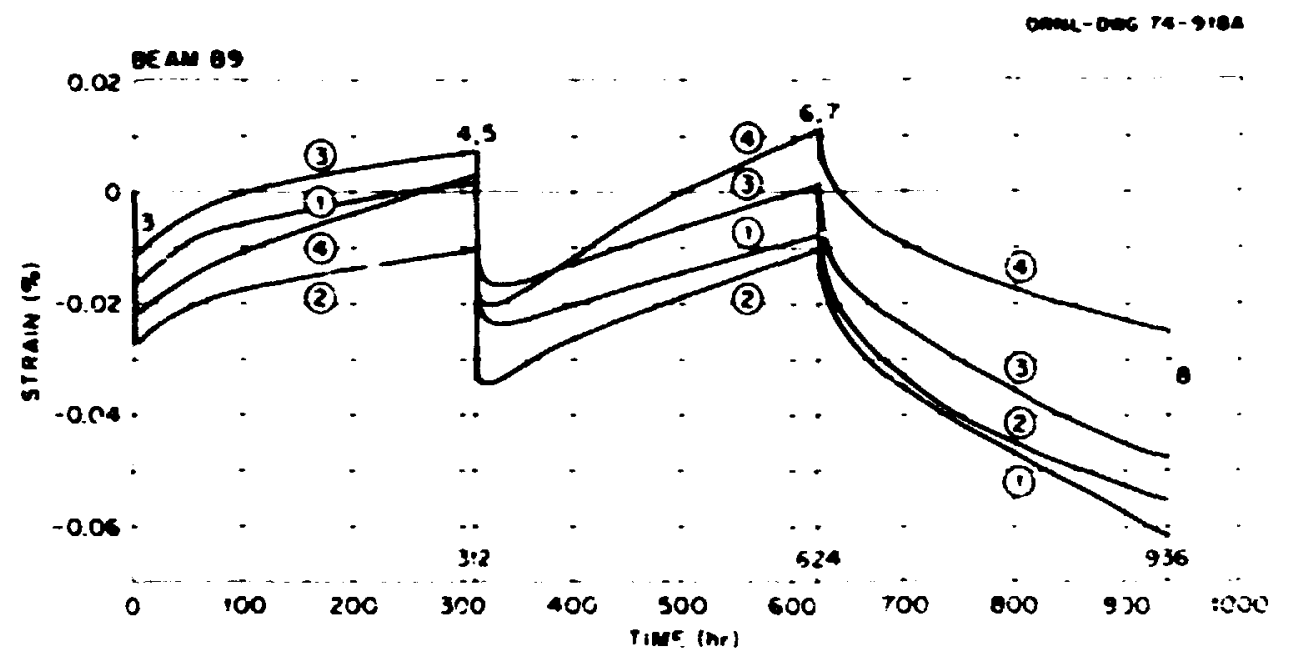

Fig. B.7. Creep strains (SGI-SG4) vs time for bean B9. Note that the signs of SGl and SG3 have been changed.

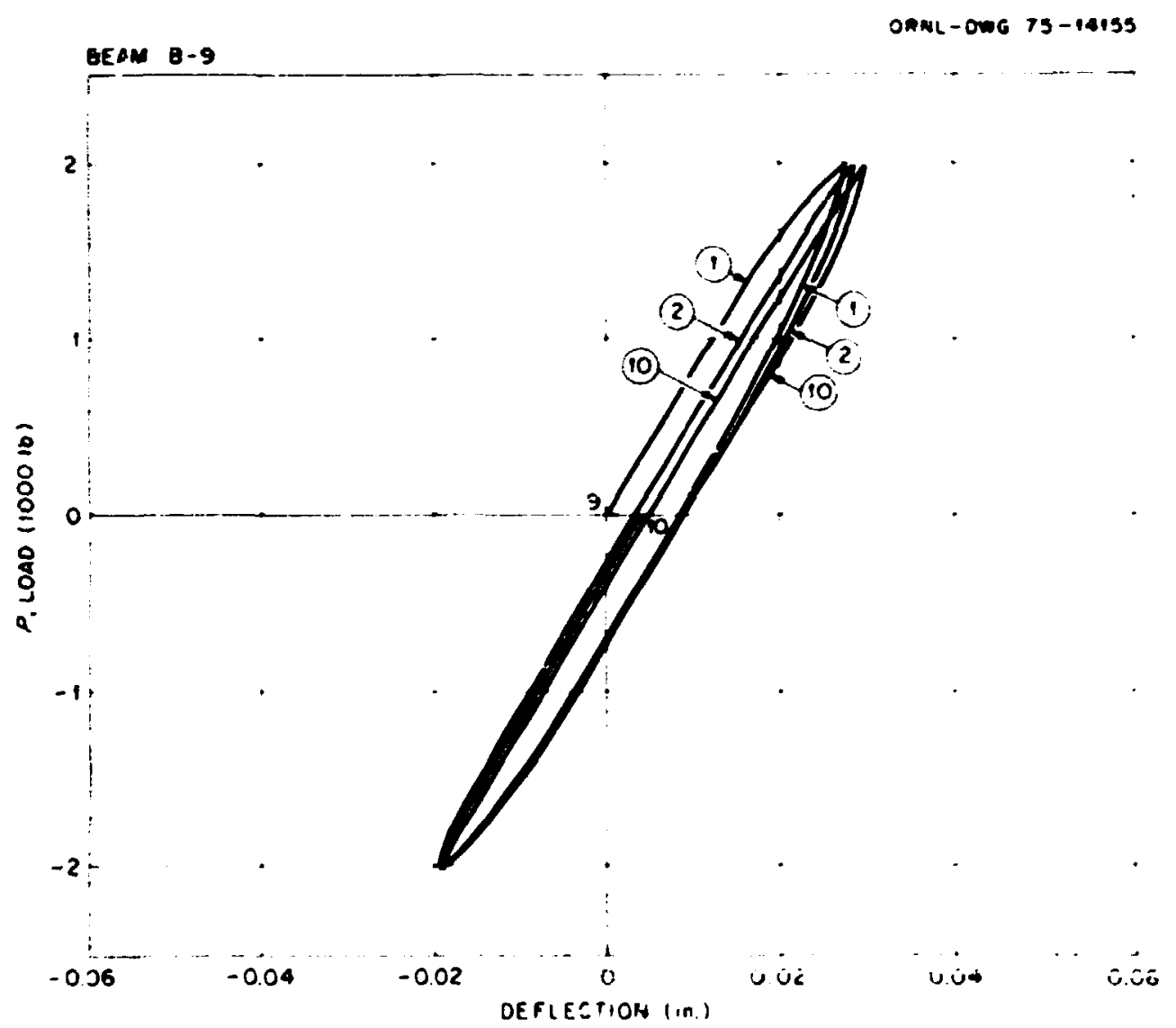

Fig. B.8. Load vs deflection (DT2) during ten short-time, postcreep load cycles of beam B9. The measured deflection was zerosd at point 9 for this plot $(1 \mathrm{t} \times 4.448=\mathrm{N}$, in, $\times 25.4=\mathrm{mm})$. 


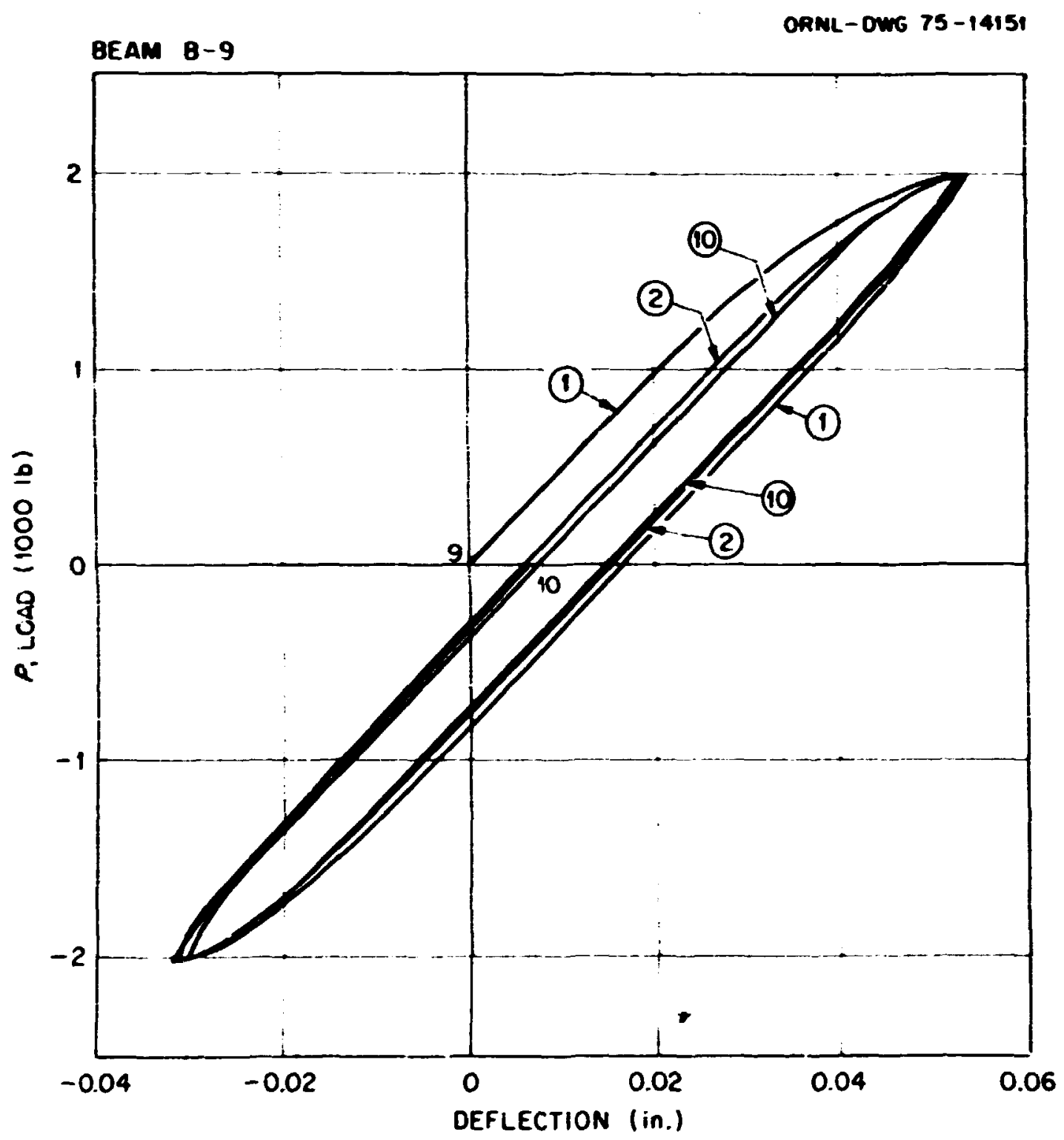

Fig. B.9. Load vs deflection (DT3) during ten short-time, postcreep load cycles of bean B9. The measured deflection was zeroed at point 9 for this plot $(1 \mathrm{~b} \times 4.448=N$, in $\times 25.4=\mathrm{mm})$. 


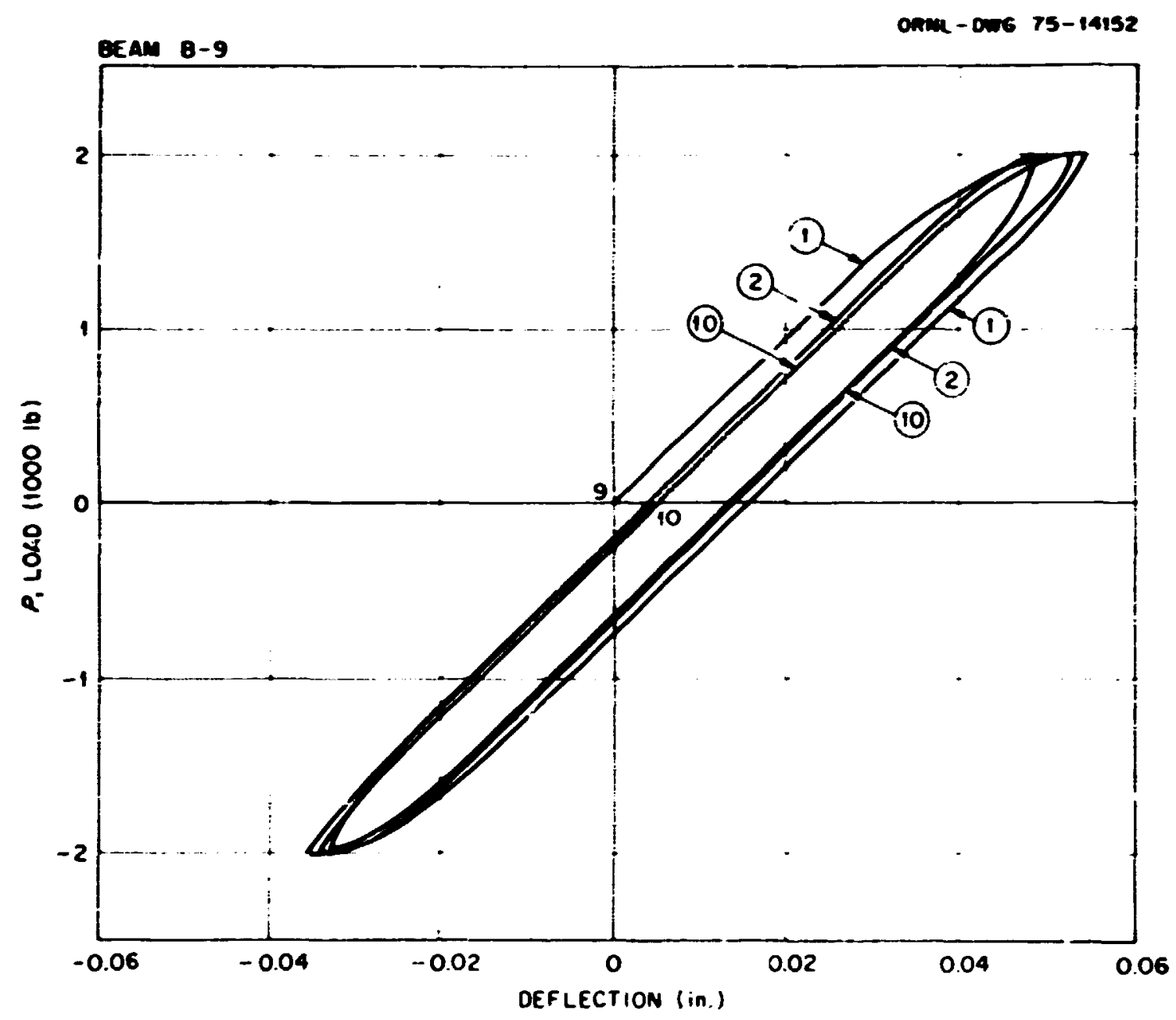

Fig. B.10. Load vs deflection (DTS) during ten short-time, poitcreep load cycles of beam B9. The measured deflection was zeroed at point 9 for this plot $(1 b \times 4.448=N$, in. $\times 25.4=m)$. 


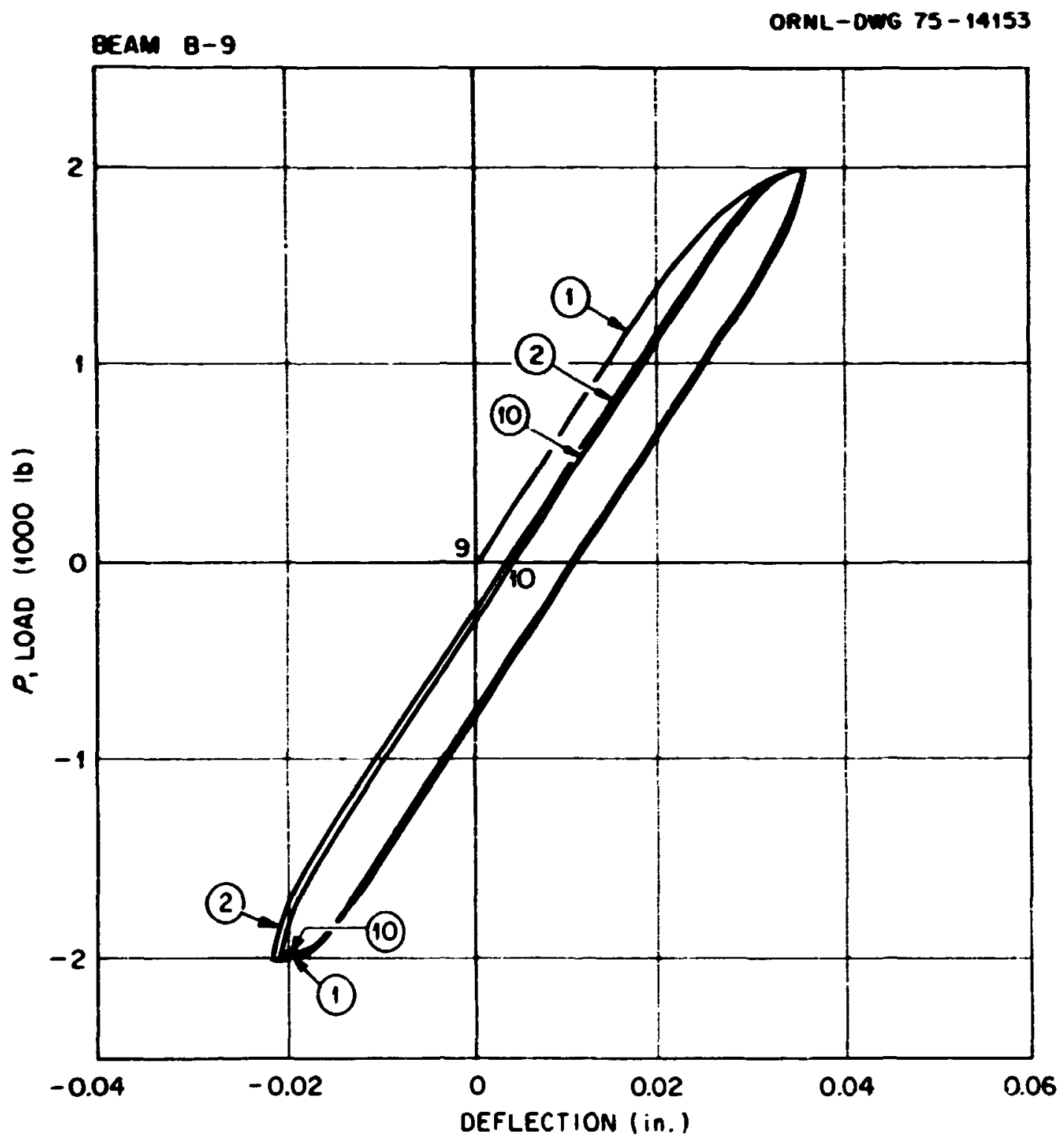

Fig. B.11. Load vs deflection (DT6) during ten short-time, postcreep load cycles of beam B9. The measured deflection was zeroed at point 9 for this plot $(16 \times 4.448=N$, in. $\times 25.4=\min )$. 


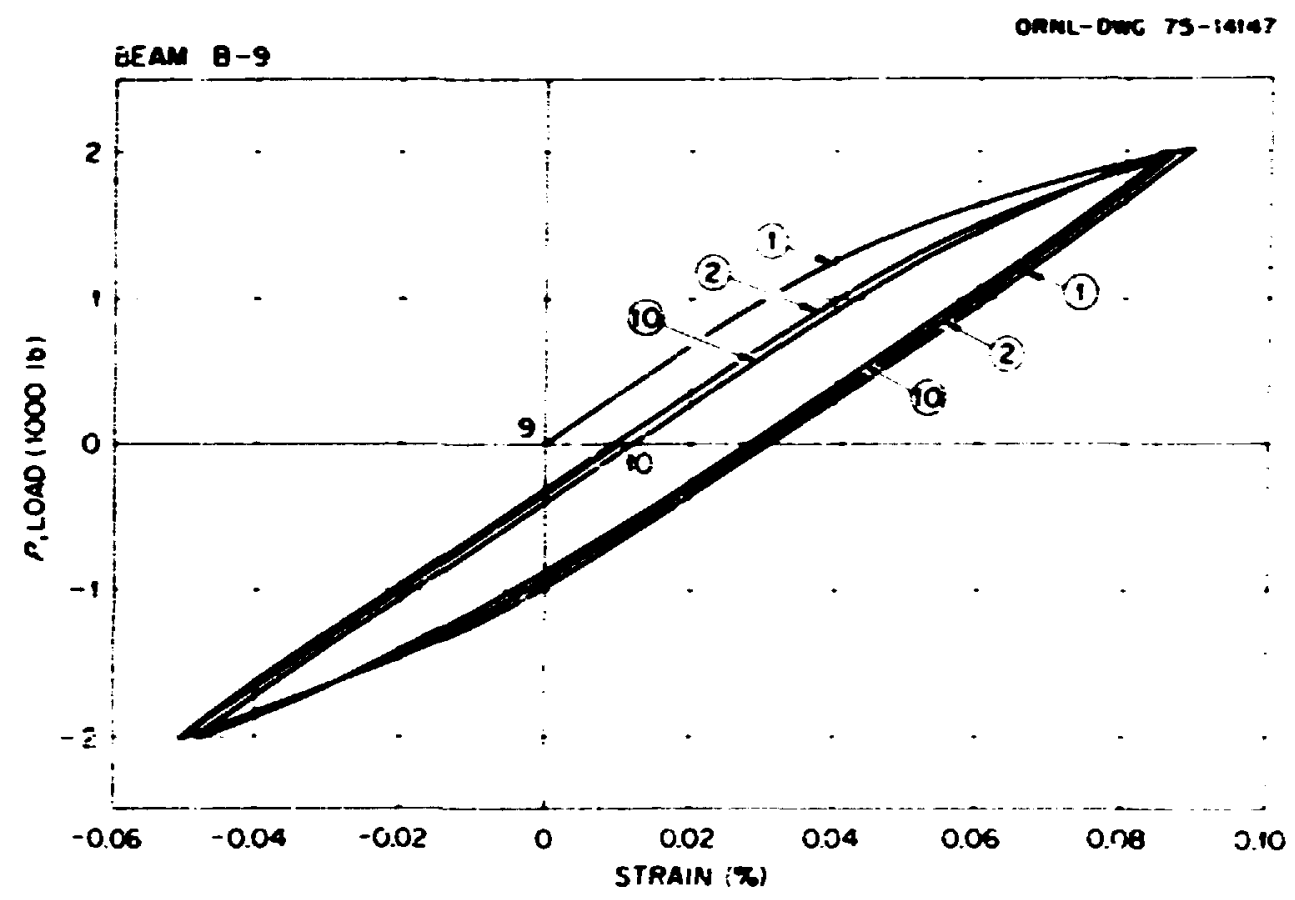

Fig. B.12. Load vs strain (SG1) during ten short-time, postcreep luad cycles of bean B9. The measured strain was zeroed at point 9 for this plot. Note that the sign of the strain has been changed ( $1 \mathrm{~b} \times$ $4.448=N$ ).

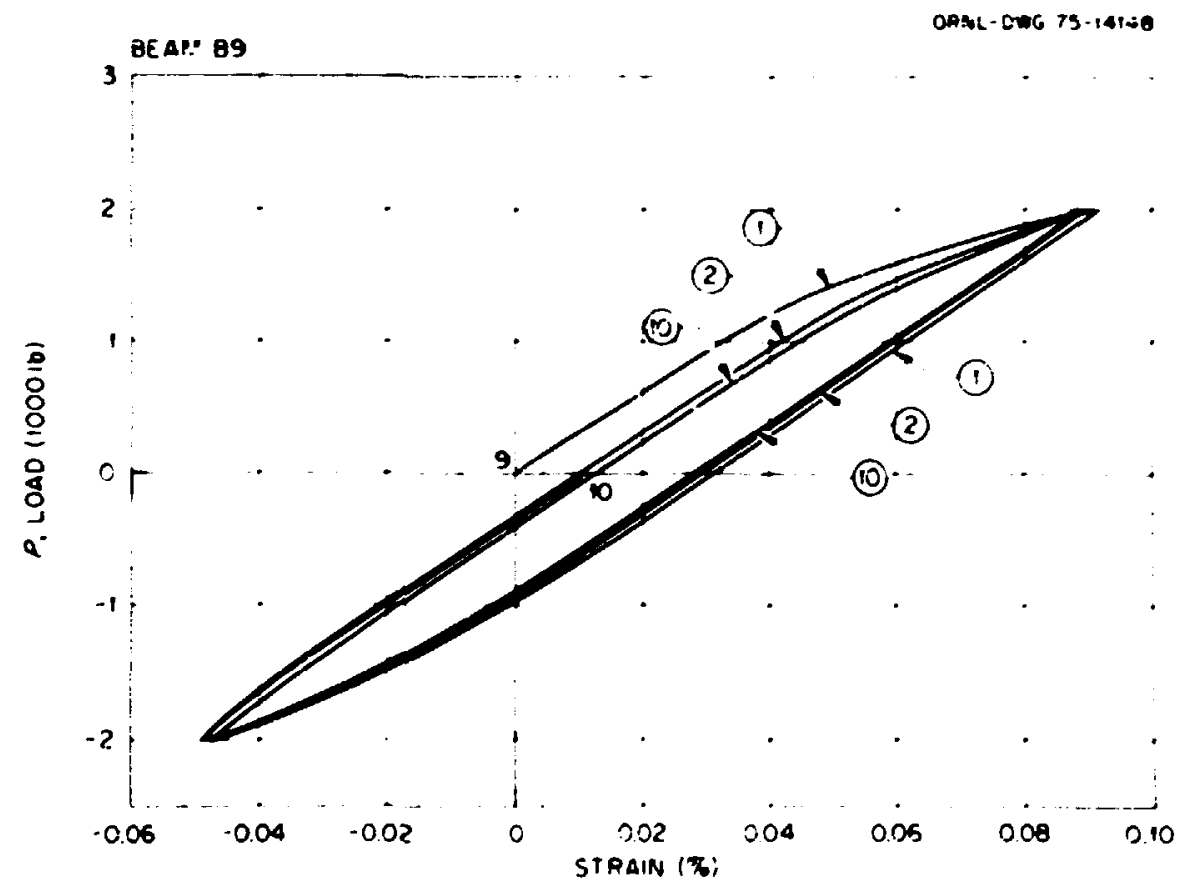

Fig. B.13. Load vs strain (SG2) during ten short-time, postcreep load cycles of bean B9. The measured strain was zeroed at point 9 for this plot $(1 \mathrm{~b} \times 4.448=N)$. 


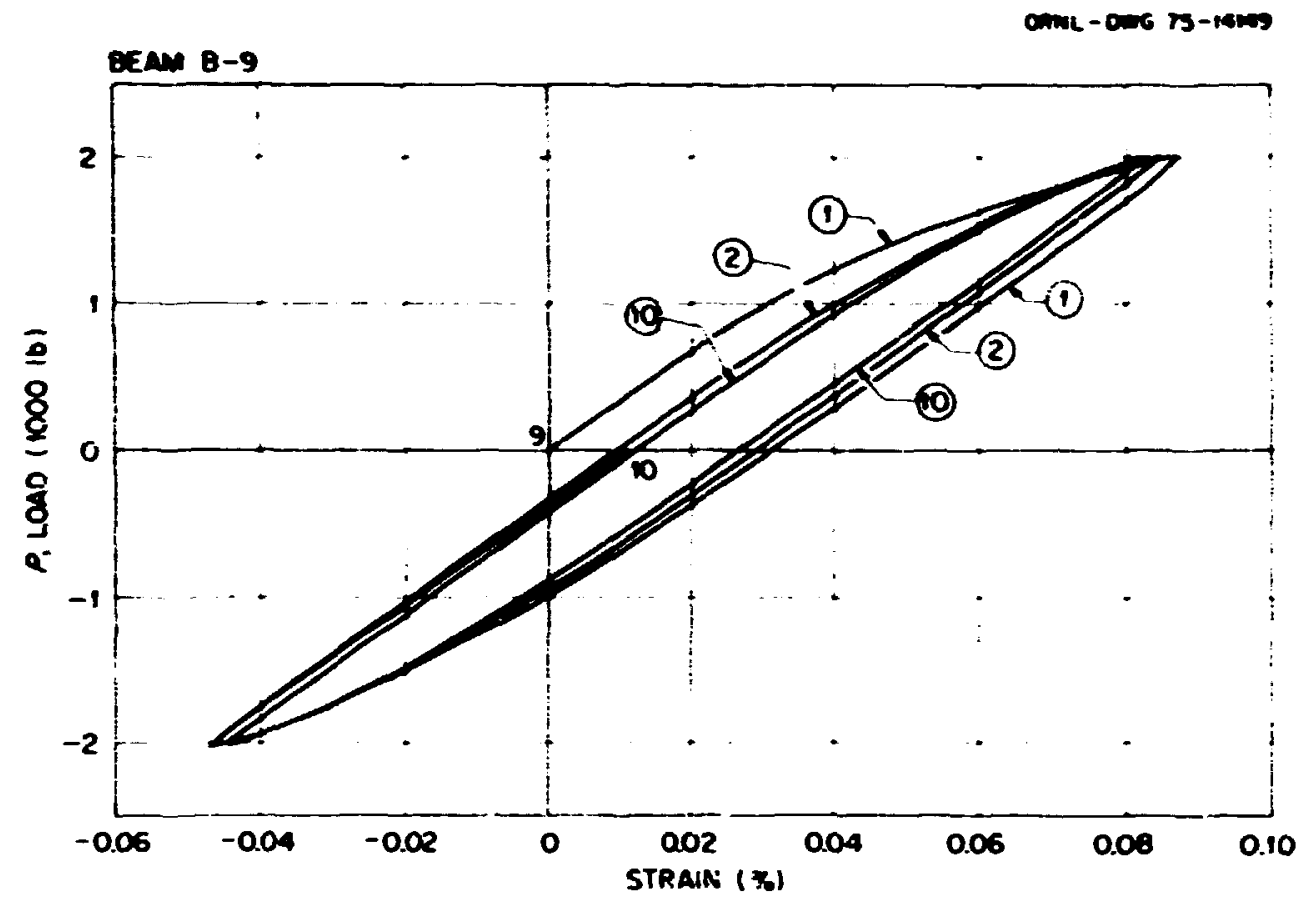

Fig. B.14. Load vs strain (SG3) during ten short-time, postcreep load cycles of bean B9. The measured strain was zeroed at point 9 for this plot. Note that the sign of the strain has been changed ( $1 b \times$ $4.448=N$ ) .

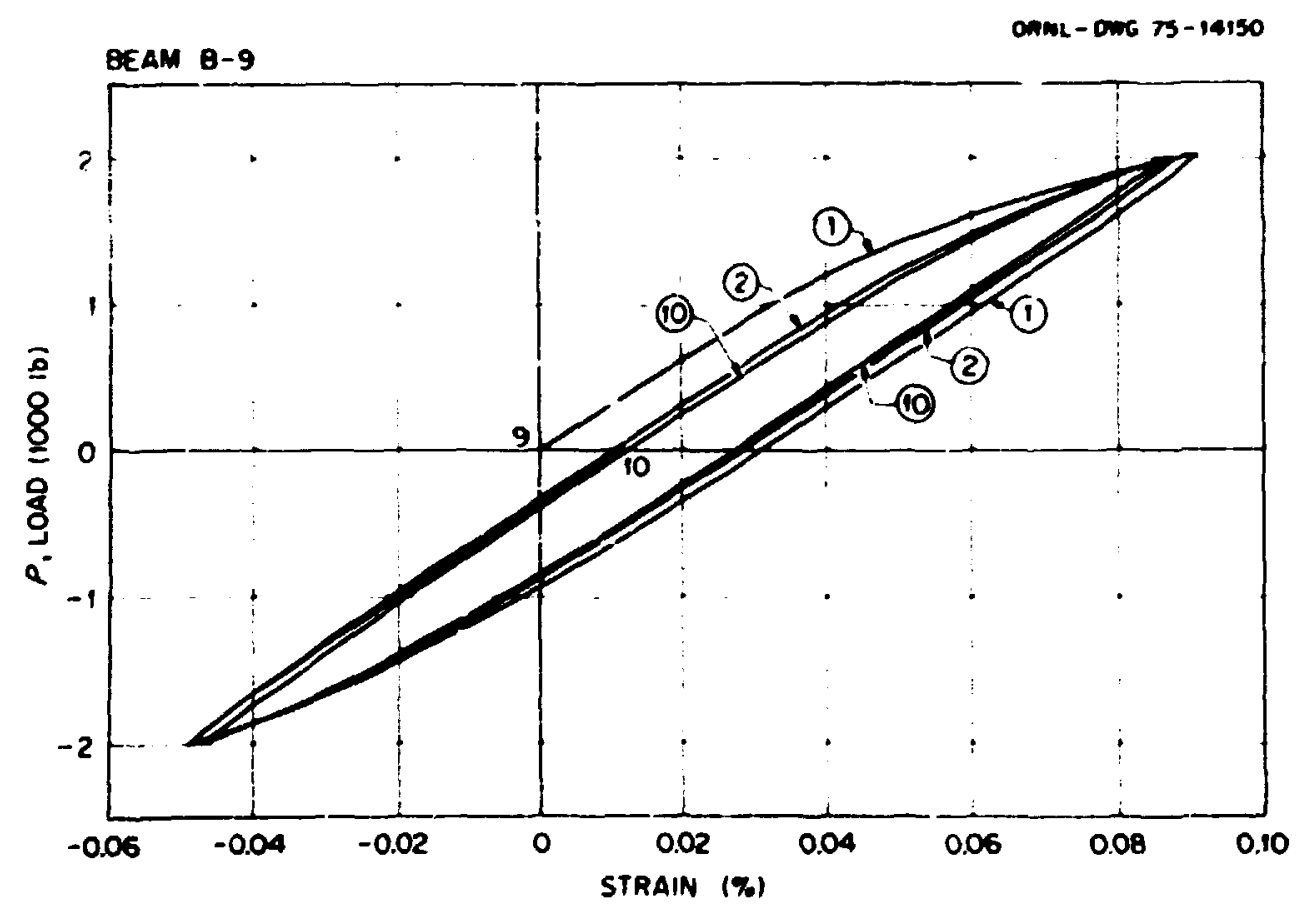

Fig. B.15. Load vs strain (SG4) during ten short-time, postcreep load cycles of beam B9. The measured strain was zeroed at point 9 for this plot $(1 b \times 4.448=N)$. 
APPENDIX C. ADDITIONAL TEST RESULTS FOR BEAH BIO

Bean $B 10$ was a load-controlled test with precreep cycles. Figure C. 1 depicts the temperatures measured during the test. As can be seen, the specimen ran at a slightly lower teaperature [about $1.1^{\circ} \mathrm{C}\left(2^{\circ} \mathrm{F}\right)$ ] than intended. The gaps in the data plots are a result of outages of the highspeed data acquisition system. During these periods, deflection and strain data were recorded by $i$ and and/or on strip-chart recorders.

Figures C. 2 through C.10 show the strain gage data obtained during the test. The response of the four gages during the ten precreep cycles is shown in Figs. C.2 through C.S. * Data for the load changes associated with the creep portions of the test are shown in Figs. C.6 and C.7, and the time-dependent data are shown in Fig. C.8." Finally, postcreep cyclic data are shown in Figs. C.9 and C.10.* Note that the absence of data for a particular gage indicates that the gage failed or began to exhibit obviously erratic behavior.

The circled numbers in the figures for the precreep and postcreep cycles denote the cycle number.

*The circled numbers in Figs. C.6 through C. 8 refer to the strain gage nuaber. 


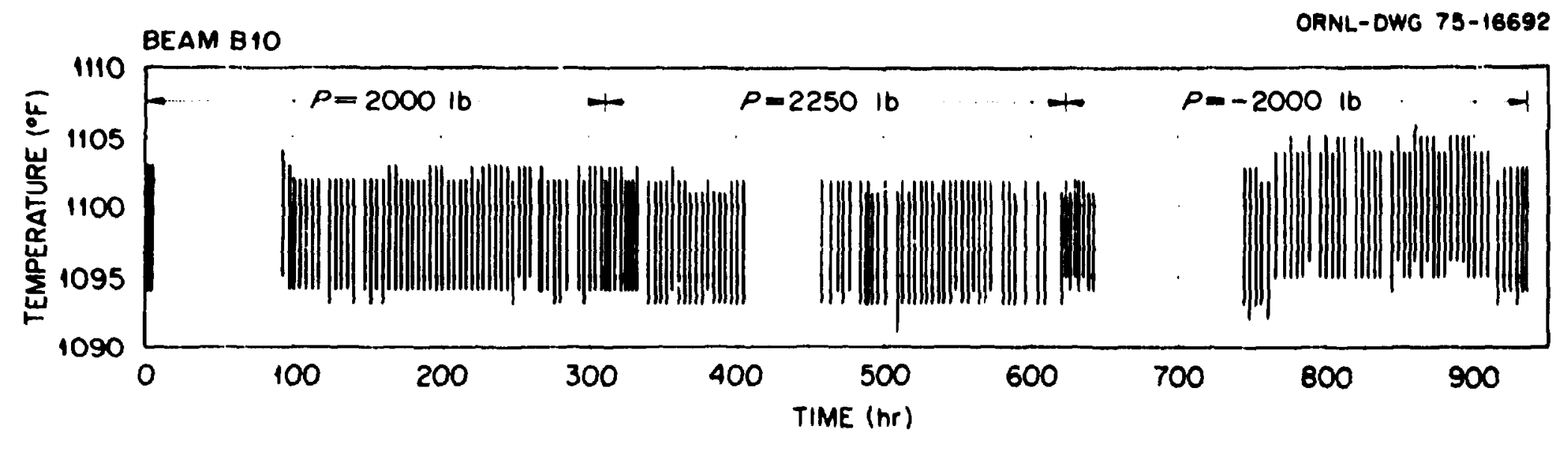

Fig. C.l. Measured temperature range over middle $406 \mathrm{~mm}$ (16 in.) of beam $\mathrm{B} 10$ during $593^{\circ} \mathrm{C}\left(1100^{\circ} \mathrm{F}\right)$ test $\left(\mathrm{Ib} \times 4.448=\mathrm{N},\left({ }^{\circ} \mathrm{F}-32\right) \times\right.$ $0.5556={ }^{\circ} \mathrm{C}$ ). 


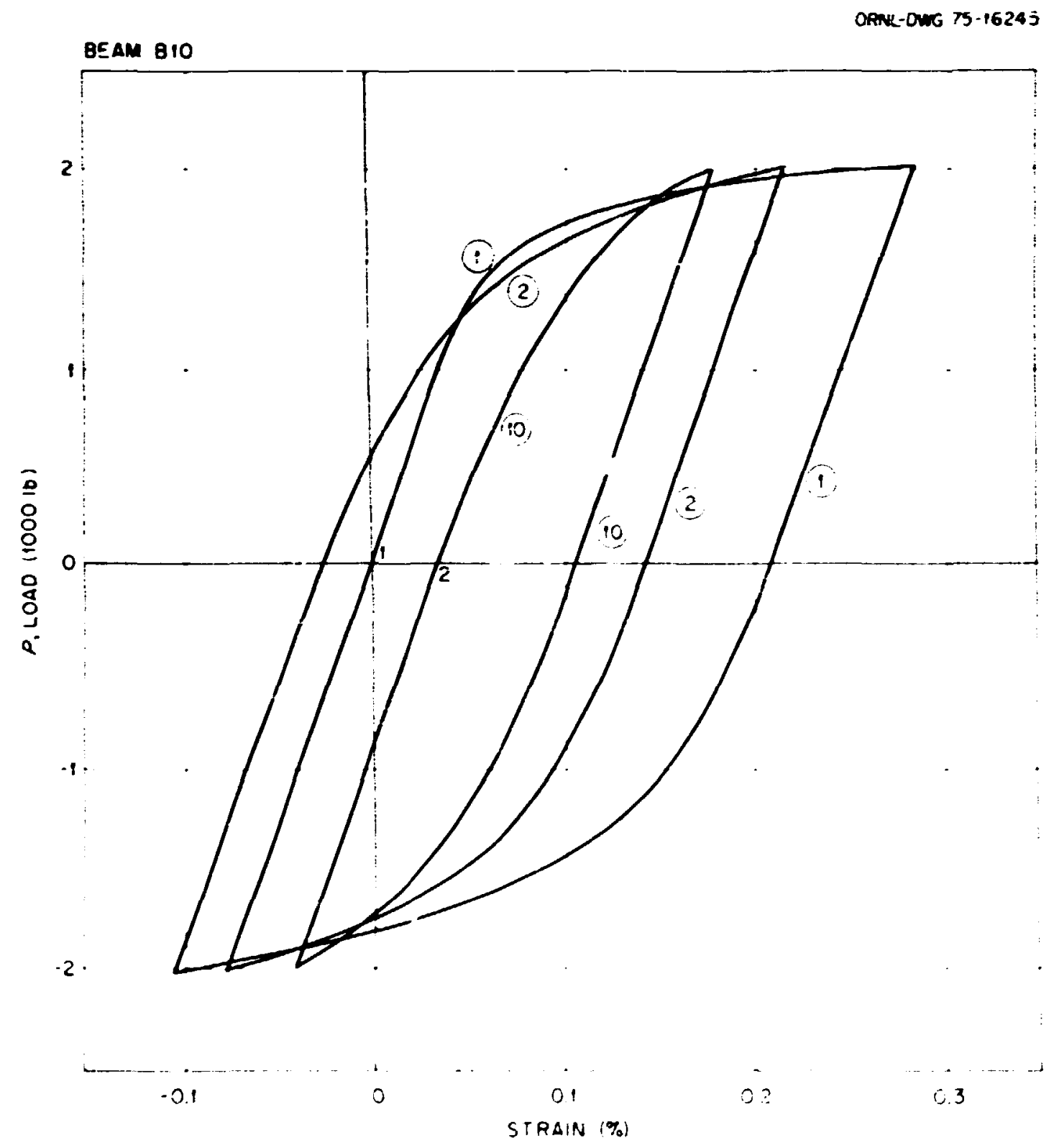

Fig. C.2. Load vs strain (SG1) during ten short-time precreep lnad cycles of beam B10. Note that the sign of the strain has been changed $(1 b \times 4.448=N)$. 


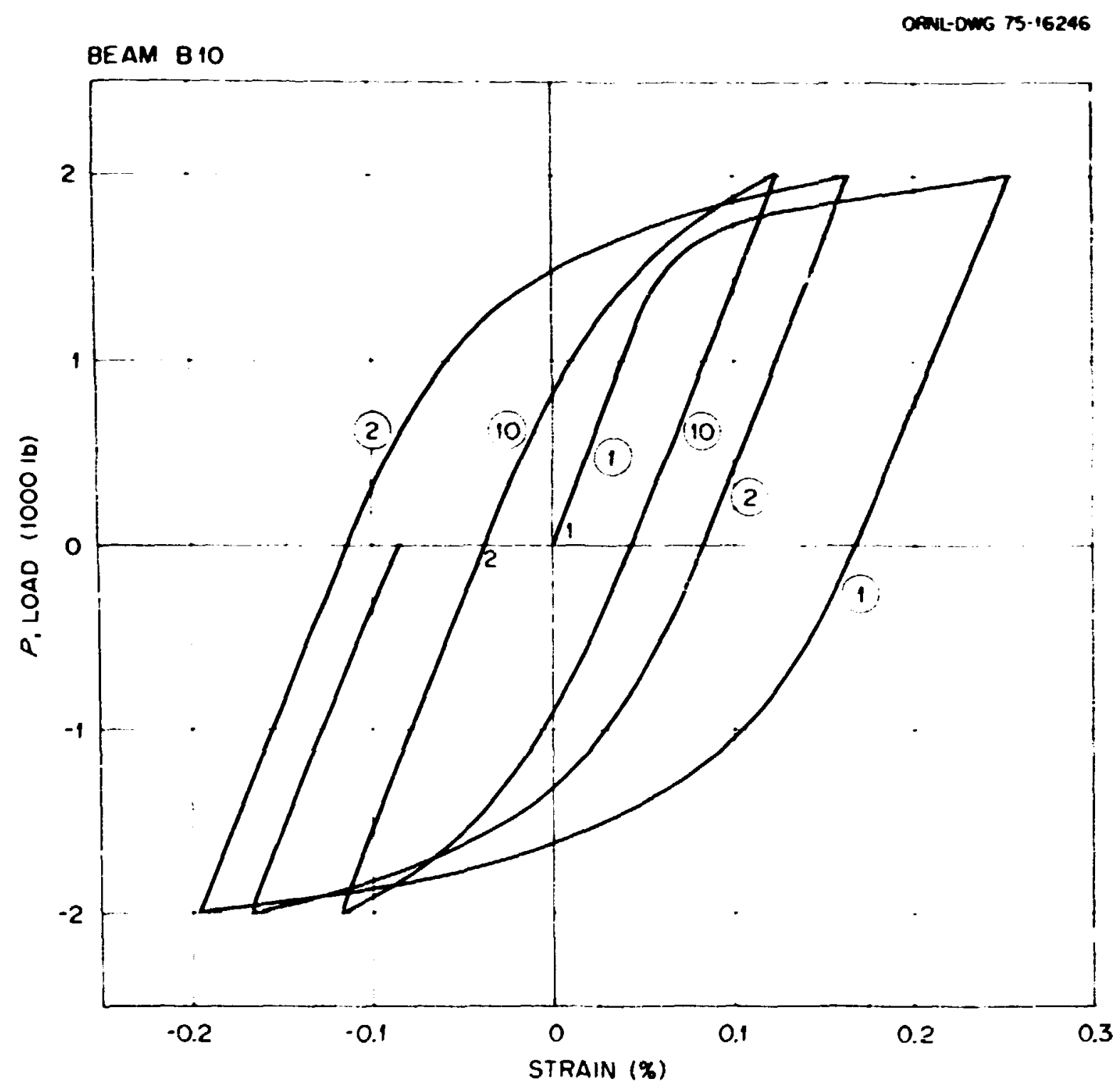

Fig. C.3. Load vs strain (SG2) during ten short-time precreep load cycles of bean $B 10(1 b \times 4.448=N)$. 


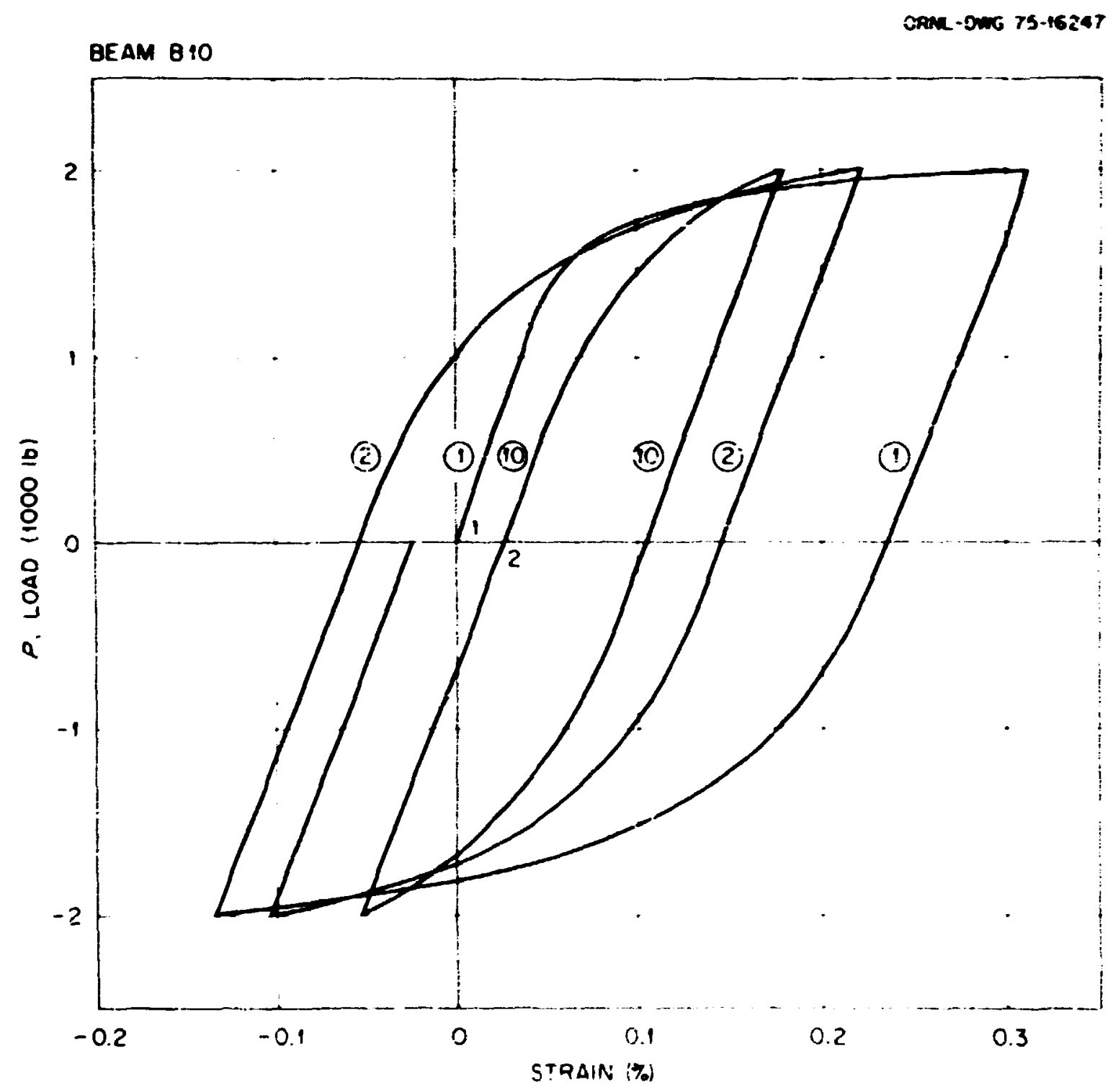

Fig. C.A. Load vs strain (GG3) during ten short-time precreep load cycles of beam B10. Note that the sign of the strain has been changed $(1 \mathrm{~b} \times 4.448=N)$. 


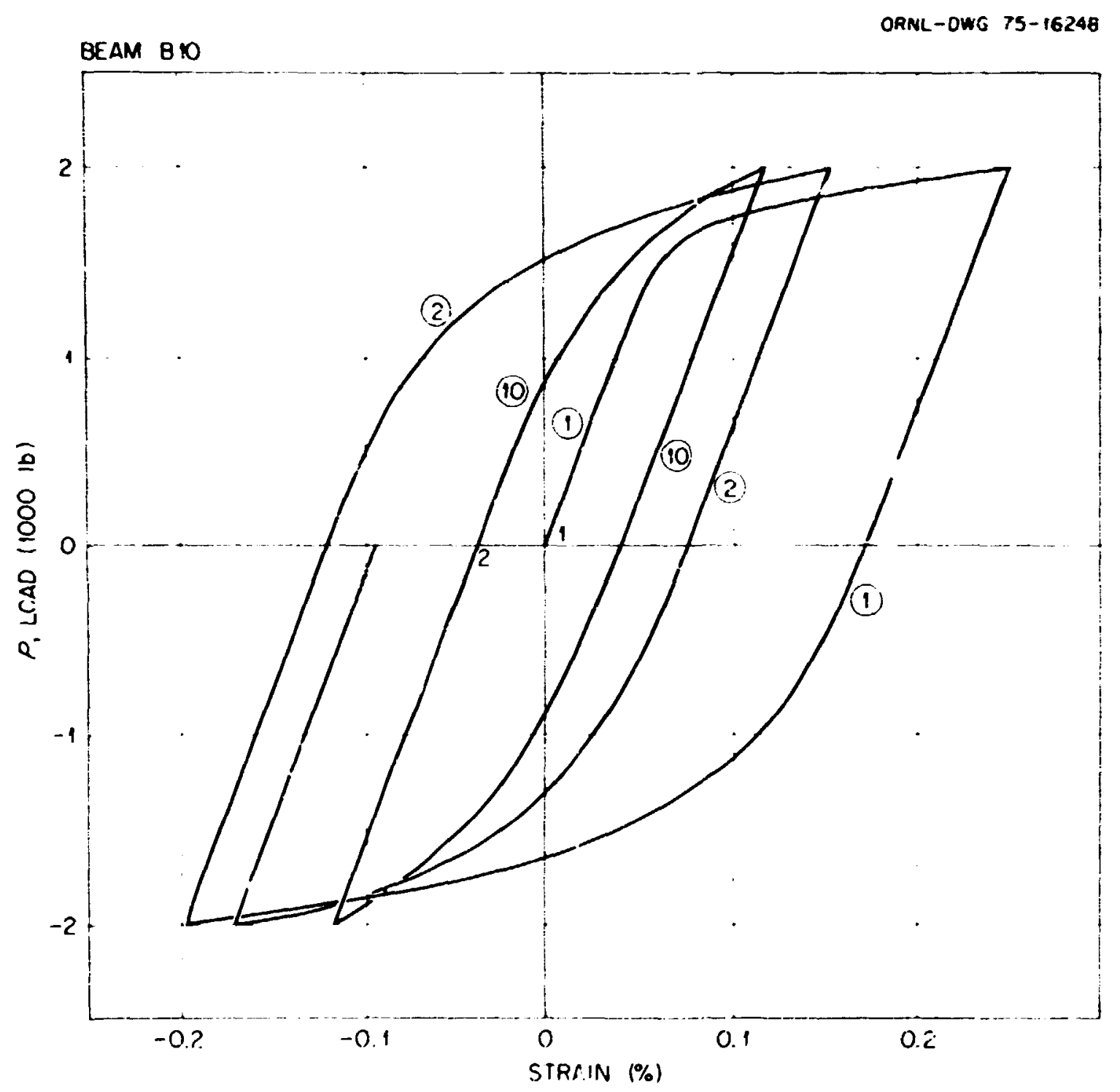

Fig. C.5. Load vs strain (SG4) during ten short-time precreep load cycles of beam $B 10(1 b \times 4.448=N)$. 


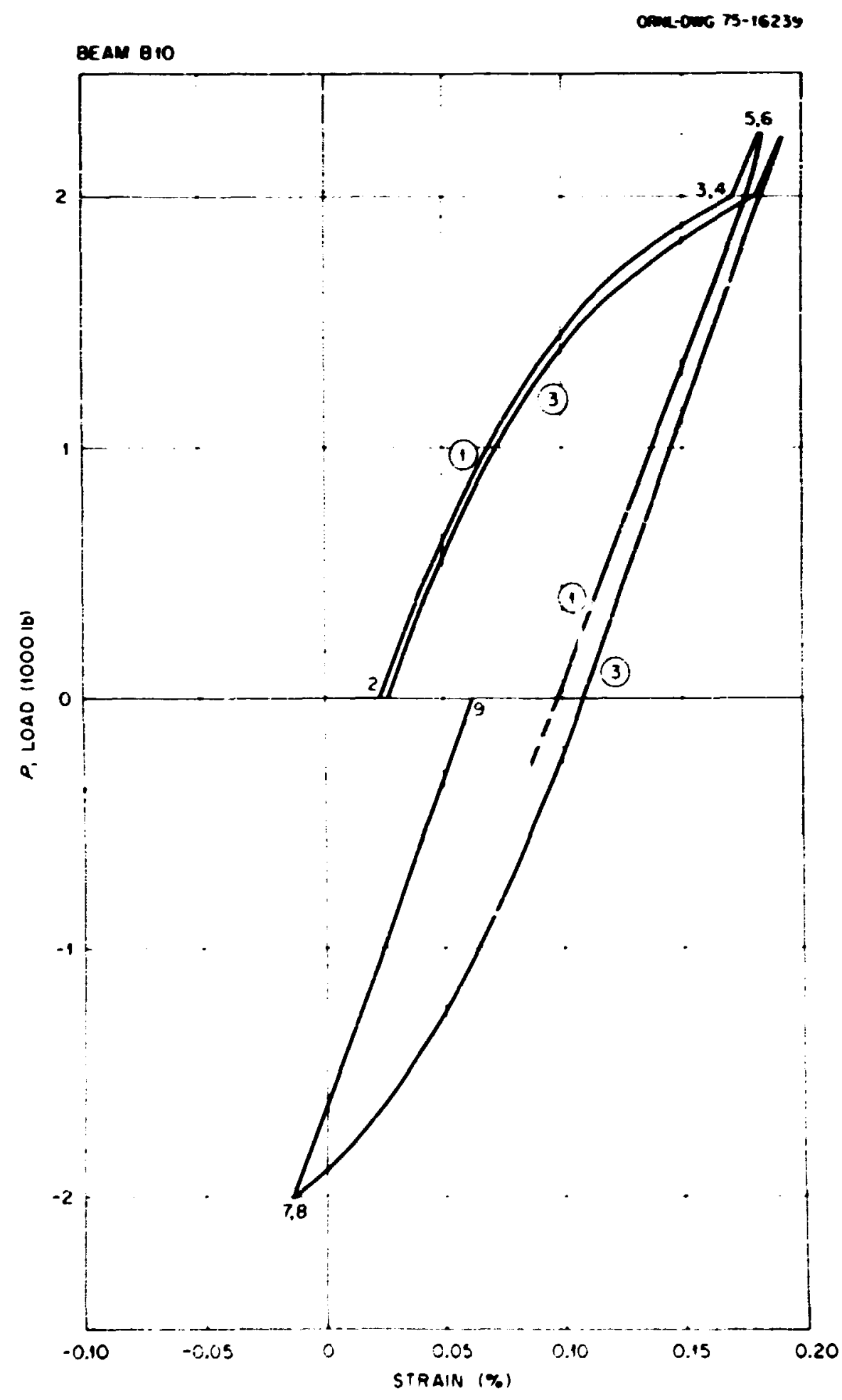

Fig. C.6. Load vs strain (SGI and SG3) for short-time load changes associated with creep portions of beam $H^{*} 0$ test. Note that the sign of the strain has been changed $(1 \mathrm{~b} \times 4.448=N)$. 


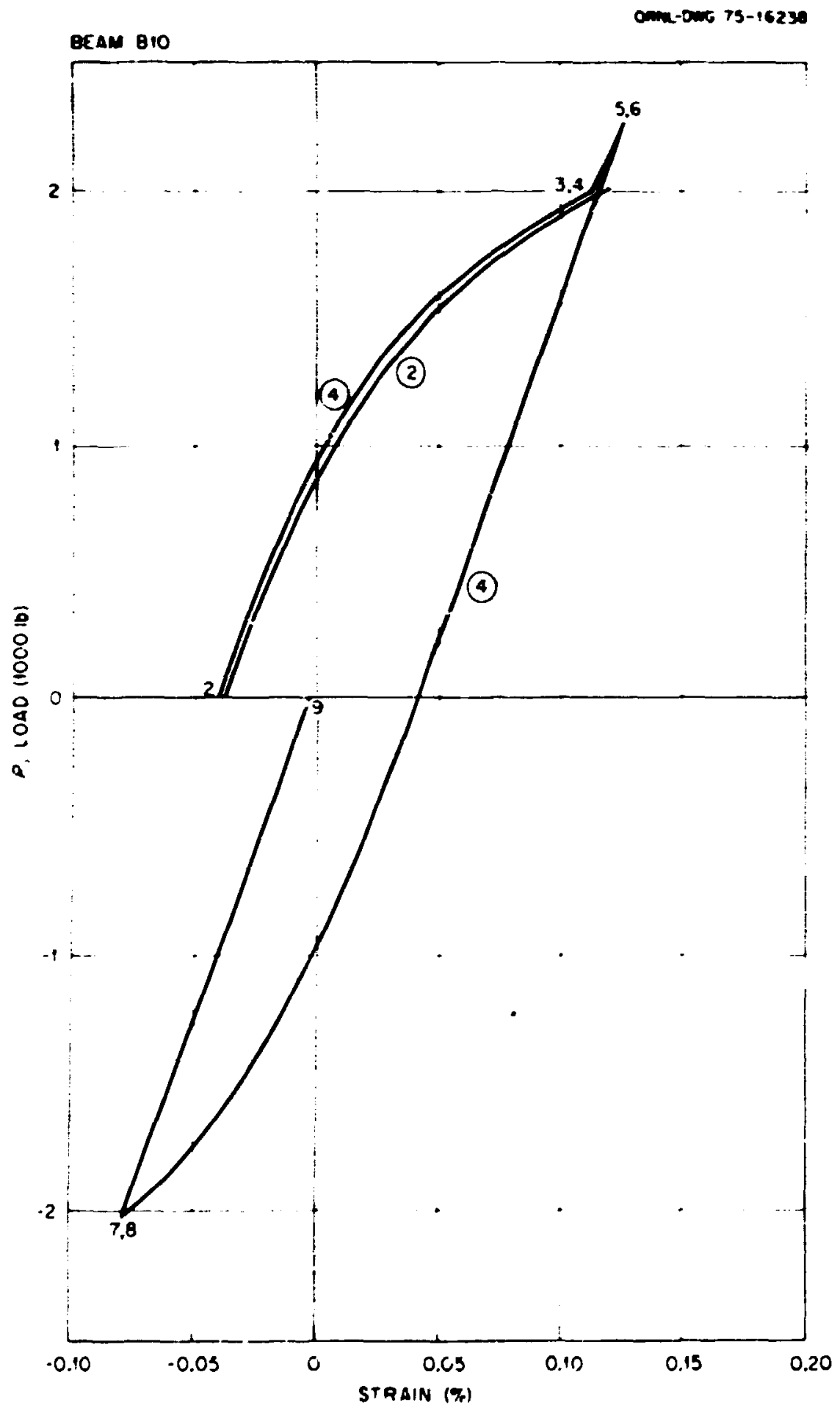

Fig. C.7. Load vs strain (SG2 and SG4) for short-time load changes essociated with creep portions of beam B10 test $(1 b \times 4.448=N)$. 


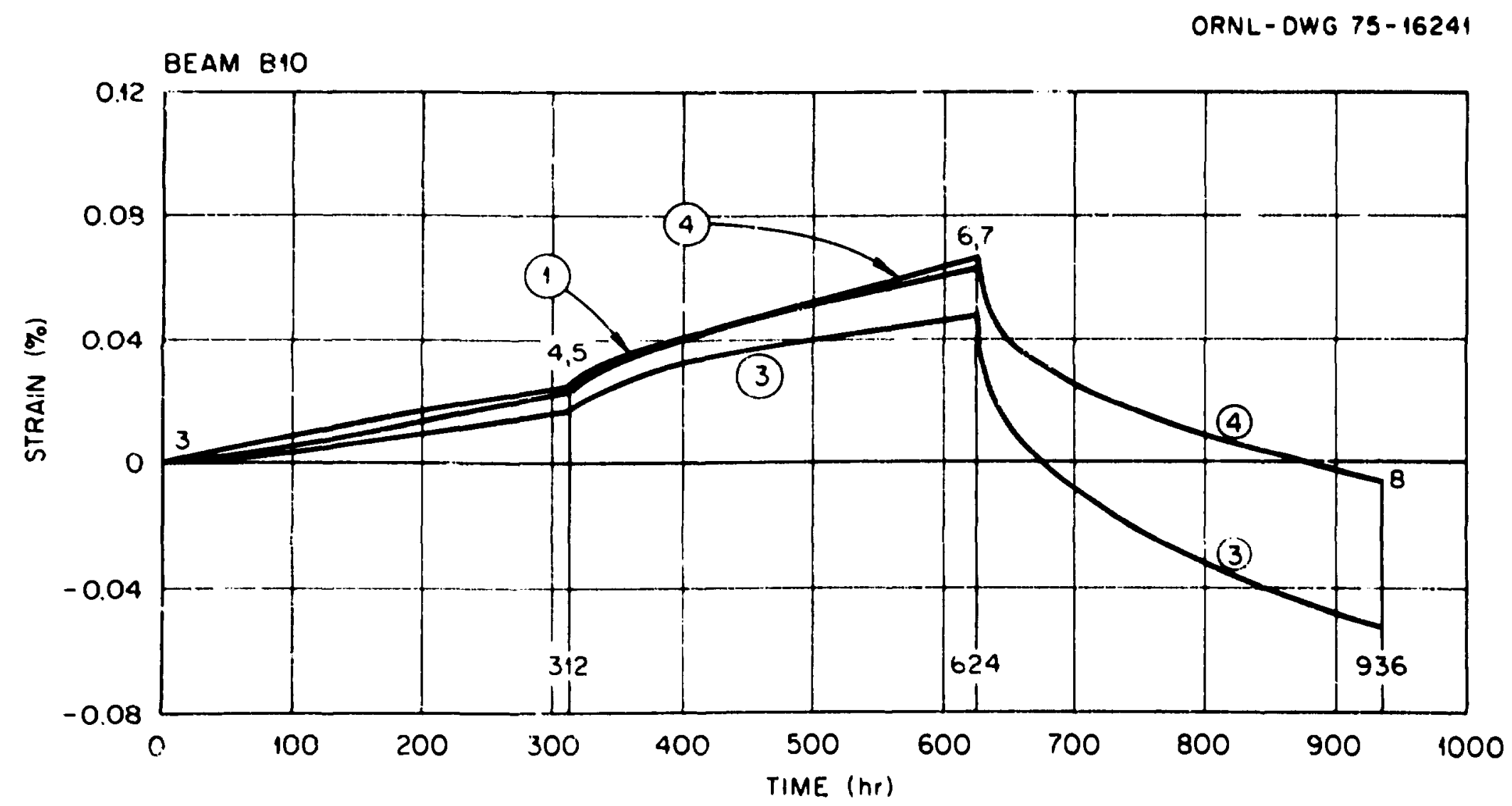

Fig. C.8. Creep strains (SG1, SG3, SG4) vs time for bean B10. Note that the signs of SGI and SLi3 have been changed. 


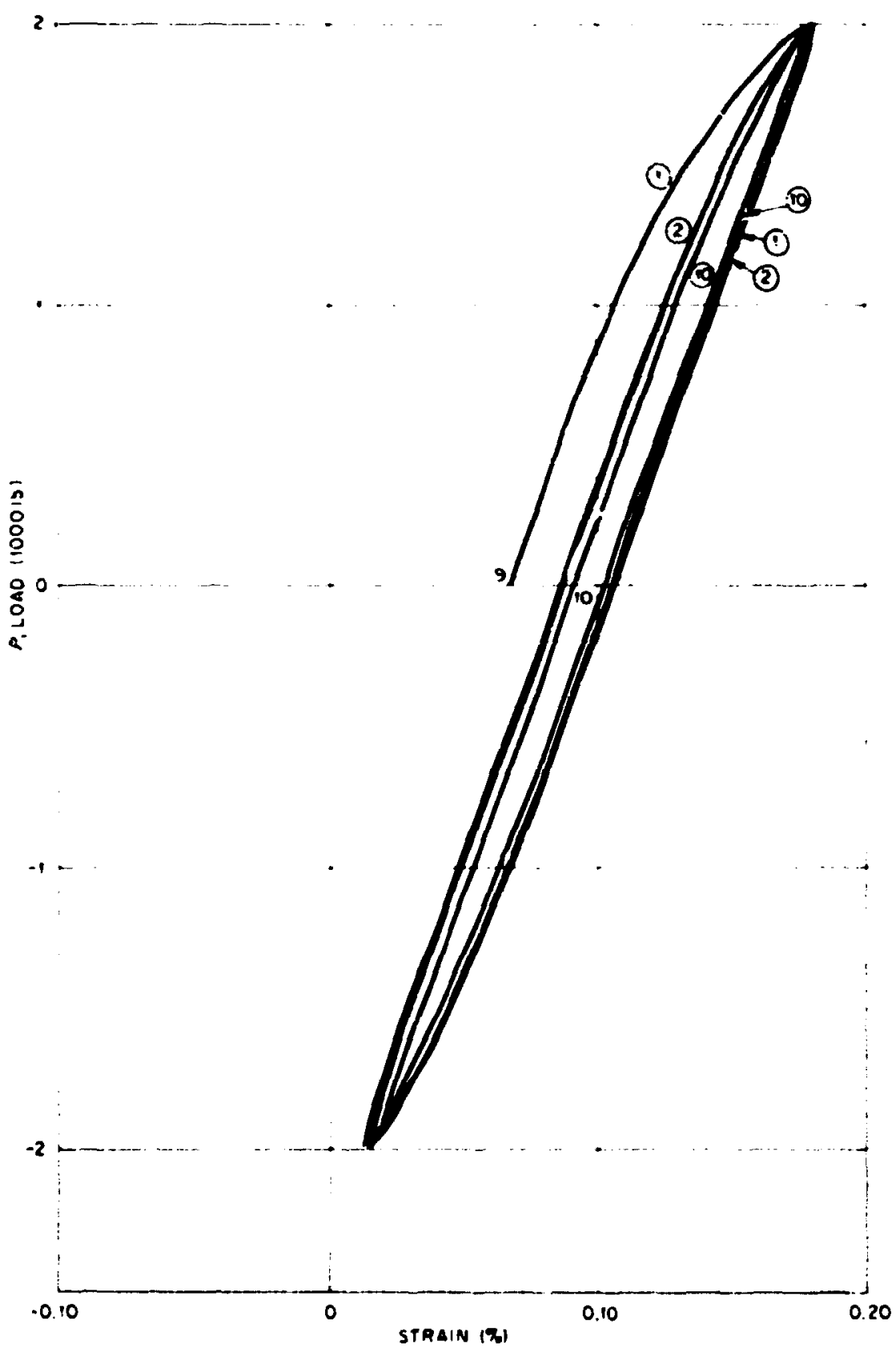

Fig. C.9. Load vs strain (SG3) during ten short-time, fostireep load cycles of beam Bl0. Note that the sign of the strain has been changed $(1 \mathrm{~b} \times 4.443=\mathrm{N})$. 
81
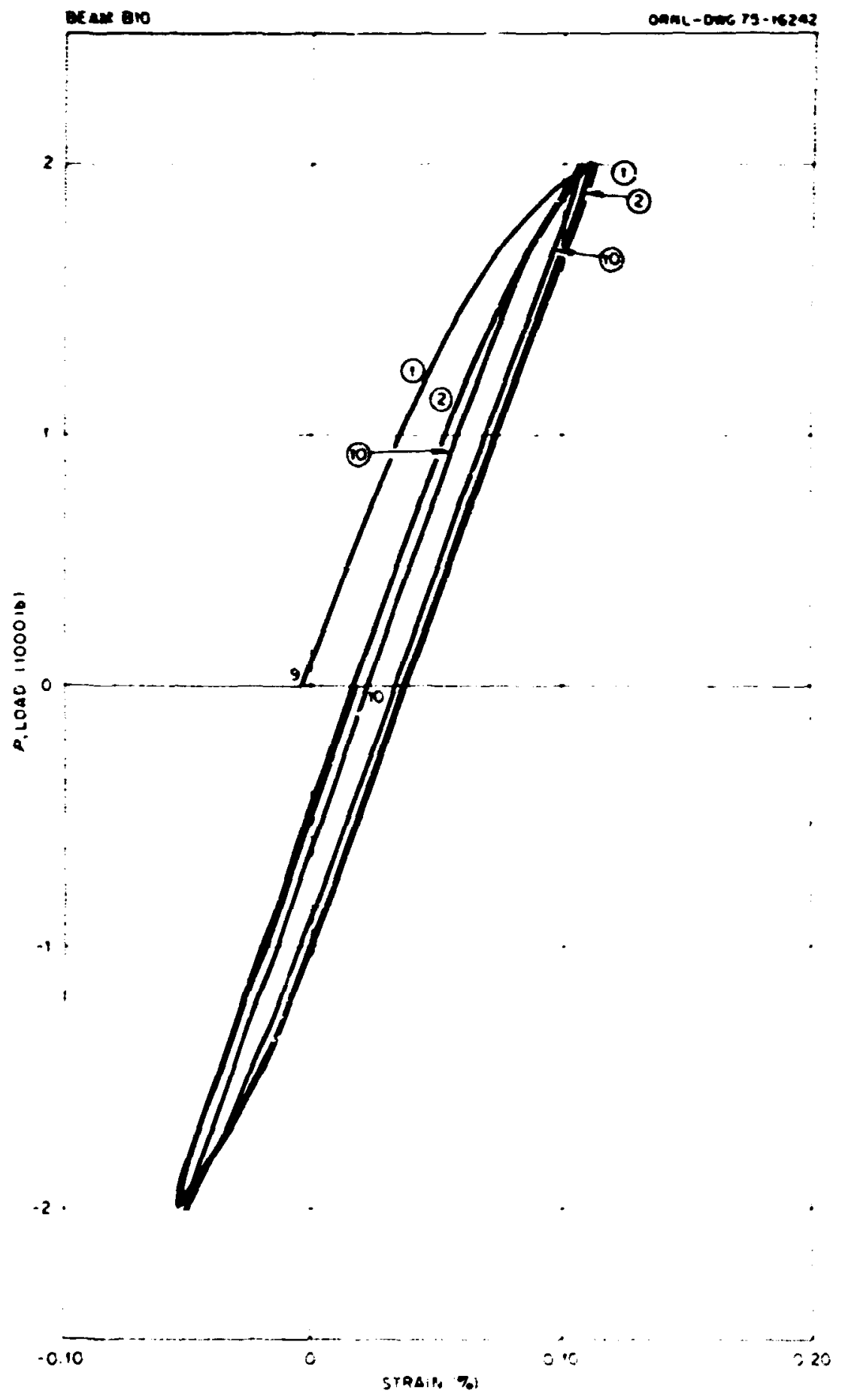

Fig. C.10. Load vs strain (SG4) during ten short-time, postcreep load cycles of beam B10 (lb $\times 4.448=N)$. 


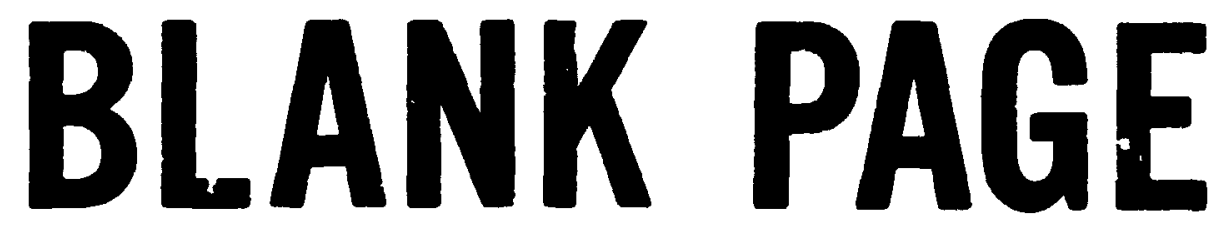


APPENDIX D. ADDITIONAL TEST RESULTS FOR BEAM B7

Bean $B 7$ was a deflection-controlled test without precreep cycles. Figure $: .1$ shows the measured teiperature ranges during the test. Generaliy, the teaperatures in this test were within the intended range.

Figures D.2 and D.3 show the load vs deflection response data for the relaxation portions of the test." Although the center deflection was hel1 constant from points 3 to 4 and 5 to 6 , deflections at other locations along the bean were not so restrained. During the load-relaxation periods these latter deflections exhibited small but erratic variations. Rather than trying to interpret and smooth out these variations, we have siaply indicated that the true data path cannot be resolved. We are confident, however, that the end poin:s are reasonable.

Figures D.4 and D.5 show the corresponding load vs strain data.* Again, thc actual paths during the load-relaxation phases of the test could not be resolved.

Figures 0.6 and D.7 depict the deflection vs time and strain vs time responses, respectively, during the load-relaxation period.* Figures D.8 through 0.15 depict the load vs deflection and load vs strain response for the postcreep cycles.**

*The circied numbers in Figs. 0.2 through 0.7 refer to gage numbers. * The circled numbers in Figs. D.8 through 0.15 denote cycle number. 


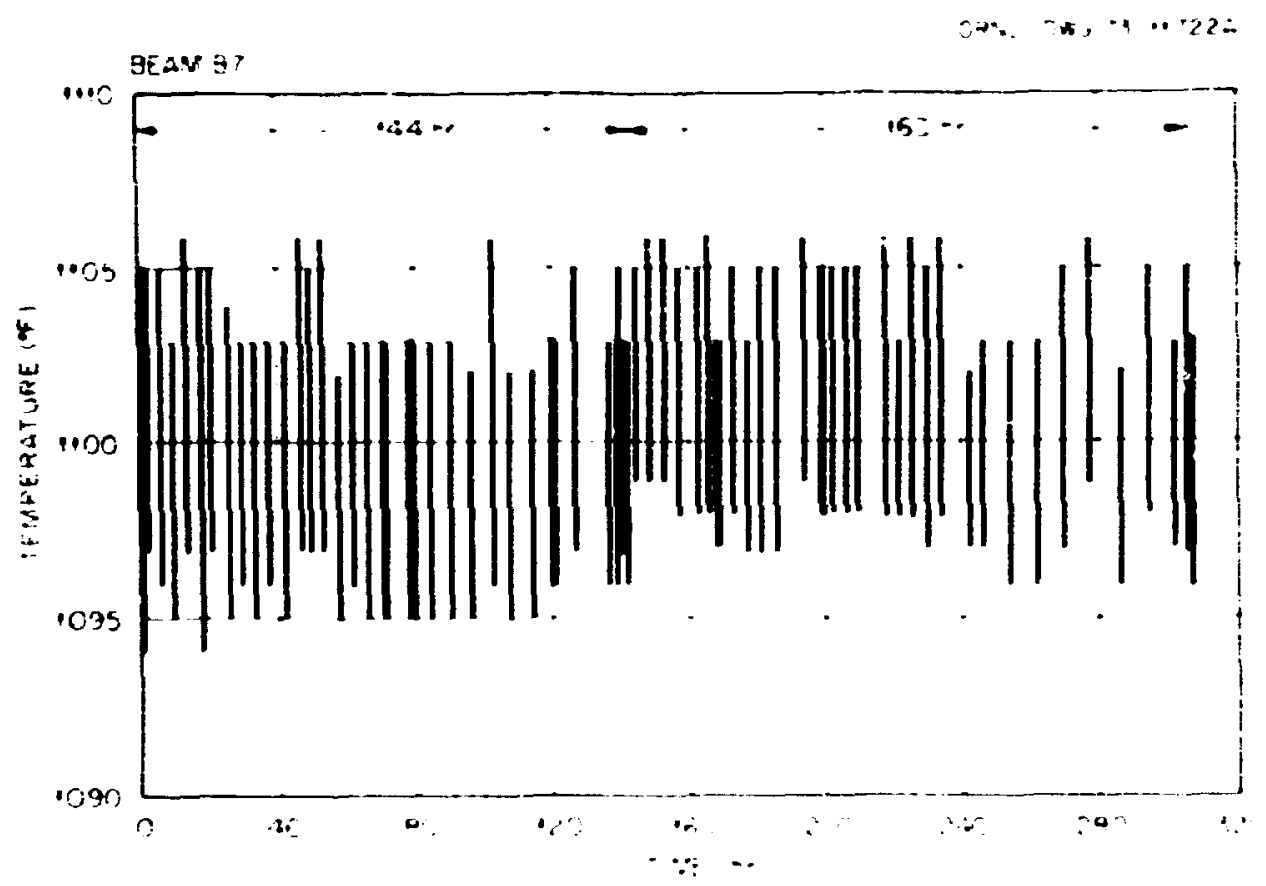

Fig. D.1. Measured temperiture range over middle 406 (16 in.) of beam $\mathrm{B} 7$ during $593^{\circ} \mathrm{C}\left(1100^{\circ} \mathrm{F}\right)$ test $\left[\left({ }^{\circ} \mathrm{F}-32\right) \times 0.5556={ }^{\circ} \mathrm{C}\right]$.

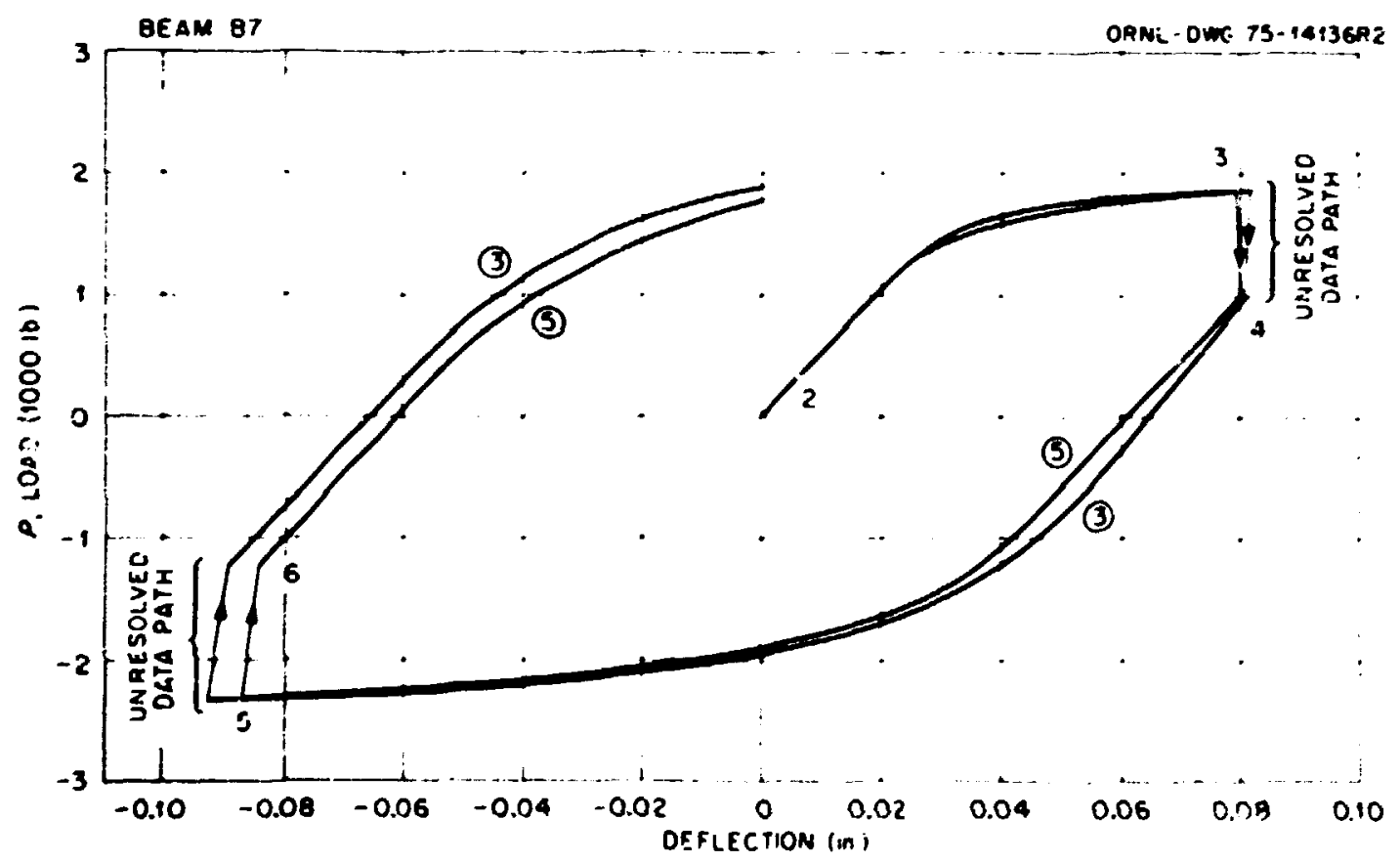

Fig. D.2. Load vs deflection (DT3 and DT5) changes associated with relaxation portions of beam B7 ( $1 b \times 4.448=N$, in. $\times 25.4=\mathrm{mm})$. 


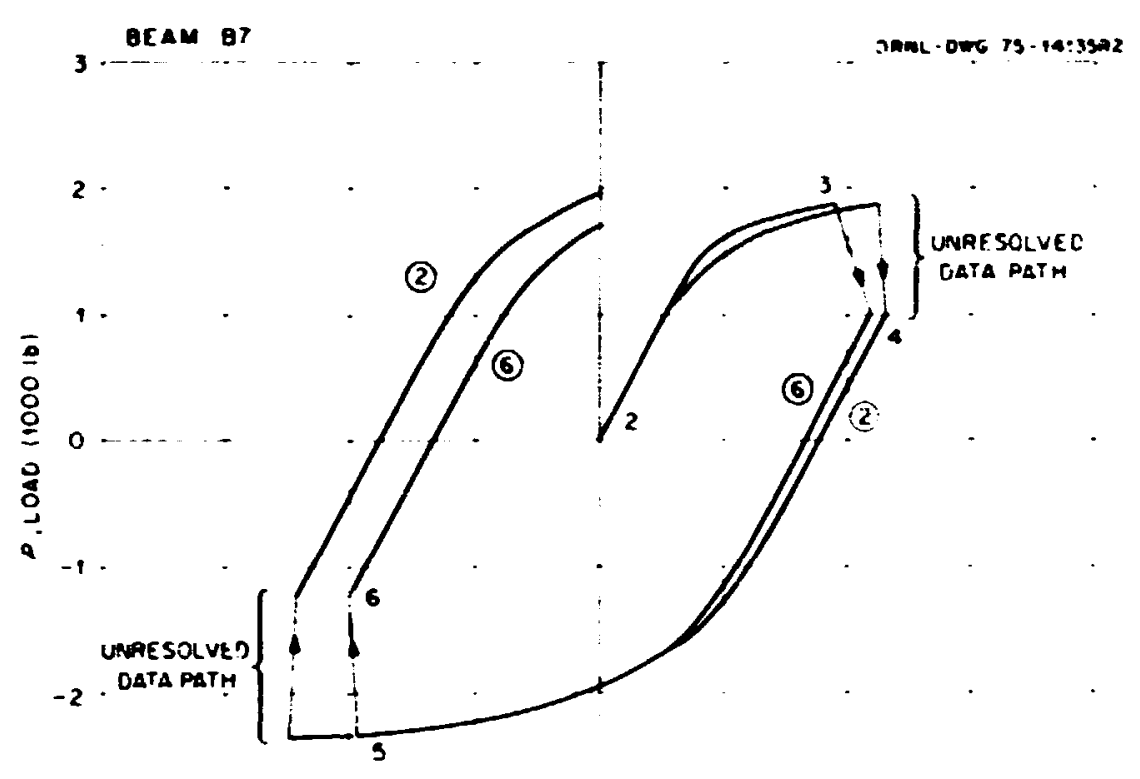

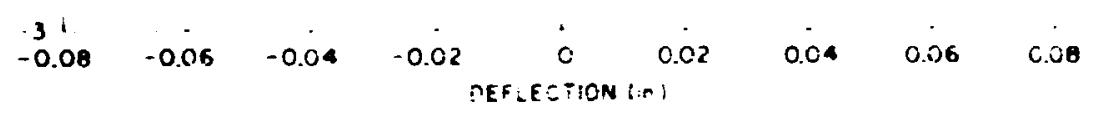

Fig. D.3. Load vs deflection (DT2 and DT6) changes associated with relaxation portions of beam B7 $(1 b \times 4.448=x$, in. $\times 25.4=\mathrm{mn})$.

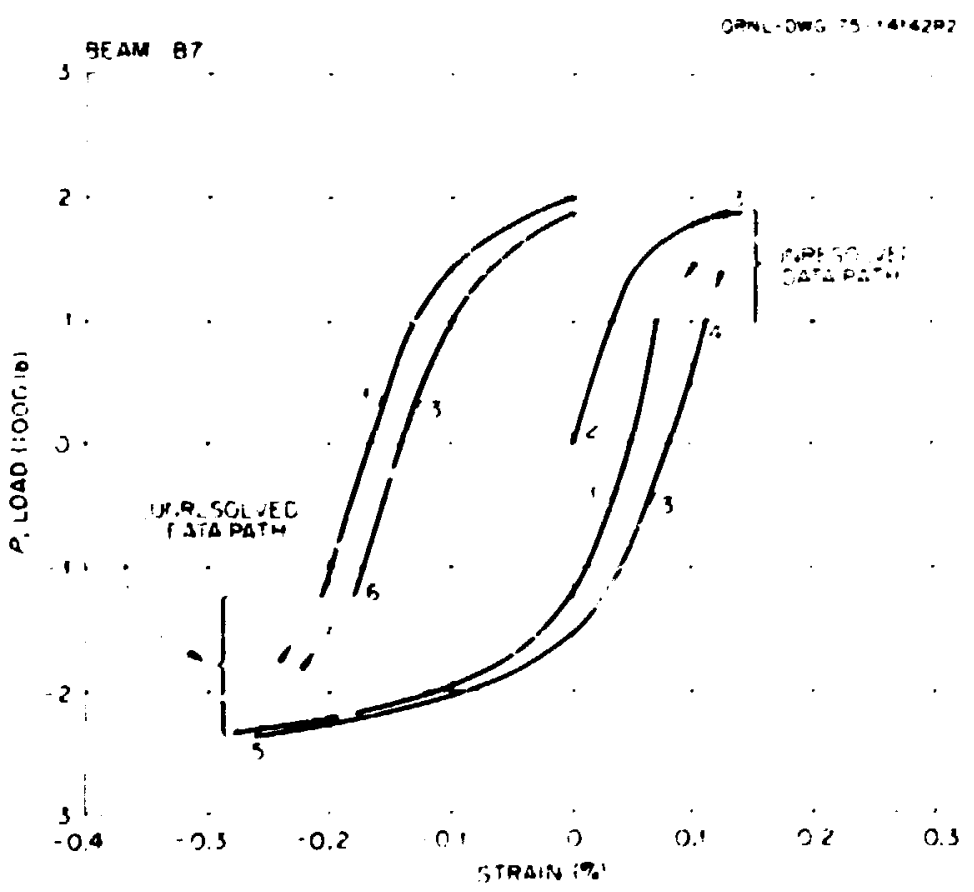

Fig. D.4. Load vs strain ( $S G i 1$ und SG3) changes associated with relaxation portions of bean B7. Note that the signs of the itrains have been changed $(1 b \times 4.448=N)$. 


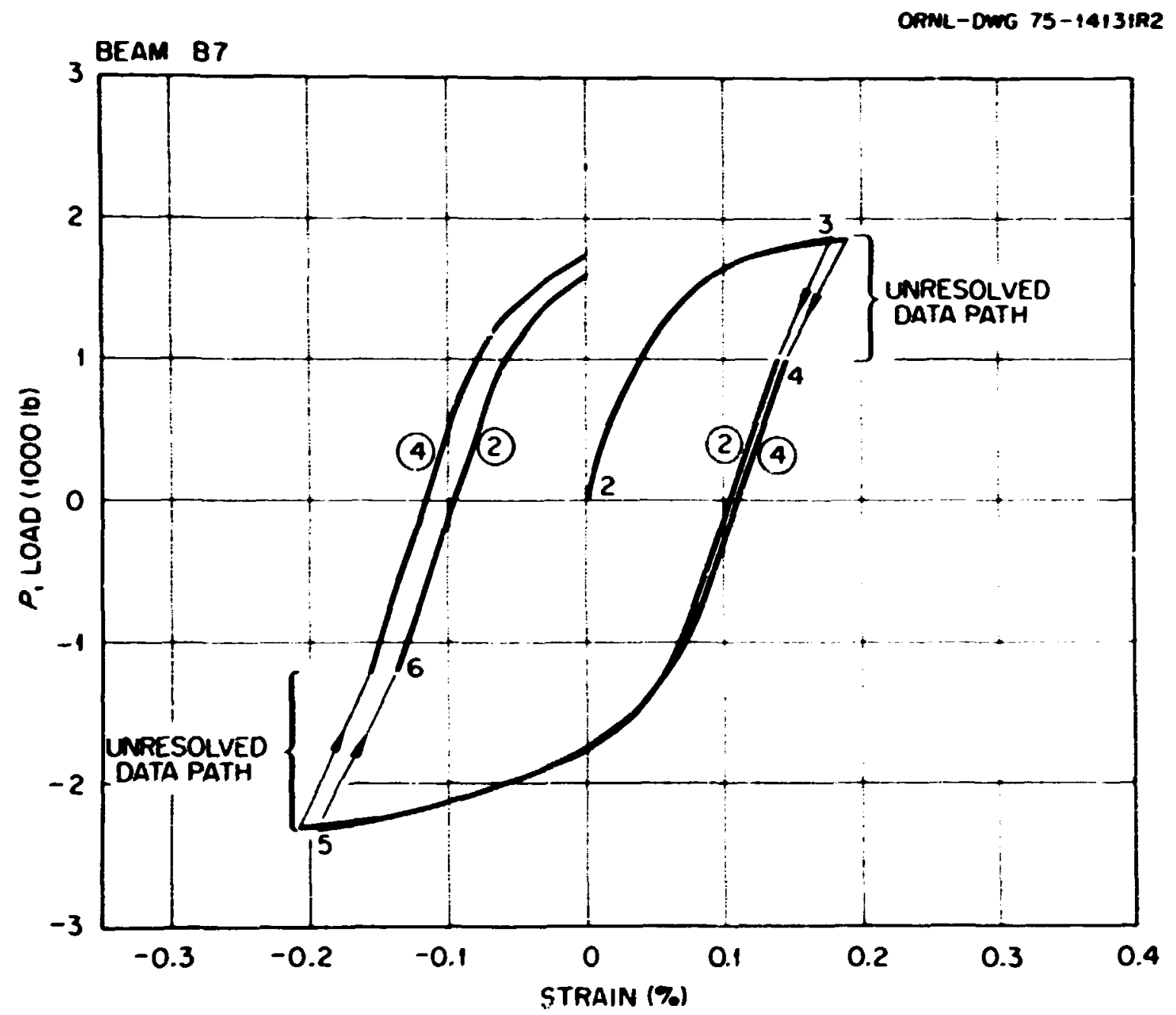

Fig. D.5. Load vs strain (SG2 and $S G 4$ ) changes associated with relaxation portions of beam $B 7$. Note that the signs of the strains have been changed $(1 b \times i 448=N)$. 


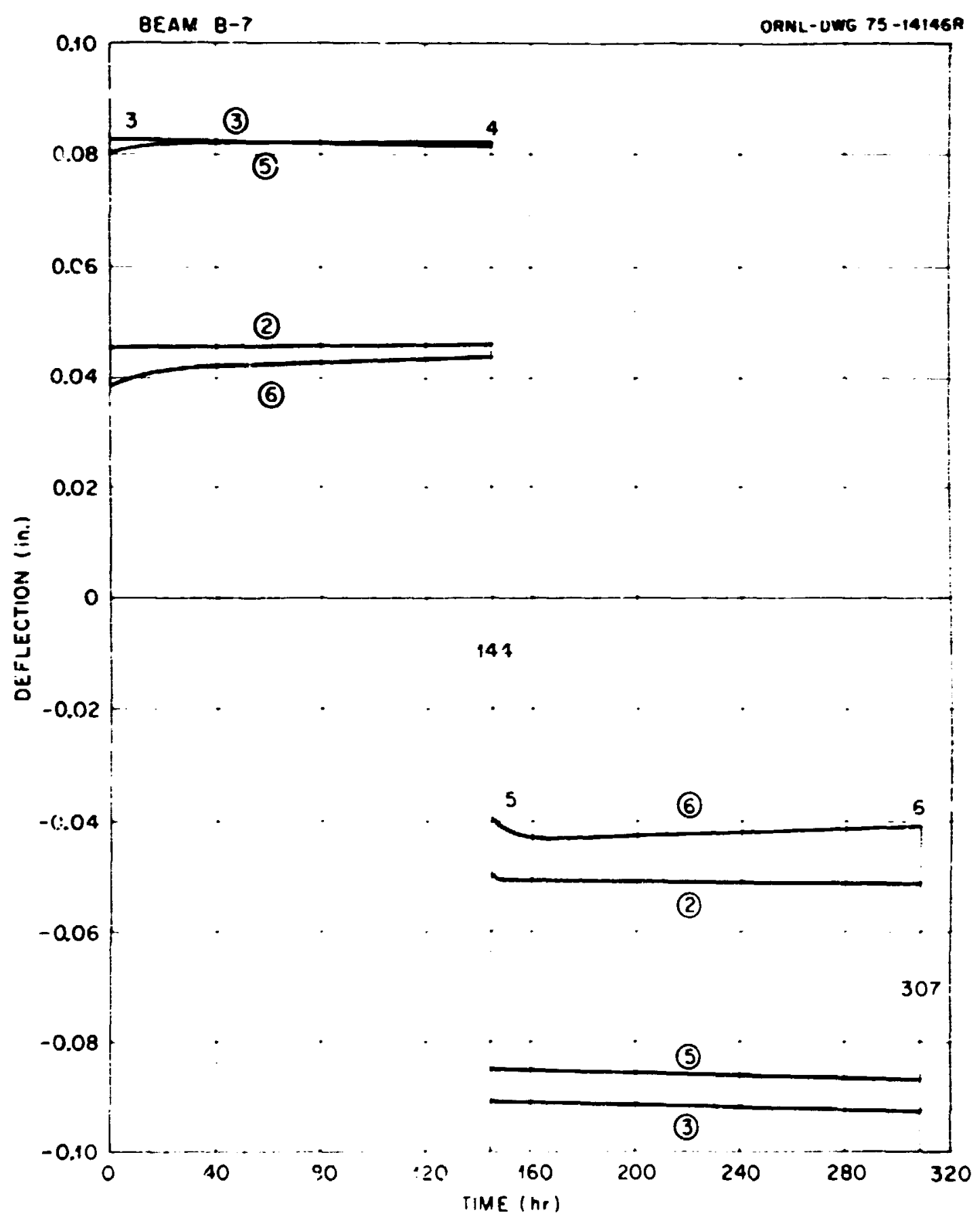

Fig. D.6. Deflection (DT2, DT3, DT5, IT6) "s time for bean B7 (in. $\times 25.4=\mathrm{mm}$ ). 
88
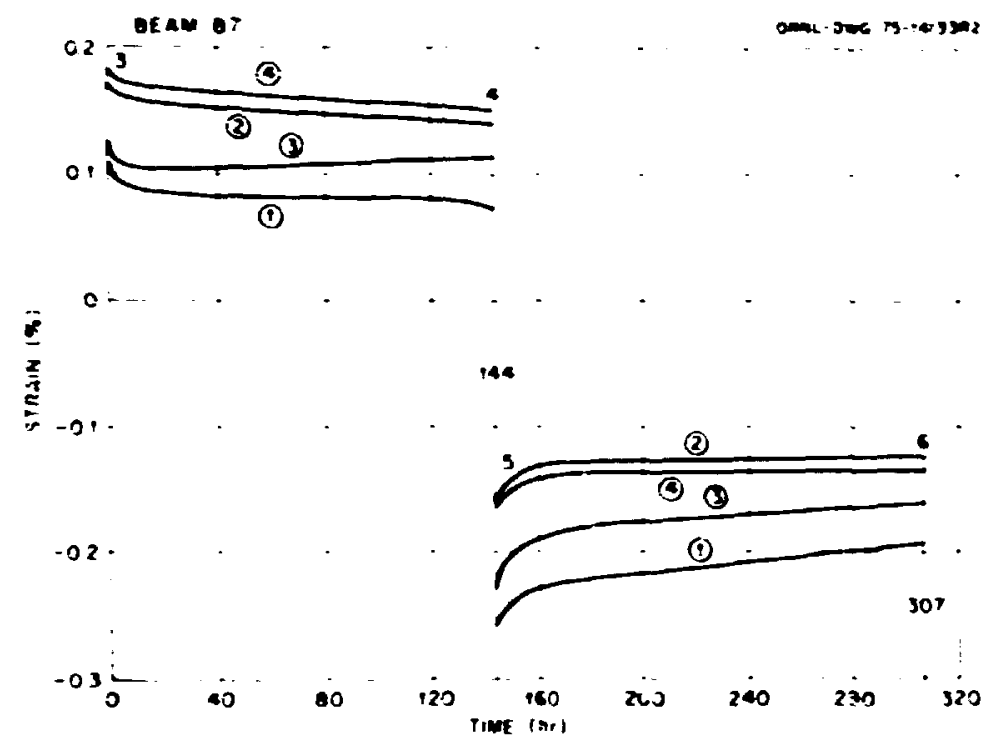

Fig. D.7. Strain (Sül-SG3) vs time for beam B7. Nite that the signs of the strains have been changed.

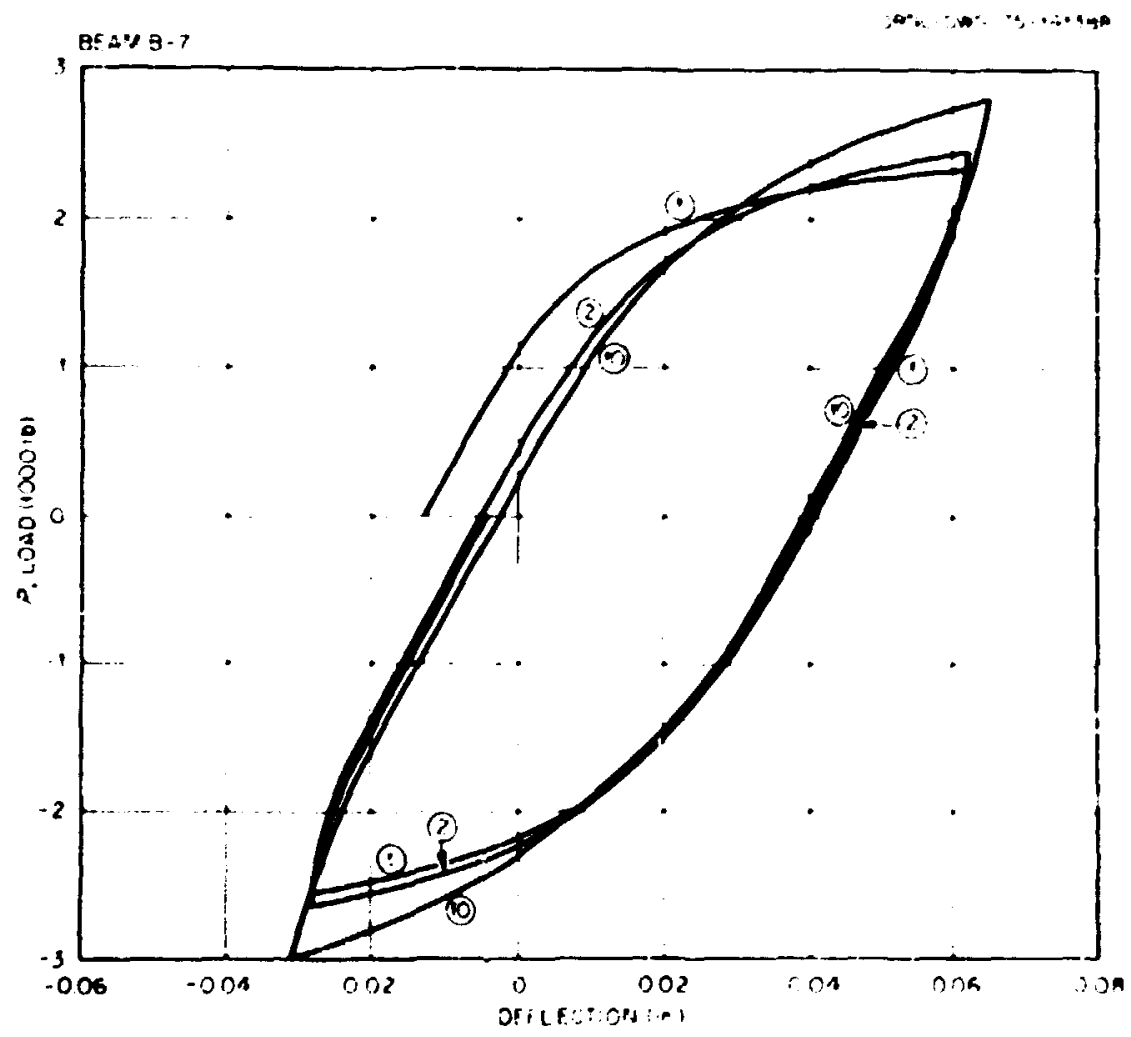

Fig. D.8. Load vs deflection (DT2) during ten short-time, postcreep deflection cycles of beam $B 7(1 b \times 4.448 \div N$, in. $\times 25.4=m n)$. 
89

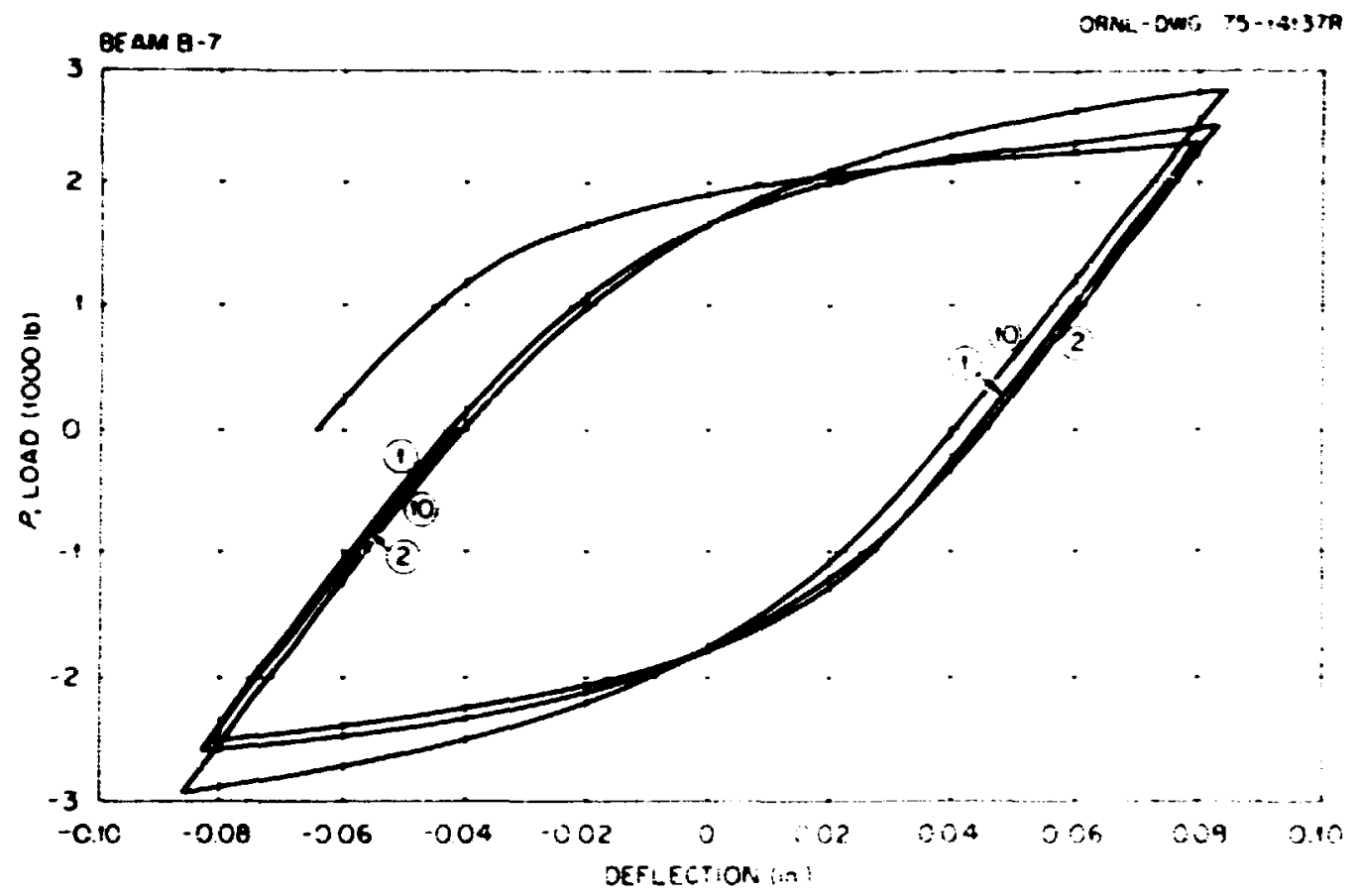

Fig. D.9. Load vs deflection (DTp) during ten short-time, postcreep deflection cycles of beam $B 7($ lb $\times 4.448=\mathrm{x}$, in. $\times 25.4=\mathrm{mm}$ ).

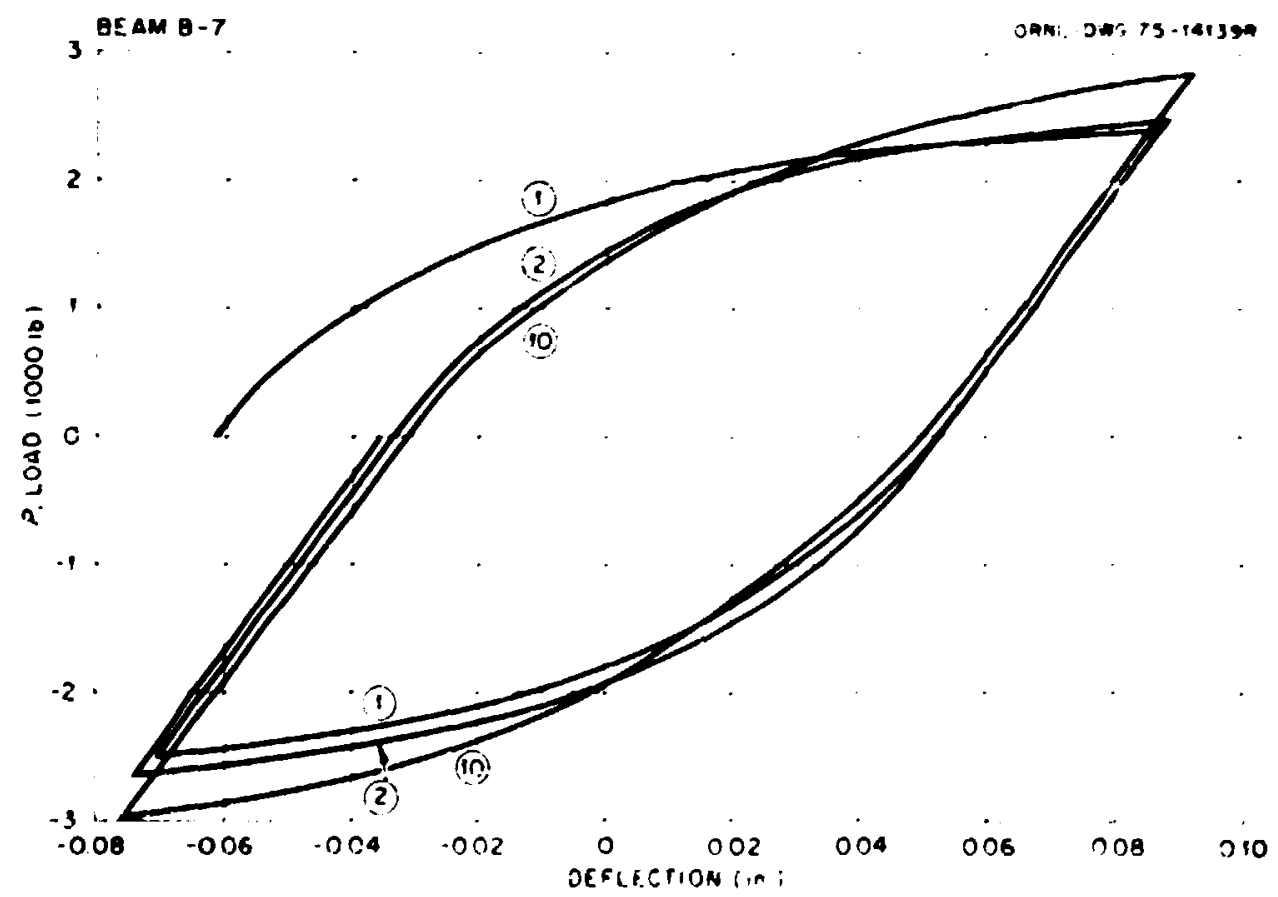

Fig. D.10. Load vs deflection (IIT) during ten short-time, postcreep deflection cycles of bean. $87(1 \mathrm{~b} \times 4.448=\mathrm{N}$, in. $\times 25.4=\mathrm{mm})$. 
90

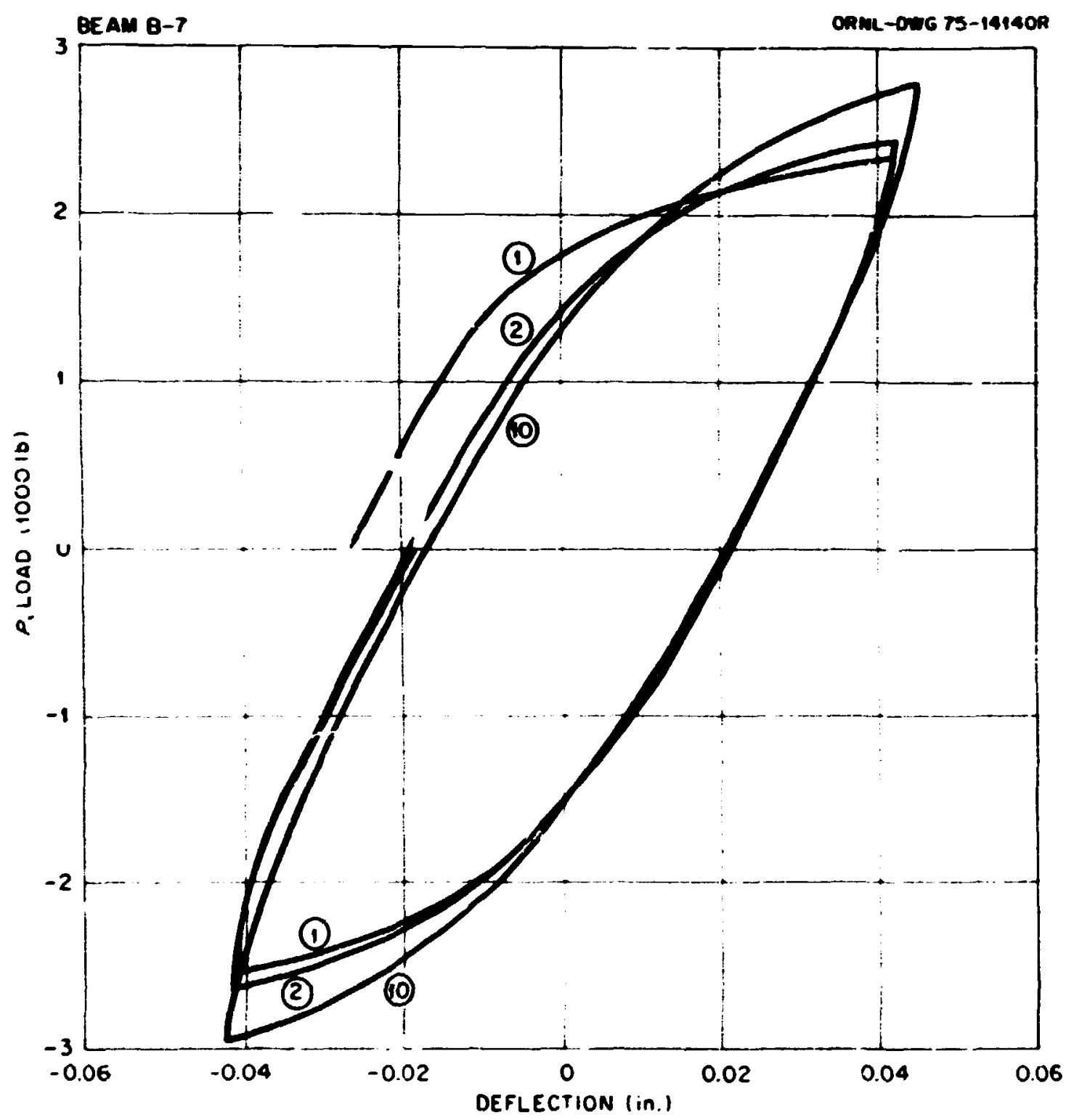

Fig. V.11. Load vs deflect: on (DT6) during ten short-time, postcreep deflection cycles of bear $B 7(1 b \times 4.448=N$, in. $\times 25.4=\pi m)$. 


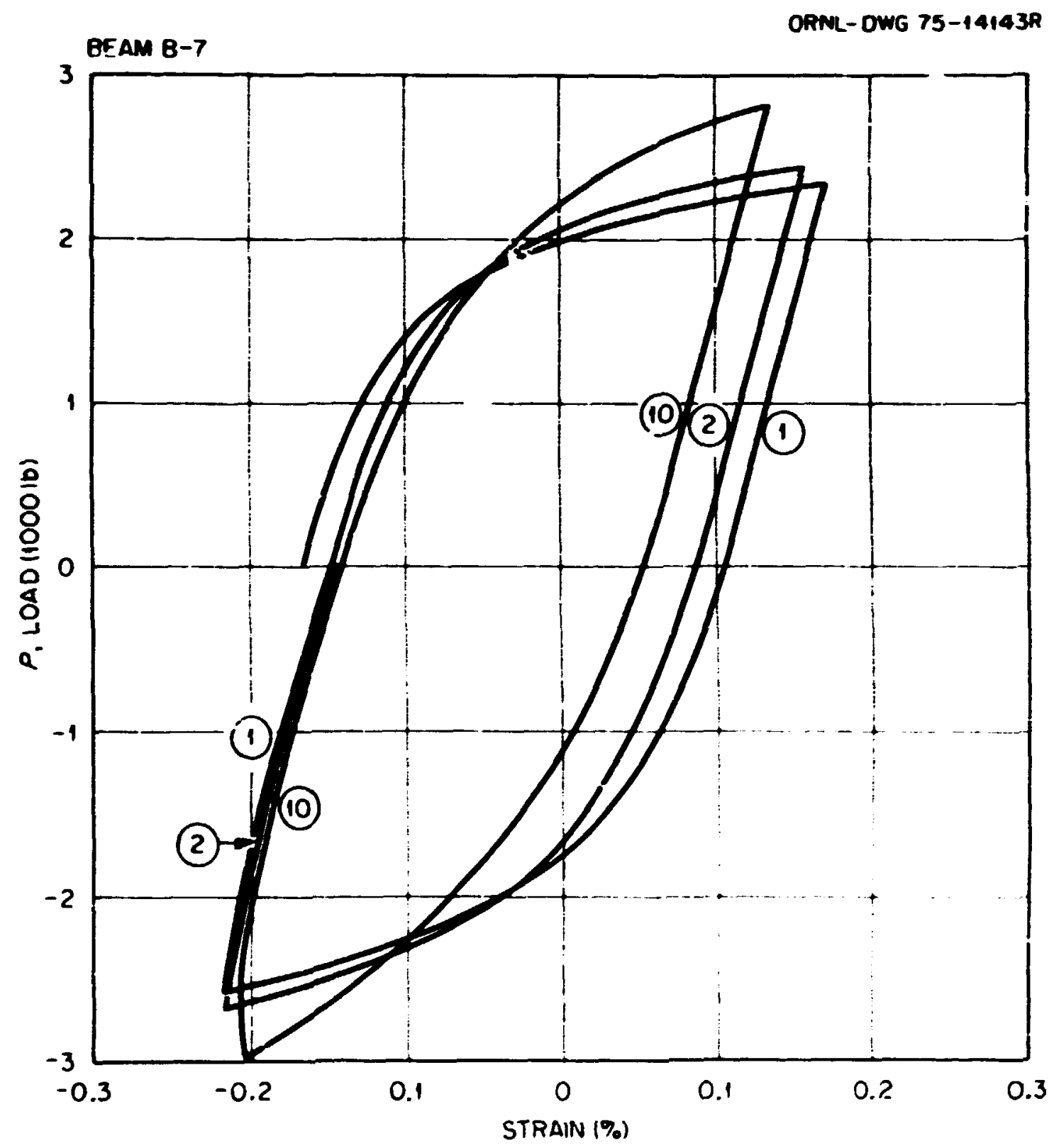

Fig. D.12. Load vs strain (SG1) during ten short-time, ; ostcreep deflection cycles of beam $B 7$. Note that the sign of the strain has been changed $(1 b \times 4.448=N)$. 


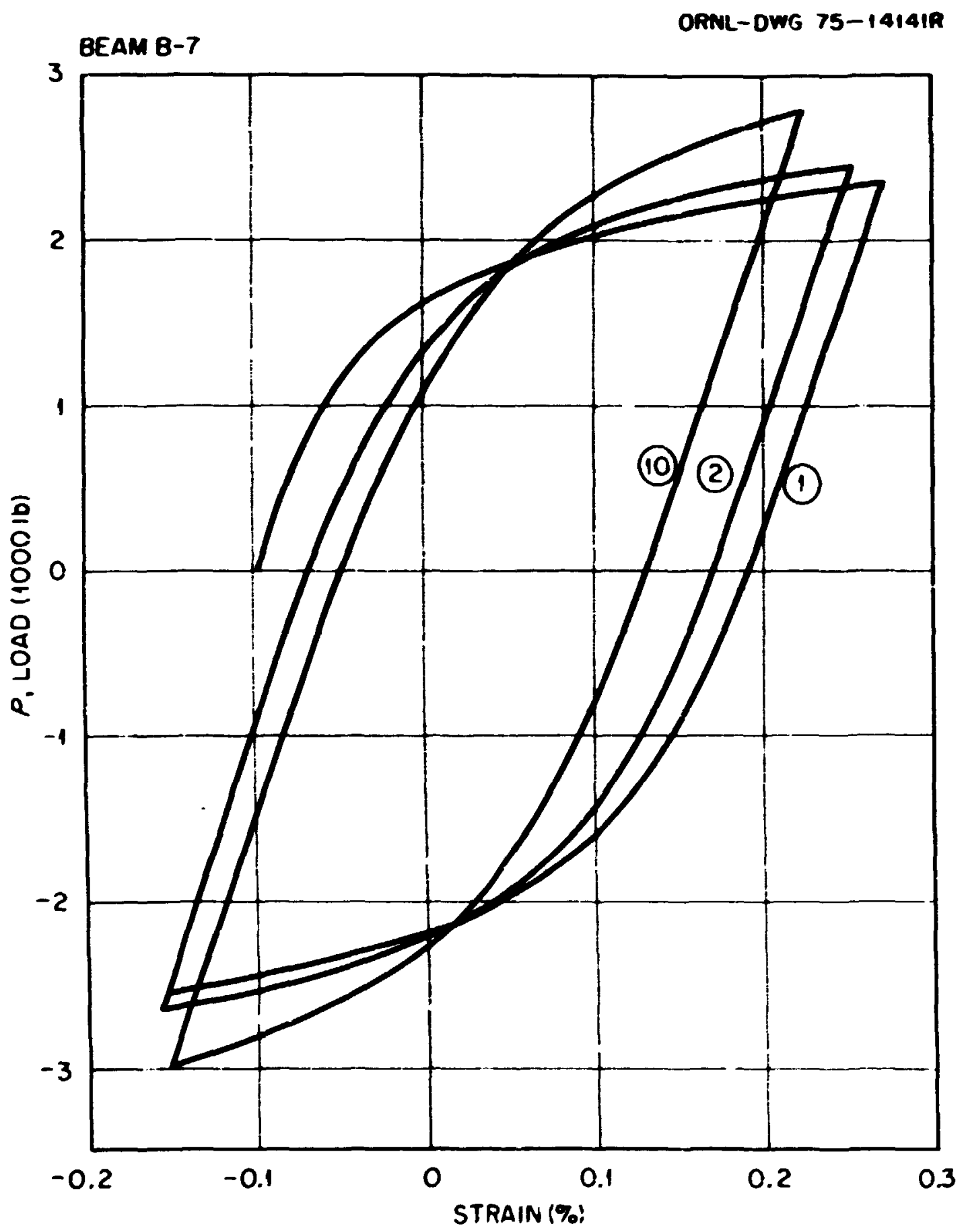

Fig. D.13. Load vs strain (SG2) during ten short-time, postcreep deflection cycles of beam $B 7(1 b \times 4.448=N)$. 


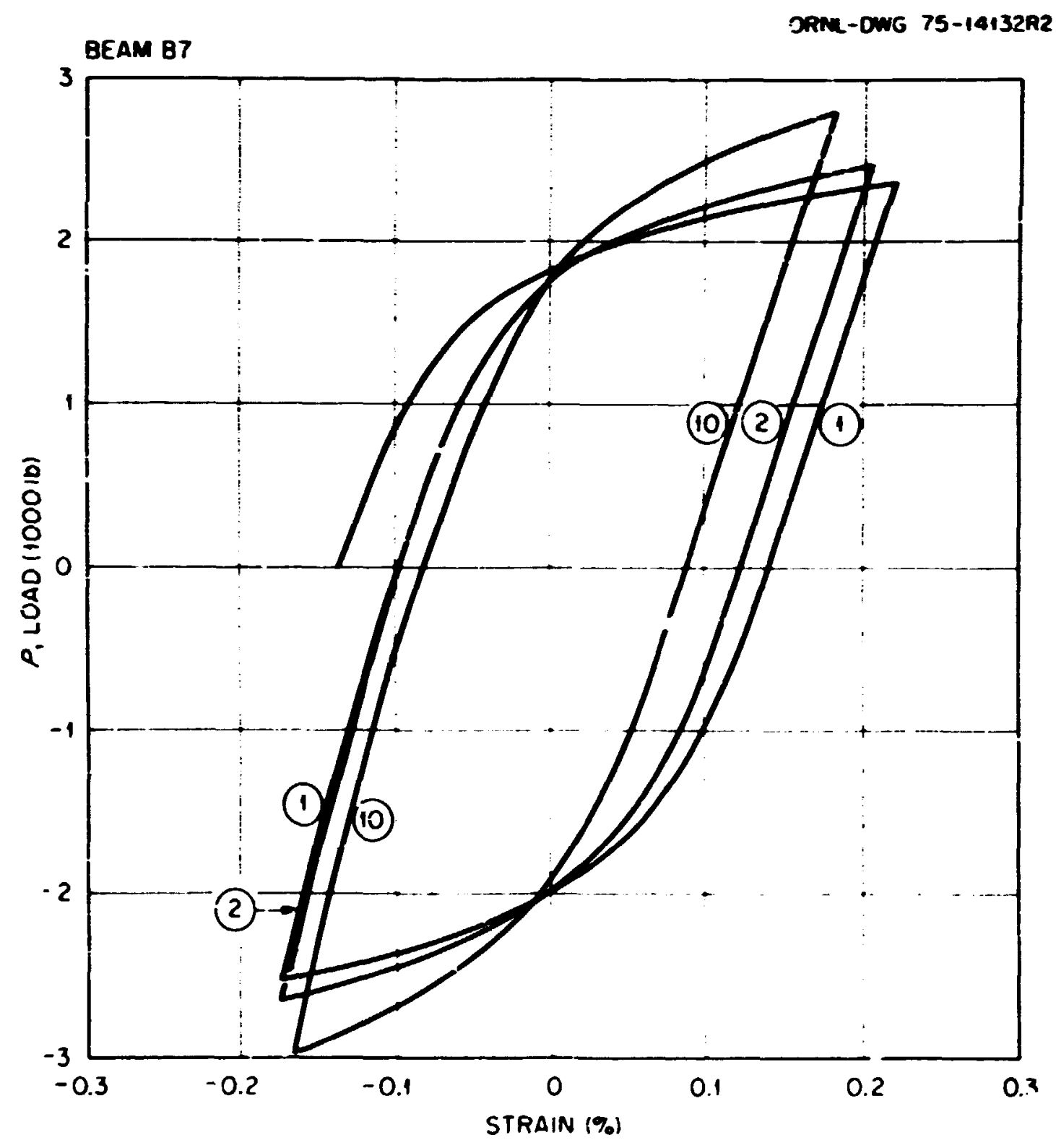

Fig. D.14. Load vs strain (SG3) during ten short-time, postcreep deflection cycles of beam $B 7$. Note that the sign of the strain has been changed $(1 b \times 4.448=N)$. 


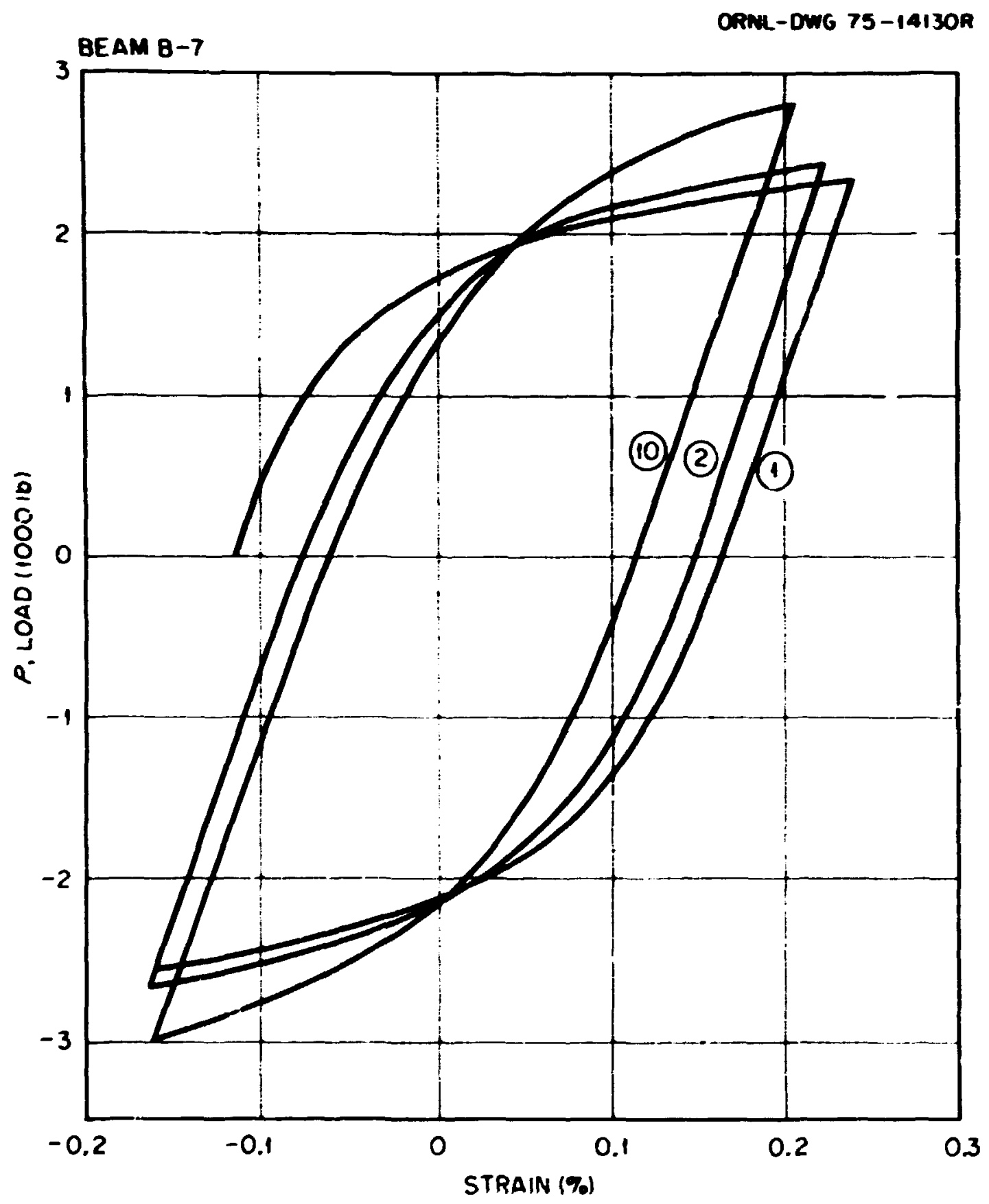

Fig. D.15. Load vs strain (SG4) diring tell short-time, postcreep deflection cycles or beam $B 7(1 \mathrm{~b} \times 4.448=N)$. 
APPENDIX E. ADDITIONAL TEST RESUTS FOR BEAM B8

Bean 88 was a deflection-controlled test with precreep cycles. The tepperature plot for the test is shown in Fig. E.1, where it can be seen that the specinen operated about $2.8^{\circ} \mathrm{C}\left(5^{\circ} \mathrm{F}\right)$ abote the intended level during the latter three-fourths of the test.

Load vs cieflection data are shown in Figs. E.2 through E.5 for the tein precreep cycles. " Load vs strain data for the precreep cycles are shown in Figs. E.6 through E.13.* Results for all eight giges used on this specimen are shown (see Fig. 3).

Load vs strain datz for the ten postcreep cycles are presentec in Figs. E.14 through E.19. * Note that gages SG4 and SG8 were inoperative during this end-of-test cyciing.

"Circled numbers in Figs. E.2 through E.19 refer to cycle number. 


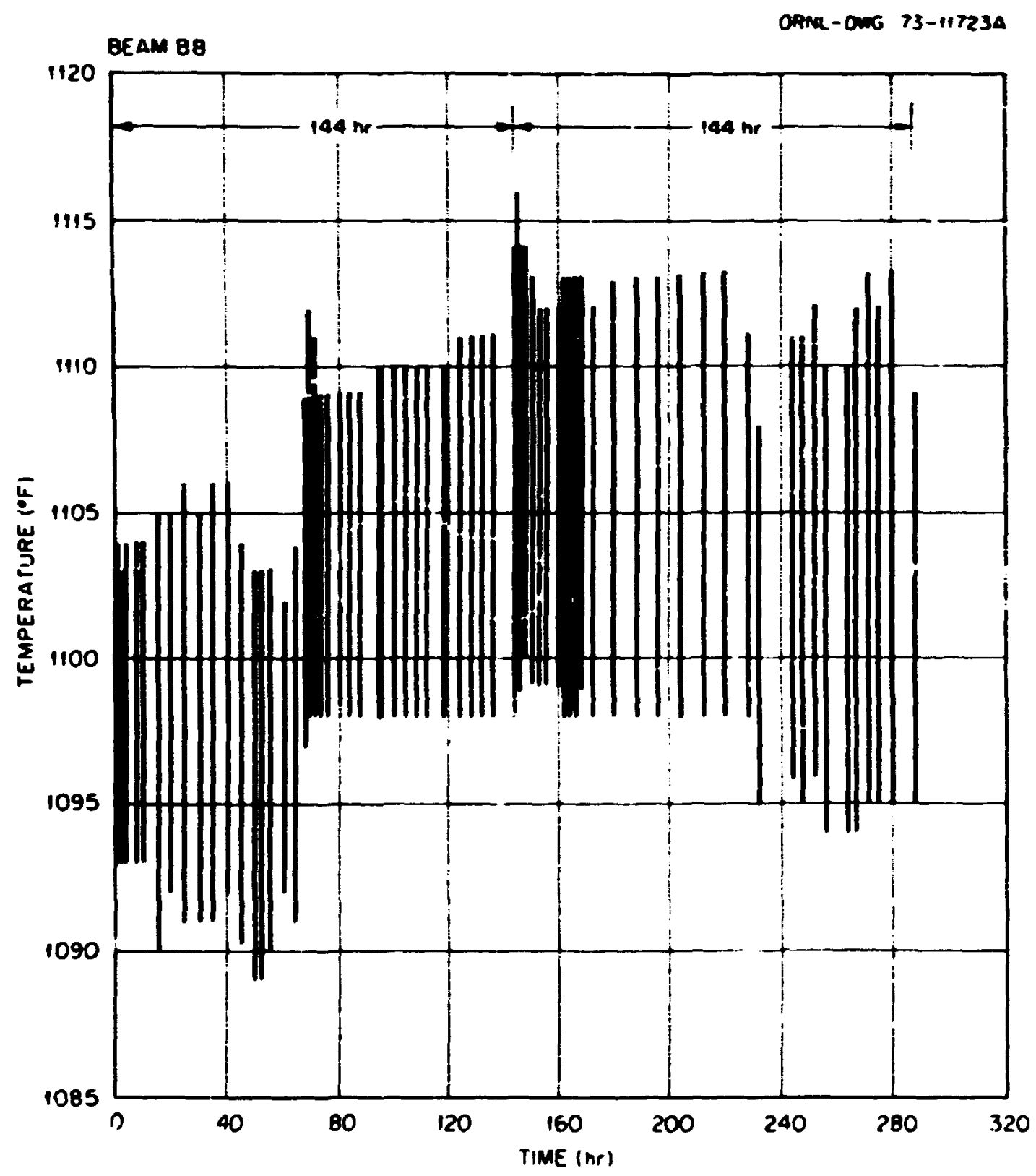

Fig. E.1. Measured temperature range over middle $406 \mathrm{~m}$ (16 in.) of bean $\mathrm{B8}$ during $593^{\circ} \mathrm{C}\left(1100^{\circ} \mathrm{F}\right)$ test $\left.\left[{ }^{\circ} \mathrm{F}-32\right) \times 0.5556={ }^{\circ} \mathrm{C}\right]$. 


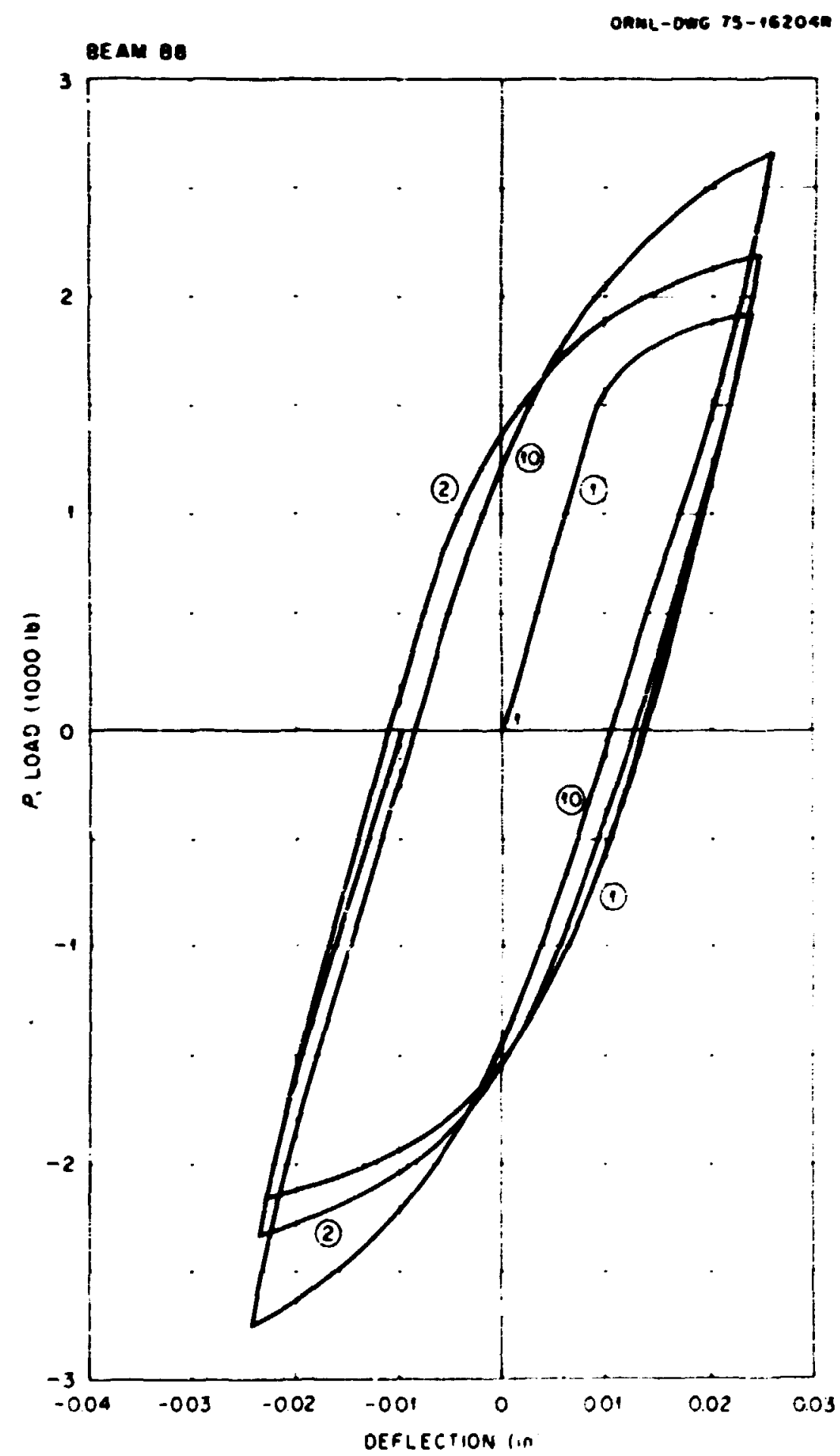

Fig. E.2. Load vs deflection (DT2) during ten short-time, precreep deflection cycles of beam $B 8(1 b \times 4.44 \%=N$, in. $\times 25.4=\mathrm{mm})$. 


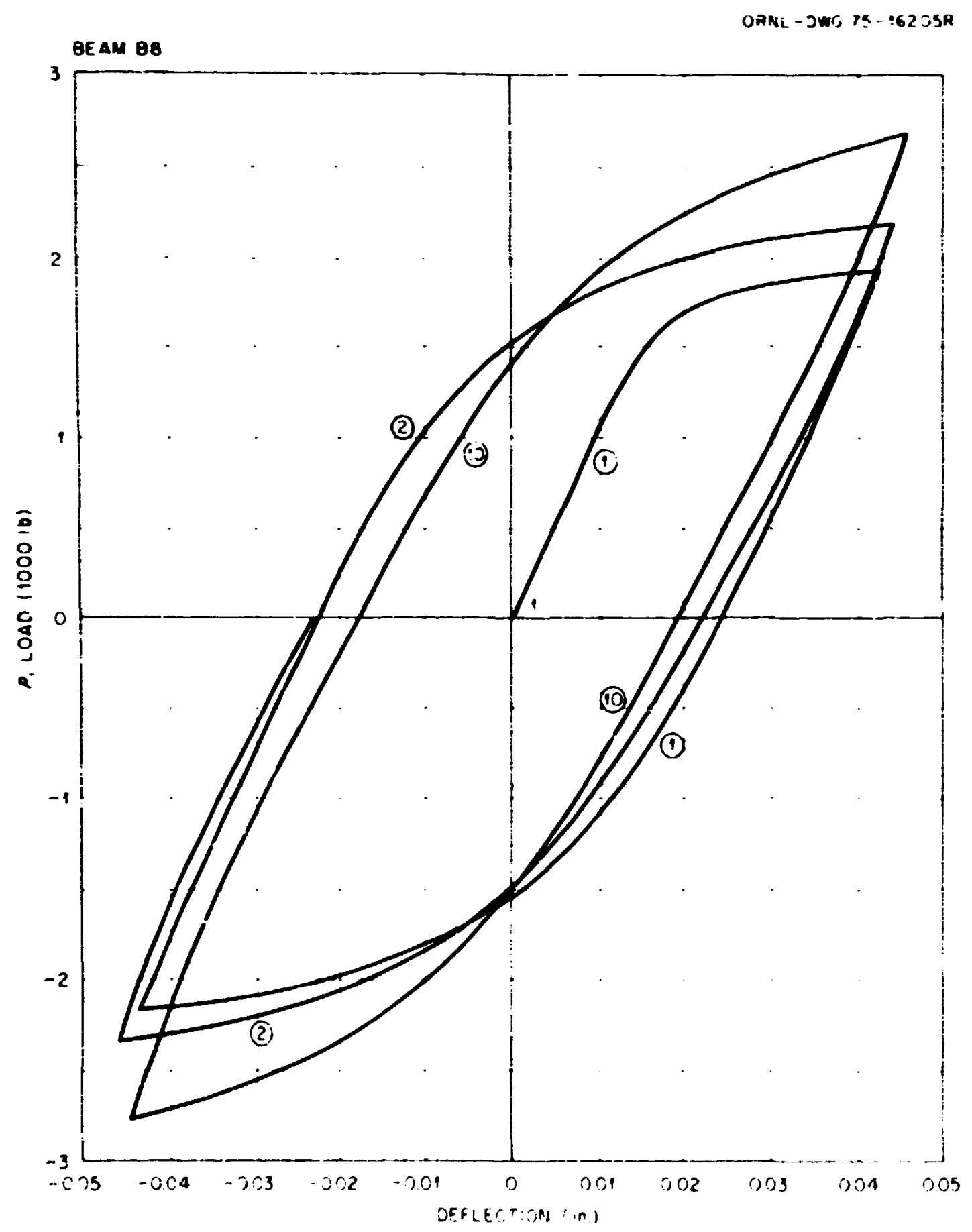

Fig. E.3. Load vs deflection (DT3) during ten short-time, precreep deflection cycles of beam $B 8(1 \mathrm{~b} \times 4.448=N$, in $\times 25.4=\mathrm{mm})$. 


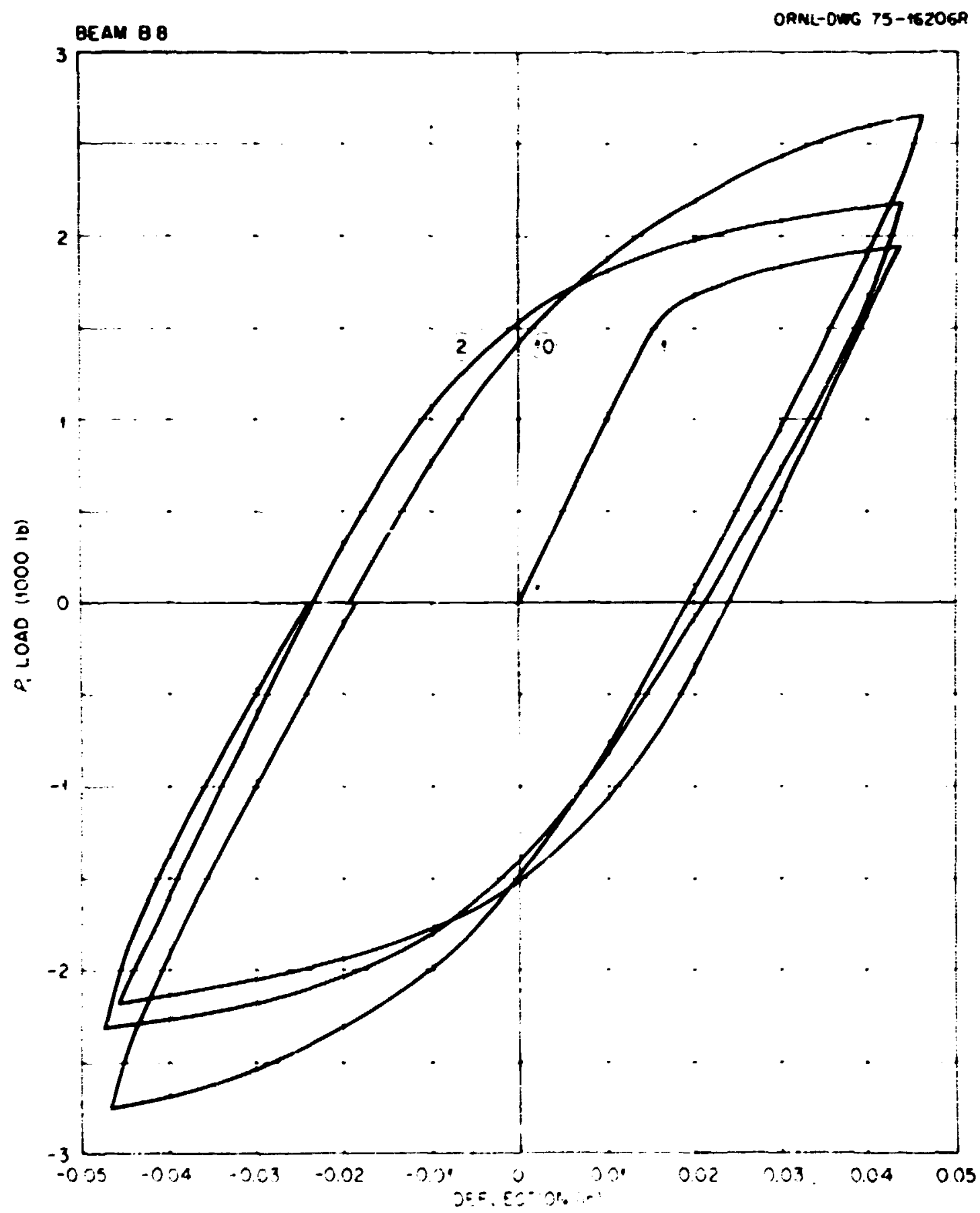

Fig. E.4. Load vs deflection (DT5) during ten short-time, precreep deflection cycles of beam $B 8(1 b \times 4.448=N$, in. $\times 25.4=\mathrm{mm}$ ). 
100

$00 m-0,55-1620 m$

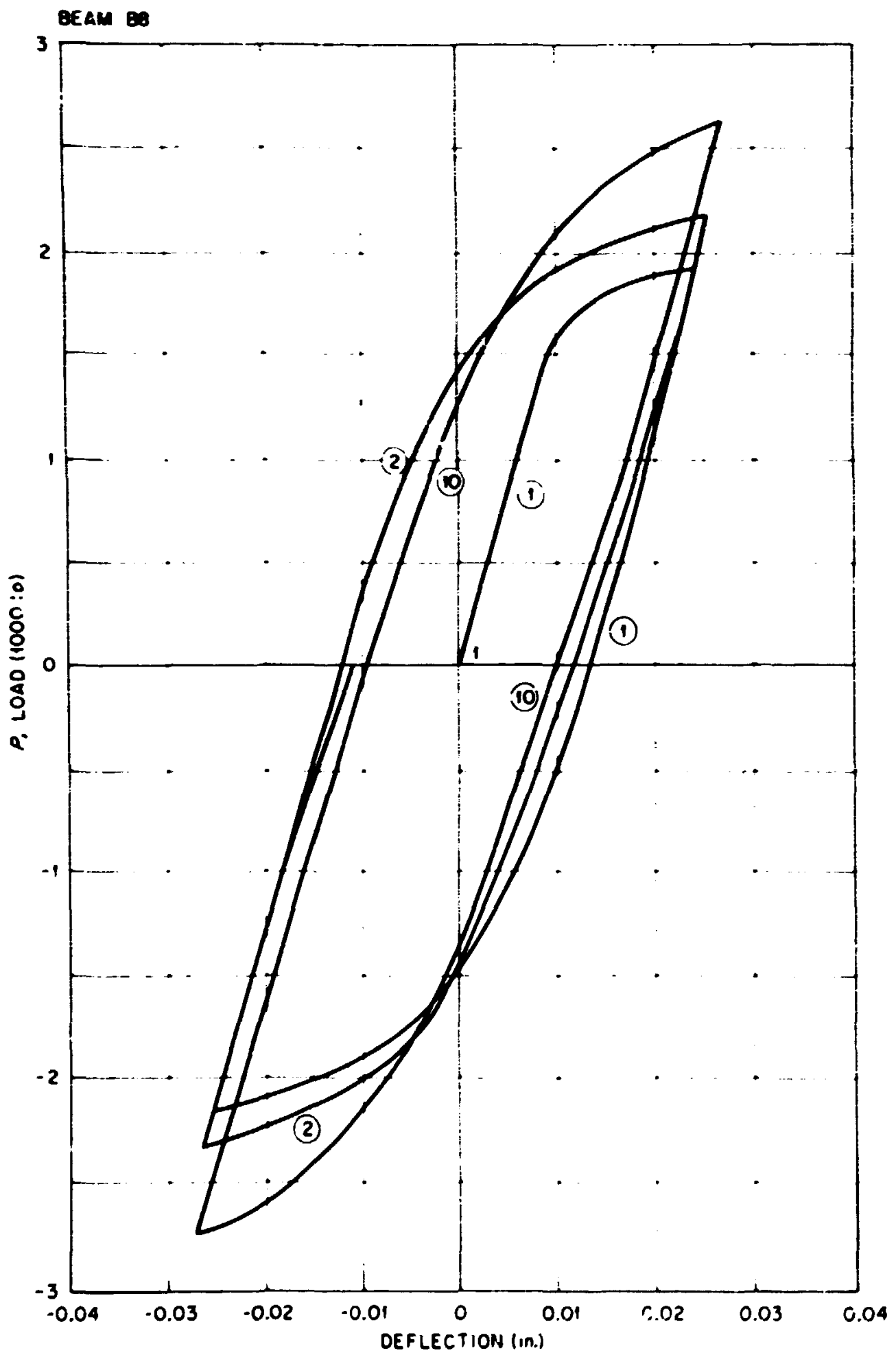

Fig. E.5. Load vs deflection (DT6) during te, short-time, precreep deflection cycles of beam $B 8(1 b \times 4.448=N$, in. $\times 25.4=m m)$. 


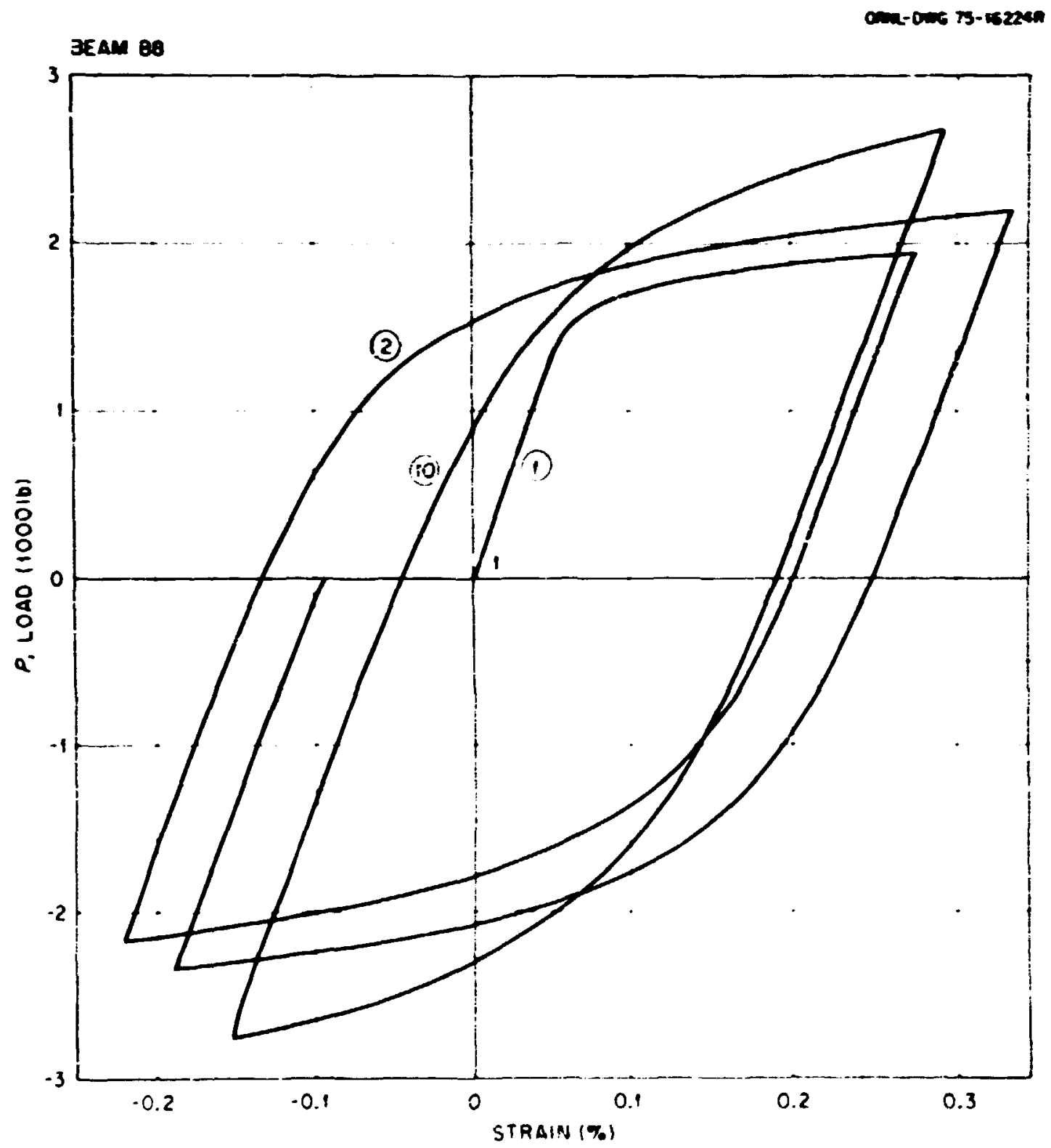

Fig. E.6. Load vs strain (SGl) during ten short-time, precreep deflection cycies of beam B8. Note that the sign of the strain has been changed $(1 \mathrm{~h} \times 4.448=\mathrm{N})$. 


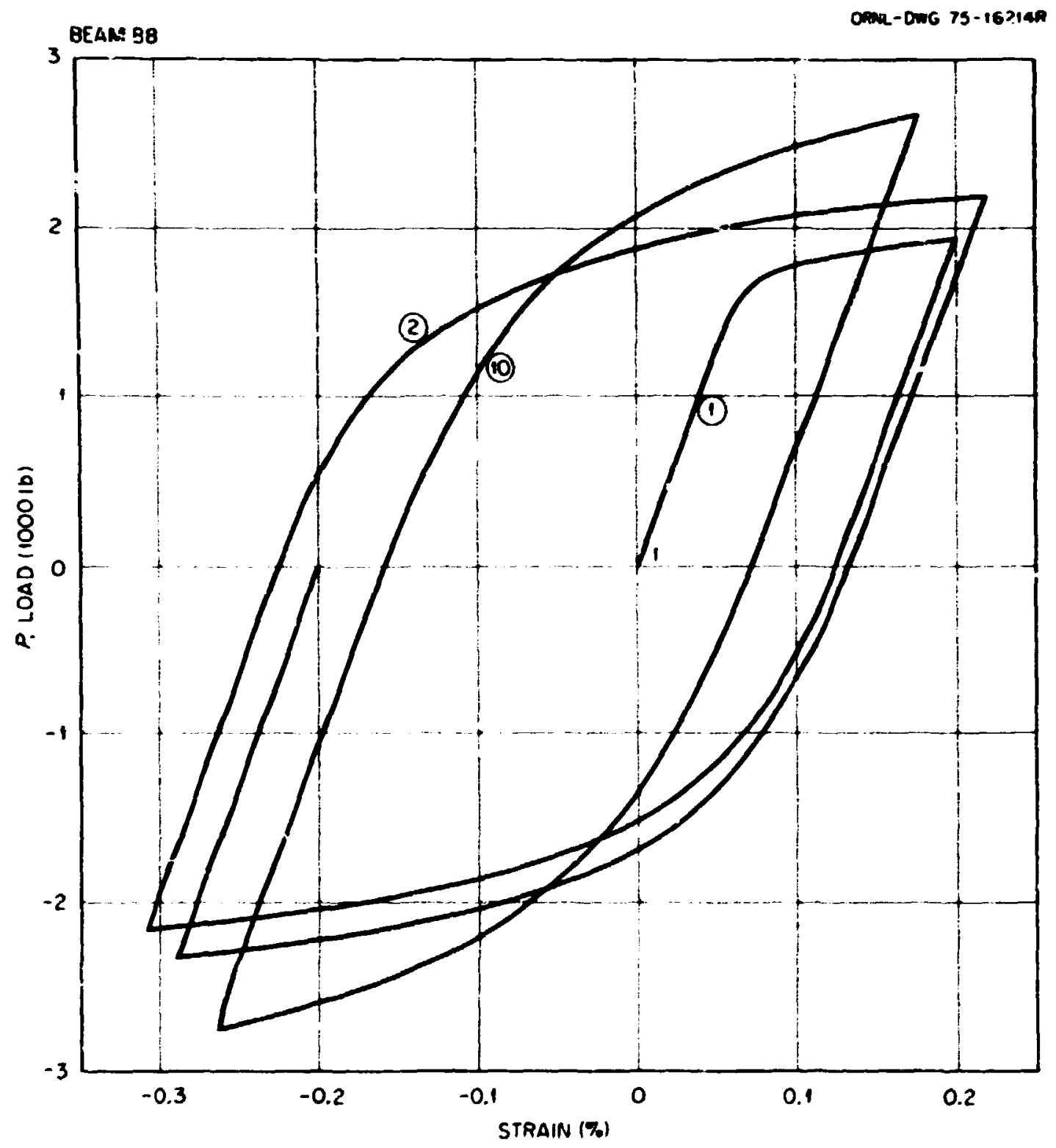

Fig. E.7. Load vs strain (SG2) during ten short-time, precreep deflection cycles of beam $B 8(1 b \times 4.448=N)$. 


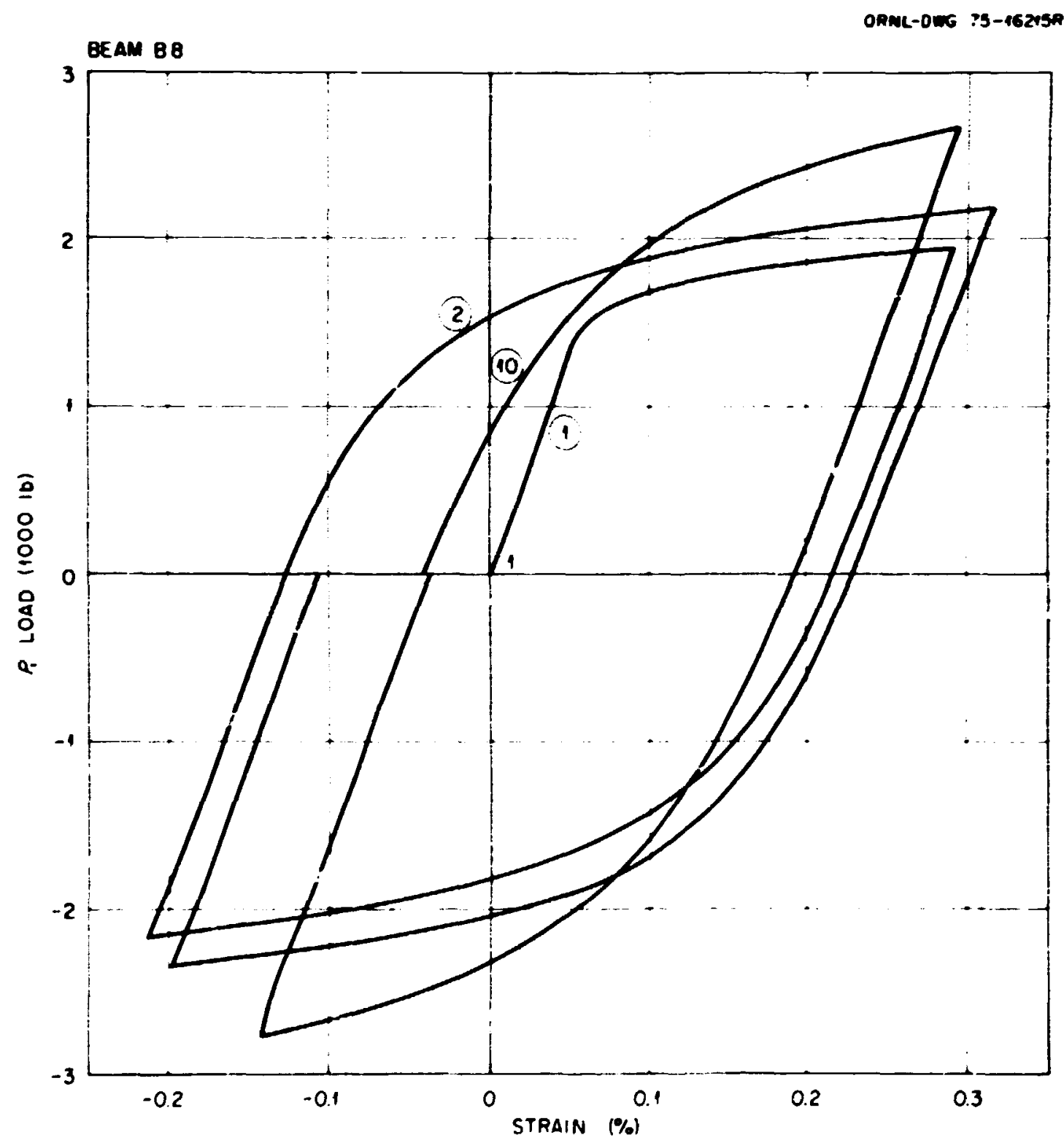

Fig. E.8. Load vs strain (SG3) during ten short-time, precreep deflection cycles of beam B8. Note that the sign of the strain has been changed $(1 b \times 4.448=N)$. 


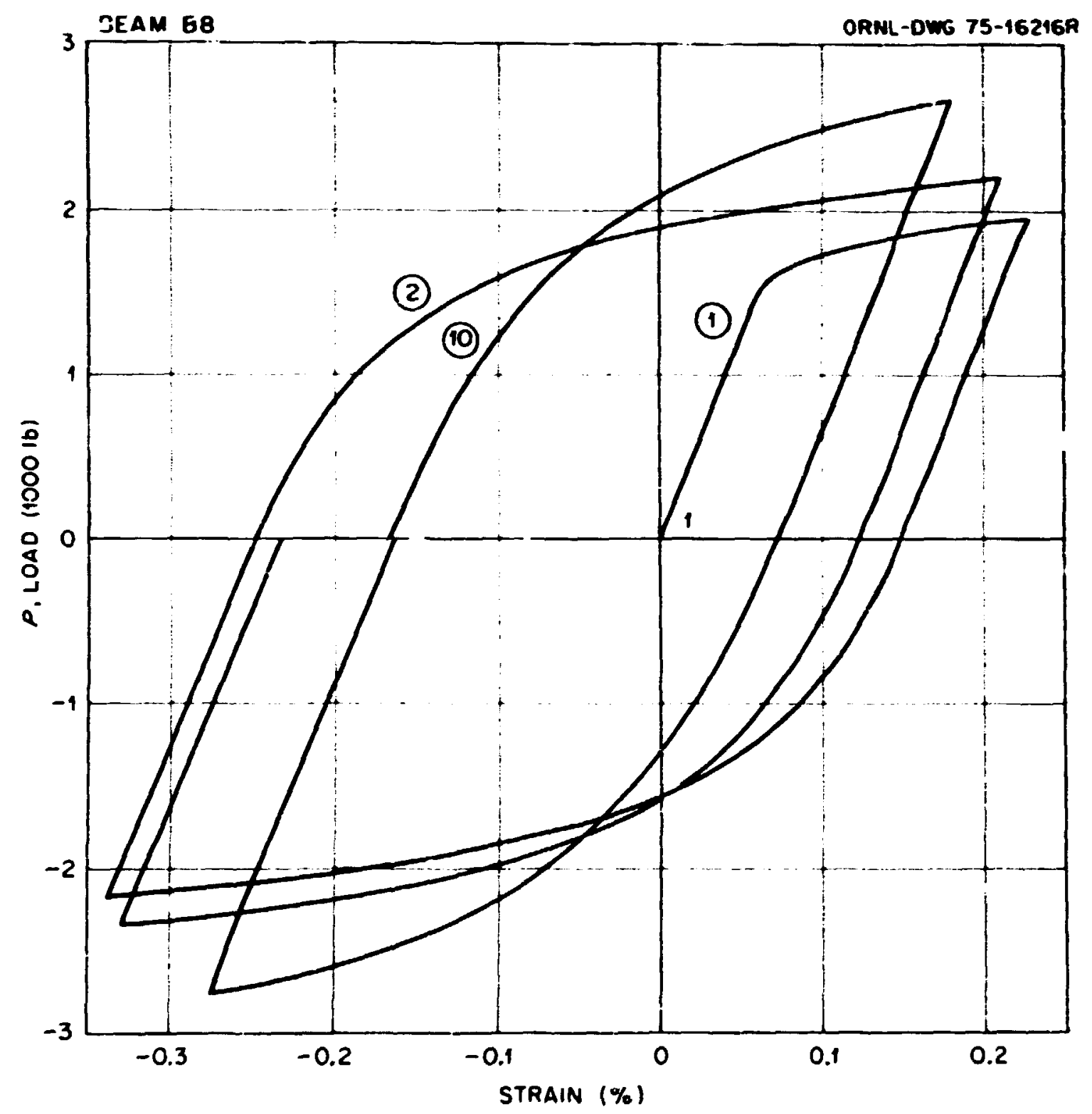

Fig. E.9. Load vs strain (SG4) during ten short-time, precreep deflection cycles of bean B8 ( $1 \mathrm{~b} \times 4.448=N)$. 
ORNL-DWG 75-16222R

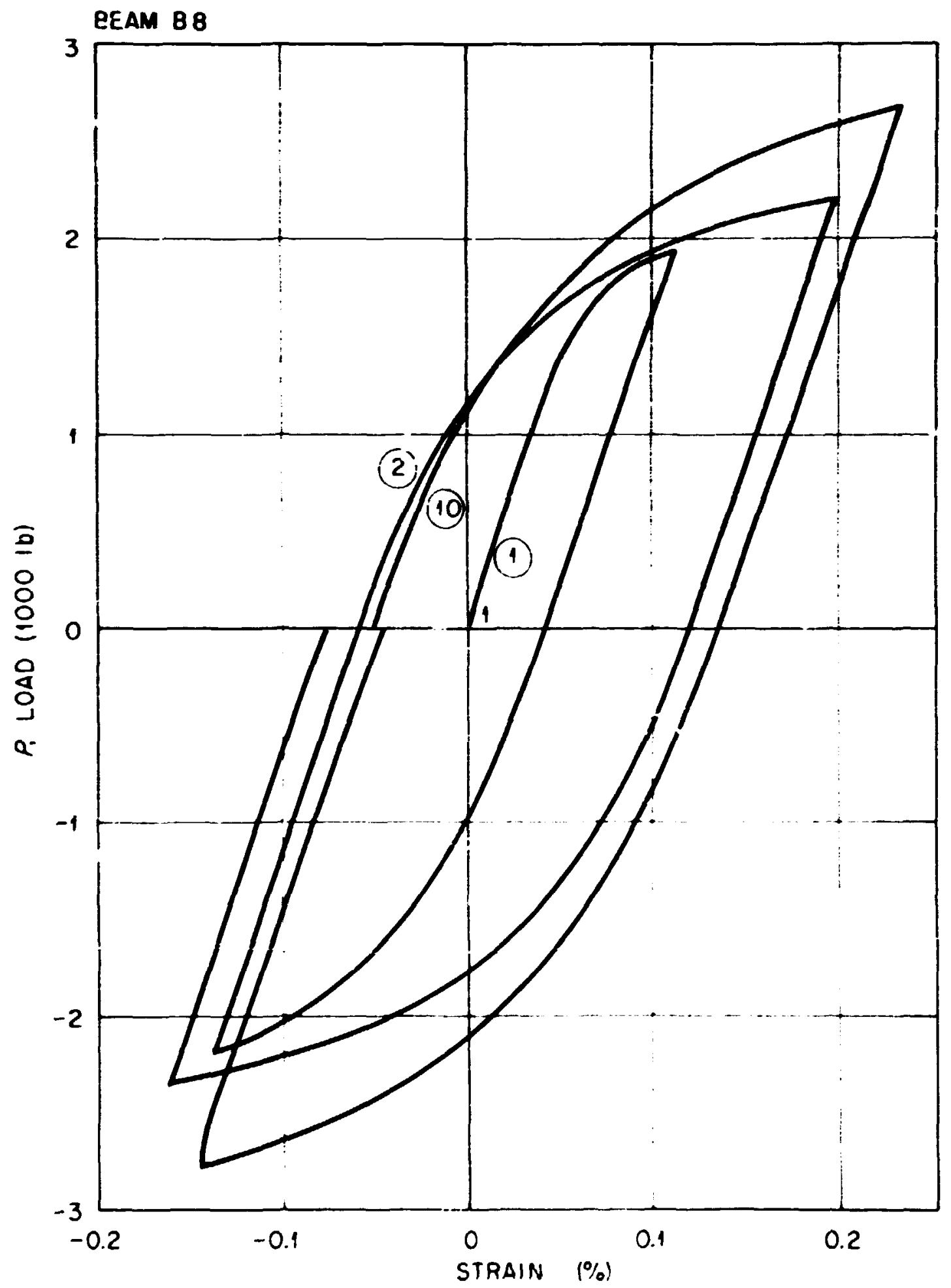

Fig. E.10. Load vs strain (SGS) during ten short-time, precreep deflection cycles of beam B8. Note that the sign of the strain has been changed $(1 b \times 4.448=N)$. 


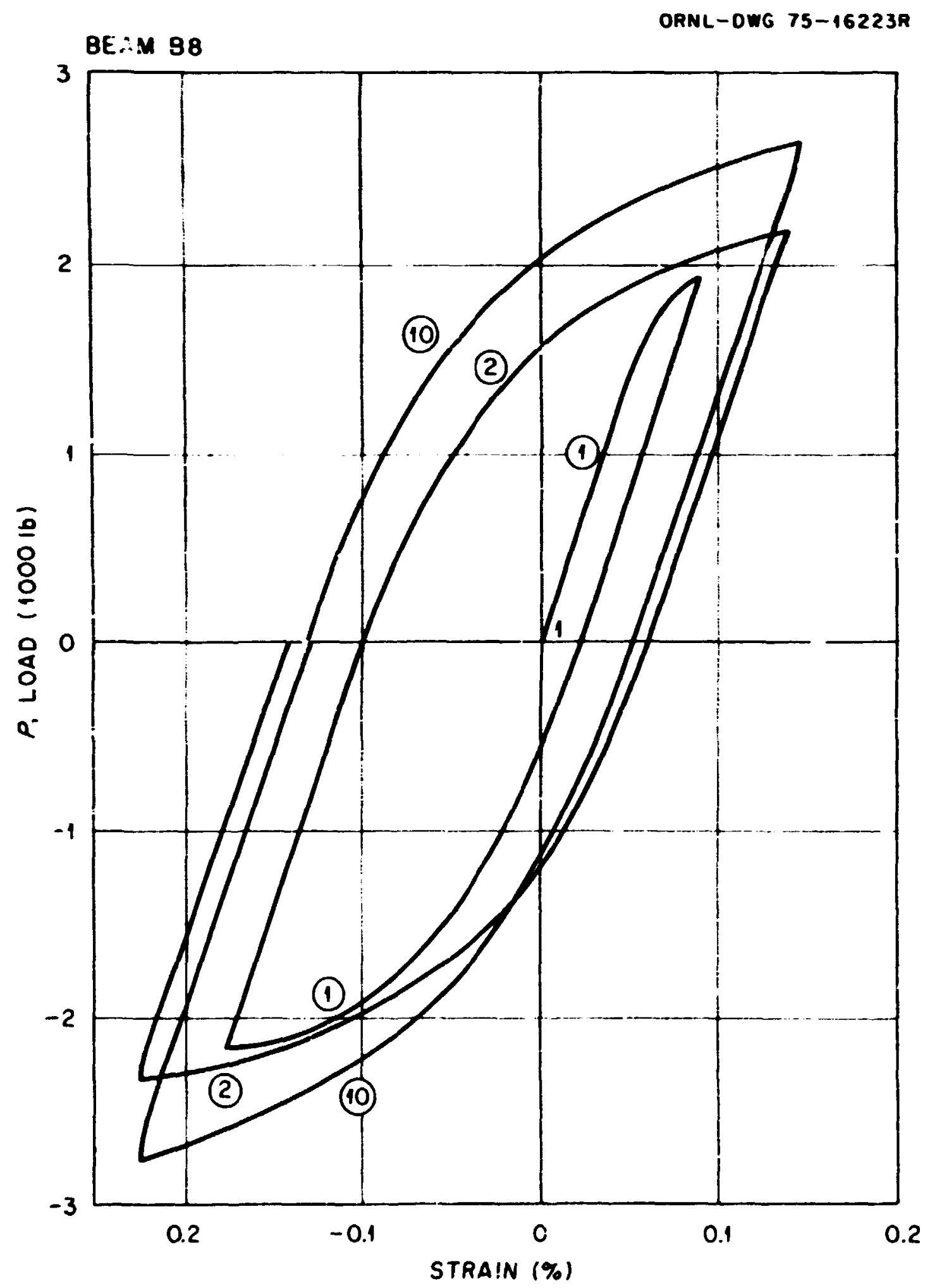

Fig. E.11. Load vs strain (SG6) during ten short-time, precreep deflection cycles of beam $B 8(1 b \times 4.448=N)$. 


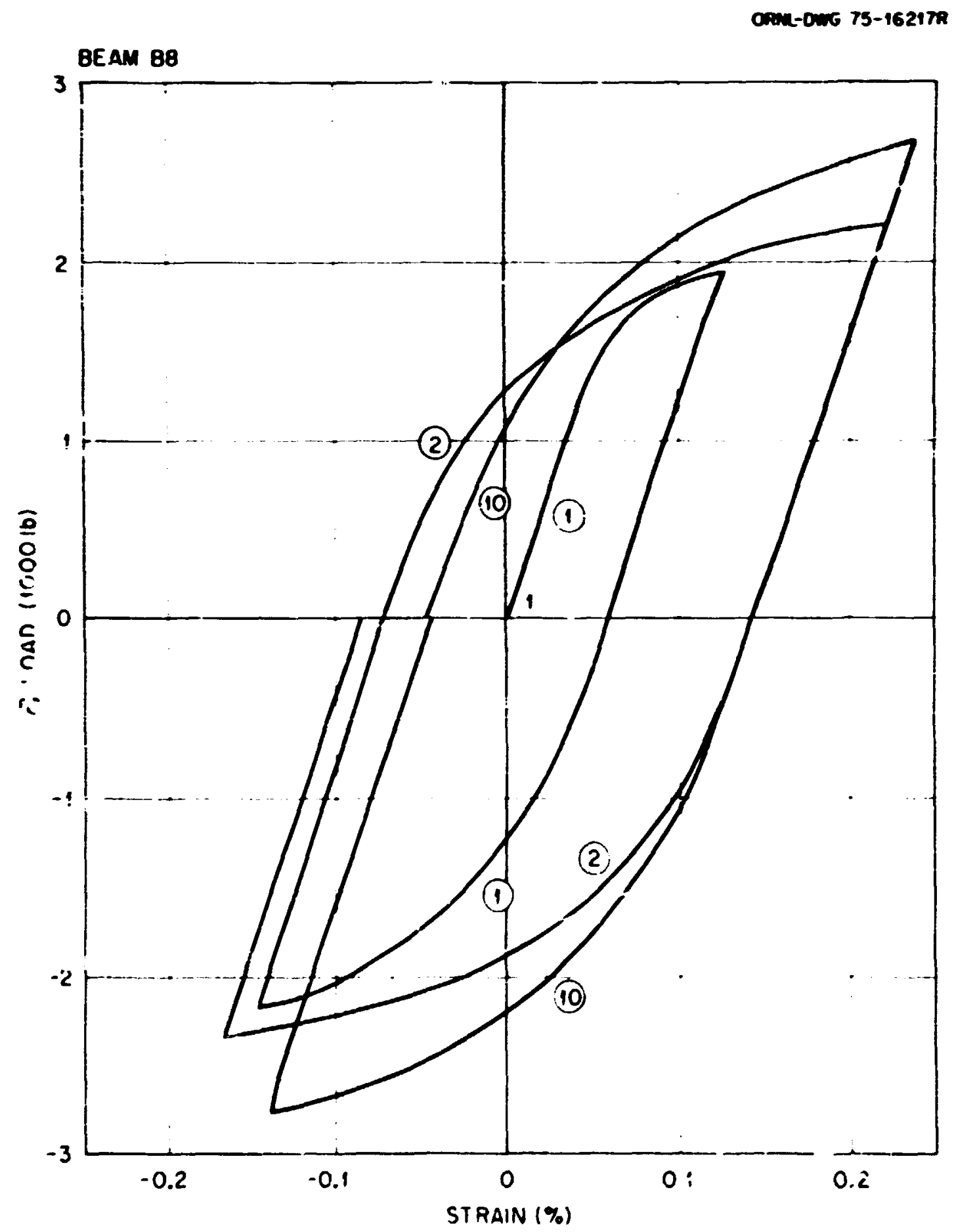

Fig. E.12. Load vs strain (SG7) during ten short-time, precreep deflection cycles of beam $B 8$. Note that the sign of the strain has been changed $(1 \mathrm{~b} \times 4.448=N)$. 
108

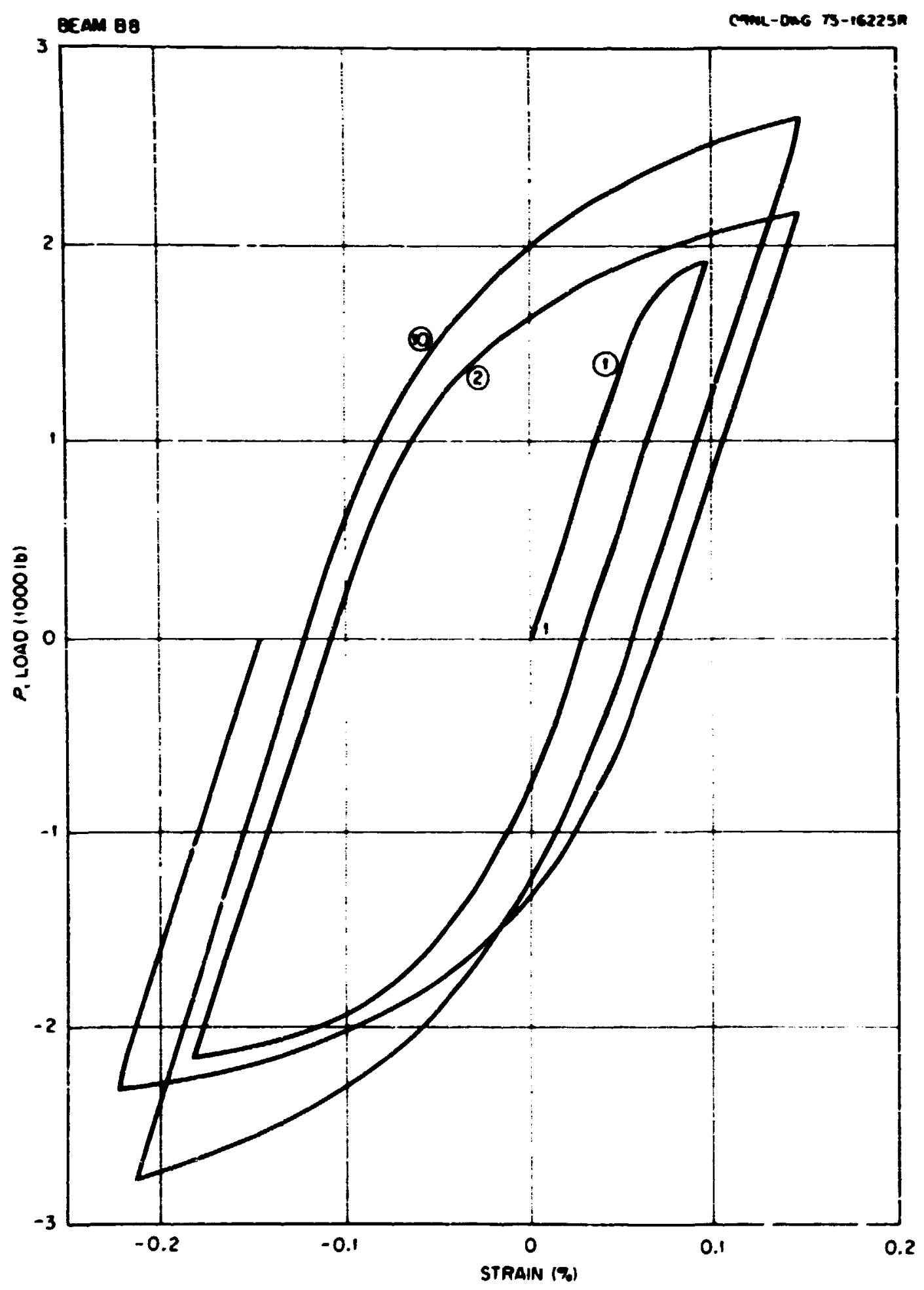

Fig. E.13. Load vs strain (SC8) during ten shurt-time precreep deflection cycles of beam B8 $(1 \mathrm{~b} \times 4.448=N)$. 


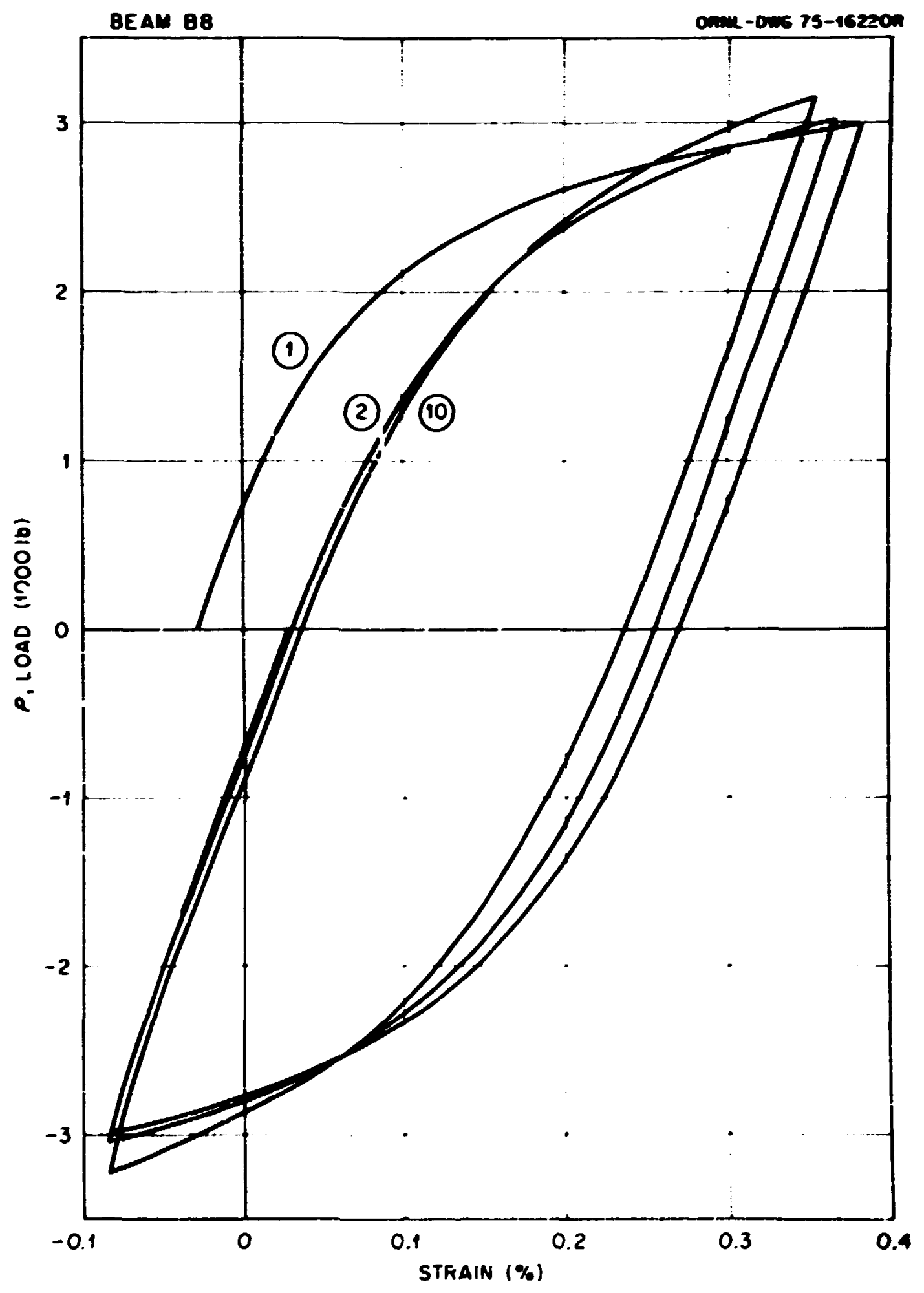

Fig. E.14. Load vs strain (SGl) during ten short-time, postcreep deflection cycles of beam B\&. Note that the sign of the strain has been changed $(16 \times 4.448=N)$. 
110

ORNL-DWG 75-16221R

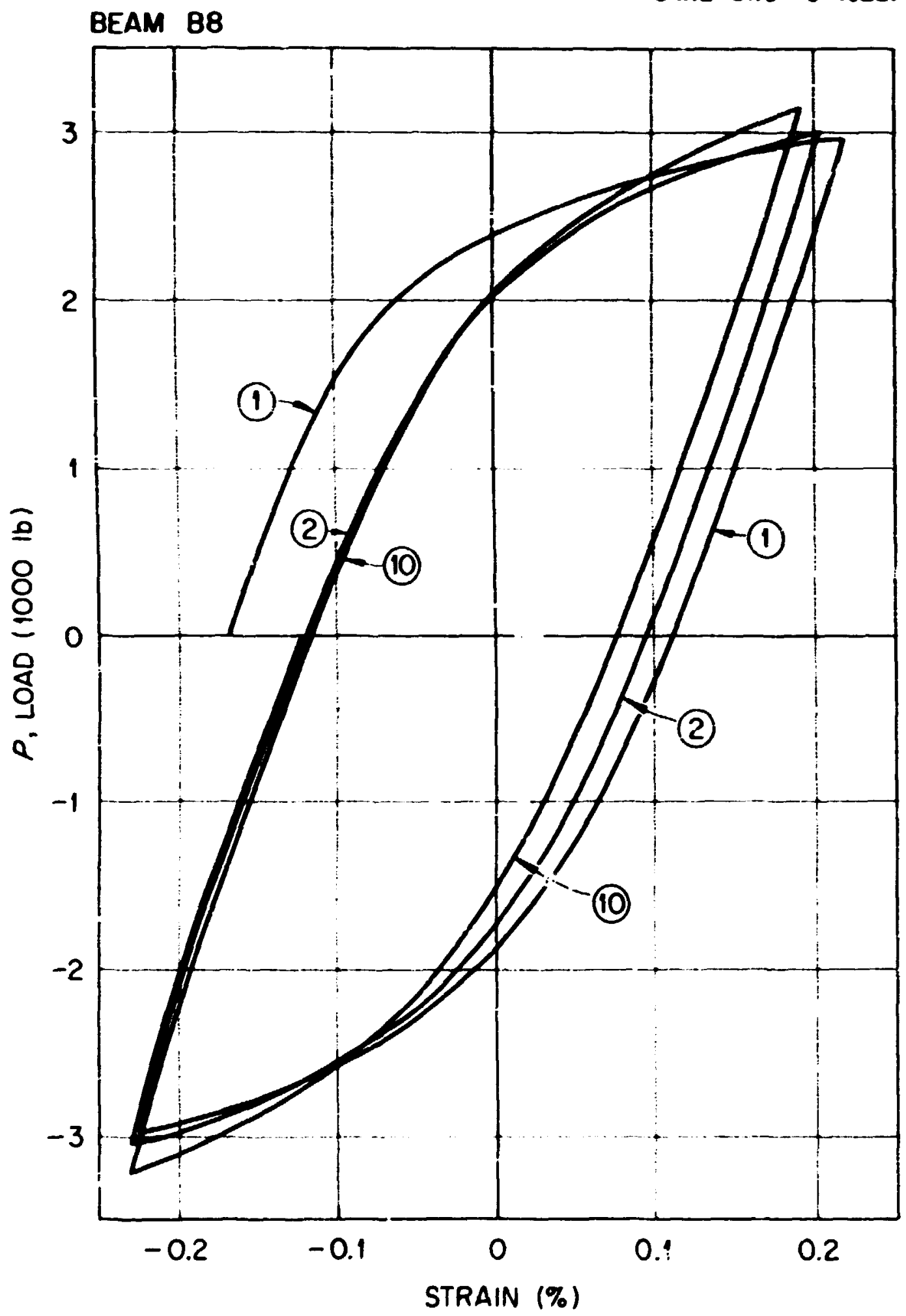

Fig. E.15. Load vs strain (SG2) during ten short-time, postcreep deflection cycles of bean B8 $(1 \mathrm{~b} \times 4.148=\mathrm{N})$. 


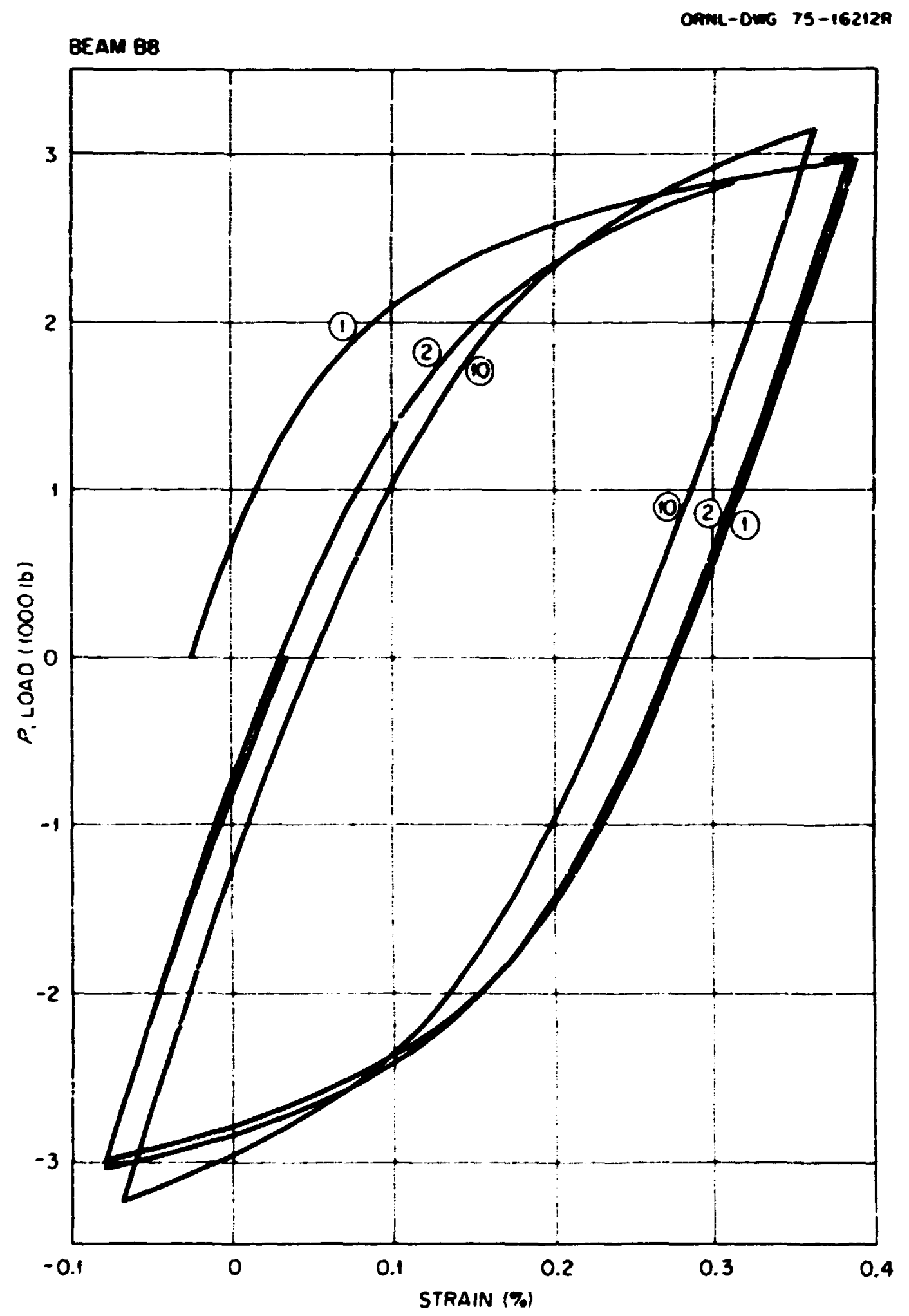

Fig. E.16. Load vs strain (SG3) during ten short-time, postcreep deflection cyrles of bean $B 8$. Note that the sign of the strain has been changed $(1 b \times 4.148=N)$. 
112

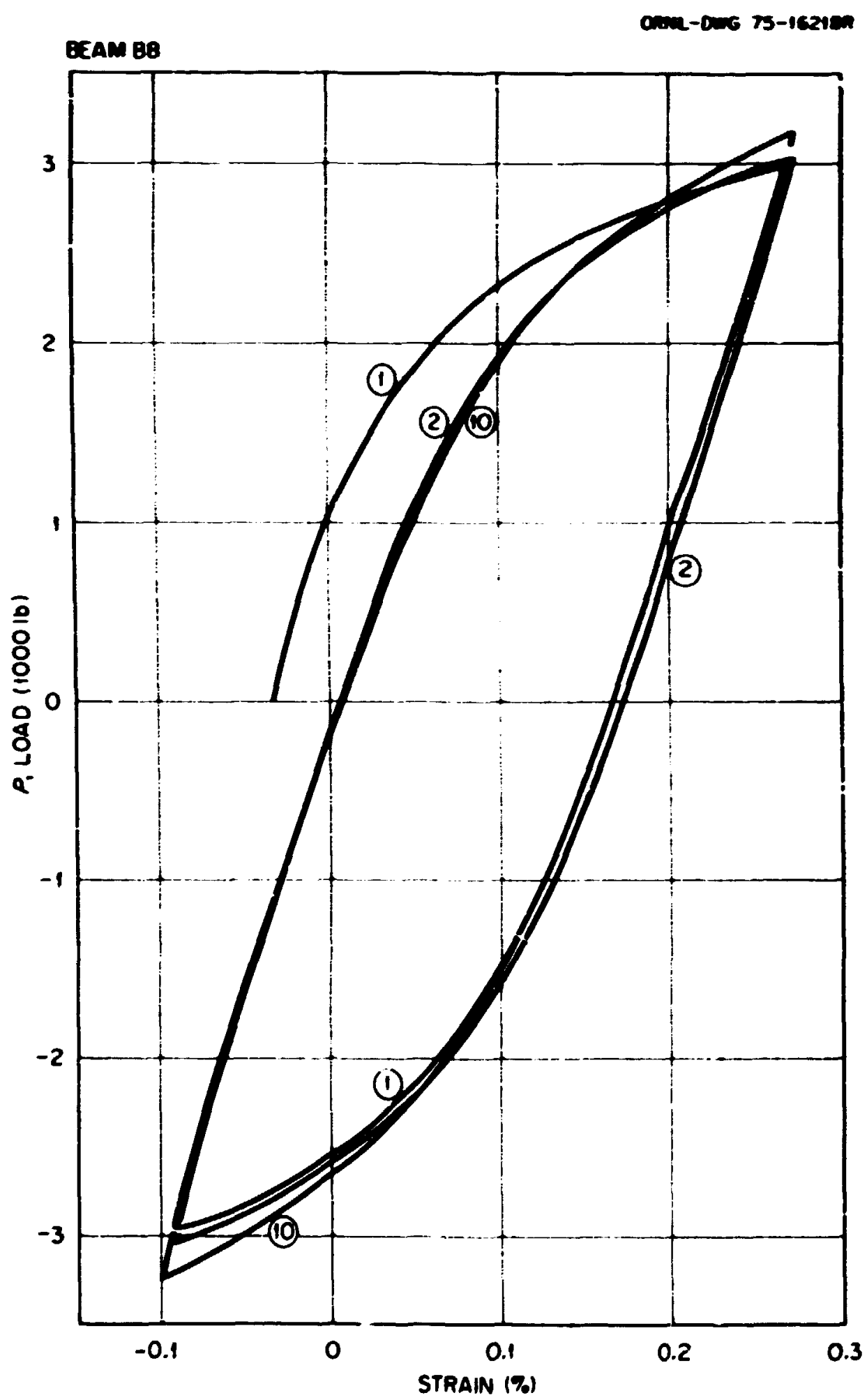

Fig. E.17, Load is strain (SGS) during ten short-time, postcreep deflection cycles of bean B8. Note that the sign of the strain has been changed $(1 \mathrm{~b} \times 4.448=N)$. 


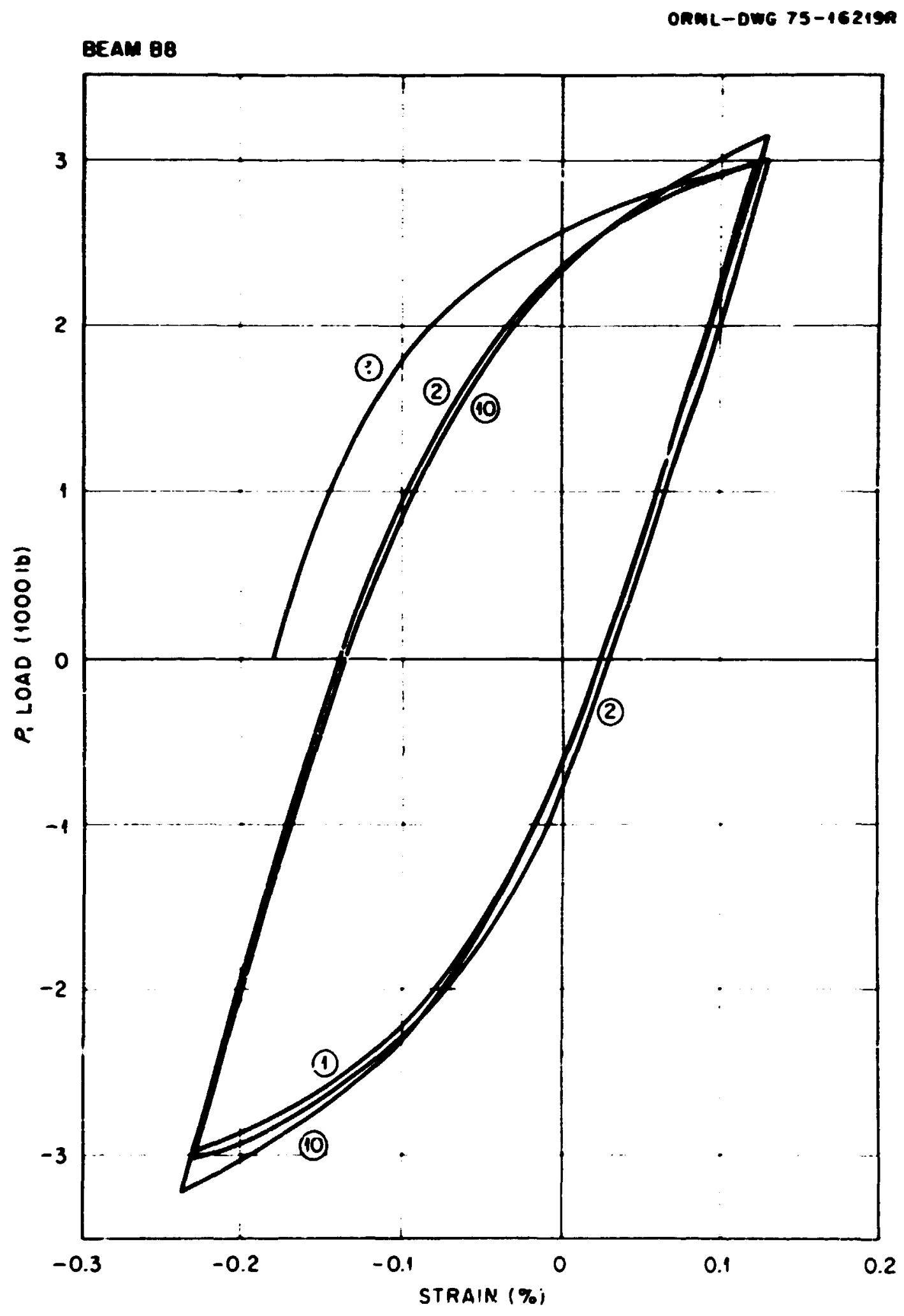

Fig. E.18. Load vs strain ( $S G 6$ ) during ten short-time, postcreep deflection cycles of bean B8. Note that the sign of the strain has been changed $(1 b \times 4.448=N)$. 


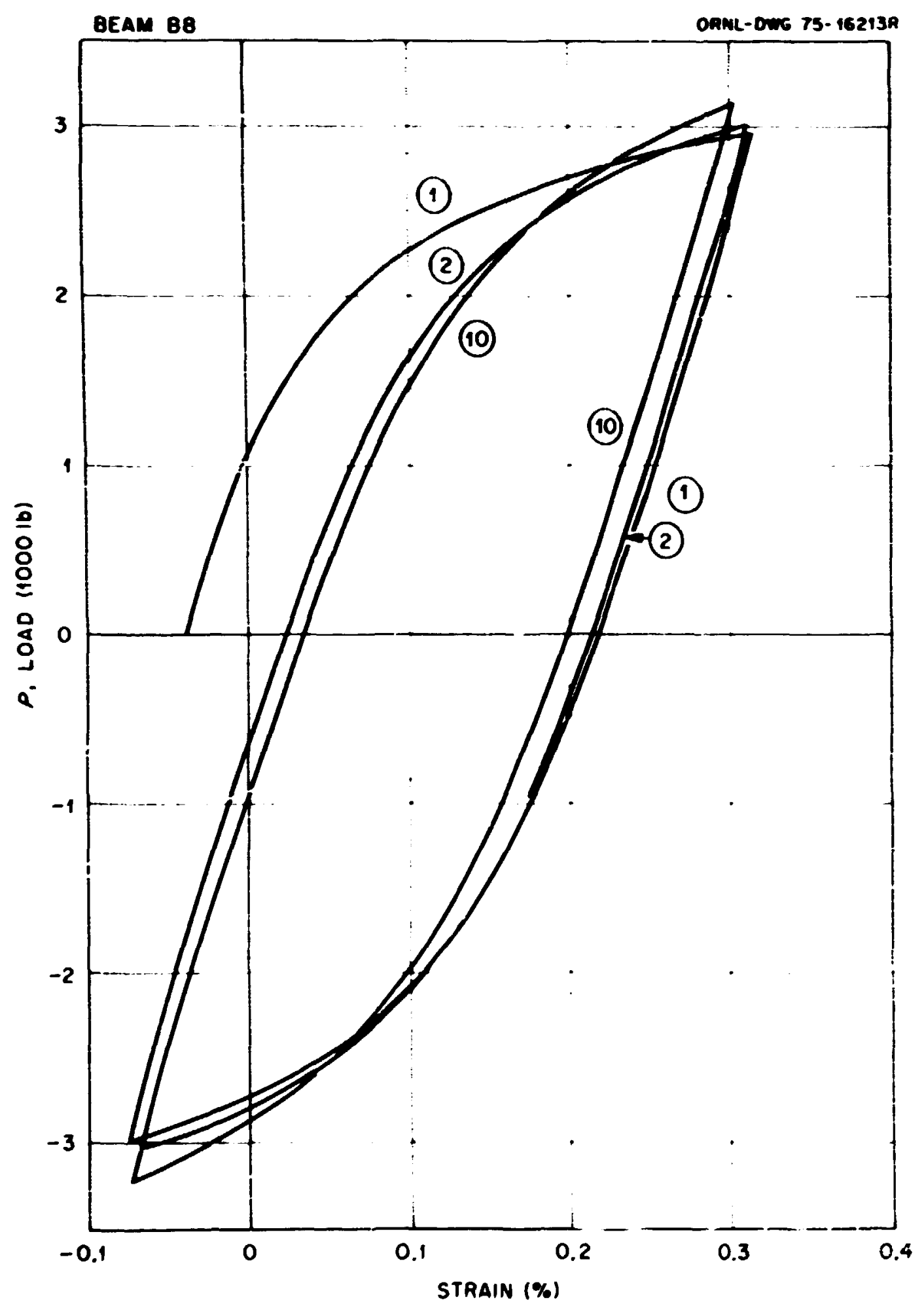

Fig. E.19. Load vs strain (SG7) during ten short-time, postcreep deflection cycles of bean B8. Note that the sign of the strain has been changed $(1 \mathrm{~b} \times 4.448=N)$. 
APPENDIX F. ADDITIONAL TEST RESULTS FOR PLATE CPS

Plati CPS was a load-controlled test without precreep cycles. The seasured teaperature ranges over the middle 342.9 (13.5 in.) of a single dianeter of the plate are depicted in Fig. F.1. These temperature ranges were those indicated by ten thernocouples, as shown in Fig. 4. Although the temperature range was adequately swall, the wean temperature was about $1.4^{\circ} \mathrm{C}\left(2.5^{\circ} \mathrm{F}\right)$ higher than desired.

Load vs deflection and load vs strain data are shown in Figs. F.2 through F.4 for the short-tine load changes associated with the creep portions of the test. * The locations of the deflection and strain measurements were shown in Fig. 4.

The deflection vs time and strain vs time data for the creep portions of the test are shown in Figs. F.5 through F.7." Finally, the load vs deflection and load vs strain data for the ten postcreep cycles are shuwn in Figs. F.8 through F.14.** Note that strain gage SG4 was inoperative throughout the test.

- Refer to Fig. 4 for locations of the deflections and strains. Circled nubers in Figs. F.2 through F.7 refer to the gage numbers.

* Circled numbers in Figs. F.8 through F.14 refer to the cycle number. 


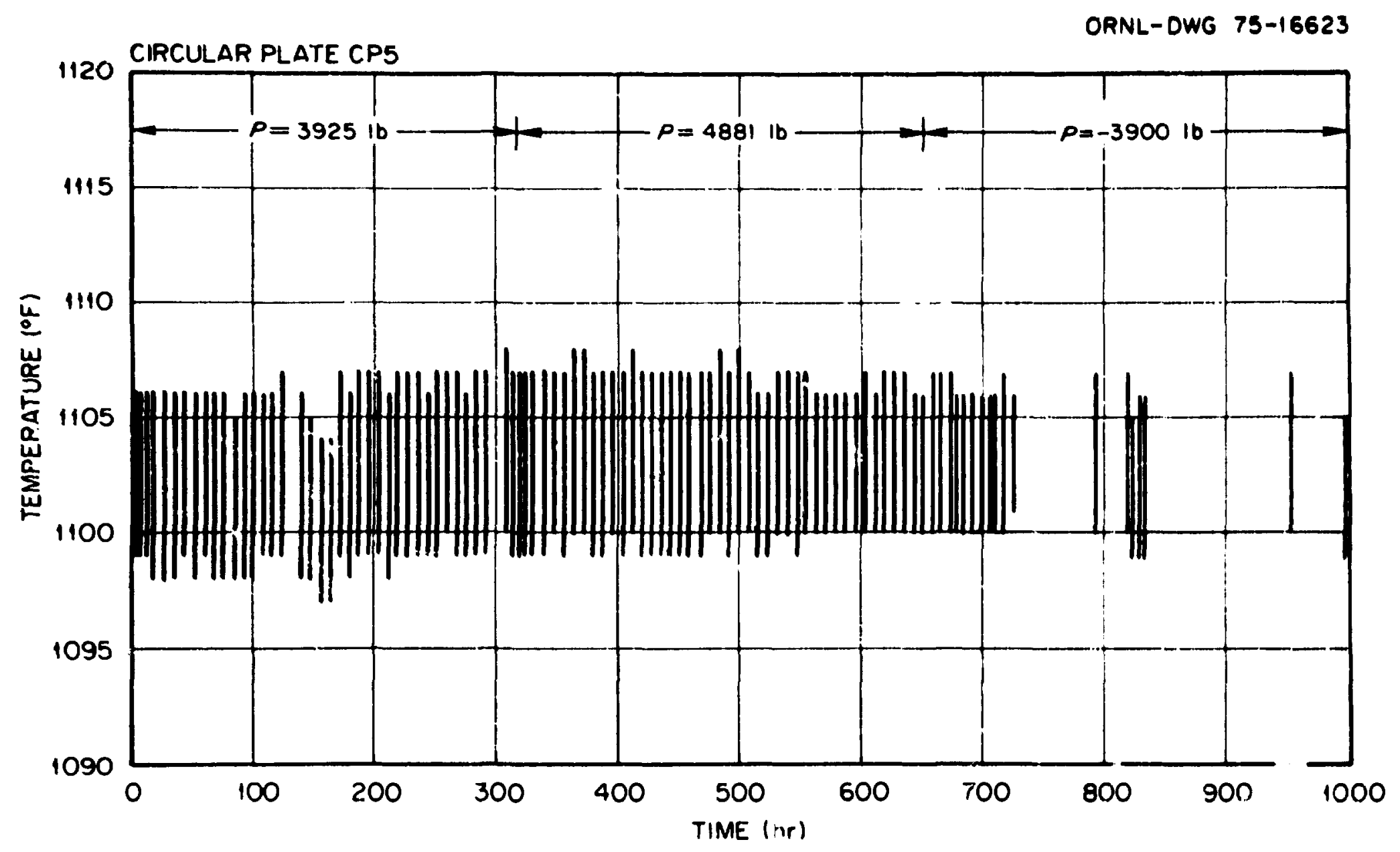

Fig. F.1. Measured temperature range over middle $338.6 \mathrm{~mm}$ (13.33 in.' of instrumented diameter of plate CP5 during $593^{\circ} \mathrm{C}\left(1100^{\circ} \mathrm{F}\right.$ ) test (1i $x$ $\left.4.448=\mathrm{N},\left({ }^{\circ} \mathrm{F}-32\right) \times 0.5556={ }^{\circ} \mathrm{C}\right)$. 


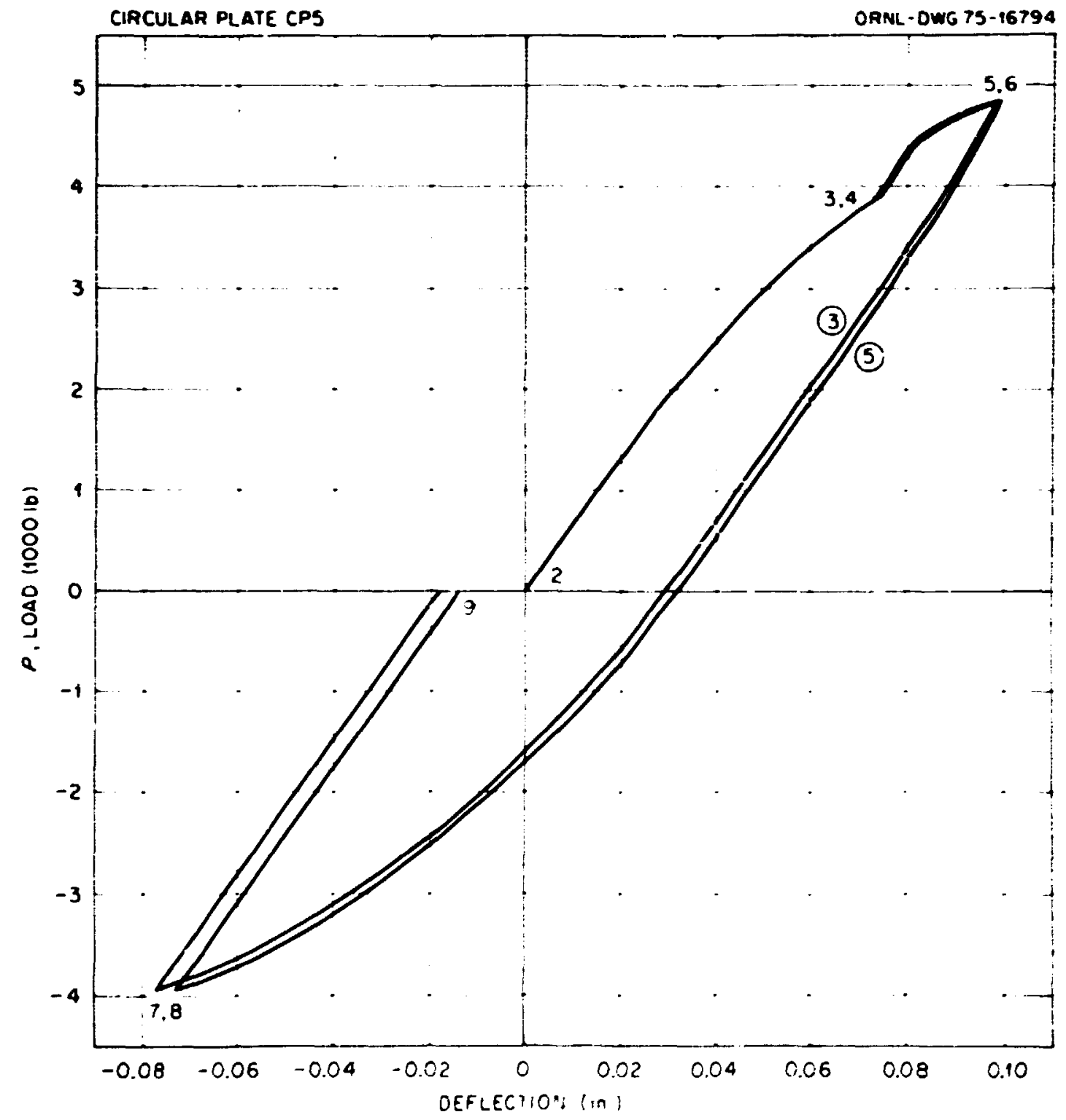

Fig. F.2. Load vs deflection (DT3 and DT5) for short-time load changes associated with creep portions of plate CF5 test $(1 \mathrm{~b} \times 4.448=$ $\mathrm{N}$, in. $\times 25.4=\mathrm{mm})$. 
118

ORNL- DWG 75- 15793

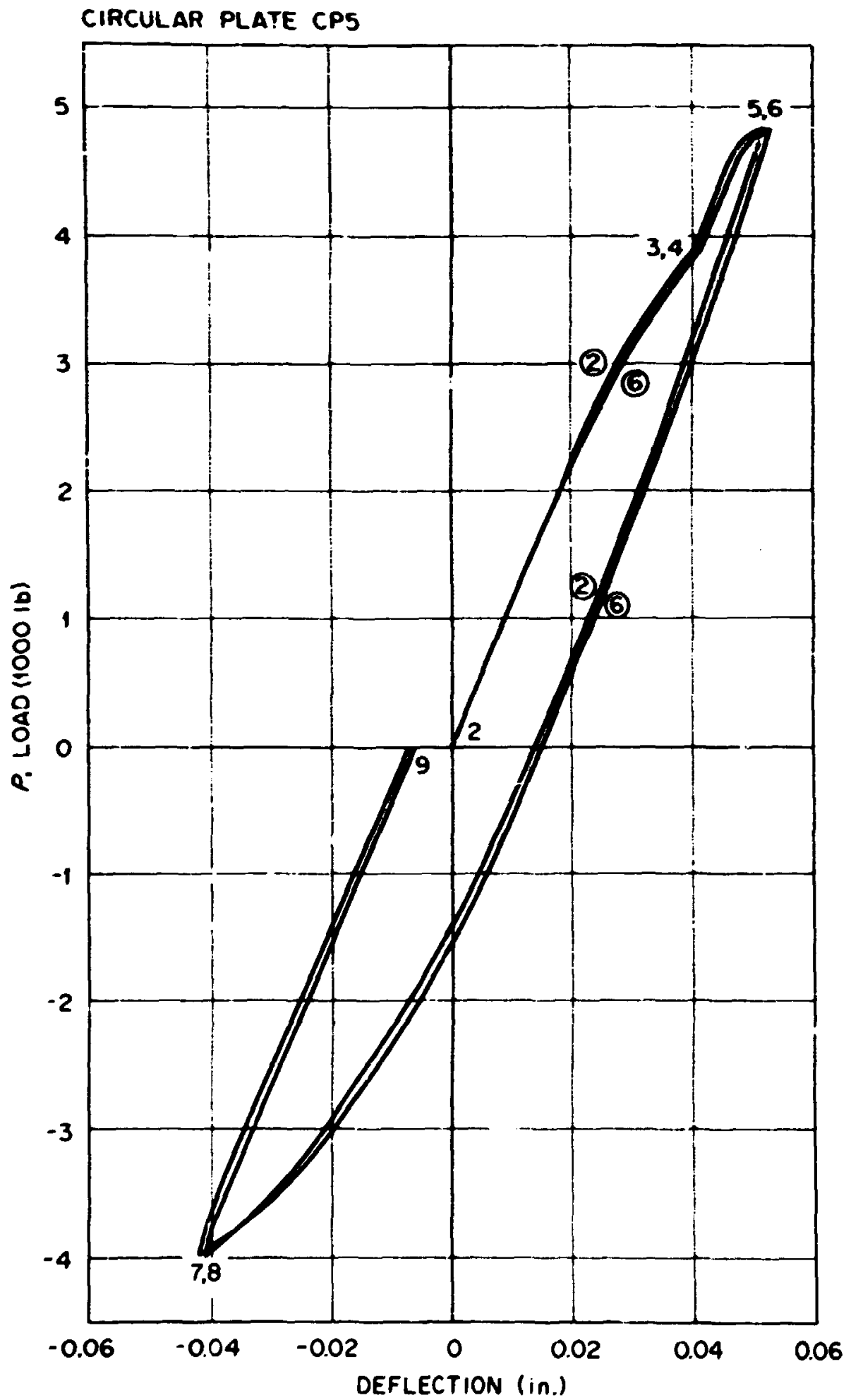

Fig. F.3. Load vs deflection (DF2 and DT6) for short-time load changes associated with creep portions of plate CPS test ( $1 \mathrm{~b} \times 4.448=$ $N$, in. $\times 25.4=m$ m). 


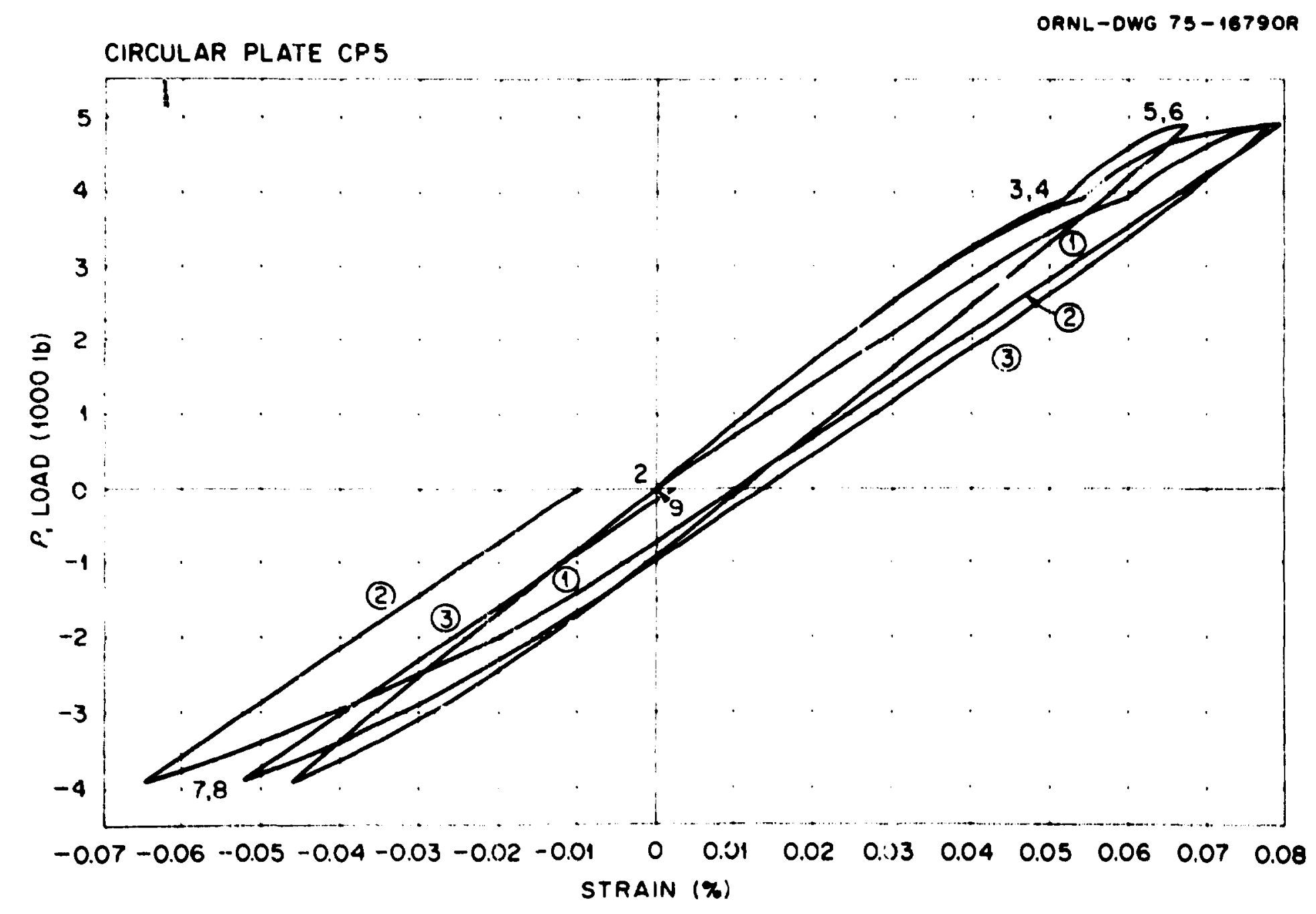

Fig. F.4. LoaJ vs strain (SGI-SG3) for short-time load chunges associated with creep portions of plate CPS test. Note that the signs of $S G I$ and $S G 3$ have been changed $(1 \mathrm{~b} \times 4.448=N)$. 


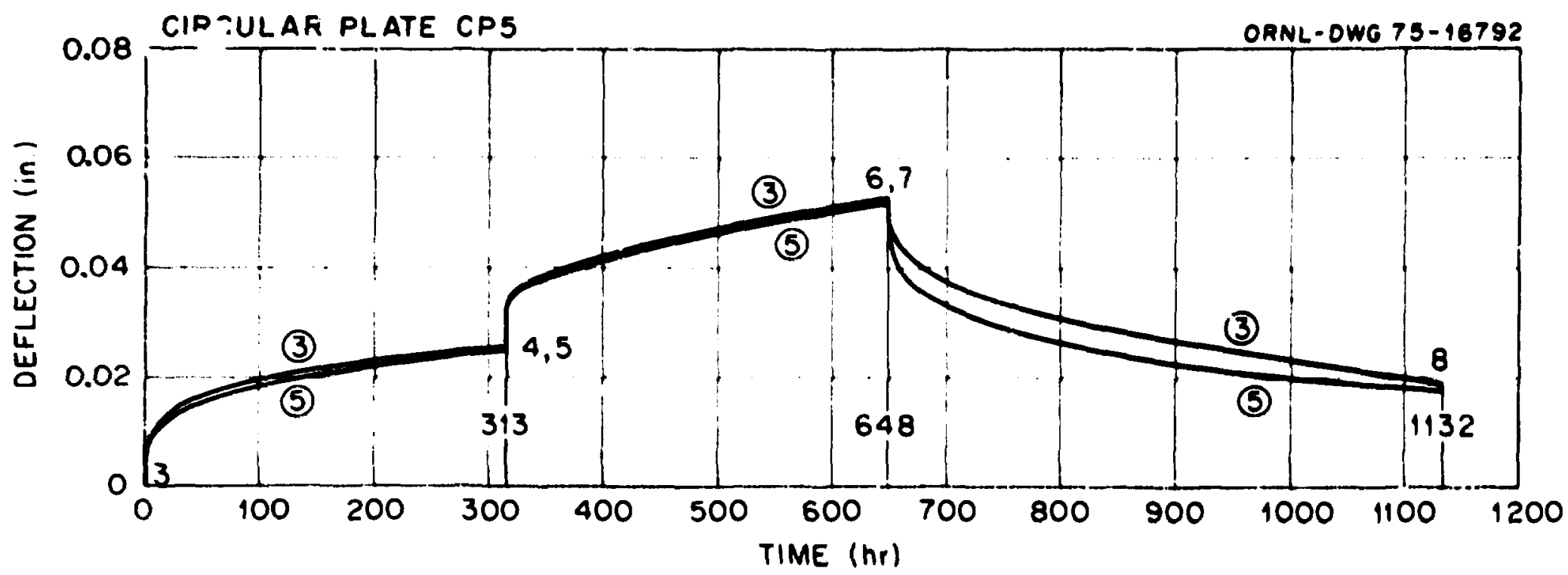

Fig. F.5. Creep deflections (DT3 and DTS) vs time for plate CP5 (in. $\times 25.4=\mathrm{mm})$. 
ORNL- DWG 75 - 16791

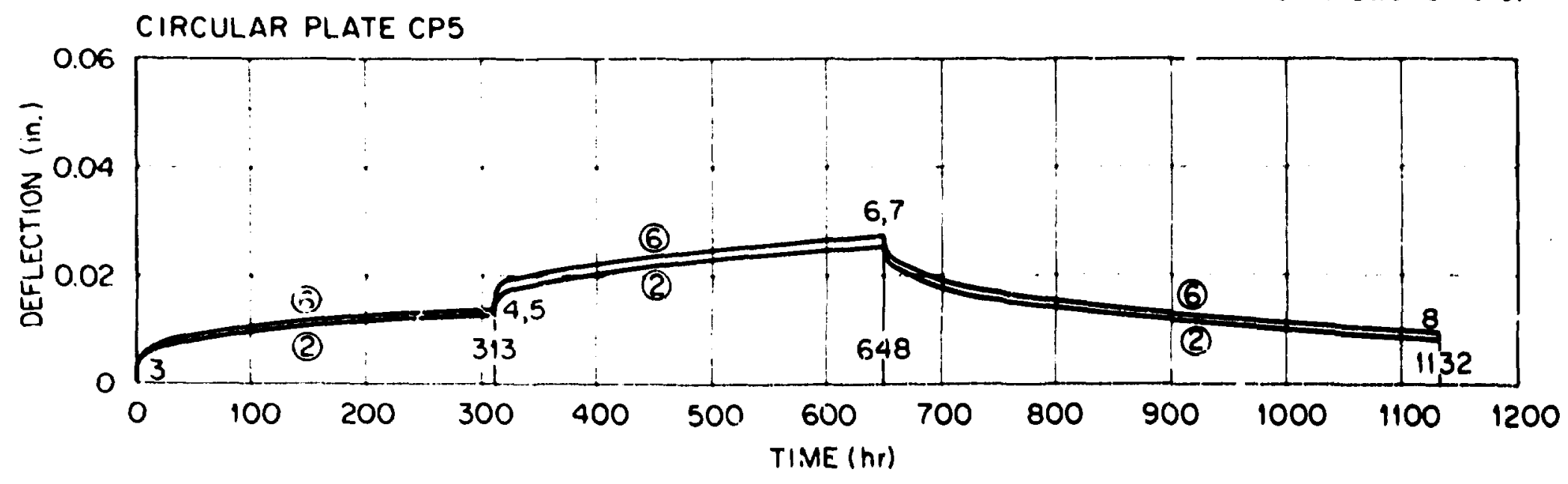

Fig. F.6. Creep deflections (OT2 and DT6) vs time for plate CPS (in. $\times 25.4=\mathrm{mm})$. 
CIRCULAR PLATE CPS

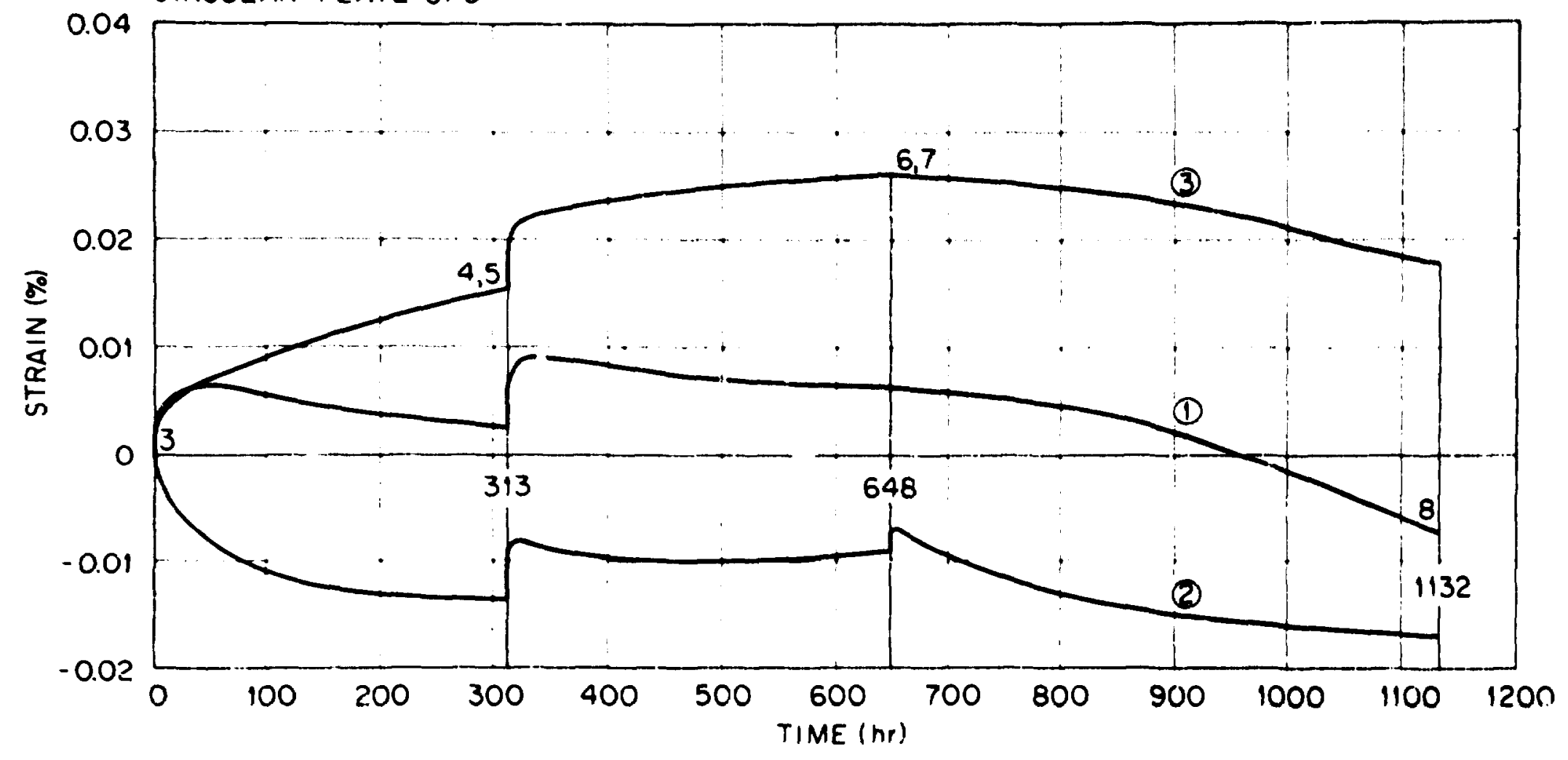

Fig. F.7. Creep strains (SCL-SG3) vs time for plate CP5. Note that the signs of $S G I$ and $S G 3$ have been changed. 
123

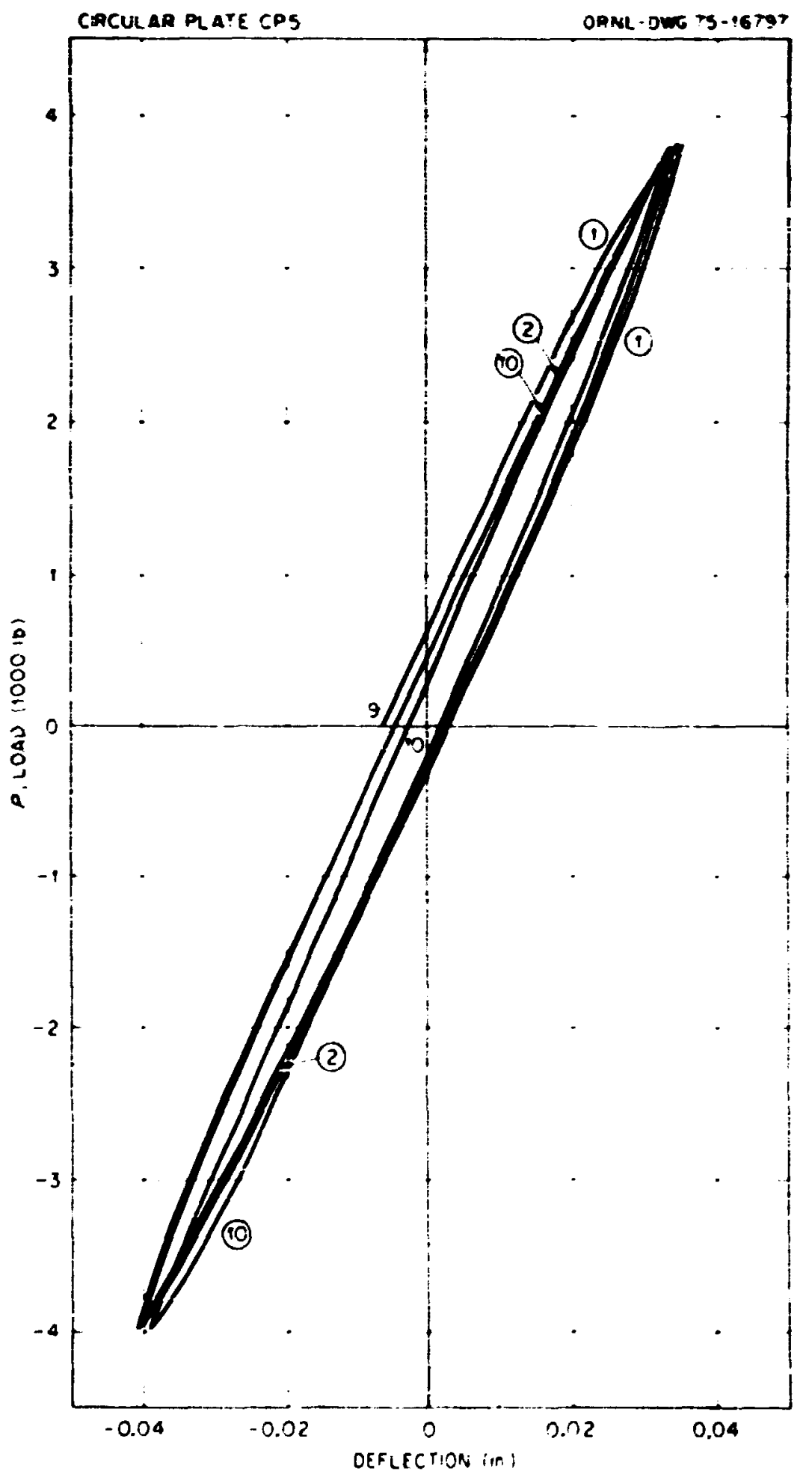

Fig. F.8. Load vs deflection (DT2) during ten short-time, postcreep load cycles of plate CPS (lb $\times 4.448=N$, in. $\times 25.4=\mathrm{mm})$. 


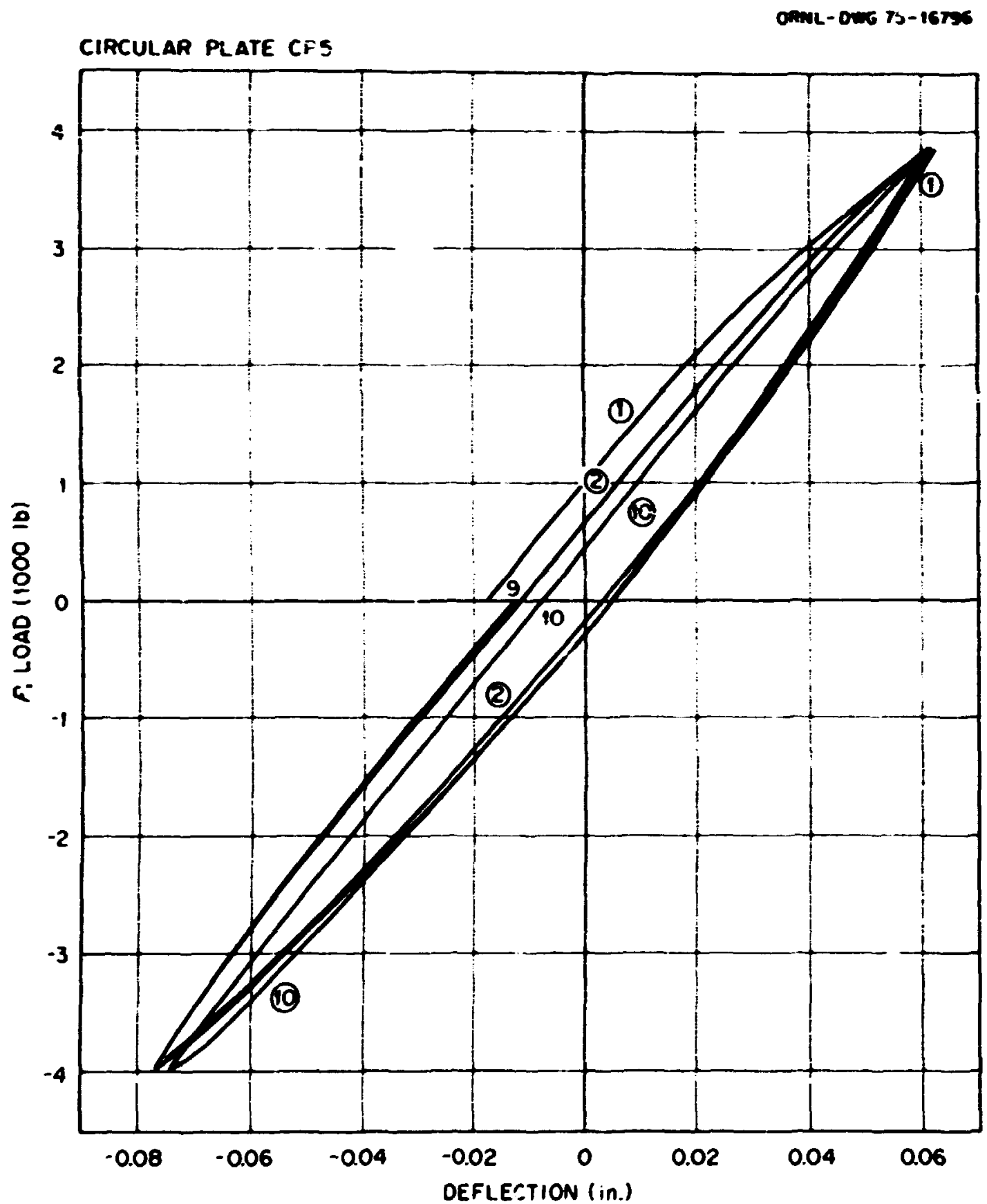

Fig. F.9. Load vs deflection (DT3) during tan short-time, postcreep load cycles of plate CP5 $(1 b \times 4.448=N$, in. $\times 25.4=m)$. 


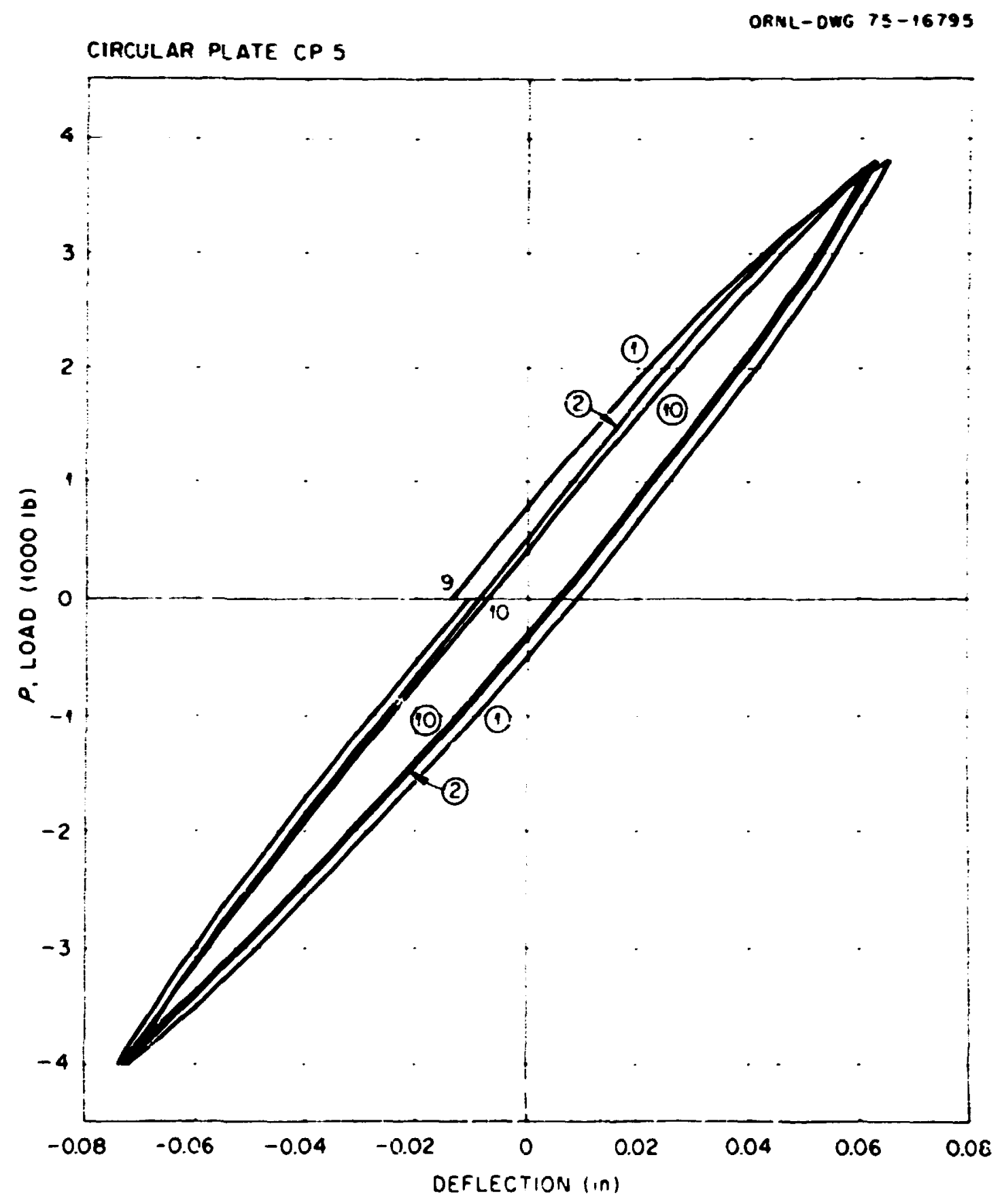

Fig. F.10. Load vs deflection (DTS) during ten short-time, postcreep load cycles of plate CPS $(\mathrm{Hb} \times 4.448=N$, in. $\times 25.4=\mathrm{mm})$. 


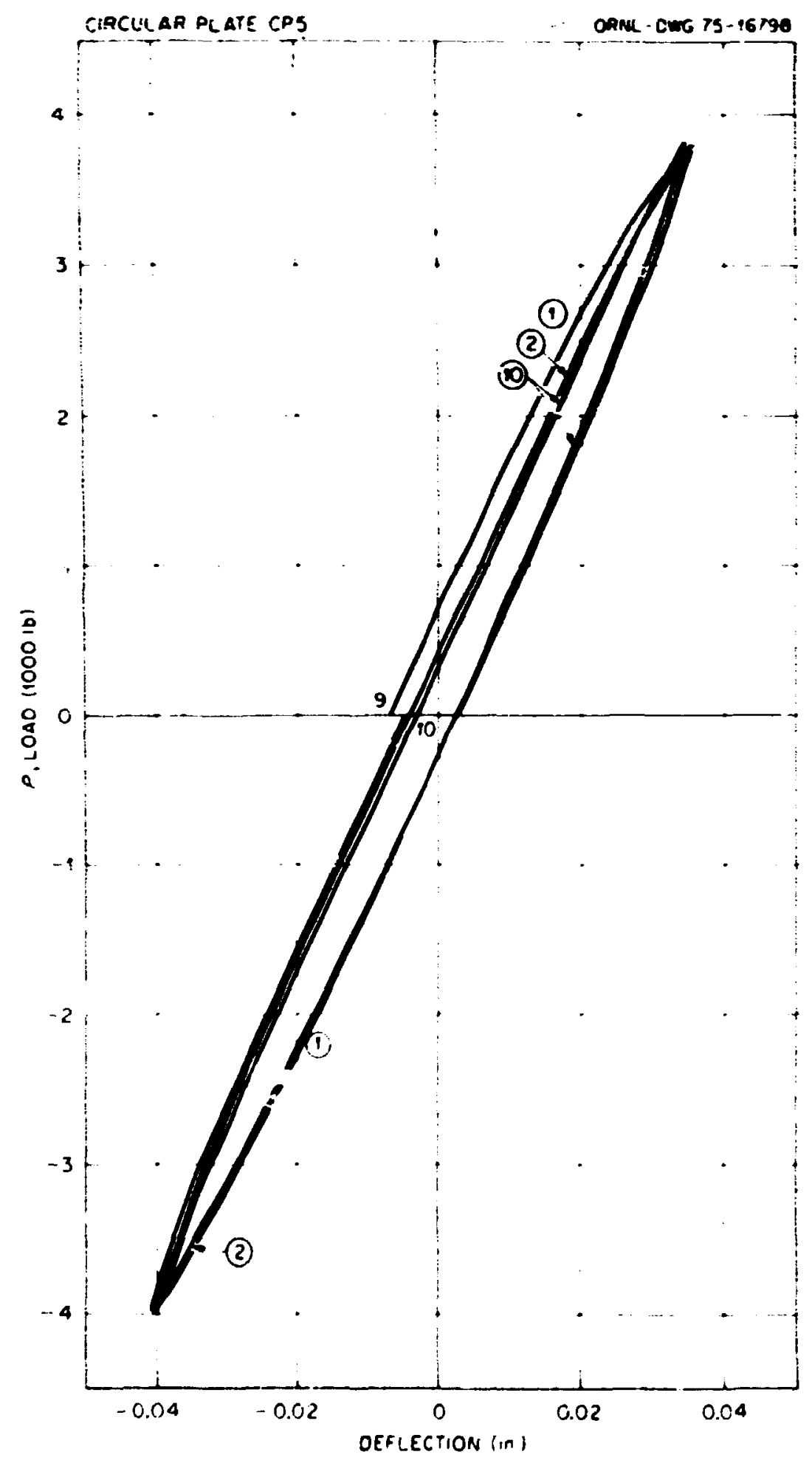

Fig. F.11. Load vs deflection (DT6) during ten short-time, postcreep load cycles of plate CP5 ( $1 \mathrm{~b} \times 4.448=N$, in. $\times 2.5 .4=\mathrm{mn})$. 


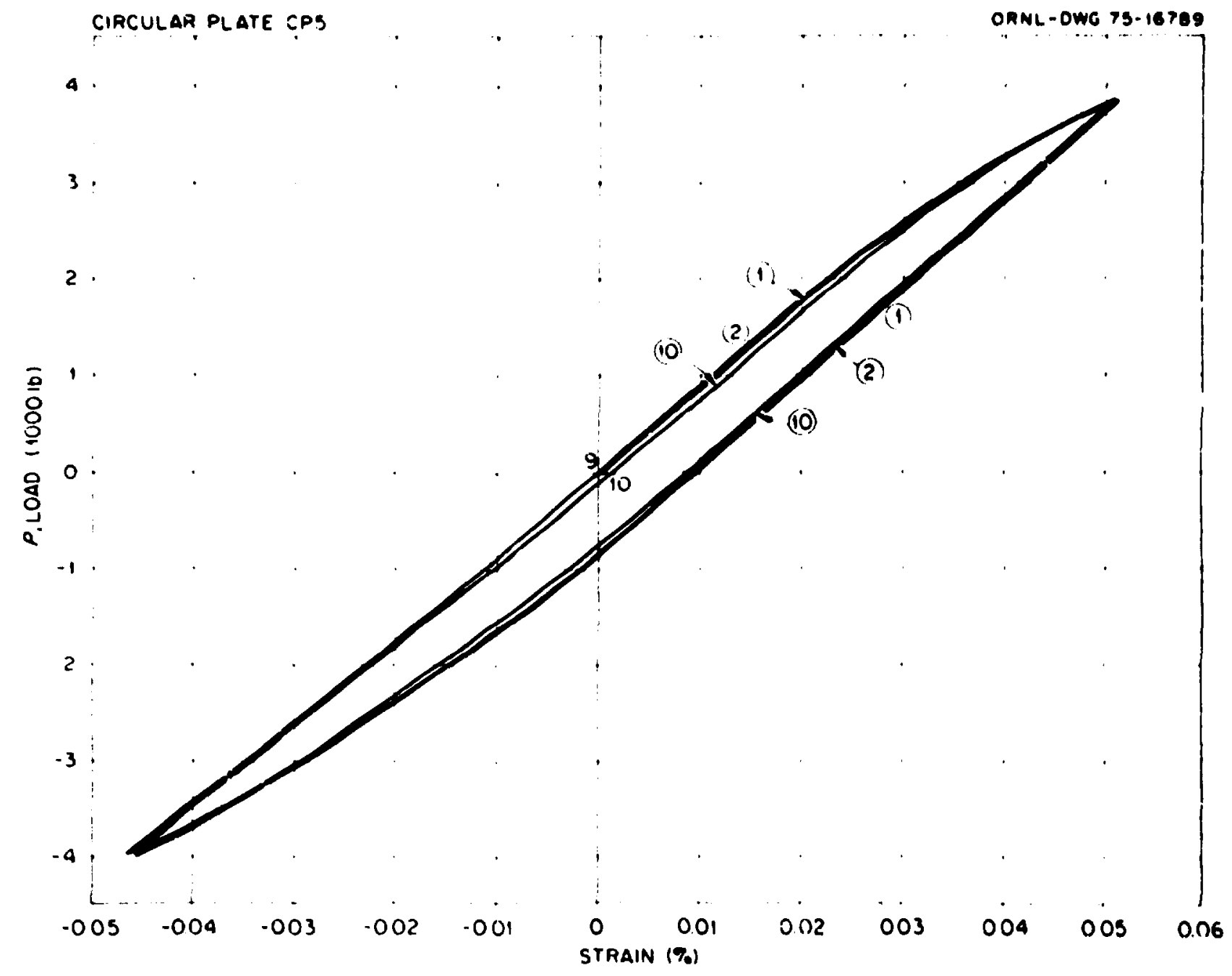

Fig. F.12. Load vs strain ( $S G 1$ ) during ten short-time, postcreep load cjeles of plate CPS. Note that the sign of the strain has been changed $(1 \mathrm{~b} \times 4.448=N)$. 


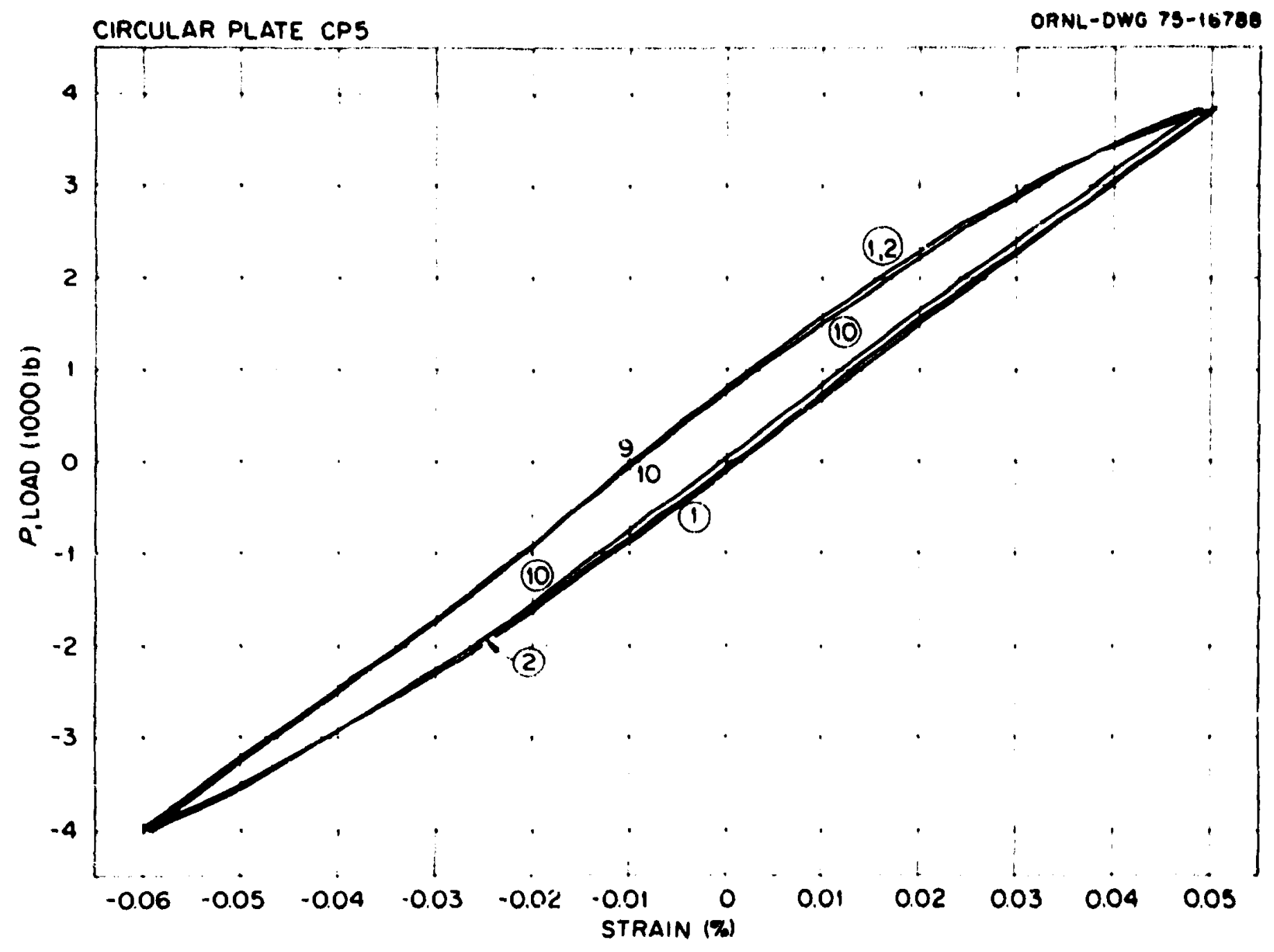

Fig. F.13. Load vs strain (SG2) during ten short-time, postcreop load cycles of plate CPS (lb $\times 4.448=N)$. 


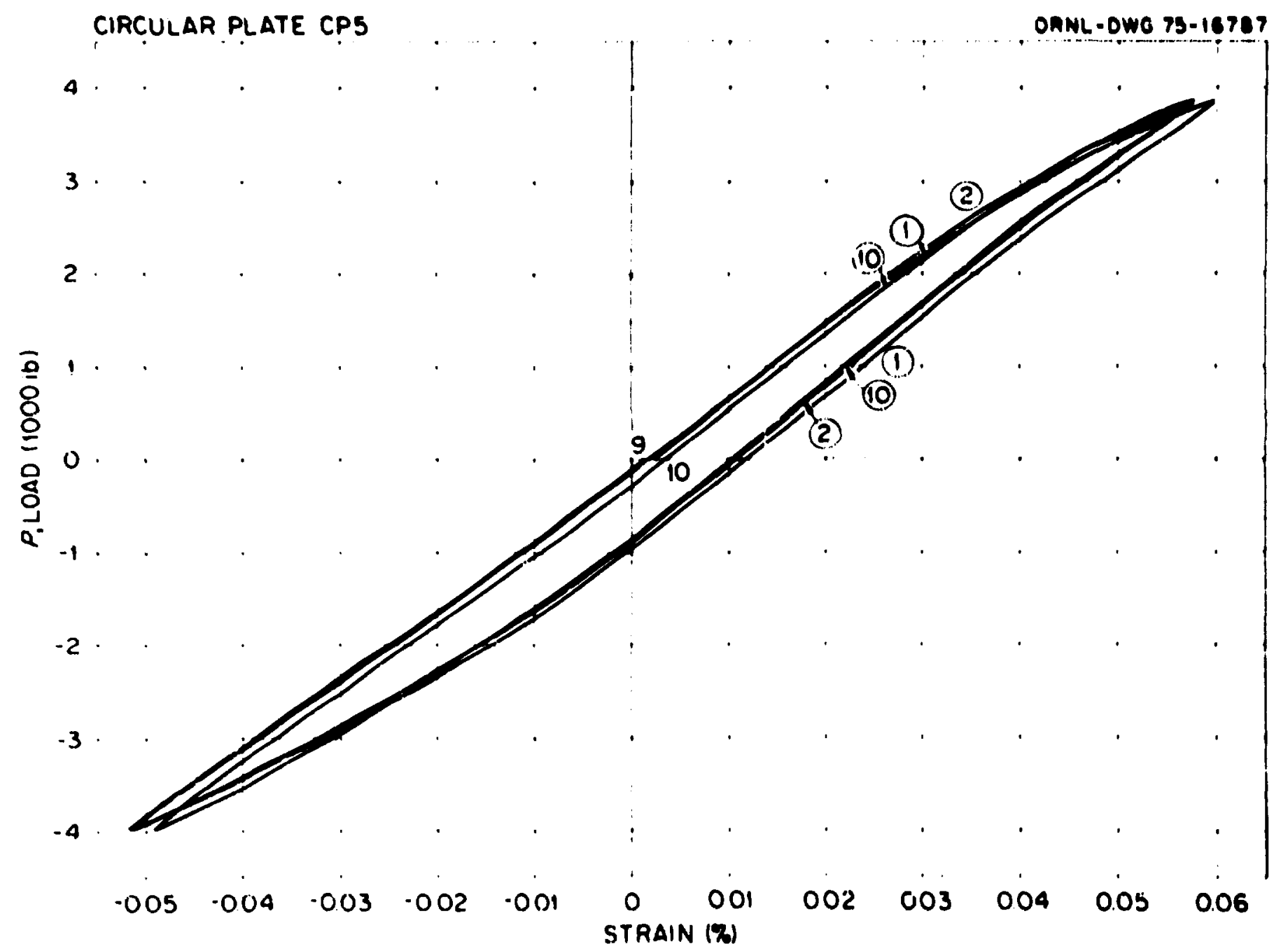

Fig. F.14. Load vs strain ( $S(i 3)$ during ten short -time, postcreep load cycles of plate CPS. Note that the sign of the strain hay been changed $(1 \mathrm{l}) \times 4.448=N)$. 


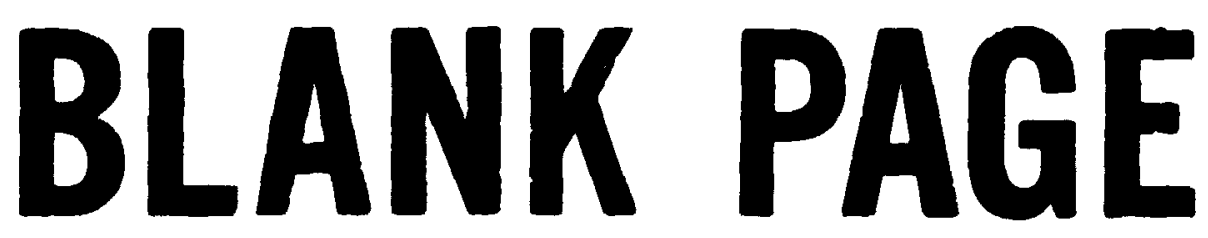


APPENDIX 6. ADDITIONAL TEST RESULTS FOR PLATE CP2

Plate CP2 was a load-controlled test with precreep cycling. The measured temperature ranges for the test are depicted in Fig. G.1. where it can be jeen that the desired temperature level and range were closely atched.

Figurzs G.2 through G.5 depict the measured load vs strain response fo: $_{2}$ the ten precreep load cycles." Companion plots for the postcreep load cycles are shown in Figs. G.6 through G.8 (gage SGl was inoperative during the end-of-test cycling).*

*Circled nubers in these figures refer to the cycle number. 


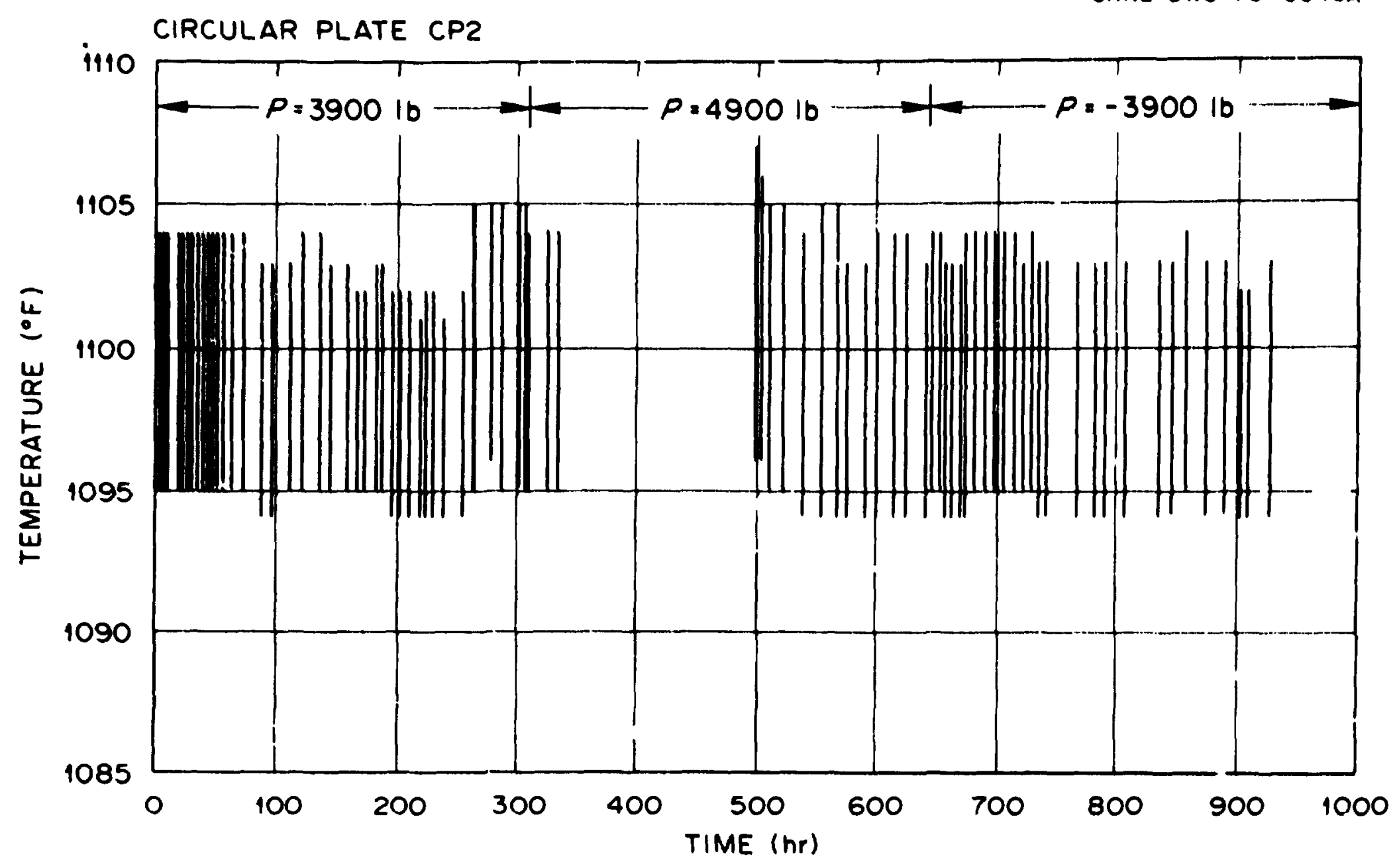

Fig. G.1, Measured temperature range over middle $338.6 \mathrm{~mm}(13.33$ in.) of instrumented diameter of plate (P2 during $595^{\circ} \mathrm{C}\left(1100^{\circ} \mathrm{F}\right)$ test $\left[16 \times 4.448=N,\left({ }^{\circ} \mathrm{F}-32\right) \times 0.5556={ }^{\circ} \mathrm{C}\right]$. 


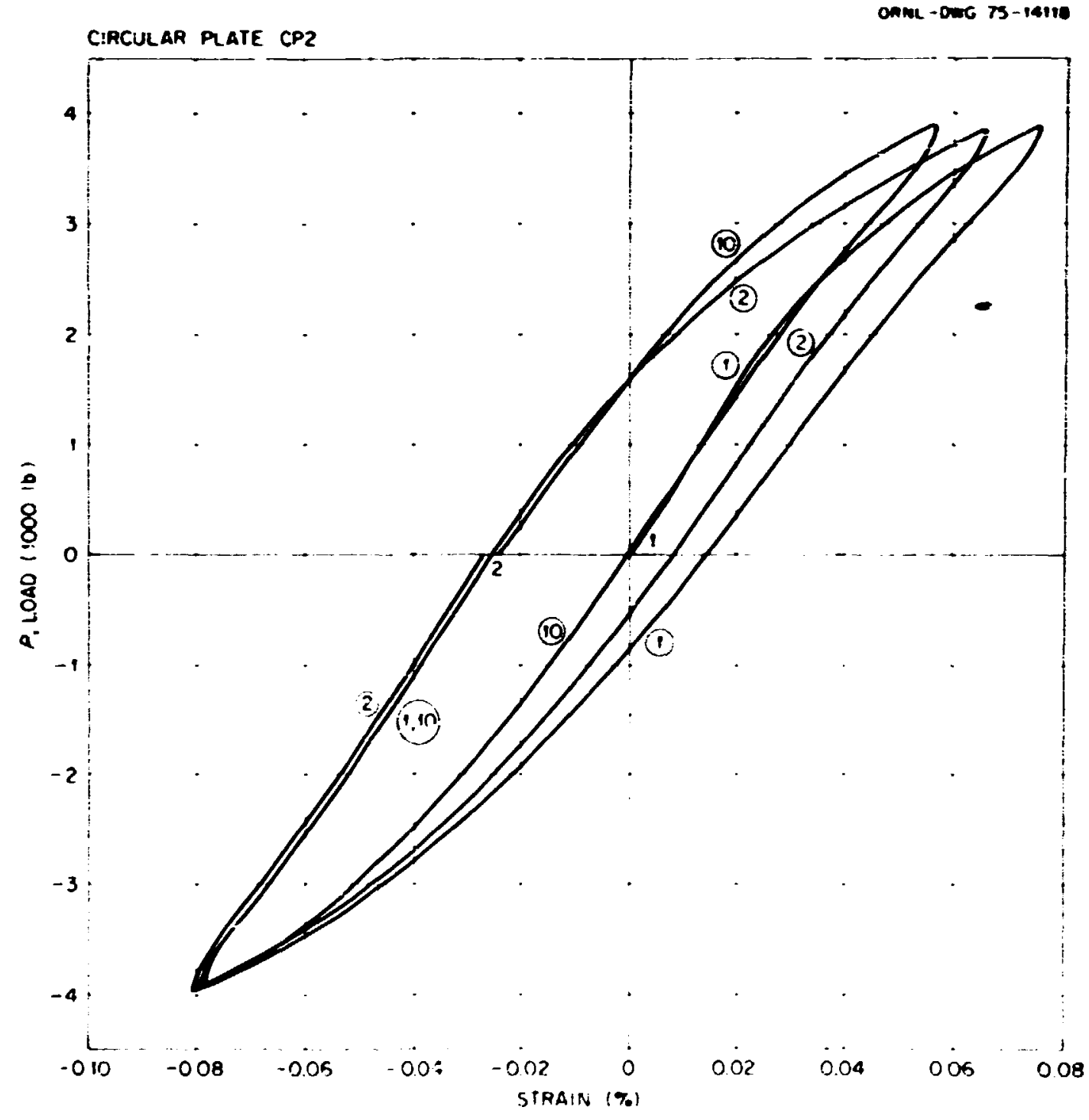

Fig. G.2. Load vs strain (SGl) during ten short-time precreep load cycles of plate CP2. Note that the sign of the strain has been changed $(\mathrm{Ib} \times 4.448=\mathrm{N})$. 
134

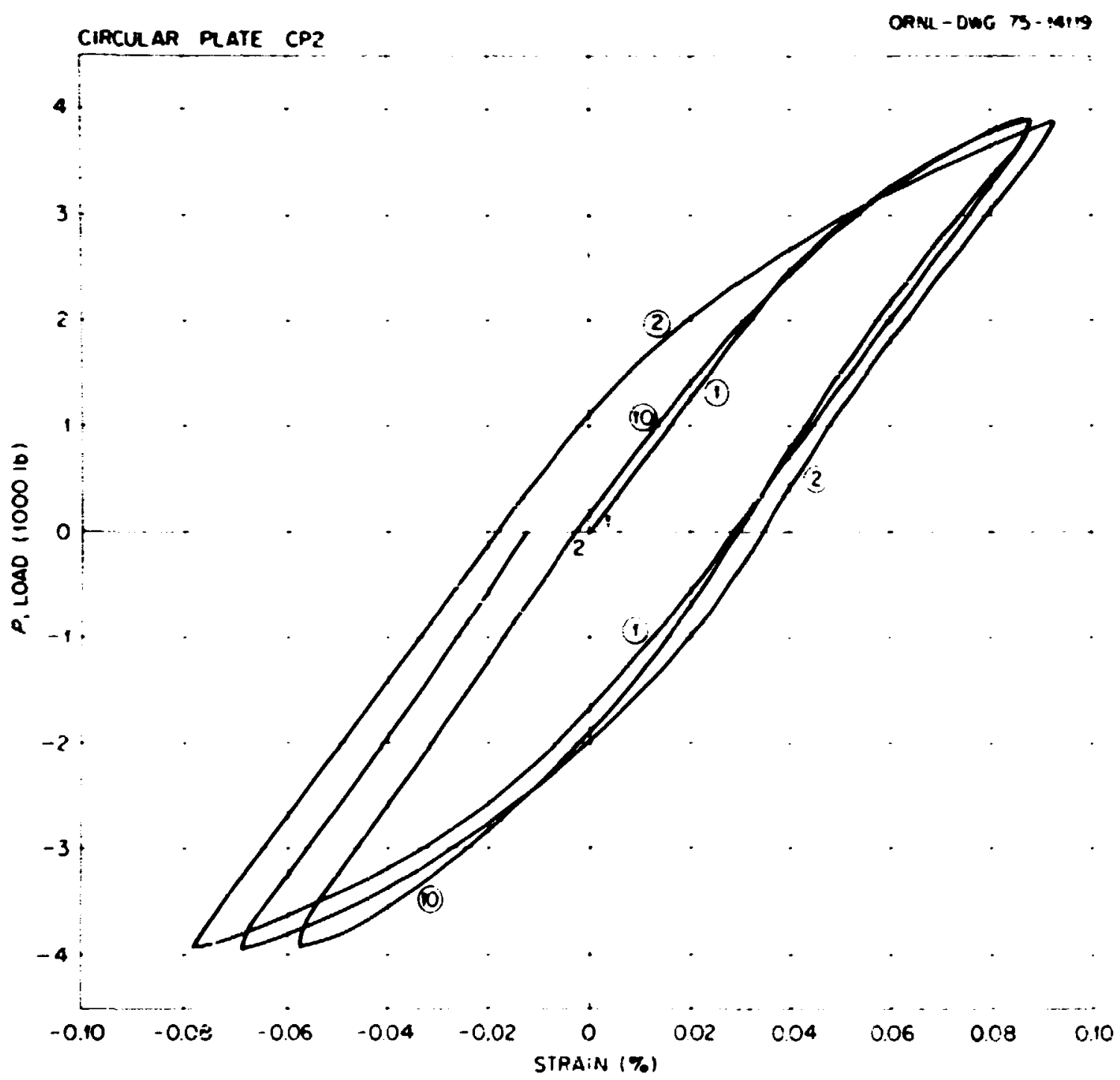

Fig. G.3. Load vs strain (SG2) during ten short-time precreep load cycles of plate CP2 ( $1 b \times 4.448=N)$. 


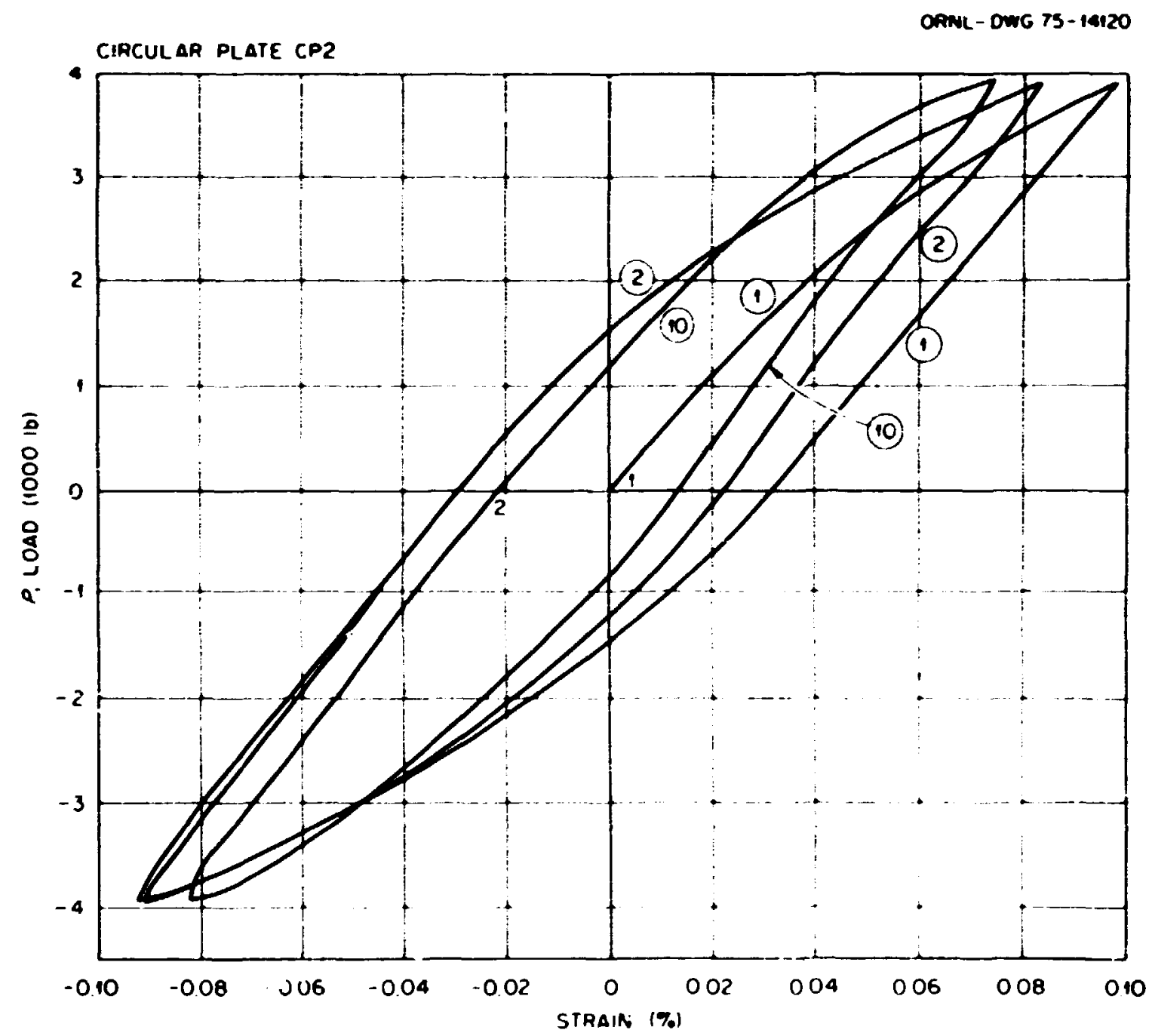

Fig. G.4. Load vs strain (SG3) during ten short-time precreep load cycles of plate CP2. Note that the sign of the strain has been changed $(1 b \times 4.448=N)$. 


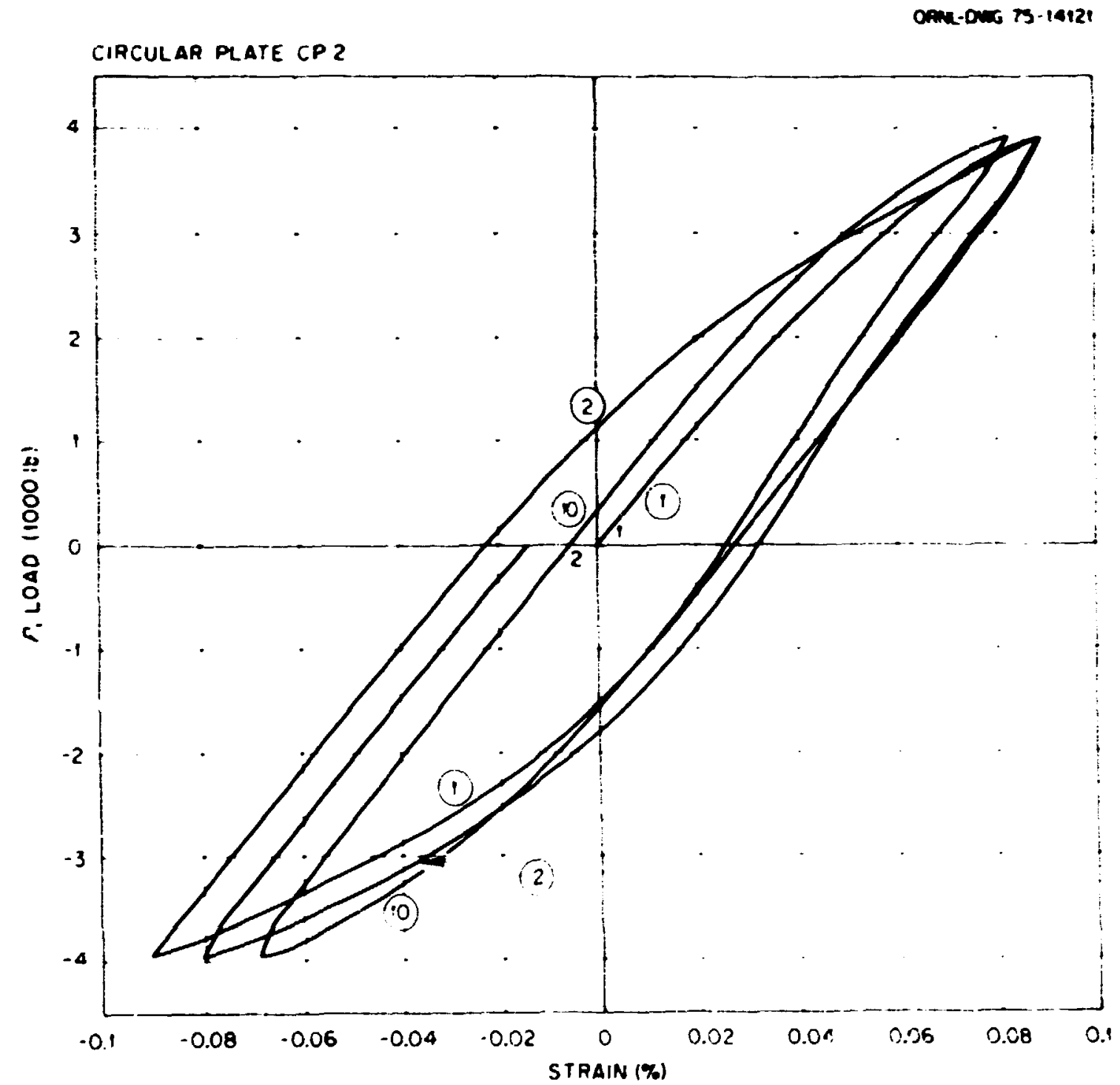

Fig. G.5. Load vs strain (SG4) during ien short-time precreep load cycles of plate CP2 $(1 b \times 4.448=N)$. 


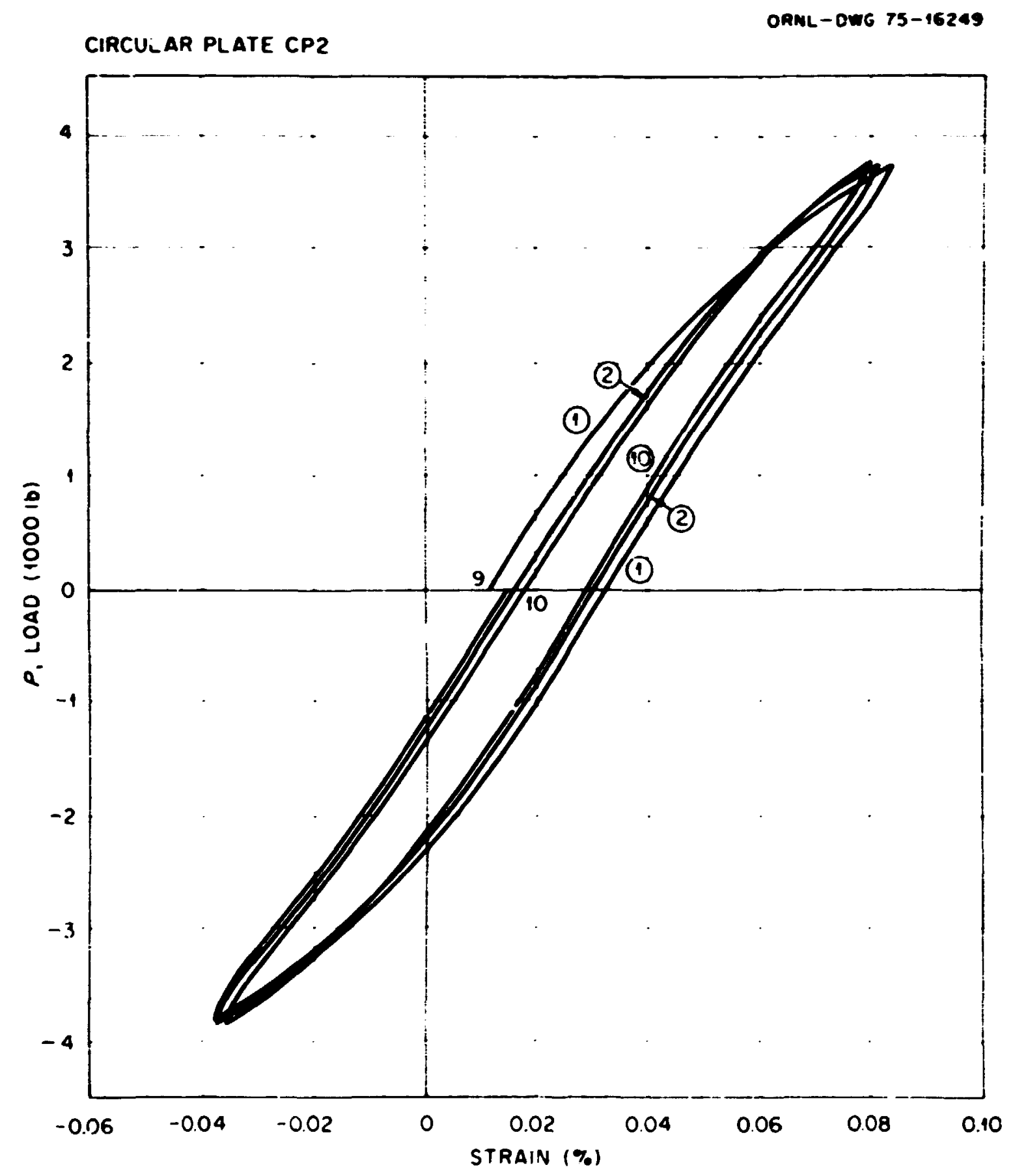

Fig. G.6. Load vs strain (SG2) during ten short-time, postcreep load cycles of plate CP2 $(1 \mathrm{~b} \times 4.448=N)$. 
138

ORML-OWG $75-16250$

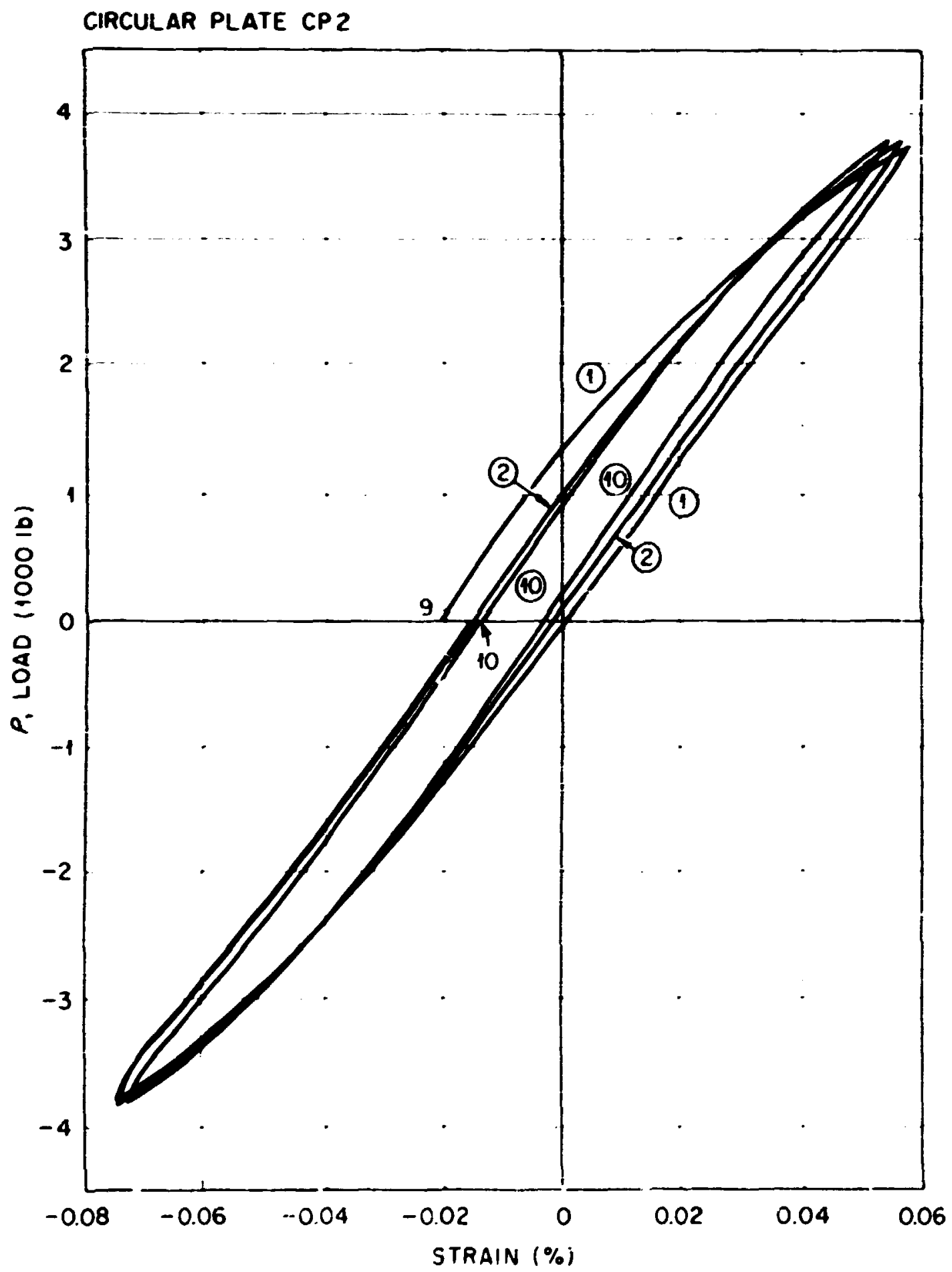

Fig. G.7. Load veer strain (SG3) during ten short-time, postcruep load cycles of plate $C P 2$. Note that the sign of the strain has been changed $(I b \times 4.448=N)$. 


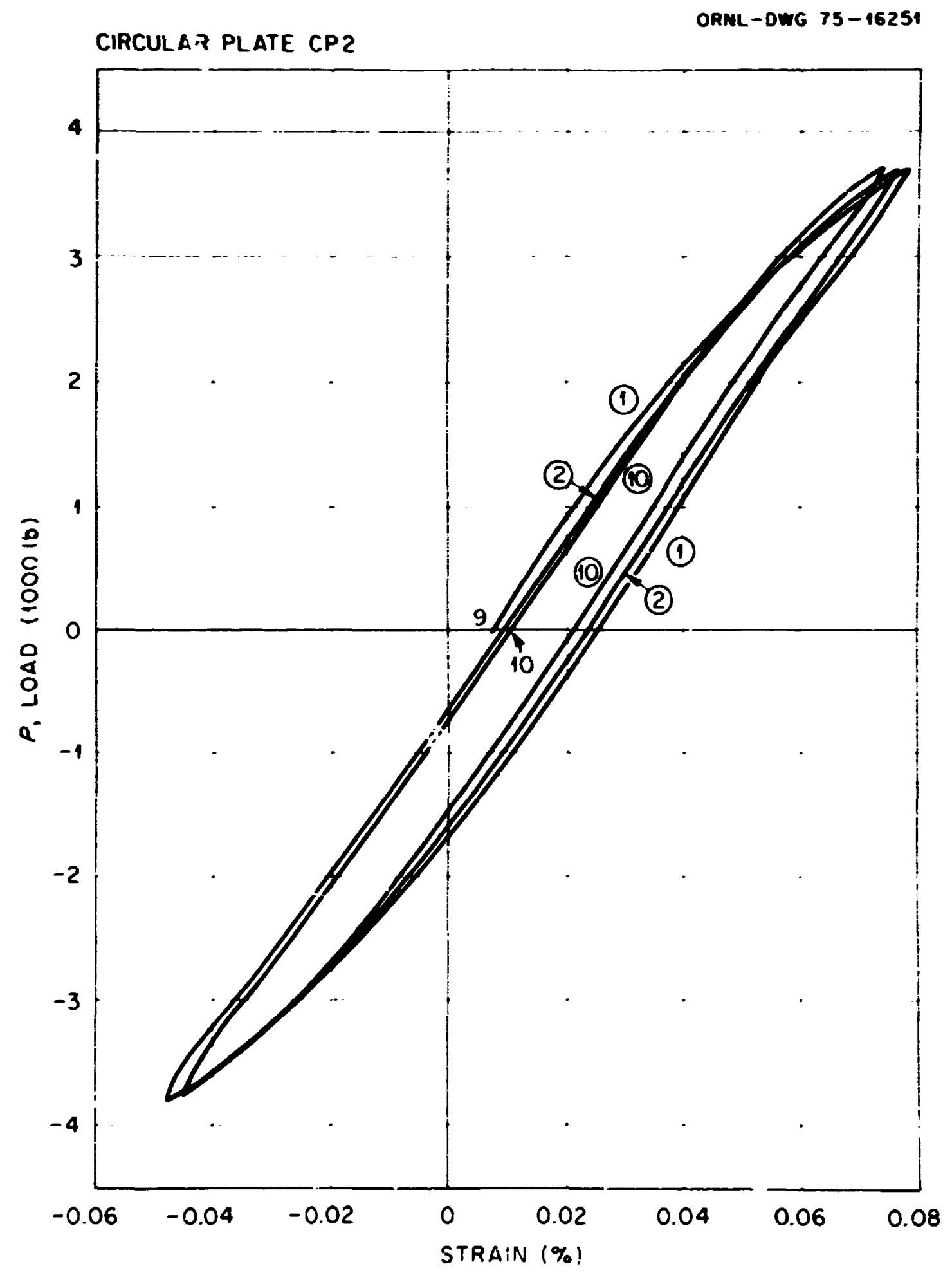

Fig. G.8. Load vs strain (SC.4) during ten short-time, postcreep load cycles of plate $\mathrm{CP} 2(1 \mathrm{~L} \times 4.448=\mathrm{N})$. 


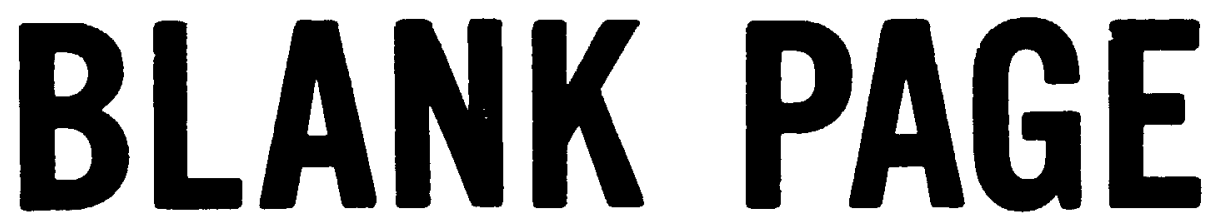


APPENDIX H. ADDITIONAL TEST RESULTS FOR PLATE CP4

Plate CP4 was a deflection-controlled test without precreef cycles. The measured temperature ranges for the test are show in Fig. H.l, where it can be seen that the plate ran about $1.4^{\circ} \mathrm{C}\left(2.5^{\circ} \mathrm{F}\right)$ higher than desired during the first two-thirds of the test.

Load vs deflection and load vs strain data are shown in Figs. H.2 through $\mathrm{H} .4$ for the deflection changes associated with the relaxation portions of the test. * Strain vs time data for the relaxation periods are shown in Fig. H.5." Load vs deflection and load vs strain data are shown in Figs. H.6 throug H.12 for the ten postcreep deflection cycles.*

"Circled numbers in Figs. H.2 through $H .5$ refer to the gage number. ber.

* Circled numbers in Figs. H.6 through H.12 refer to the cycle num- 


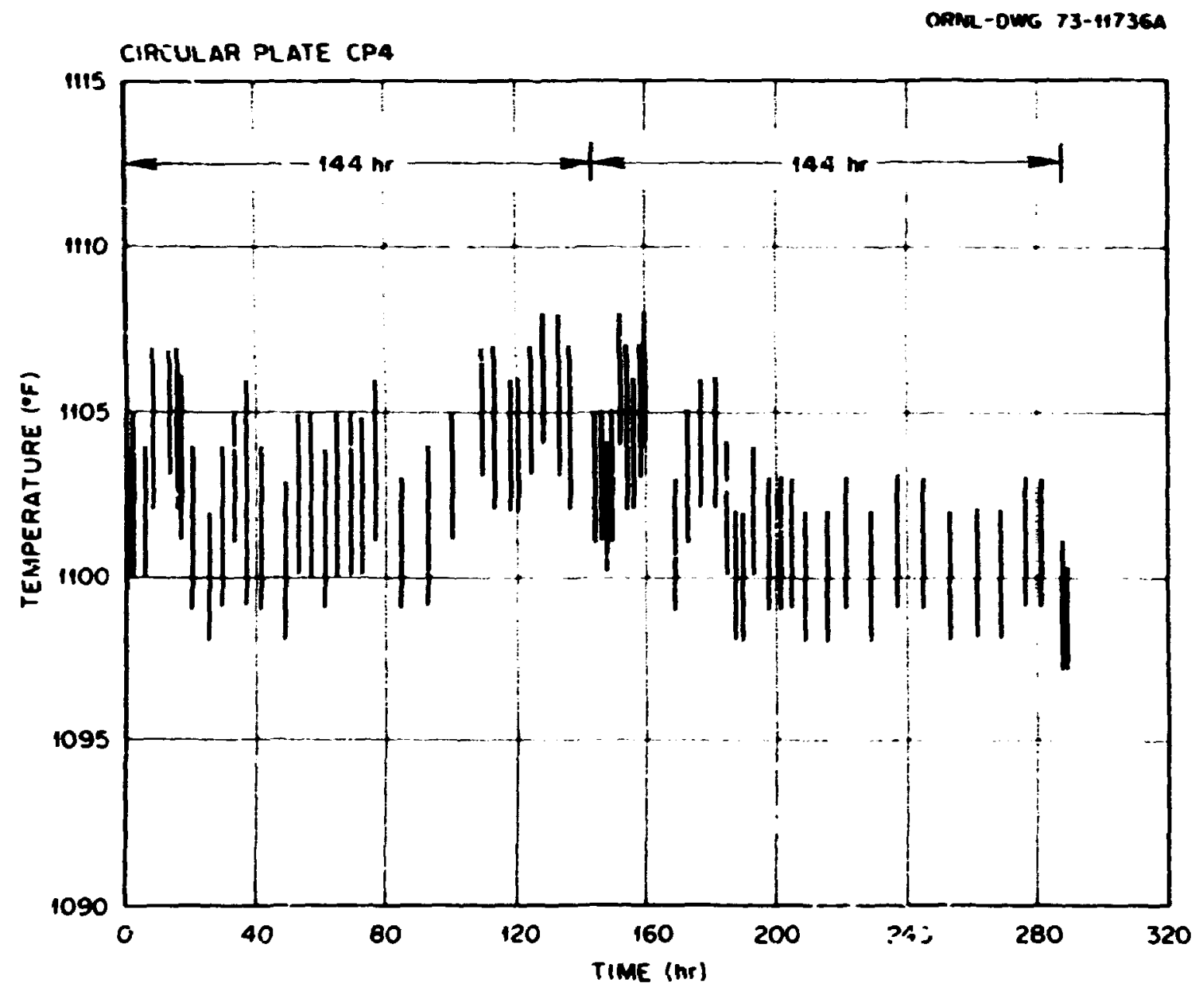

Fig. H.1. Measured temperature range over middle $338.6 \mathrm{~mm}$ !13.33 in.) of instrumented diameter of plate $\mathrm{CP} 4$ during $593^{\circ} \mathrm{C}\left(1100^{\circ} \mathrm{F}\right)$ test $\left[\left({ }^{\circ} \mathrm{F}-32\right) \times 0.5556={ }^{\circ} \mathrm{C}\right]$. 


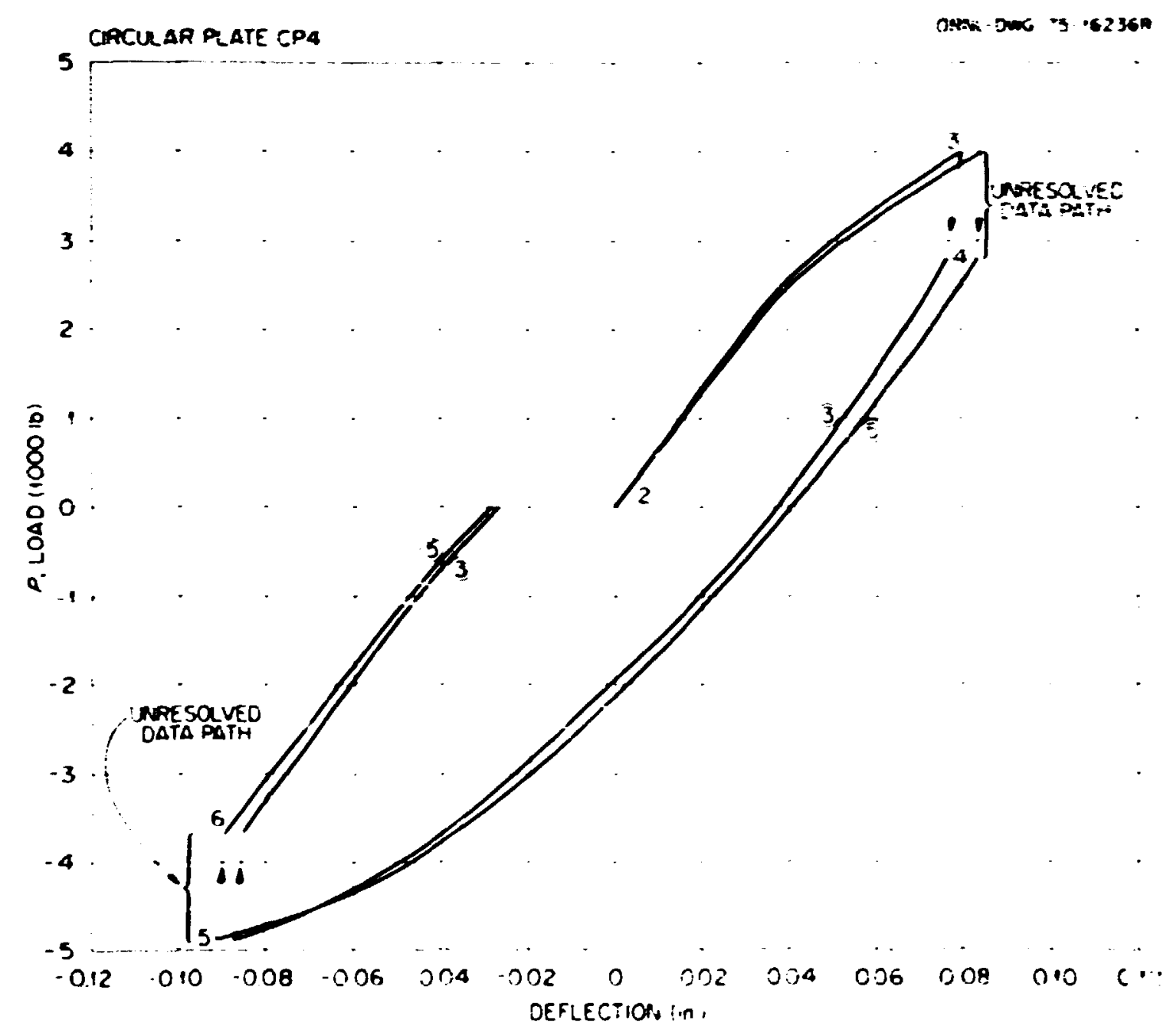

Fig. II.2. Load vs deflection (DT3 and DTS) changes associated with relaxation portions of plate CP4 ( Ib $\times 4.448=x$, in. $\times 25.4=$ in). 
144

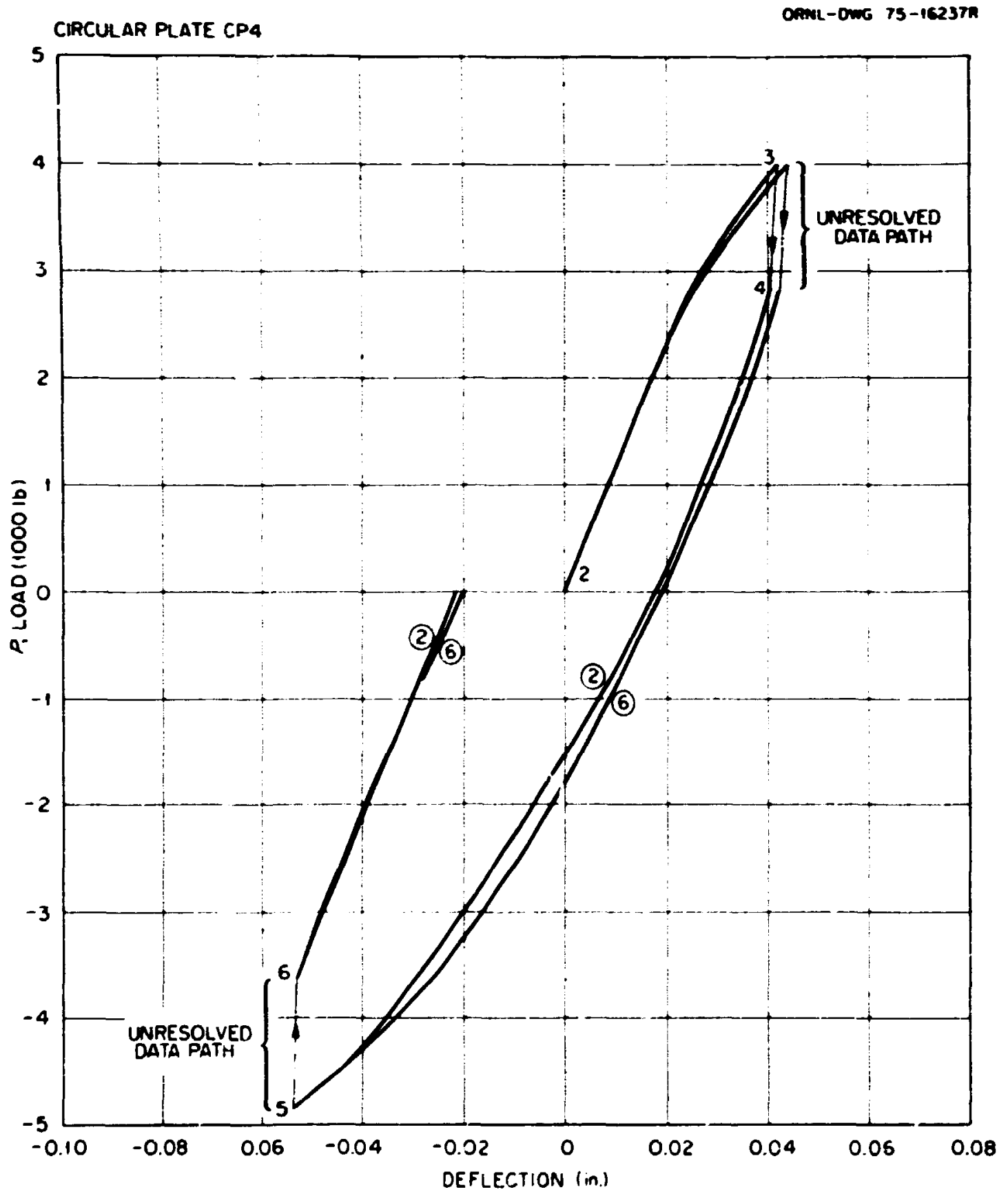

Fig. H.3. Load vs deflection (DT2 and DT6) changes associated with relaxation portions of plate CP4 $(1 \mathrm{~b} \times 4.448=N$, in, $\times 25.4=\mathrm{mm})$. 


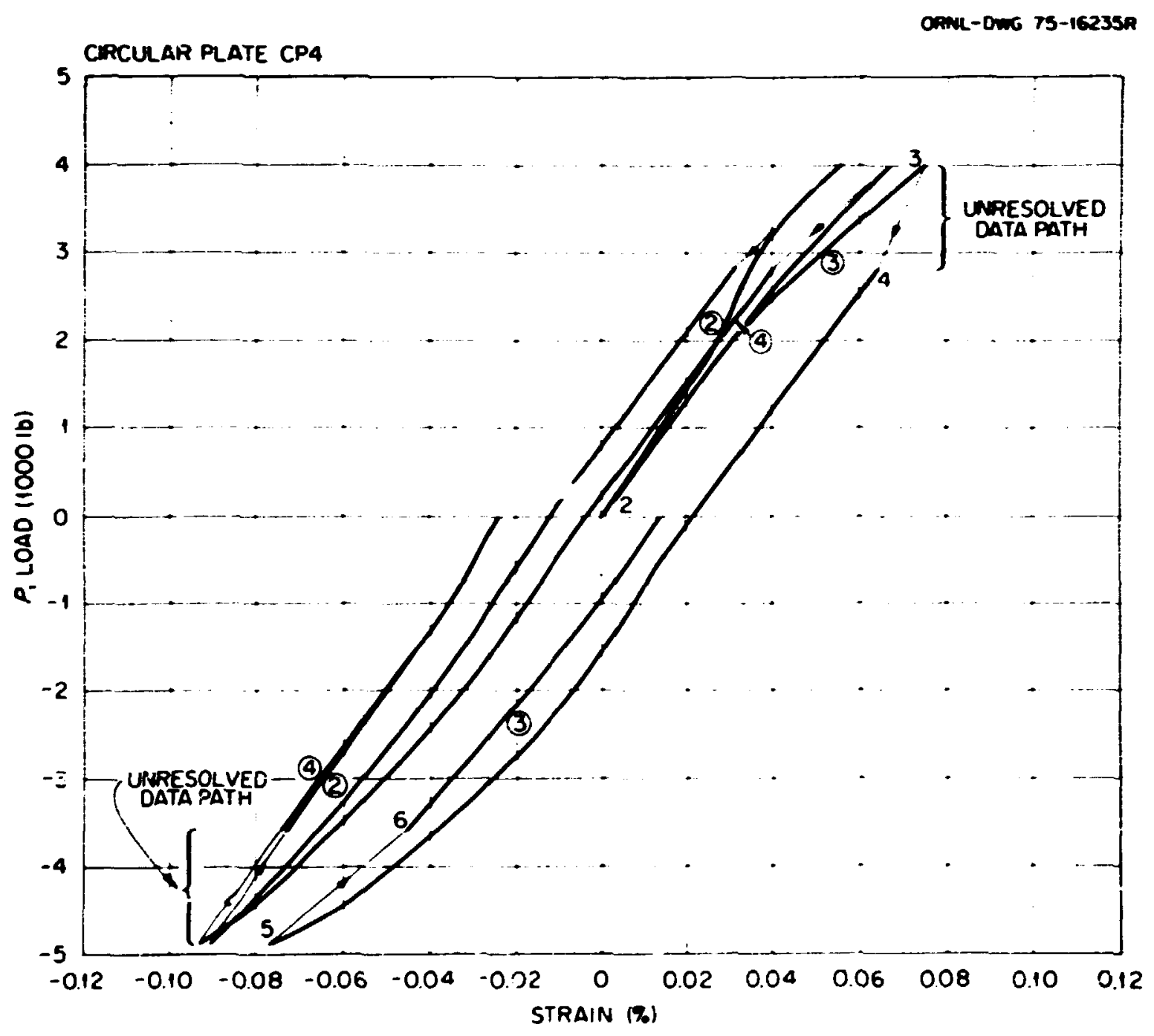

Fig. H.4. Load vs strain (SG2-SG4) changes associated with relaxation portions of plate CP4. Note that the sign of the SGI strain has been changed $(\mathrm{Ib} \times 4.448=N)$. 


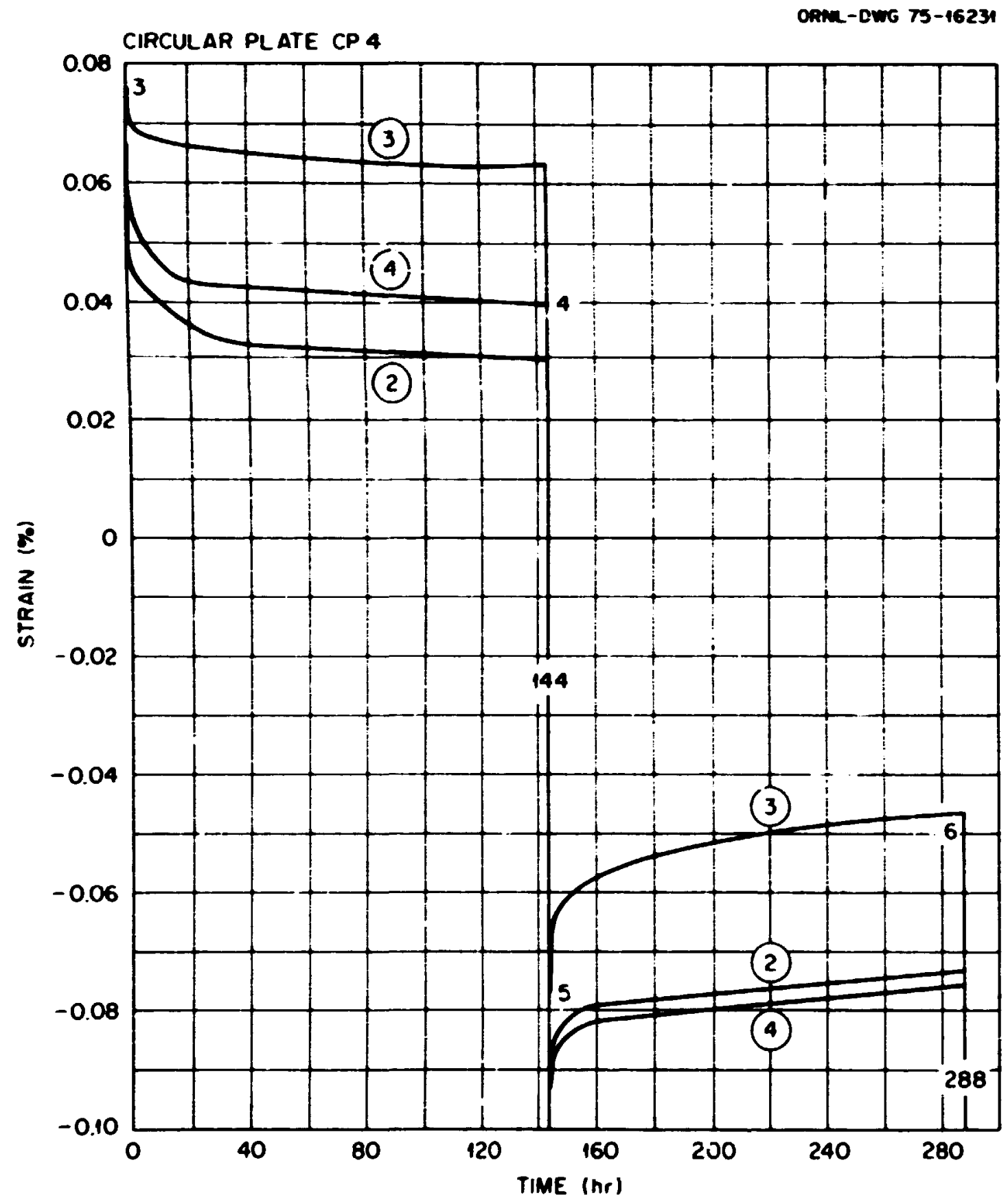

Fig. H S. Strain (SG2-SG4) vs time for plate CP4. Note that the sign of the SG3 strain has been changed. 


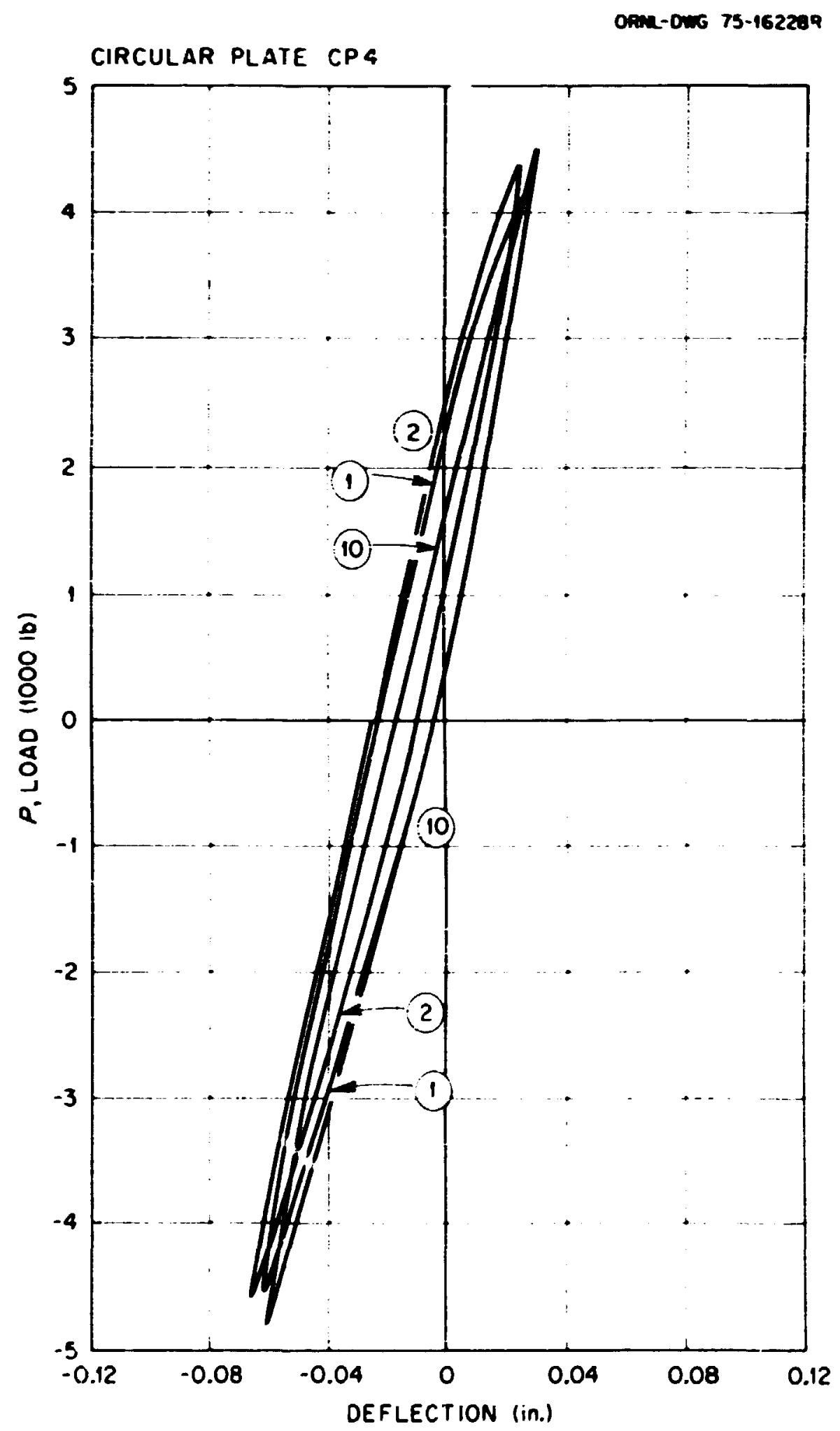

Fig. H.6. Load vs deflection (DT2) during ten short-time, postcreep deflection cycles of plate CP4 $(1 b \times 4.448=N$, in. $\times 25.4=\mathrm{mm})$. 
148

orin-0w6 75-16230n

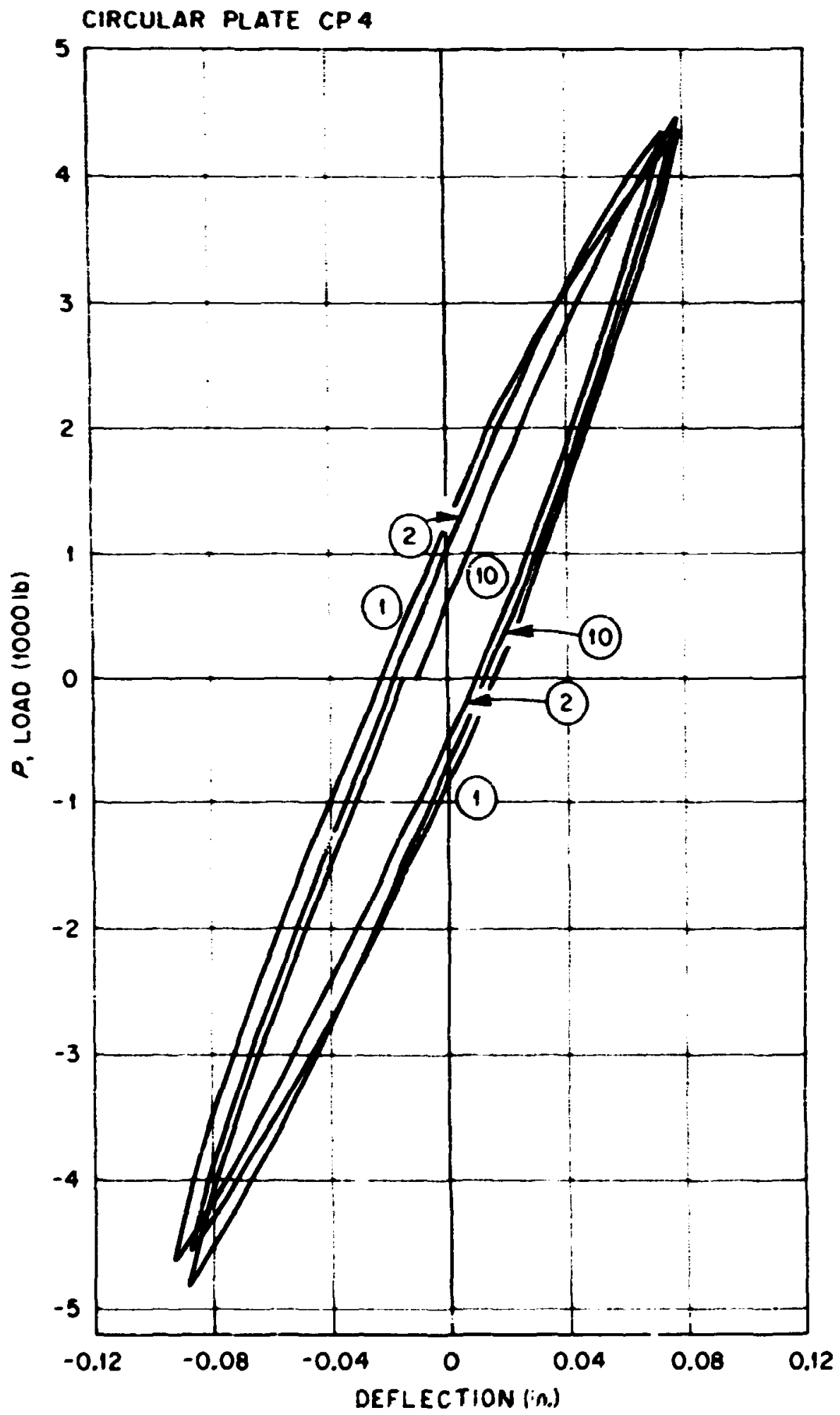

Fig. H.7. Load vs deflection (DT3) diring ten short-tine, postcreep deflection cycles of plate CP4 (1b $\times 4.448=N$, in. $\times 25.4=\mathrm{mm})$. 


$$
1
$$




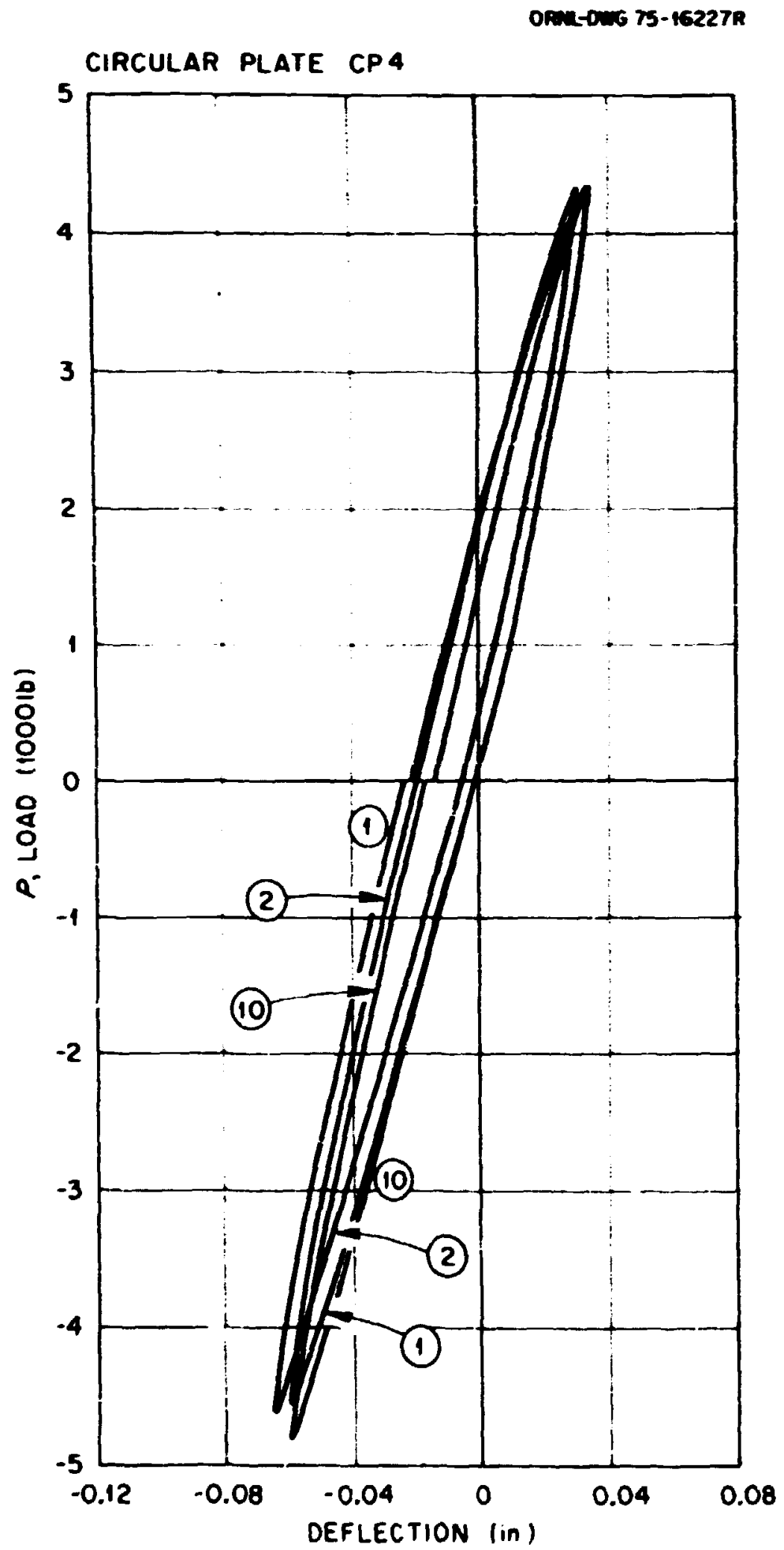

Fig. H.9. Load vs deflection (DT6) during ten short-time, postcreep deflection cycles of plate CP4 $(1 \mathrm{~b} \times 4.448=N$, in. $\times 25.4=\mathrm{m})$. 
151

ORET-OWG 75-15234A

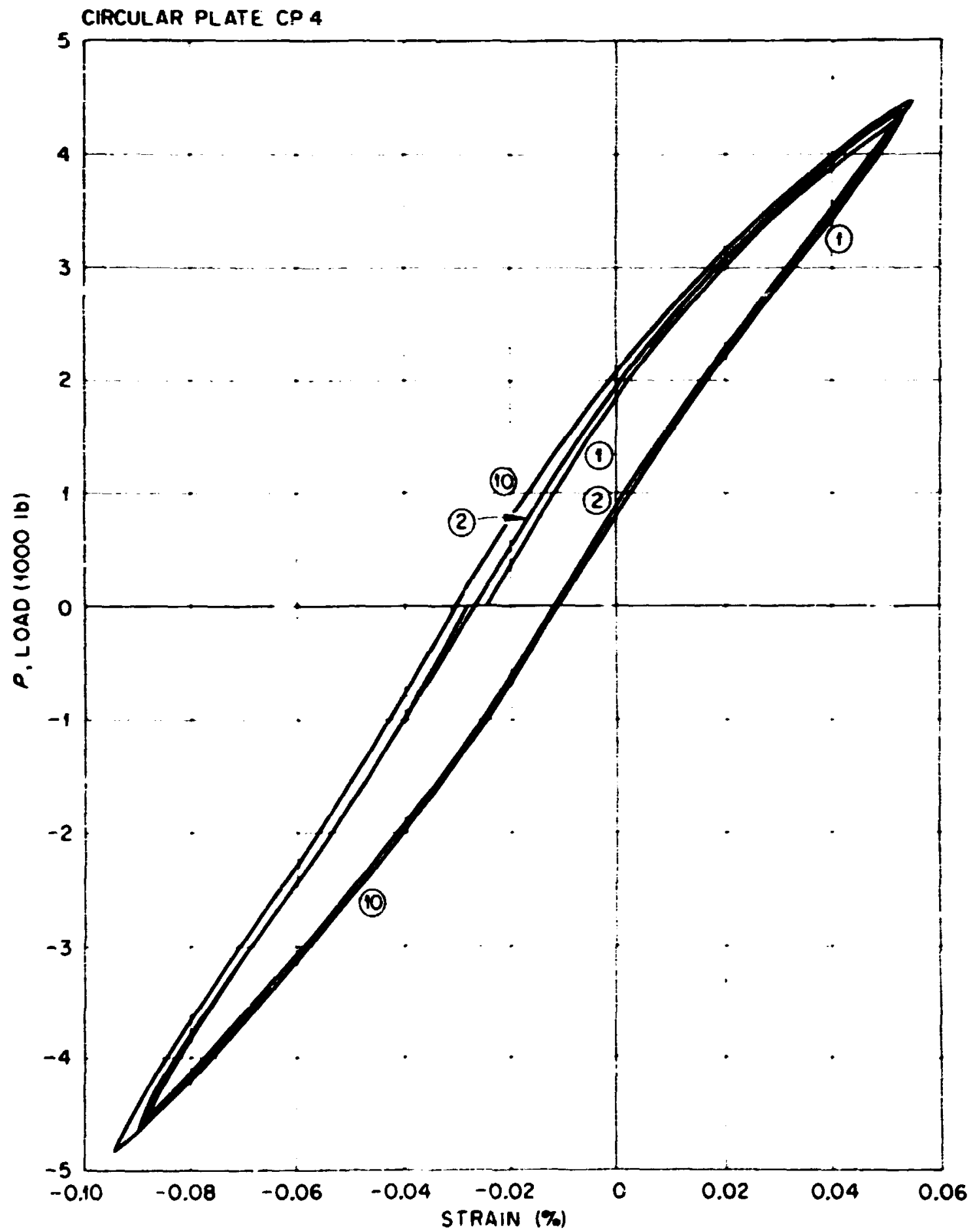

Fig. 1.10. Load vs strain (SG2) during ten short-time, postcreep deflection cycles of plate CP4 $(1 b \times 4.448=N)$. 


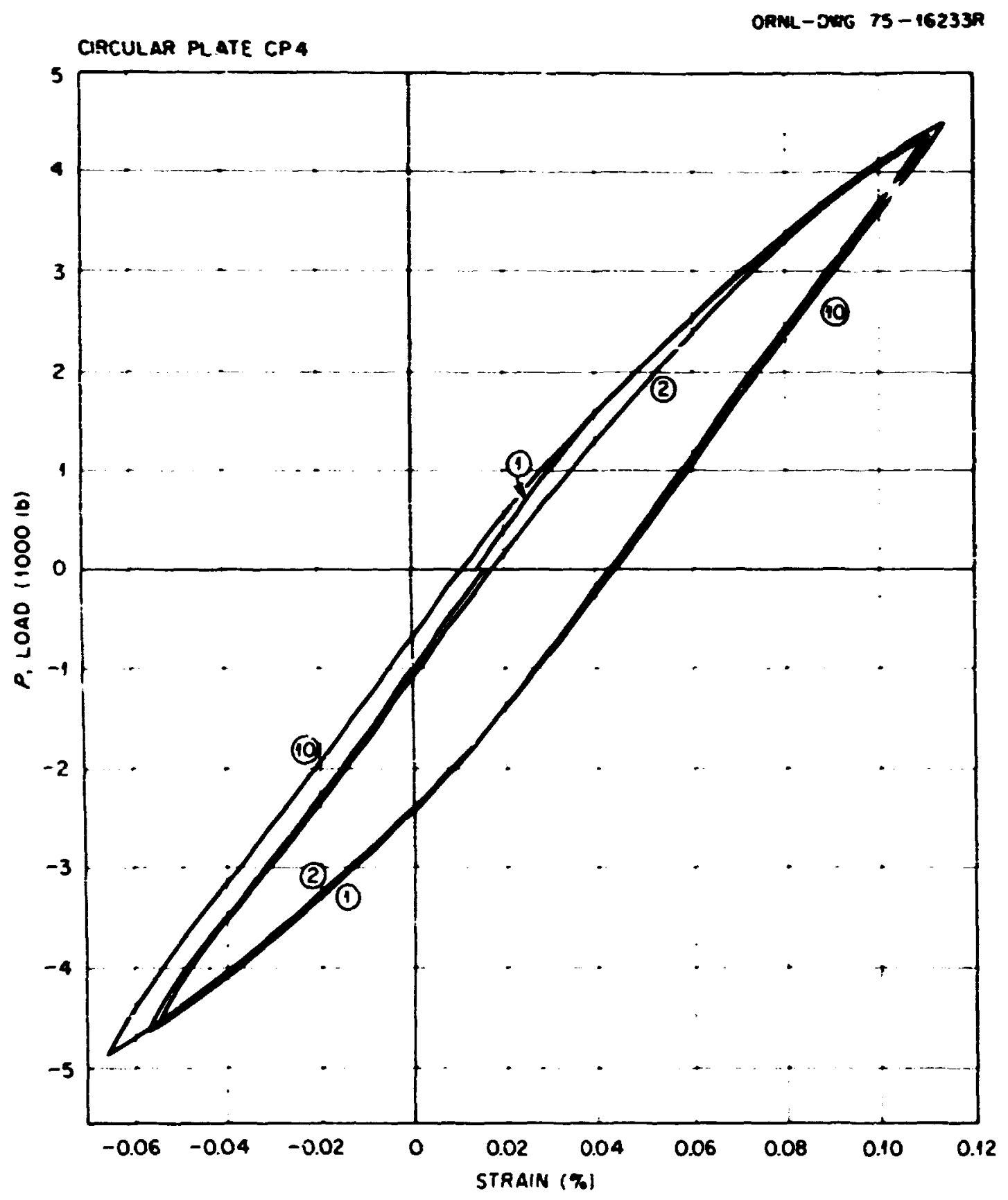

Fig. H.11. Load vs strain (SG3) during ten short-time, postcreep deflection cycles of plate CP4. Note that the sign of the strain has been changed $(1 \mathrm{~b} \times 4.448=N)$. 


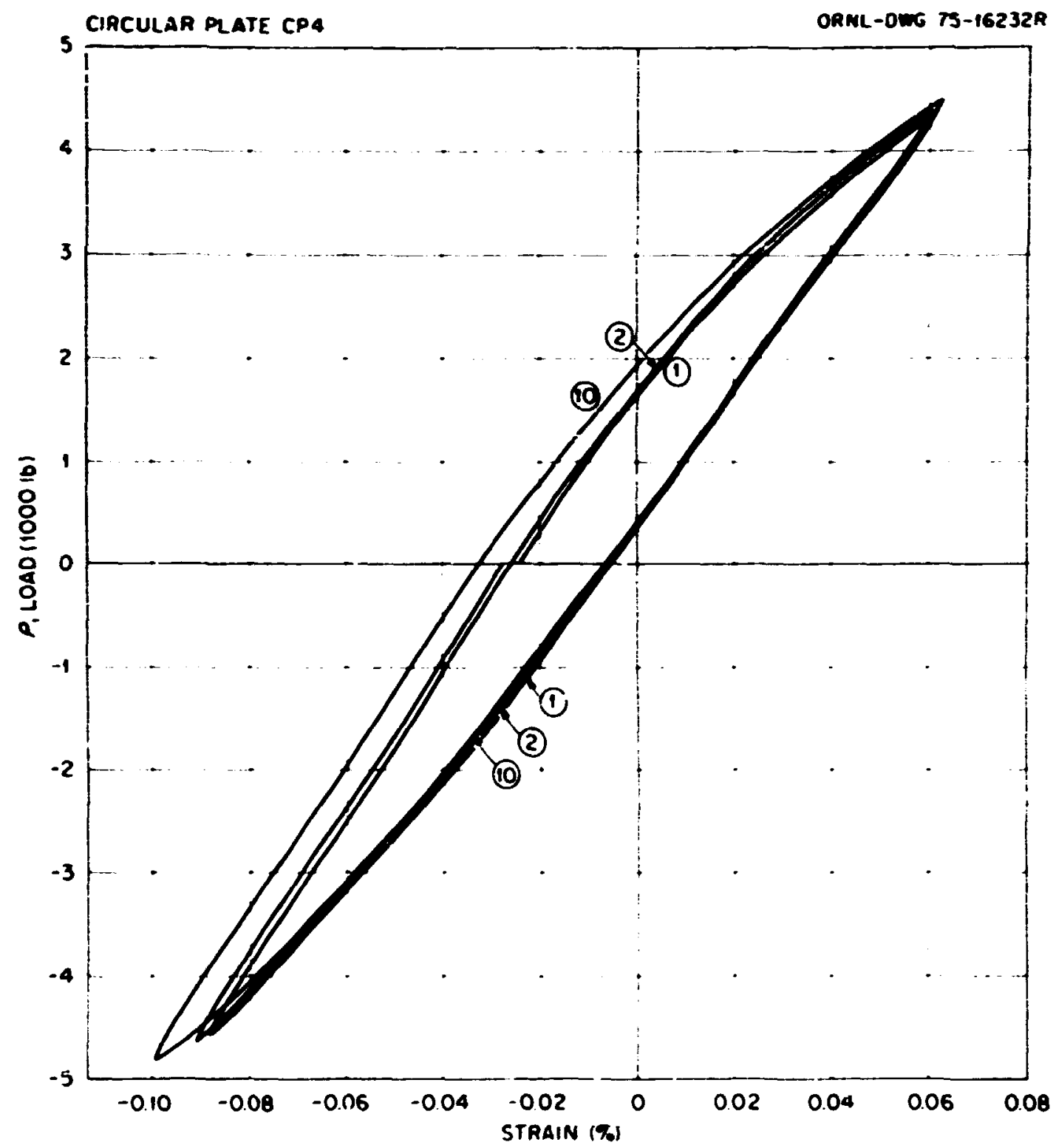

Fig. H.12. Load vs strain (SG4) during ten short-time, postcreep deflection cycles of plate CP4 $(1 b \times 4.448=N)$. 


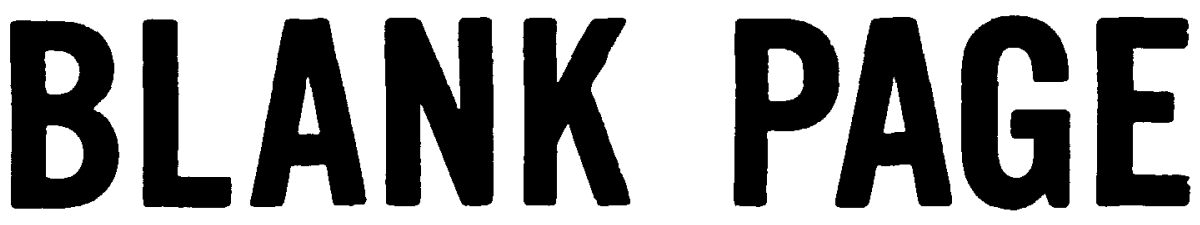


APPENDIX I. ADDITIONAL TEST RESULTS FOR PLATE CP3

Plate CP3 was a deflection-controlled test with precreep deflection cycles. The measured temperature ranges for the test are depicted in Fig. I.1. In this case the temperatures were very closely controlled, well within the goal of $593 \pm 2.78^{\circ} \mathrm{C}\left(11 \mathrm{CO} \pm 5^{\circ} \mathrm{F}\right)$.

No additional deflection and strain data were processed for tinis plate test.

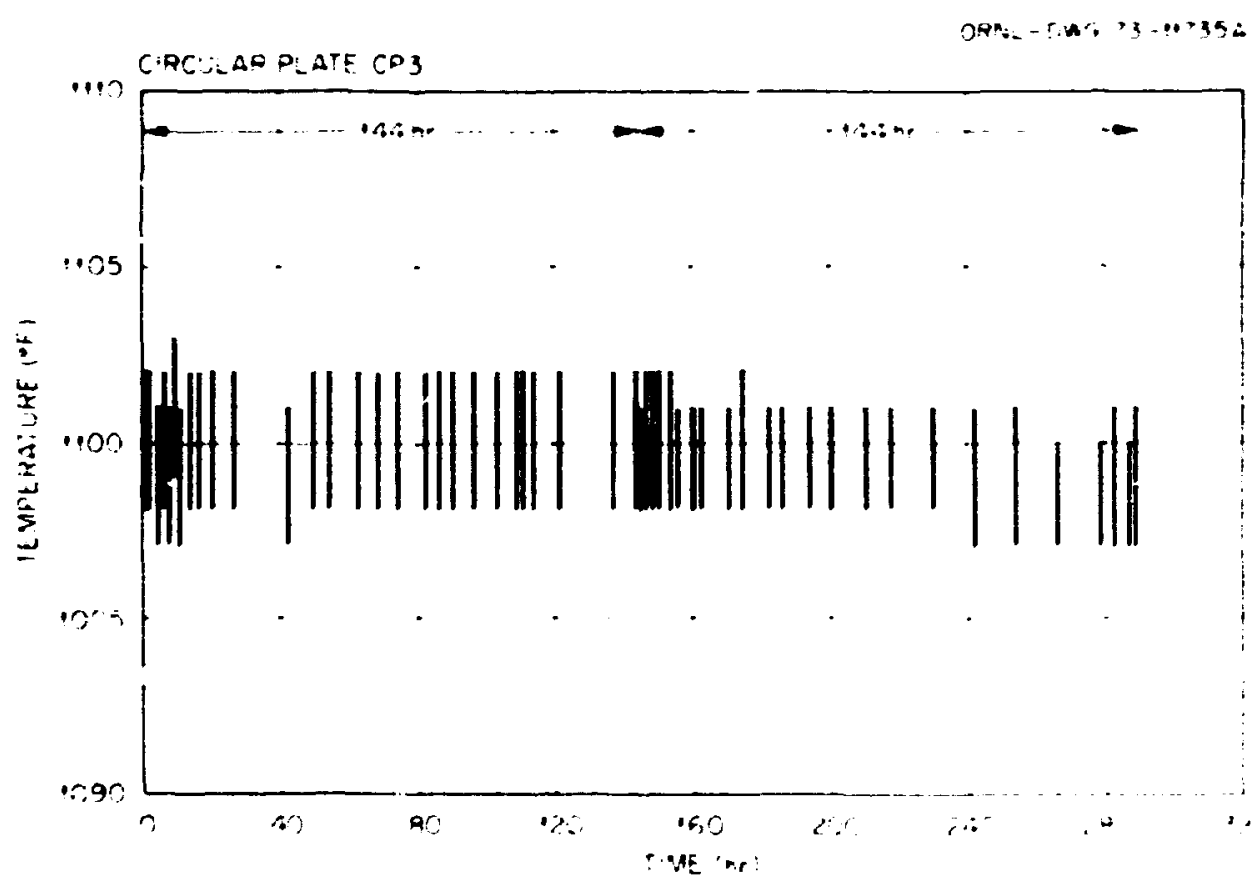

Fig. 1.1. Mensured temperature range over middle $338.6 \mathrm{~mm}(13.33$ in.) of instrumented diameter of plate $\mathrm{CP3}$ during $593^{\circ} \mathrm{C}\left(1100^{\circ} \mathrm{F}\right)$ test $\left[\left({ }^{\circ} \mathrm{F}-32\right) \times 0.5556={ }^{\circ} \mathrm{C}\right]$. 


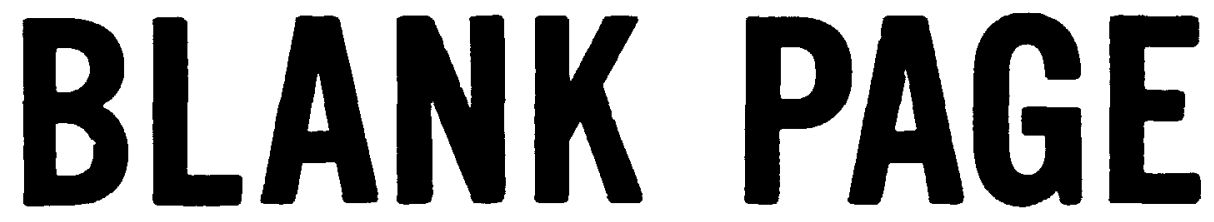


APPENDIX J. TIYE-DEPEVDEKT BEHAYIOR OF AILTECH

SUA25 STRAIX GAGES AT $593^{\circ} \mathrm{C}\left(1100^{\circ} \mathrm{F}\right)$

The Ailtech wodeI SG 25 weldable resistance strain gages used in the bean and plate tests are rated by the eanufacturer as being suitable for short-term static strain measurenents at texperatures to $6 i y^{\circ} \mathrm{C}\left(1200^{\circ} \mathrm{F}\right)$. The gages do drift with time at high temperatures, but this drift was ainiaized in these tests 'y pretest conditioning of the gages as described in Section 3.2.

In addition to the active gages used on each specimen, two identical gages were mounted in each case on an unstrained block of typs 304 stainless steel, and one of tinese blocks was attached to eaci of tia test speciwens. These reference gages were monitored for drift tiroughout each tes; representative results are shown in Fig. J.I for five of che siructural spccirens.

Although the oiserved drift rates are probably less than those reported by the gage manufacturer, they are nevertheless significant rci:ltive to the time-dependent strains measured in the bean and piate tests. and they are not consistent from gage to aage. Consequently, hic do not believe that the measured $t$ ime-dependent strains can be reliably adjuste, using these drift data, to obtain quantitative strain informaion. qual. itatively, however, the measured time-dependent strains are belicred to be indicative of the behavioral trends and stiould serve a uicful puriose in that respect.

We believe that the short-tine strain data (associated with pre-anl postcreep cycling and with load and deflection changes) are csicntially unaffected by the slow drift. This helicf is supportcd by the accuracy and consistency of the measured elastic responses throughout sach test.

In sumary, we believe that the short-time strain gage data arc accurate and reliable bu: that the time-dependent data can he uscd onl $\because$ in :. qualitative sense. 


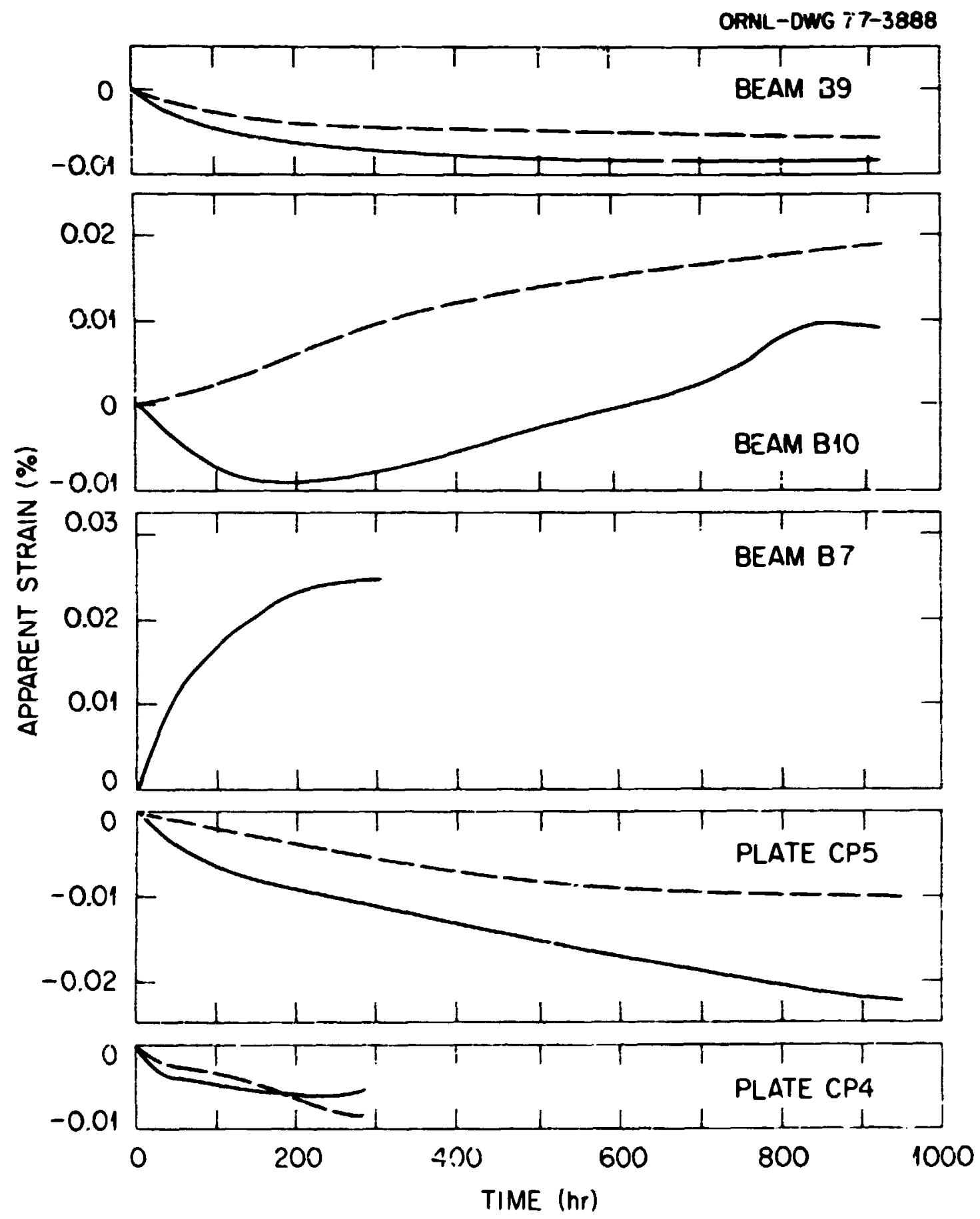

Fig. J.1. Typical apparent strains from reference gages on unstressed blocks attached to bean and plate specimens. 